\title{
The role of mood, habitual goals and primed goals in painful and non-painful task persistence
}

Citation for published version (APA):

Ranson, S. (2014). The role of mood, habitual goals and primed goals in painful and non-painful task persistence. [Doctoral Thesis, Maastricht University]. Uitgeverij BOXPress.

https://doi.org/10.26481/dis.20141211sr

Document status and date:

Published: 01/01/2014

DOI:

10.26481/dis.20141211sr

Document Version:

Publisher's PDF, also known as Version of record

\section{Please check the document version of this publication:}

- A submitted manuscript is the version of the article upon submission and before peer-review. There can be important differences between the submitted version and the official published version of record.

People interested in the research are advised to contact the author for the final version of the publication, or visit the DOI to the publisher's website.

- The final author version and the galley proof are versions of the publication after peer review.

- The final published version features the final layout of the paper including the volume, issue and page numbers.

Link to publication

\footnotetext{
General rights rights.

- You may freely distribute the URL identifying the publication in the public portal. please follow below link for the End User Agreement:

www.umlib.nl/taverne-license

Take down policy

If you believe that this document breaches copyright please contact us at:

repository@maastrichtuniversity.nl

providing details and we will investigate your claim.
}

Copyright and moral rights for the publications made accessible in the public portal are retained by the authors and/or other copyright owners and it is a condition of accessing publications that users recognise and abide by the legal requirements associated with these

- Users may download and print one copy of any publication from the public portal for the purpose of private study or research.

- You may not further distribute the material or use it for any profit-making activity or commercial gain

If the publication is distributed under the terms of Article $25 \mathrm{fa}$ of the Dutch Copyright Act, indicated by the "Taverne" license above, 


\section{The Role of Mood, Habitual Goals and Primed Goals in Painful and Non-Painful Task Persistence}


Cover design: $\quad$ Rika Van Dycke

Printed \& Lay Out by: Proefschriftmaken.nl II Uitgeverij BOXPress

Published by:

Uitgeverij BOXPress, 's-Hertogenbosch 


\section{The Role of Mood, Habitual Goals and Primed Goals in Painful and Non-Painful Task Persistence}

Proefschrift

Ter verkijging van de graad van doctor aan de Universiteit Maastricht, op gezag van Prof. Dr. L.L.G. Soete, Rector Magnificus, volgens het belsuit van het College van Decanen, in het openbaar te verdedigen op 11 december om 16.00 uur

door

Saskia Maria Gabriella Ranson 


\section{Promotor}

Prof. Dr. J.W.S. Vlaeyen

\section{Copromotor}

Dr. P. Karsdorp

\section{Beoordelingscommissie}

Prof. Dr. G. Kok (voorzitter)

Prof. Dr. S. Morley

Prof. Dr. H. Aarts

Prof. Dr. J. Verbunt

Dr. C. Martijn 


\section{Content}

Chapter 1 General Introduction

Chapter 2 Distinct Combinations of Avoidance, Pacing and Persistence Behavior are Associated with Disability and Depression in Musculoskeletal Pain

Chapter 3 No Mood-as-Input Effects for Primed Hedonic and Achievement Goals. Only Habitual Goal Preferences Predict Task Persistence

Chapter 4 Testing the Activation of Primed Hedonic and Achievement Goals

Chapter 5 Pain Catastrophizing, Threat, and the Informational Value of Mood: Task Persistence During a Painful Finger Pressing Task

Chapter 6 Goal Preferences Predict Physical Task Persistence in Patients with Chronic Back Pain

Dankwoord 


\section{Chapter 1}

\section{General Introduction}
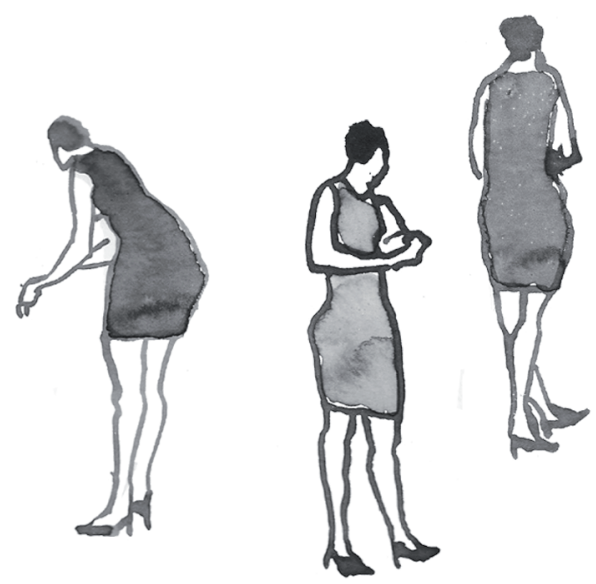


\begin{abstract}
A prevailing model that provides an explanation for the development of chronic pain, is the Fear-Avoidance model. Despite the accumulating evidence in favour of the Fear-Avoidance model, it appears less applicable when pain disability is associated with pain syndromes involving increased levels of activity and persistence behavior rather than avoidance behavior. A promising alternative model that provides an explanatory framework for both persistence behavior and avoidance behavior associated with pain disability is the Mood-asInput model. This model proposes a statistical interaction between current mood and goals (stop rules). The Mood-as-Input model predicts that the same mood state can have differential effects on task persistence, dependent on the goal context in which it appears, being either an achievement or a hedonic context. To date, this model has primarily been tested with the use of explicit goal instructions. The main objective of this dissertation is to test the applicability of the Mood-as-Input Model by means of goal priming and by habitual goal preferences, and in particular to the domain of chronic pain. In this introduction, the state of the art evidence for the Mood-as-Input model will be discussed and the advantages of the Mood-as-Input model in light of other models explaining task persistence (the Fear-Avoidance model, the Mood-Congruency model, the Behavioral Goal-Congruency model, the Ergomania model, the Avoidance-Endurance model, and the Operant-Behavioral model) will be highlighted. Finally, the main research questions for the present dissertation are formulated and the outline is presented.
\end{abstract}




\section{Introduction}

Chronic pain is a major health care and societal problem, due to its high economic and personal impact. In the Netherlands, $18 \%$ of the population ( 3 million people) suffers from chronic pain complaints, seriously affecting the quality of their social and working lives (Breivik, Collett, Ventafridda, Cohen, \& Gallacher, 2006). One of the important problems that people with chronic pain have to deal with is an impaired task performance and the reduced ability to accomplish daily activities (Moore, 2009). Individuals with persistent pain are often struggling to manage their tasks of daily living, deciding when to stop or to continue with activities, trying to avoid painful activities or to the contrary, trying to continue with actions despite the pain. Purely biomedical models that propose a one to one relationship between pain severity, tissue damage, and disability are insufficient to explain impaired task performance (Moore, 2009; Vlaeyen, Crombez, \& Goubert, 2007). The perceived pain intensity is not always related to the degree of task interference. For example, it has been shown that negative emotions that are associated with pain are more predictive for task performance than pain itself (Crombez, Vlaeyen, Heuts, \& Lysens, 1999). In this respect, cognitive models that take into account the meaning of the pain, for example patients' catastrophic beliefs about pain, have become more influential than purely biomedical models in explaining pain disability and impaired task performance.

Impaired task performance, in the sense of experiencing problems with deciding when to stop or to continue with daily activities, can take on different forms, ranging from avoidance behavior, resulting in decreased activity levels, to persistence behavior resulting in increased activity levels in spite of the pain. In general, three broad categories of behavioral activity related strategies have been distinguished: avoidance, pacing, and persistence (or confronting) behavior ${ }^{1}$ (McCracken \& Samuel, 2007). These behavioral strategies have been suggested to influence physical and emotional functioning in chronic pain (Fordyce, 1976). While the disabling effects of long-term avoidance behavior have been well established (Asmundson, Norton, \& Allerdings, 1997; Vlaeyen \& Linton, 2000), the effects of persistence and pacing behavior remain unclear. Some studies suggest that not only avoidance behavior but also persistence behavior can lead to disability (Andersen, Haahr \& Frost, 2007; Feuerstein, et al., 2005; Garcia-Campayo, Pascual, Alda, \& Ramirez, 2007, Van Houdenhove, Neerinckx, Onghena, Lysens \& Vertommen, 2001). The potential disabling effects of persistence behavior are suggested to be associated with overuse and tissue damage (Barr \& Barbe, 2002). However, the cognitive-behavioral mechanisms behind the potential disabling effects of persistence behavior are still poorly understood. In the following paragraphs we will discuss and evaluate several theoretical models that may provide an 
explanation for task persistence in chronic pain. In the light of these, the advantages of a new promising model, the Mood-as-Input model, in explaining the disabling effects of both avoidance and persistence behavior will be introduced.

\section{Models Explaining Task Persistence in Chronic Pain}

\subsection{The Operant-behavioral Model}

One of the oldest and most widely studied psychological pain models is the OperantBehavioral model. It postulates that pain behaviors are a major component of the pain problem, and that they are subject to environmental contingencies (Fordyce, 1976). Pain behaviors are defined as verbal and nonverbal indications that serve to communicate the fact that a person is experiencing pain, such as facial expressions, moaning and guarded movement (Turk, Wack, \& Kerns, 1985). In the acute phase of pain, pain behaviors might be adaptive, minimizing further harm and thus protecting the body (Sullivan, 2008; Williams, 2002) but they can become dysfunctional in the long run when they persist in situations where pain is no longer a threat signal. According to the operant learning theory (Skinner, 1953), behavior is a function of its consequences, with positive reinforcement of pain behaviors leading to increased likelihood of their occurrence, and punishment leading to their extinction. In this way operant conditioning can influence activity levels and task persistence during pain. More specifically, pain exacerbation as a consequence of activity can function as a punisher, leading to a decrease of activity levels and /or avoidance of the specific activity. Resting is often followed by pain decrease, which may act as a negative reinforcer (avoidance learning), leading to higher frequency of resting.

Based on the Operant-Behavioral model, there are a number of studies concerning 'graded activity', investigating whether degree of task persistence can be put under operant control. Graded activity is a stepwise treatment in which activities become reinforced in a timecontingent or goal-contingent rather than a pain-contingent way, and is aimed at gradually increasing activity levels (Fordyce, 1976). Although some studies have demonstrated that graded activity is beneficial for conditions such as low back pain and chronic fatigue syndrome, compared to no intervention or to standard medical care (Moss-Morris, Sharon, Tobin \& Baldi, 2005; White, Goldsmith, Johnson, Potts, Walwyn, et al., 2011), evidence is not univocal (Veenhof, Köke, Dekker, Oostendorp, Bijlsma, Van Tulder, et al., 2006; Vonk, Verhagen, Twisk, Koke, Luiten \& Koes, 2009; van der Giessen, Speksnijder \& Helders, 2012). Furthermore, treatment outcome studies do not directly test the underlying operant mechanisms that play a role in the establishment and maintenance of activity levels.

However, a number of experimental studies have been published supporting an operant mechanism underlying verbal pain reports. In an experimental study in healthy undergraduate students, Joliffe and colleagues (2004) studied verbal reinforcement of 
pain reports after receiving painful ischemic stimuli from a blood-pressure cuff that either remained stable over time or decreased over time. In one condition, the subjects were positively reinforced by means of encouraging statements such as 'that's it' or 'very good' when their pain rating exceeded that of the previous trial, while the other group received no reinforcement. As expected, the mean pain reports of reinforced subjects were significantly higher than those of the non-reinforced subjects, both when the intensity of the cuff was stable over trials, and when it decreased. Similar results were found in patients as well. Flor (2002) examined the effects of operant conditioning of verbal pain reports in both chronic back pain patients and matched healthy controls. Half of each group was verbally reinforced for increased pain reports, while the other half was reinforced for decreased pain reports. Results showed that pain reports could be brought under operant control, with up-conditioned groups reporting more pain than the down-conditioned groups.

The strict Skinnerian version of the Operant-Behavioral model has been criticized because of its exclusive focus on external behavioral influences and its underestimation of the importance of cognitive and motivational processes. However, in the course of the years there has been a shift from strict behaviorism with a sole focus on observable behavior towards contextual behaviorism, focusing on a broader range of behaviors including thoughts, motivations and rule governed behavior. An example of such a post-Skinnerian theory is Relational Frame Theory (RFT). It focuses on how people associate stimuli that they did not directly experience. According to RFT, the building block of human language and higher cognition is 'relating'; the human ability to create links between stimuli. People do not only learn to relate events through direct observation, but also by means of arbitrary contextual rules (i.e. verbal, social conventions), in which direct observation of events is not necessary (Barnes Holmes, Barnes Holmes, McHugh, \& Hayes, 2004). Unfortunately, RFT principles have not been applied in the chronic pain area so far.

In summary, although within the operant tradition there is supportive evidence that verbal pain report can be put under operant control, univocal evidence in favor of graded activity is missing. Furthermore studies examining the operant mechanisms for graded activity are lacking. A disadvantage of the strict version of the operant model is that it does not take into account contextual factors such as for example mood and goals. In this respect, contextual behaviorism seems more promising.

\subsection{The Fear-Avoidance Model}

The Fear-Avoidance model has been a prevailing model explaining the development of chronic nonspecific pain for the last two decades (Leeuw, et al., 2007). It proposes that avoidance behaviour may be functional in the short term but that in the long run, it may become dysfunctional. The Fear-Avoidance model's key concept is the catastrophic (mis) 
interpretation of pain, leading into a vicious circle of fear of pain, avoidance behaviour and disability. It is assumed that avoidance behavior over time leads to a weaker musculoskeletal system that becomes less tolerant of activity, leading to an overall increase in average pain intensity and disability in the long run (Reeves, 2006). There is accumulating evidence in favour of the Fear-Avoidance model (Vlaeyen, Kole-Snijders, Boeren, \& van Eek, 1995; Vlaeyen \& Linton, 2000). The model has been examined in a number of studies, by measuring pain tolerance, with participants being instructed to persist in a task until they can no longer tolerate the pain (Crombez, Vervaet, Lysens, Baeyens, \& Eelen, 1998; Crombez et al., 1999; Swinkels-Meewisse, Roelofs, Oostendorp, Verbeek, \& Vlaeyen, 2006; Vlaeyen, Kole-Snijders, Boeren, \& van Eek, 1995). In accordance with the Fear-Avoidance model, the majority of these studies showed that pain-related fear and catastrophizing were associated with more disability and less pain tolerance (Crombez, Vervaet, Lysens, Baeyens, \& Eelen, 1998; Crombez, et al., 1999; Swinkels-Meewisse, Roelofs, Oostendorp, Verbeek, \& Vlaeyen, 2006; Vlaeyen, Kole-Snijders, Boeren, \& van Eek, 1995). In an early study of Vlaeyen et al. (1995) chronic back patients had to perform a weight-lifting task, lifting a bag of $5.5 \mathrm{~kg}$ with the dominant arm and patients high in pain-related fear were shown to stop this task much earlier than patients low in pain-related fear. Also, Crombez et al. $(1998,1999)$ found the same association between pain-related fear and physical performance using a weight-lifting task and a knee-extension-flexion task, even when controlling for pain intensity. In a recent meta-analysis, including 41 studies, a robust, positive association between pain-related fear and disability was demonstrated, consistent with the Fear-Avoidance model. The observed association had a moderate to large effect size and was stable across demographic and pain characteristics (Zale, Lange, Fields, \& Ditre, 2013).

However, despite the accumulating evidence in favour of the Fear-Avoidance model, its scope is rather limited to pain syndromes associated with avoidance behaviour, and it seems difficult to apply the model to pain syndromes that are associated with persistence behavior (Vlaeyen \& Morley, 2004). Furthermore the literature reports some inconsistent results that cannot be explained by the Fear-Avoidance model.

Firstly, in some studies it was found that negative mood and pain catastrophizing gave rise to longer instead of shorter tolerance times. In one study, Van den Hout, Vlaeyen, Houben, Soeters, \& Peters (2001) found better instead of worse performances after experimentally induced negative mood. Similarly, in a cold pressure study (Severeijns, van den Hout, \& Vlaeyen, 2005) with healthy volunteers, longer tolerance times were observed in participants who were given a threatening instruction leading to increased negative mood. Furthermore, in some studies negative affectivity and pain catastrophizing were found to be unrelated to pain tolerance in behavioral performance tasks (de Gier, Peters, \& Vlaeyen, 2003). These results suggest that other contextual factors beside fear-avoidance variables 
(fear of pain, pain catastrophizing, fear-avoidance beliefs) might play a role in explaining behavioral performance in painful tasks.

Secondly, the Fear-Avoidance model does not take into account that pain often occurs in a context of goal pursuit in which pain-avoidance goals often compete with other alternative goals (Schrooten \& Vlaeyen, 2010; Van Damme, Crombez, \& Eccleston, 2008). For example people with pain may not only have the goal to avoid or minimize pain, but they may also pursue goals to successfully complete personally valued non pain-related activities (Crombez, Eccleston, Van Damme, Vlaeyen, \& Karoly, 2012).

Third, the Fear-Avoidance model mainly focuses on the consequences of negative affect and neglects the potential role of positive affect in influencing task performance.

\subsection{Mood-Congruency Theories}

Mood-Congruency models focus on the role of mood in predicting task performance. Generally, they assume mood congruent effects on behavior (Bower, 1981; Isen, Shalker, Clark, \& Karp, 1978; Mayer, Gaschke, Braverman, \& Evans, 1992), which refers to a match between the valence of a person's mood and his or her behaviour. Mood congruent effects were found on a variety of different tasks such as probability judgment, person perception, categorization judgment and decision making processes. For example, positive mood has been shown to produce more favorable impression formations than negative mood (Mayer et al., 1992). In the domain of pain, mood congruent effects on pain tolerance have been demonstrated with studies showing reduced pain tolerance after induction of negative affect (Carter, et al., 2002; de Wied \& Verbaten, 2001), and increased pain tolerance after positive mood induction (de Wied \& Verbaten, 2001).

In the case of task persistence, Mood-Congruency theories would predict that negative mood retrieves negative evaluations of goal achievement, which would encourage task persistence (Meeten \& Davey, 2011). In line with this reasoning, task persistence under negative mood conditions has been demonstrated in Obsessive Compulsive Disorder and depressive rumination. However, mood congruent effects are not always observed. In general, stronger mood congruency effects are found for positive than for negative mood (Bower, 1981; Forgas \& Bower, 1987). To account for this lack of symmetry in mood congruent effects, Mood-Congruency theories have resorted to overriding processes such as mood regulation processes. One such principle is the mood repair hypothesis, stating that people with negative mood states are motivated to repair their mood into a more positive mood state leading to weaker or no mood congruency for negative mood (Clark \& Isen, 1982; Schwarz \& Clore, 1983).

A major problem with Mood-Congruency theory is that it cannot explain why mood congruency should be seen as basic processing, and mood incongruent processing as being an 
overriding process. Furthermore, mood is a very general concept, and the Mood-Congruency theory suffers from the same limitation as the Fear-Avoidance model in that it does not take into account the motivational context.

\subsection{Behavioral Goal-Congruency Model}

Task performance has also been studied from the perspective of the goal-setting theory (Locke \& Latham, 1990, 2002). This theory has primarily focused on motivation in work settings, but has shown to apply to all kinds of domains where motivation plays a role. The theory assumes a congruency between the difficulty of the task and the energy invested in the task. Pursuing difficult goals as compared to easy goals prolongs effort and thus affects task persistence, resulting in a trade-off between time spent on a task and the intensity of the effort needed to accomplish the task. In the domain of pain, research has shown that both goal specification and goal difficulty influence pain tolerance. Goal specification has shown to increase pain tolerance (Stevenson, Kanfer, \& Higgins, 1984). Furthermore it has been demonstrated that individuals with higher pain-specific self-efficacy (which is correlated with higher goal setting) show greater pain tolerance (Keefe, Lefebvre, Maixner, Salley, \& Caldwell, 1997; Willams \& Kinney, 1991). A disadvantage of the goal set theory is that it does not take into account that goals do not operate in a vacuum but can be influenced by contextual variables, such as current mood states.

\subsection{The Ergomania Model}

The Ergomania model stems from the psychodynamic tradition, and focuses on the possible role of hyperactivity as a predisposing factor for chronic pain syndromes. It views persistence behavior in pain patients as an expression of overcompensated dependency needs, excessive bodily narcissism, masochism and perfectionism (Van Houdenhove \& Neerinckx, 1999). In an exploratory study Van Houdenhove and colleagues (1995), investigated the pre-morbid lifestyle of patients with chronic pain and chronic fatigue syndrome and found that they reported a higher level of "action-proneness" (the extent to which one is oriented toward direct action and achievement) as compared to control groups. In a subsequent study (Van Houdenhove et al., 2001), a possible confounding factor, the patients' idealization of their previous attitude towards action, was ruled out as an explanation for the results; thus further supporting the hypothesis that a high level of "action-proneness" may play a predisposing, and maintaining role in chronic pain and chronic fatigue syndrome. However, the results are preliminary, and are subject to a number of limitations such as the operationalization of 'hyperactivity' in terms of 'action-proneness'. Another limitation is its retrospective measurement and the reliance on self-reports only. The main problem with the Ergomania 
model, however, is that the constructs are difficult to operationalize for the purpose of experimental investigation.

\subsection{Avoidance-Endurance Model}

The Avoidance-Endurance model (Hasenbring, Hallner, \& Rusu, 2009; Hasenbring, Plaas, Fischbein, \& Willburger, 2006; Hasenbring \& Verbunt, 2010) builds on both the fearavoidance and the Ergomania model placed within a "coping with stress" (Lazarus \& Folkman, 1984) framework. It offers a theoretical account aimed at understanding both increased and decreased levels of activity in patients with chronic pain. The AvoidanceEndurance model proposes that there are at least two different maladaptive types of coping styles that lead to chronic pain in the long run: fear-avoidance coping and endurance coping. In line with these coping strategies, the model describes three subgroups of patients: the "avoiders", the "persisters", and a more functional "adaptive" group. Avoiders display painavoidance behavior, which is associated with fear, anxiety, catastrophizing and fear-avoidance beliefs. In contrast, persisters show a behavioral tendency to finish current activities in spite of pain. This latter behavioral style can be associated with two different kinds of cognitive/ affective response patterns: the "Eustress endurance" response pattern, showing persistence behavior that is accompanied by ignoring and minimizing pain experiences and high positive mood despite pain, and the "distress endurance" response pattern characterized by endurance behavior in combination with thought suppression, anxiety and depression. Both endurance responses are assumed to lead to overuse of muscles, joints and discs and as consequence increased pain. In contrast to the maladaptive group, the adaptive group shows a high degree of flexibility between fear-avoidance responses and endurance responses and as a consequence is predicted to report less pain and disability in the long run.

Evidence for the Avoidance-Endurance model is still scarce. The study of Hasenbring et al. (2009) is one of the first providing supportive evidence for some key constructs of the Avoidance-Endurance model. Factor analysis of a newly developed questionnaire to measure avoidance coping and endurance coping responses (the Avoidance Endurance Questionnaire) demonstrated that avoidance and endurance responses are separable concepts. Overall, the avoidance related responses were associated with more pain and more disability, whereas the endurance responses were associated with more pain but less disability. In two other studies using subgroups of patients, some preliminary evidence was found for maladaptive fearavoidance coping and endurance coping (Hasenbring, 2012, Rusu \& Hasenbring, 2008). In the latter study, an adaptive and a dysfunctional group were distinguished with the dysfunctional group showing more anxiety/depression, help-/hopelessness, catastrophizing and thought suppression compared to the adaptive group. However, while the groups were distinguished on pain-related cognitions, they did not differ in avoidance behavior or endurance behavior. 
In a prospective study, four subgroups were compared (an adaptive group, a fear-avoidance group, a distress-endurance and an eustress-endurance group) at baseline and at 6 month follow up on several coping variables (Hasenbring et al. 2012). In line with the predictions of the Avoidance-Endurance model, the eustress-endurance patients reported more pain intensity than the adaptive group, but less disability than both the fear-avoidance group and the distress-endurance patients. These findings support the prediction that there is a subgroup of endurance patients who develop a high pain intensity accompanied with low disability. However, caution is warranted in generalizing from these results as the findings are correlational in nature, and therefore do not clarify the causal relationship between endurance responses, pain and disability.

Although the Avoidance-Endurance model is appealing, it is mainly a descriptive one based on different cognitive, affective and behavioral responses to pain, lacking a theoretical framework elucidating the exact mechanisms that could explain under which circumstances individuals show more or less task persistence in painful activities. More specifically it does not specify the motivational mechanisms behind endurance or avoidance responses. Furthermore, the exact relationship between endurance behavior and disability remains unclear. It is stated that endurance behavior is initially associated with less disability, but that in the in the long run patients may eventually switch from endurance behavior to avoidance behavior and develop disability due to physical overload. However the model does not specify the exact conditions and parameters that determine this switch (Hasenbring, 2010; Karsdorp \& Vlaeyen, 2009b).

\subsection{The Mood-as-Input Model}

The above described models all assume that task performance can be explained by simple main effects. The Mood-as-Input model is a slightly more complicated model in the sense that it predicts a statistical interaction between mood and goals. In the next paragraphs, the Mood-as-Input model will be explained in further detail and its advantages compared to the models described above will be highlighted.

The Mood-as-Input model stems from social psychology, and focuses on the relationship between mood and task performance (Martin, et al., 1993). It was developed as an answer to the limitations of the Mood-Congruency models. The Mood-as-Input model can explain both mood-congruent and mood-incongruent effects because it considers mood in a motivational context. It proposes that people process not only their mood but also the context in which their mood is experienced. In this way, mood that is experienced in a different context can have different motivational implications.

The basic prediction of Mood-as-Input model is that task performance is the resultant of mood and the stop rule that the individual adopts for the task. The concept 'stop rule' 
is relatively new. It was introduced by Martin (1993) and refers to subjective rules, which guide people in their decisions to either terminate or to continue with open-ended tasks. For example, in an experiment individuals were instructed to stop with an impression formation task when they had enough information to form an impression, or to stop when they no longer enjoyed the task (Martin, 1993). In the former case individuals adopted an achievement goal, while in the latter case they adopted a hedonic goal. Thus, within the scope of Mood-asInput theory, two different contexts are relevant: achievement and hedonic contexts. Both are associated with two different processing goals that people can adopt during task performance: 1) Hedonic goals, during which individuals focus on the question 'Am I enjoying this task?", and 2) Achievement goals, where the focus is on the question "Am I satisfied with the result of the task?".

The Mood-as-Input hypothesis predicts that task persistence on an open-ended task is determined by a combination of these processing goals (stop rules) and the valence of the mood. More specifically, it predicts that the combination of positive mood with a hedonic goal leads to greater task persistence than the combination of the same positive mood with an achievement goal. On the other hand, a combination of negative mood and achievement or hedonic goals leads to the opposite behaviour pattern: a negative mood combined with a hedonic goal leads to less task persistence than the same negative mood combined with an achievement goal (see figure 1). The rationale behind this line of thought is that people use their mood as information to evaluate the progress they make on their goals. In an achievement context, a positive mood state signals that one has achieved the goals of the task, leading to task discontinuance, while in a hedonic context, the same positive mood means that participants are still enjoying the task, leading to task continuance. A negative mood state is supposed to result in an opposite behavioural pattern: in an achievement context it signals that not enough progress has been made, leading to task continuance; while in a hedonic context it signals that the task is no longer enjoyable, leading to task discontinuance. In this way the Mood-as-Input model predicts a statistical interaction between mood and processing goals.

Within the scientific literature a distinction is made between mood and emotion. In comparison with emotions, moods are diffuse and global, and lacking in intentionality. (Siemer, 2005). Overall, studies examining the Mood-as-Input hypothesis have mainly used general negative or positive mood in investigating Mood-as-Input effects. So far, only one study examined if discrete negative moods of the same valence (i.e. anger, sadness and anxiety) interact with goals to affect processing in a Mood-as-Input framework (Meeten \& Davey, 2012). Results revealed no significant inherent differences in processing depending on the type of discrete negative mood that was experienced; supporting the view that the overall valence and not the specific emotion is the important affective factor in Mood-asInput effects. 


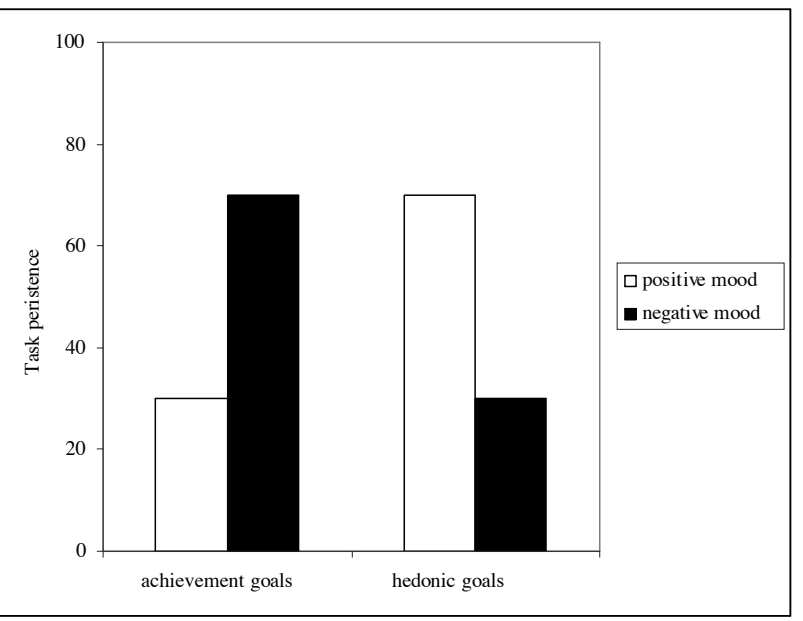

Figure 1. Graphical representation of the Mood-as-Input hypothesis, predicting an interaction effect between mood and goals on task persistence.

In the course of the years, evidence for the Mood-as-Input account has been accumulated within different clinical domains: obsessive compulsive disorder (Davey, Startup, Zara, MacDonald, \& Field, 2003; MacDonald \& Davey, 2005; MacDonald \& Davey, 2005; Van den Hout, Kindt, Luigjes, \& Marck, 2007), general anxiety disorder (Startup \& Davey, 2001, 2003) and depression (Hawksley \& Davey, 2010; Watkins \& Mason, 2002), and across different tasks. For an overview of studies see Table 1. In the following paragraphs the state of the art evidence for the Mood-as-Input model will be discussed including the overall results, the research population, the mood induction and goal induction procedures, and the outcome measures used.

It is striking that the overwhelming majority of studies found evidence in support of the Mood-as-Input model, using explicit goal (stop rules) instructions. The few studies that failed to demonstrate Mood-as-Input effects are studies that "measured" stop rules instead of experimentally manipulating them. In two studies which, instead of giving explicit goal instructions, used a questionnaire to measure hedonic and achievement goals in the domain of workaholism, no interaction effects between mood and naturally adopted goals were found (Wijhe 2011a; 2011b). Furthermore, Turner \& Wilson (2010) failed to demonstrate Mood-as-Input effects in the domain of worrying, in young adolescents, when stop rules were measured with a questionnaire. However, with three studies finding Mood-as-Input effects using questionnaires to measure stop rules (Davey et al., 2005; Startup \& Davey, 2001; 2003), results are ambiguous, and the question remains whether the Mood-as-Input model is valid when no explicit goal instructions are used.

Although the Mood-as-Input model has been applied to different clinical domains such as Obsessive Compulsive Disorder, General Anxiety Disorder, and depression, evidence comes from analogue experimental studies using primarily non-clinical, student populations. 
Only one study used a clinical population, applying the Mood-as-Input model to physical task persistence in the domain of pain (Karsdorp, Nijst, Goossens, \& Vlaeyen, 2010). This study demonstrated that explicit achievement goal instructions as opposed to hedonic goal instructions significantly enhance task persistence, defined as task duration during a painful weight-lifting task in patients with work-related upper extremity pain. These effects were found above and beyond the effect of pain-related fear (Karsdorp, et al., 2010). Additionally, an independent effect of mood was found with individuals in a positive mood demonstrating longer task persistence than individuals in a negative mood state. However no interaction effect of mood and goals was found. Hence the question remains whether the Mood-as-Input model applies to the domain of pain. So far evidence for the applicability of the Mood-asInput model to the domain of pain is scarce and further research is needed, as the Mood-asInput model could provide an explanation for the cognitive-behavioral mechanisms behind the potential disabling effects of both avoidance behavior and persistence behavior, which is currently lacking in pain research.

The overview of Mood-as-Input studies (Table 1) shows that some studies only assessed current mood state but that the majority of the studies used a mood induction procedure to manipulate mood. Most studies induced general positive versus negative mood; occasionally, a neutral mood condition was used. Overall, two mood induction procedures can be distinguished: mood induction by means of film fragments or by means of music fragments. In order to optimize mood induction and decrease demand characteristics, it seems important that participants do not make a direct link between the mood-induction procedure and mood measures (Rottenberg, Ray, \& Gross, 2007). In the Mood-as-Input literature, there are a number of studies using the same mood manipulation procedure, consisting of the following music fragments: Gyorgy Ligety, Lux Aetarna for negative mood induction, and Vivaldi, Four seasons for positive mood induction (Davey et al., 2003; Hawksley and Davey, 2010; MacDonald \& Davey, 2005a, 2005 b; Startup \& Davey, 2001, 2003; Turner et al., 2010; van den Hout et al. 2007; Wright, 2005). However, these studies did not report controlling for demand characteristics by disguising the purpose of the mood manipulation. The advantages of film fragments to music fragments is that they are easier to implement into an experimental procedure aimed at disguising the purpose of the mood manipulation, thus entailing lower levels of demand characteristics. Furthermore it is supposed to establish mood activation across a broader range of response systems (Rottenberg et al., 2007).

Overall, results of mood induction in the Mood-as-Input literature show that mood manipulations mainly affect the relative difference between positive and negative mood condition directly after the mood induction. It is more difficult to establish a significant increase in a target mood between pre- and post-mood induction. Especially in the case of positive mood induction, some studies failed to increase positive mood as compared to baseline conditions or as opposed to a neutral mood condition (Davey et al., 2003; Hawksley 
and Davey, 2010; MacDonald \& Davey, 2005a, 2005b; Startup \& Davey, 2001, 2003; Wright, 2005). Other studies did not measure baseline mood (Martin et al., 1993, Martin et al. 2007; van den Hout 2007, Sana et al., 1996, 200, 2003) or did not report pre- and postdifferences within mood conditions (Turner et al., 2010). Mood induction literature shows that it is a common feature of mood induction procedures that positive mood is more difficult to induce than negative mood and persists for less time after the induction than negative mood (Gerrards-Hesse, Spies, \& Hesse, 1994; Philippot, 1993).

The dependent variable used in Mood-as-Input research is task persistence in an open- ended task. In the majority of the Mood-as-Input studies, task persistence is operationalized as the number of steps in an open-ended task (such as number of steps in a catastrophizing or rumination, the number of sentences read during an impression formation task, the number of birds listed, the number of checks performed in a checking task). Another way to operationalize is as time spent on a task or task duration. A closer look at the nature of the tasks that are used in Mood-as-Input research reveals that they have a primary cognitive as opposed to instrumental focus (e.g. the impression formation task (Martin, et al., 1993), listing bird names (Martin, et al., 1993), the error correction task (Davey, Startup, Zara, MacDonald, \& Field, 2003; MacDonald \& Davey, 2005; MacDonald \& Davey, 2005; van den Hout, Kindt, Luigjes, \& Marck, 2007), the depression rumination task (Hawksley \& Davey, 2010; Watkins \& Mason, 2002) and the catastrophizing worry task (Startup \& Davey, 2001, 2003; Turner \& Wilson, 2010). As pain patients particularly have problems with physical activities, physical instead of cognitive task persistence is especially relevant in the domain of pain, and the question remains whether the Mood-as-Input model also applies when tasks are used which have a primarily motor focus and a physical instead of a cognitive load.

Compared to the above-described models, the Mood-as-Input model seems a more promising model to account for task persistence in chronic pain. One of the advantages of Mood-as-Input model is that it may account for findings that are inconsistent with the Fear-Avoidance model. For example, some pain studies have found better instead of worse performances under negative mood conditions (de Gier, et al., 2003; Severeijns, et al., 2005; van den Hout, et al., 2001). These findings might suggest that variables other than fearavoidance variables, such as goal- related variables could play a role in explaining task persistence. The Mood-as-Input model could explain these finding by predicting a statistical interaction between mood and goals leading to a greater or a lesser extent of task persistence under negative mood conditions dependent on whether an achievement goal or hedonic goal is adopted. In the context of pain, the goal to avoid pain (pain-avoidance goal) might be a particular case of a general hedonic goal. In line with Mood-as-Input theory, negative mood in combination with achievement goals would signal that not enough progress has been made, leading to greater task persistence than negative mood in combination with hedonic (pain-avoidance) goals signaling that the task is no longer enjoyable. In the long run two 


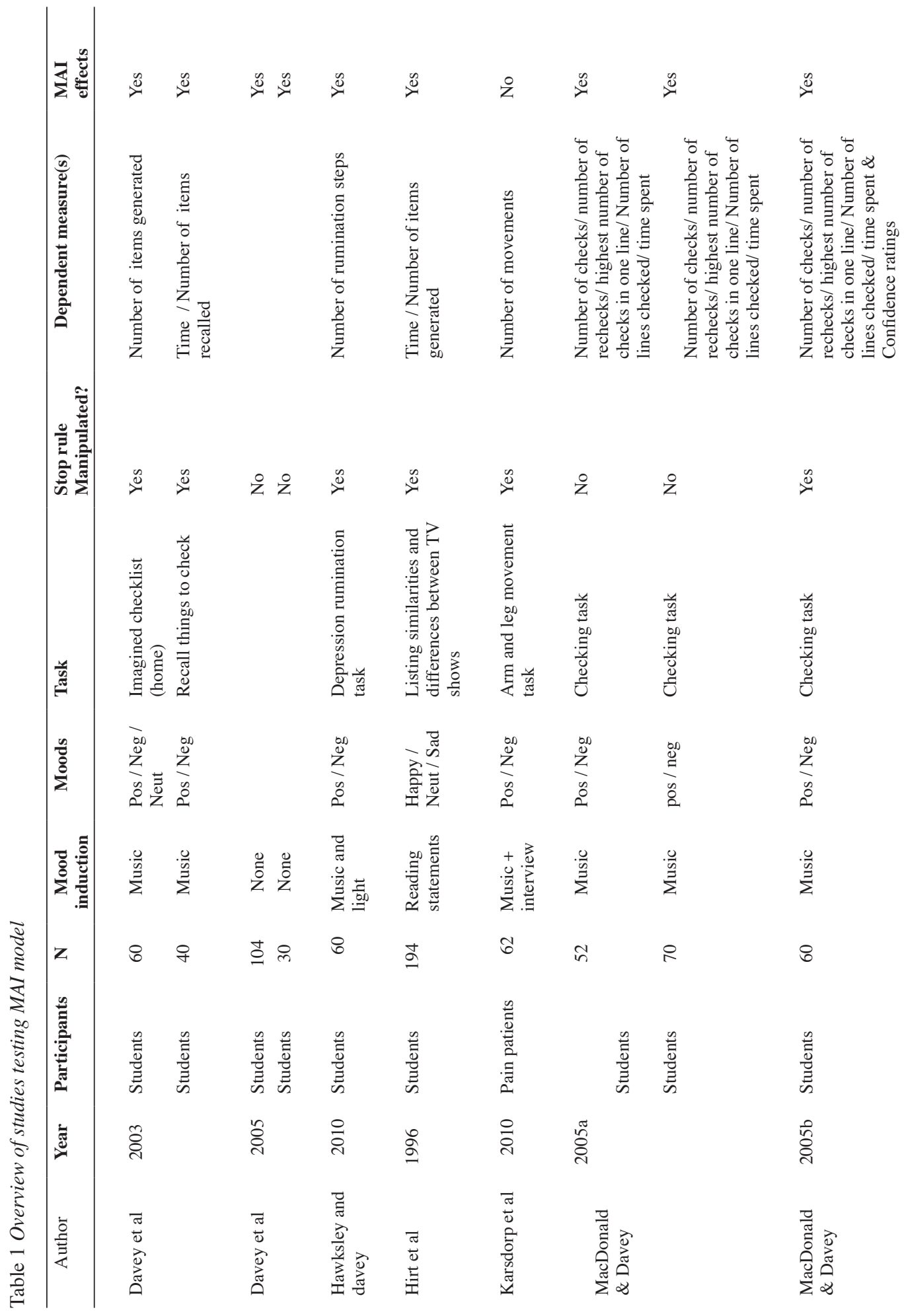




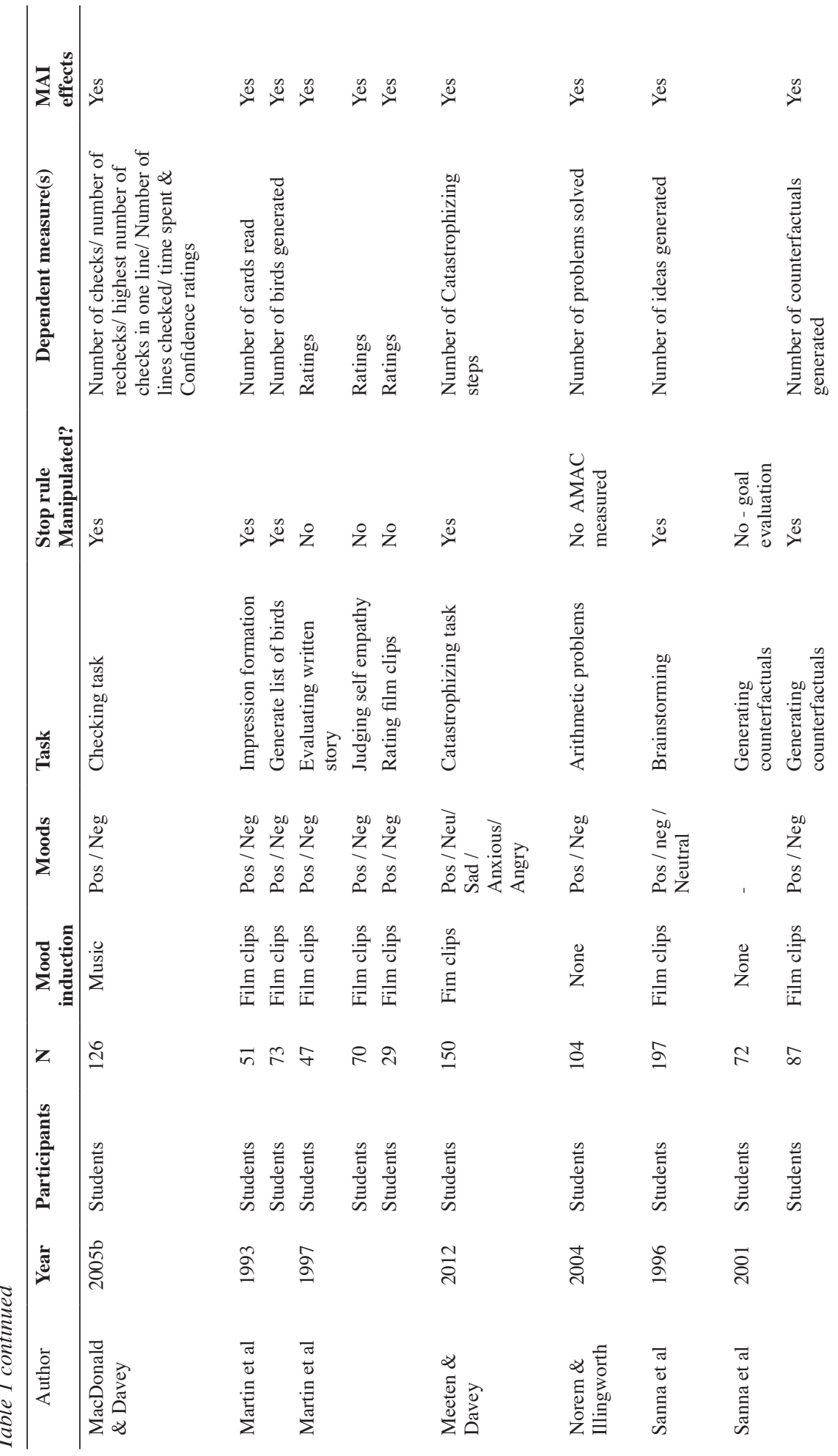




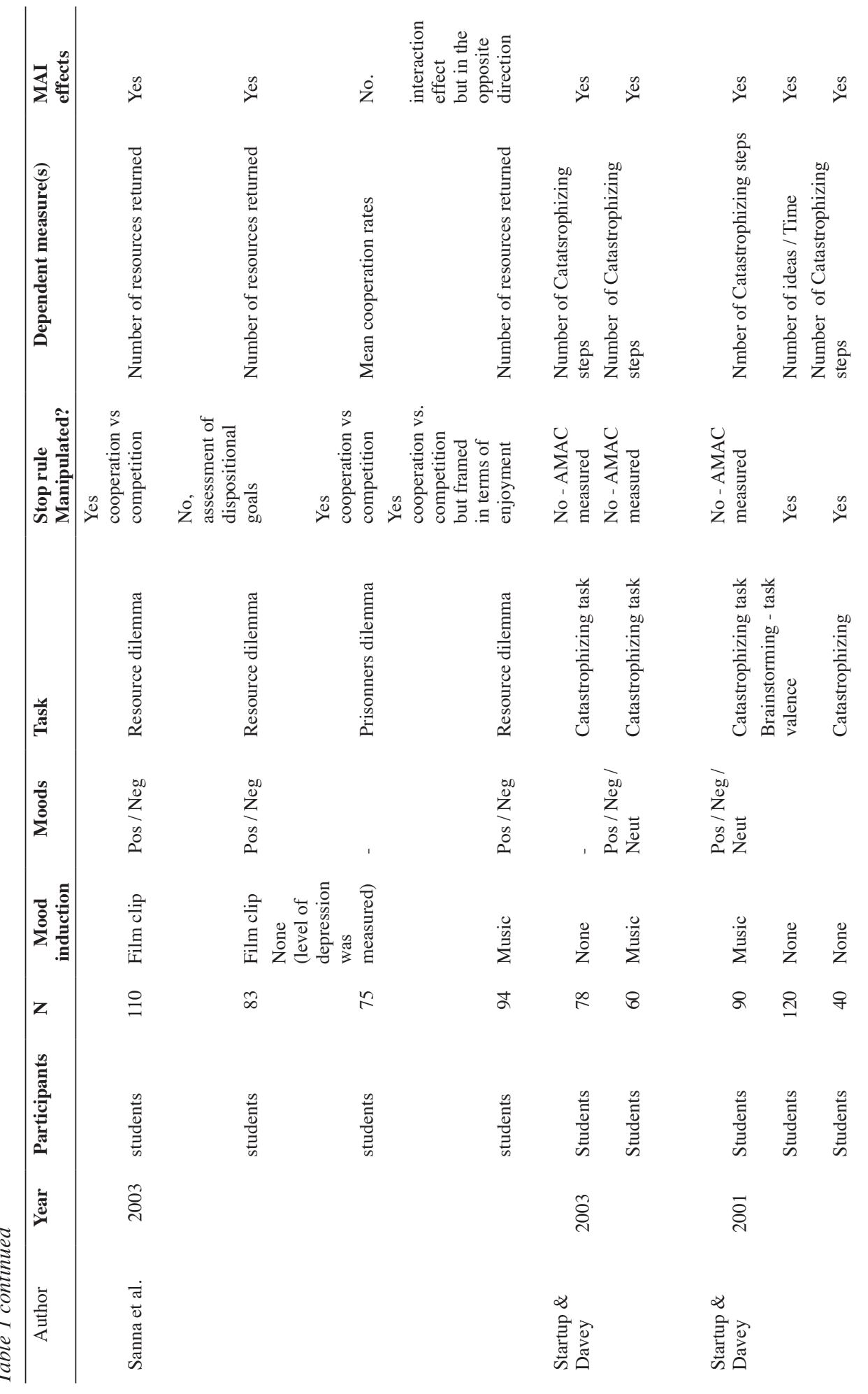




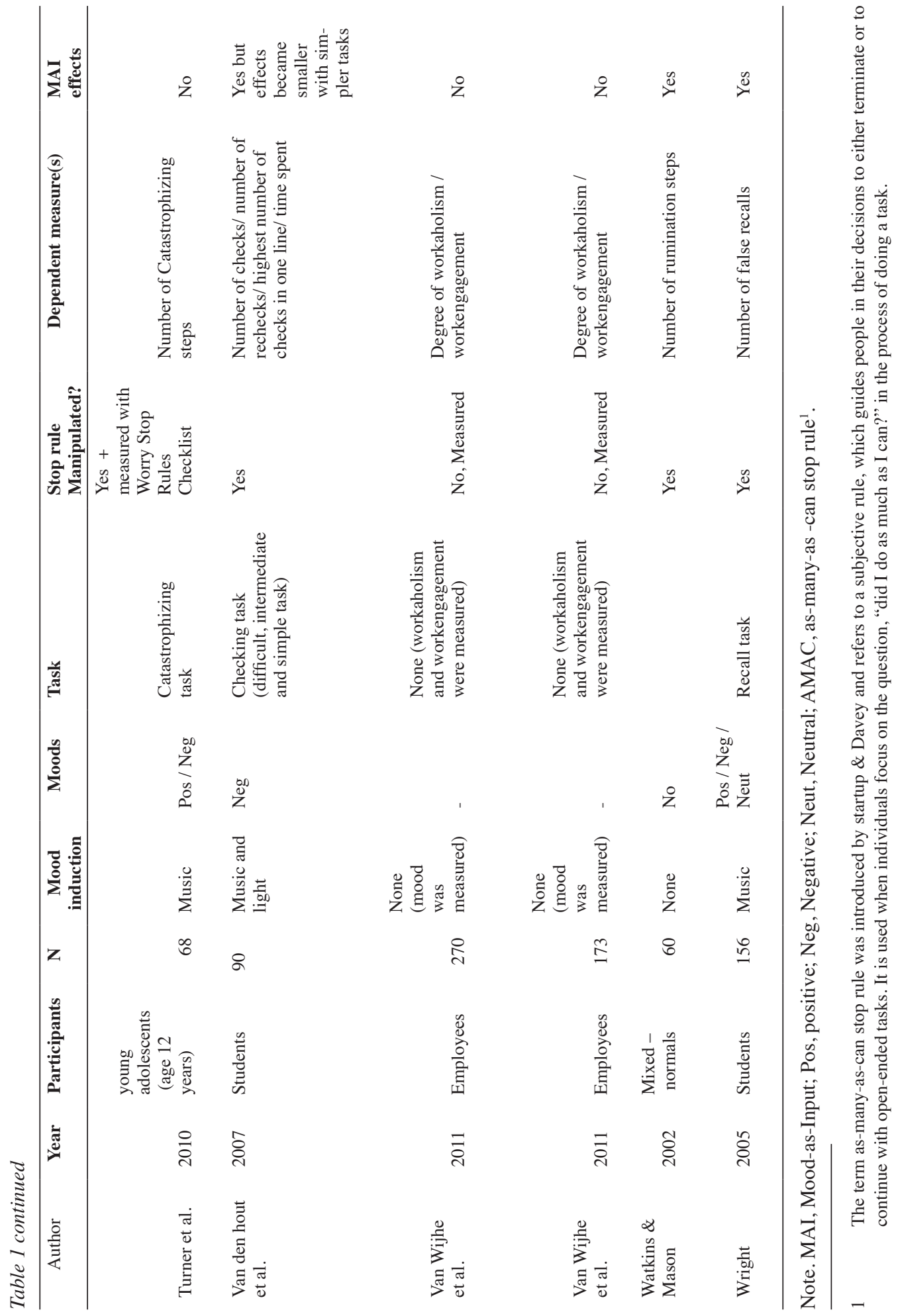


pathways to disability can be distinguished: avoidance behavior is thought to be associated with disability through disuse, while persistence behavior is thought to be associated with disability through overuse.

A particular strength of applying the Mood-as-Input model to the domain of pain is that, compared to the Fear-Avoidance model, it can explain a wider range of behaviors, incorporating the predictions of the Fear-Avoidance model concerning avoidance behavior but also offering an explanation for increased levels of activity. Moreover, it might explain fluctuations in task performance and activity levels of chronic pain patients as a function of changing mood and /or goals (Figure 2).

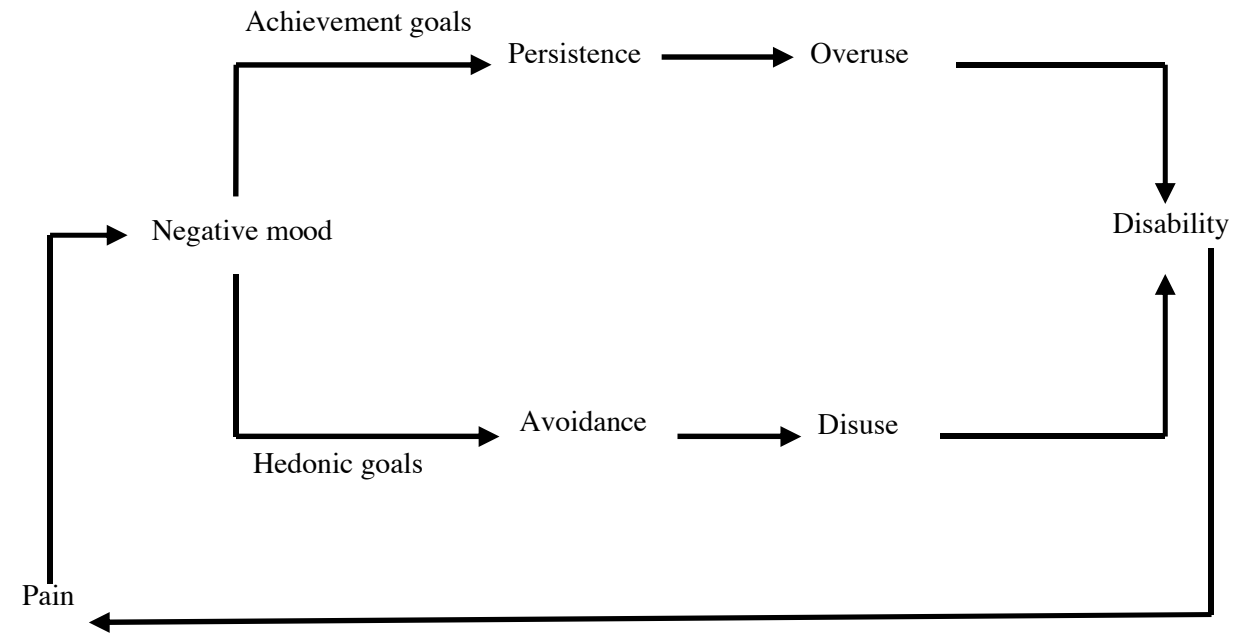

Figure 2. Graphical representations of the pathways leading to disability as predicted by the Moodas-Input model when applied to pain. The Mood-as-Input model incorporates the predictions of the Fear-Avoidance model, linking avoidance behavior to disability but also offers an explanation for the disabling effects of increased levels of activity (Vlaeyen \& Morley, 2004).

In comparison to the Avoidance-Endurance model, the Mood-as-Input model proposes one underlying mechanism explaining both increased and decreased levels of activity. More specifically, Mood-as-Input adds a motivational mechanism, taking into account that pain does not occur in a vacuum but in a context of goal pursuit. The Mood-as-Input approach seems also more parsimoniously than the mood congruency approach because it can explain both mood-congruent and incongruent effects with a single mechanism without resorting to overriding principles. Compared to goal-setting theory, the Mood-as-Input model has the advantage that it takes into account a broader range of contextual factors, acknowledging that goals are often accompanied by mood states that could possibly influence the interpretation of these goals and their effect on behavior. 


\section{Focus and Outline of the Present Dissertation}

The overview of the Mood-as-Input literature presented above reveals that the Mood-asInput model has mainly been experimentally tested using explicit verbal instructions to activate goals. As in everyday life a lot of activities are performed without following explicit verbal instructions, an unresolved question is whether the Mood-as-Input model still applies when other than explicit goal instructions are used. The main objective of this thesis is to investigate the applicability of Mood-as-Input model to the domain of pain when goals are 1) induced by means of supraliminal or subliminal goal priming, or 2) assessed using habitual goal preferences.

\subsection{Goal Priming}

Research form the area of social psychology has shown that achievement goals can be induced by means of supraliminal or subliminal priming (Bargh, Chen, \& Burrows, 1996; Bargh \& Ferguson, 2000; Bargh, Gollwitzer, Barndollar, \& Trotschel, 2001; Custers et al. 2009; Eitam, Hassin, \& Schul, 2008; Hart \& Albaracin, 2009; Oikawa, 2004; Shanz \& Latham, 2009; Stajkovic, Locke, \& Blair, 2006) In the case of supraliminal priming, participants are aware of the stimulus input, but unaware of the consequence of their goals on subsequent behaviour; in the case of subliminal priming, participants are unaware of both the stimulus input that evokes the goal and the subsequent influence on their behaviour. The mechanism underlying goal priming is based on the idea that contextual cues can activate a mental goal representation, which can in turn influence behaviour (Bargh, 1990, 2006). Repeated experience of a goal in a certain context can lead to the association of that goal with the characteristics of the context. This can influence behaviour by means of context cues that trigger goal directed behaviour (Bargh, 2006). Considering the accumulating evidence for the priming of achievement goals, it seems plausible that also the goals of the Mood-as-Input model (achievement and hedonic goals) can be primed.

\subsection{Habitual Hedonic and Achievement Goals}

Research shows that priming effects are subtle. Goal priming manipulations are often short-lived, and can easily be overruled by other variables, such as individual differences in habitual goal preferences. Another way to study the Mood-as-Input model without the use of explicit goal instructions is, instead of experimentally manipulating goal preferences by means of goal priming, measuring personal habitual preferences for achievement versus hedonic goals. Habitual goal preferences are defined as preferences that people naturally adopt for one particular goal in favour of another conflicting goal (Karsdorp \& Vlaeyen, 2011). Some Mood-as-Input studies investigated the role of naturally adopted hedonic and 
achievement goals or habitual goals on task persistence. In the domain of workaholism (Van Wijhe, Peeters, \& Schaufeli, 2011) and Obsessive Compulsive Disorder (Davey, Startup, MacDonald, Jenkins, \& Patterson, 2005), main effects of achievement goals on task persistence were found. In the domain of pain, so far no research has been conducted studying the influence of habitual goals and mood on task persistence. In order to assess habitual goals in the domain of pain the Goal Pursuit Questionnaire was developed (Karsdorp \& Vlaeyen, 2009a). A particular feature of the Goal Pursuit Questionnaire is that it measures the relative strength of habitual goal preferences for hedonic versus achievement goals, rather than the strength of the preference of each goal separately. In chapter 6 of this dissertation, the combined influence of habitual goals and mood is investigated in patients with chronic back complaints. In line with the Mood-as-Input hypothesis an interaction between mood and habitual goals is expected.

\subsection{Moderating Effects}

Within the priming literature it has been shown that the effect of goal-related stimuli can be moderated by habitual goals (Aarts, et al., 2005; Fitzsimons \& Bargh, 2003; Karremans, Stroebe, \& Claus, 2006; Radel, Sarrazin, \& Pelletier, 2009; Strahan, Spencer, \& Zanna, 2002). For example, research has demonstrated that the presentation of help-related stimuli increased helpful behavior only in people with strong pre-existing goals of helping (Aarts, 2005; Fitzimons \& Bargh, 2003; Strahan et. al.2002). Likewise, it was found that achievement-related stimuli promoted an achievement goal and the inhibition of a fun goal in individuals with chronically high achievement motivation. The same achievement primes promoted a fun goal and the inhibition of an achievement goal in individuals with chronically low achievement motivation (Hart \& Albarracin, 2009).

Given the above-described results, it seems plausible that within the Mood-asInput framework, the influence of mood and primed achievement and hedonic goals on task persistence might be moderated by habitual goals. More specifically, we expect for example that primed achievement goals in combination with mood only influence persistence behaviour in individuals with strong habitual preferences for achievement over hedonic goals and not in individuals with opposite preferences. This hypothesis will be tested in chapter 3 of this dissertation.

\subsection{Hedonic and Achievement Goals in a Pain Context: the Role of Pain Catastrophizing}

As described above, the Mood-as-Input model proposes that the interaction between contextual factors such as mood and goals predicts task persistence. In the domain of pain, pain catastrophizing, defined as a set of exaggerated negative cognitive and emotional beliefs 
that are activated during actual or anticipated painful stimulation (Quartana, Campbell, \& Edwards, 2009) has shown to influence task persistence. Pain catastrophizing is characterized by the tendency to magnify the threat value of a pain stimulus, by feelings of helplessness and by a relative inability to inhibit pain-related thoughts in the context of pain (Sullivan, Bishop, \& Pivik, 1995). According to the Fear-Avoidance model, pain catastrophizing is supposed to play a causal role in the avoidance of painful situations (Vlaeyen \& Linton, 2000). However, this relationship is not always found in the available literature (McGowan, Sharpe, Refshauge, \& Nicholas, 2009; Meredith, Strong, \& Feeney, 2006; Rhudy, et al., 2009; Severeijns, et al., 2005). This might suggest that other contextual factors such as mood and the threat value of a situation could play a role in strengthening or weakening the relationship between pain catastrophizing and the degree of task persistence. Within the framework of the Mood-asInput model, pain catastrophizing may be associated with the adoption of a pain-avoidance goal, particularly in pain threatening situations. In the context of pain, negative and positive mood may give different information about whether an activity is threatening or safe. This hypothesis is further supported by evidence from the anxiety literature. In line with studies demonstrating that high trait anxious individuals tend to infer danger on the basis of their negative moods (Arntz, Rauner, \& van den Hout, 1995; Gangemi, Mancini, \& van den Hout, 2007; Wells \& Papageorgiou, 2001), it could be that high trait catastrophizing individuals infer danger on the basis of their negative mood and safety on the basis of positive mood, particularly in a pain threatening context. In this respect, an interesting question is whether mood and threat context moderate the relationship between pain catastrophizing and painful task persistence. This will be investigated in chapter 5 of this dissertation.

\subsection{The Main Research Questions}

As noted above, the state of the art evidence for the Mood-as-Input model leaves some interesting questions that remain unanswered. The following research questions will be addressed in the present dissertation.

1. What is the relationship between the different activity-related behavioral strategies (avoidance, persistence and pacing) and levels of functioning? Are there particular combinations of behavioral strategies that are more dysfunctional than others?

2. Can achievement and hedonic goals be primed by means of supraliminal or subliminal priming?

3. Do the predictions based on the Mood-as-Input model hold when primed goals or habitual goals are used instead of explicit goal instructions?

4. Do the predictions based on the Mood-as-Input model hold within a high and low pain threatening context? 
5. Do the predictions based on the Mood-as-Input model hold in patients with chronic back pain, when habitual goal preferences are used instead of explicit goal instructions.

In order to answer these questions we will, in a first step, explore whether activity-related behavioral strategies (avoidance, persistence or pacing) predict physical and emotional functioning in patients with chronic pain. Subsequently, we will investigate whether the combination of mood and hedonic and achievement goals influence non-painful task persistence in a healthy population, and whether the hedonic and achievement goals can be made more accessible by means of supraliminal or subliminal priming. Furthermore the role of pain catastrophizing (as a proxy for the adoption of a pain-avoidance goal) and mood on painful task persistence will be studied within a high threatening or low threatening context in a healthy population. Finally, the role of mood and habitual hedonic and achievement goals will be studied in patients with chronic back complaints.

\subsection{Outline of the Dissertation}

Chapter 2 concerns a correlational study testing relationships between activity levels and levels of functioning (Study I). As the Mood-as-Input model offers a theoretical framework for the understanding of both increased in decreased levels of activity in the domain of pain, we will explore the relationship between activity-related behavioural strategies (avoidance, persistence and pacing) and functioning (disability, depression and pain intensity) in patients with chronic pain.

Chapter 3 presents a first attempt to experimentally investigate the Mood-as-Input model with supraliminal primed achievement and hedonic goals in a healthy population using a non-painful task (Study II). In addition to inducing achievement and hedonic goals by means of priming, habitual goals will be measured with the novel Goal Pursuit Questionnaire (Karsdorp \& Vlaeyen, 2011). In line with the Mood-as-Input model, task persistence is expected to be a function of the interaction between primed goals and mood. Additionally it is expected that participants' habitual goals would moderate the effect of goal primes on task persistence. Task persistence will be measured with an impression formation task, and mood will be induced with positive or negative film fragments.

In chapter 4, we further examine whether the goals of the Mood-as-Input model (achievement and hedonic goals) can be made more accessible by means of supraliminal or subliminal priming (Study III). Supraliminal priming will be done with a scrambled sentence task and subliminal priming with a brief and masked presentation of goal words. Goal accessibility will be measured with a lexical decision task. 
Chapter 5 examines the role of pain catastrophizing and current mood within a high or low threatening pain context (Study IV). It is predicted that pain catastrophizing would be related to less performance duration when participants experience negative moods, but to greater task persistence when participants experience positive moods. Moreover, it was predicted that this effect would be most pronounced in a high threatening pain context. In a healthy population, either positive or negative mood is induced using film fragments. The threat value of the situation is manipulated with high or low threat task instructions, and task persistence on a painful finger pressing will be measured. In contrast to previous Mood-asInput studies, this study measures physical instead of cognitive task persistence.

In chapter 6, the role of mood and the habitual preference for achievement versus pain-avoidance or hedonic goals in physical task persistence is examined in a group of patients with chronic back pain complaints (Study V). Participants receive either a positive or negative mood induction and subsequently perform a weight-lifting task. Goals are not experimentally manipulated; instead the participants' habitual goals are measured with the Goal Pursuit Questionnaire. In line with the Mood-as-Input model, an interaction between habitual goal and mood on task persistence is tested. More specifically, it is predicted that individuals who have stronger preferences for habitual achievement goals relative to painavoidance goals will show greater task persistence when they are in a negative mood than when they are in a positive mood. With respect to the hedonic goal, the opposite pattern is expected.

Finally, chapter 7 summarizes the findings and provides a critical discussion of the studies presented in this thesis. Furthermore, this chapter presents some conceptual considerations and recommendations, and new directions for further research. 


\section{References}

Aarts, H., Chartrand, T. L., Custers, R., Danner, U., Giel, D., Jefferies, V. E., et al. (2005). Social stereotypes and automatic goal pursuit. Social Cognition, 23(6), 465-490.

Arntz, A., Rauner, M., \& van den Hout, M. (1995). "If I feel anxious, there must be danger": exconsequentia reasoning in inferring danger in anxiety disorders. Behavior Research and Therapy, 33(8), 917-925.

Asmundson, G. J., Norton, G. R., \& Allerdings, M. D. (1997). Fear and avoidance in dysfunctional chronic back pain patients. Pain, 69(3), 231-236.

Andersen, J.H., Haahr, J.P., Frost, P. (2007). Risk for more severe regional musculoskeletal symptoms: a two-year prospective study of a general working population. Arthritis \& Rheumatism, 56, $1355-1364$.

Bargh, J. A. (2006). What have we been priming all these years? On the development, mechanisms, and ecology of nonconscious social behavior. European Journal of Social Psychology, 36, 147-168.

Bargh, J. A., Chen, M., \& Burrows, L. (1996). Automaticity of social behavior: direct effects of trait construct and stereotype-activation on action. Journal of Personality and Social Psychology, $71(2), 230-244$.

Barnes Holmes, Y., Barnes Holmes, D., McHugh, L., \& Hayes, S.C. (2004). Relational frame theory: some implications for understanding and treating human psychopathology, International Journal of Psychology and Psychological Therapy, 4, 355-375.

Barr, A.E., Barbe, M.F. (2002). Pathophysiological tissue changes associated with repetitive movement: a review of the evidence. Physical Therapy, 82,173-87.

Bower, G. H. (1981). Mood and Memory. American Psychologist, 36(2), 129-148.

Breivik, H., Collett, B., Ventafridda, V., Cohen, R., \& Gallacher, D. (2006). Survey of chronic pain in Europe: prevalence, impact on daily life, and treatment. European Journal of Pain, 10 (4), 287-333.

Carter, L. E., McNeil, D. W., Vowles, K. E., Sorrell, J. T., Turk, C. L., Ries, B. J., et al. (2002). Effects of emotion on pain reports, tolerance and physiology. Pain Research and Management, 7(1), 21-30.

Clark, M. S., \& Isen, A. M. (1982). Toward understanding the relationship between feeling states and social behavior In A. Hastorf \& A. M. Isen (Eds.), Cognitive Social Psychology (pp. 73-108). New York: Elsevier.

Crombez, G., Eccleston, C., Van Damme, S., Vlaeyen, J. W., \& Karoly, P. (2012). Fear-avoidance model of chronic pain: the next generation. Clinical Journal of Pain, 28(6), 475-483.

Crombez, G., Vervaet, L., Lysens, R., Baeyens, F., \& Eelen, P. (1998). Avoidance and confrontation of painful, back-straining movements in chronic back pain patients. Behavior Modification, 22(1), 62-77.

Crombez, G., Vlaeyen, J. W., Heuts, P. H., \& Lysens, R. (1999). Pain-related fear is more disabling than pain itself: evidence on the role of pain-related fear in chronic back pain disability. Pain, 80(1-2), 329-339. 
Davey, G. C., Startup, H. M., MacDonald, B. A., Jenkins, D., \& Patterson, K. (2005). The use of 'as many as can' versus 'feel like continuing' stop rules during worrying. Cognitive Therapy and Research, 29(2), 155-169.

Davey, G. C., Startup, H. M., Zara, A., MacDonald, C. B., \& Field, A. P. (2003). The perseveration of checking thoughts and mood-as-input hypothesis. Journal of Behavior Therapy and Experimental Psychiatry, 34(2), 141-160.

de Gier, M., Peters, M. L., \& Vlaeyen, J. W. (2003). Fear of pain, physical performance, and attentional processes in patients with fibromyalgia. Pain, 104(1-2), 121-130.

de Wied, M., \& Verbaten, M. N. (2001). Affective pictures processing, attention, and pain tolerance. Pain, 90(1-2), 163-172.

Ersek, M., Turner, J. A., \& kemp, C. A. (2006). Use of the chronic pain coping inventory to assess oder adults' pain coping strategies. The Journal of Pain, 7(11), 833-842.

Feuerstein, M., Nicholas, R. A., Huang, G. D., Haufler, A. J., Pransky, G., \& Robertson, M. (2005). Workstyle: development of a measure of response to work in those with upper extremity pain. Journal of Occupational Rehabilitation, 15(2), 87-104.

Fitzsimons, G. M., \& Bargh, J. A. (2003). Thinking of you: nonconscious pursuit of interpersonal goals associated with relationship partners. Journal of Personality and Social Psychology, 84(1), 148-164.

Flor, H., Knost, B., \& Birbaumer, N. (2002).The role of operant conditioning in chronic pain: an experimental investigation. Pain , 95, 111-118.

Fordyce, W. (1976). Behavioral methods for chronic pain and inllness. Saint Louis: The C.V. Mosby Company.

Forgas, J. P., \& Bower, G. H. (1987). Mood Effects on Person-Perception Judgements. Journal of Personality and Social Psychology, 53(1), 53-60.

Gangemi, A., Mancini, F., \& van den Hout, M. (2007). Feeling guilty as a source of information about threat and performance. Behavior Research and Therapy, 45(10), 2387-2396.

Garcia-Campayo, J., Pascual, A., Alda, M., \& Ramirez, M. T. (2007). Coping with fibromialgia: usefulness of the chronic pain coping inventory-42. Pain, 132, 68-76.

Gatzounis, R., Schrooten, M., Crombez, G., \& Vlaeyen, J. (2012). Operant learning theory in pain and chronic pain rehabilitation. Current Pain and Headache Reports, 16, 117-126.

Gerrards-Hesse, A., Spies, K., \& Hesse, F. W. (1994). Experimental inductions of emotional states and their effectiveness: A review. British Journal of Psychology, 85, 55-78.

Hart, W., \& Albarracin, D. (2009). The effects of chronic achievement motivation and achievement primes on the activation of achievement and fun goals. Journal of Personality and Socical Psychology, 97(6), 1129-1141.

Hasenbring, M. I., Hallner, D., \& Rusu, A. C. (2009). Fear-avoidance- and endurance-related responses to pain: development and validation of the Avoidance-Endurance Questionnaire (AEQ). European Journal of Pain, 13(6), 620-628. 
Hasenbring, M. I., Plaas, H., Fischbein, B., \& Willburger, R. (2006). The relationship between activity and pain in patients 6 months after lumbar disc surgery: do pain-related coping modes act as moderator variables? European Journal of Pain, 10(8), 701-709.

Hasenbring, M. I., \& Verbunt, J. A. (2010). Fear-avoidance and endurance-related responses to pain: new models of behavior and their consequences for clinical practice. Clinical Journal of Pain, 26(9), 747-753.

Hawksley, J., \& Davey, G. C. (2010). Mood-as-input and depressive rumination. Behavior Research and Therapy, 48(2), 134-140.

Isen, A. M., Shalker, T. E., Clark, M., \& Karp, L. (1978). Affect, Accessibility of Material in Memory, and Behaviour: A Cognitive Loop? . Personality and Social Psychology, 36(1), 1-12.

Jensen, M. P., Turner, J. A., Romano, J. M., \& Strom, S. E. (1995). The Chronic Pain Coping Inventory: development and preliminary validation. Pain, 60(2), 203-216.

Jolliffe, C.D., Nicholas, M.K. (2004). Verbally reinforcing pain reports: an experimental test of the operant model of chronic pain. Pain, 107, 167-75.

Karremans, J. C., Stroebe, W., \& Claus, J. (2006). Beyond Vicary's fantasies: The impact of subliminal priming and brand choice. Journal of Experimental Social Psychology, 42(6), 792-798.

Karsdorp, P. A., \& Vlaeyen, J. W. (2009a). Active avoidance but not activity pacing is associated with disability in fibromyalgia. Pain, 147, 29-35.

Karsdorp, P. A., \& Vlaeyen, J. W. (2009b). Chronic pain: avoidance or endurance? European Journal of Pain, 13(6), 551-553.

Karsdorp, P. A., Nijst, S. E., Goossens, M. E., \& Vlaeyen, J. W. (2010). The role of current mood and stop rules on physical task performance: An experimental investigation in patients with workrelated upper extremity pain. European Journal of Pain, 14(4), 434-440.

Karsdorp, P. A., \& Vlaeyen, J. W. (2011). Goals matter: both achievement and pain-avoidance goals are associate with pain severity and disability in patients with musculoskeletal pain. Pain, $152,1382-1390$.

Keefe, F. J., Lefebvre, J. C., Maixner, W., Salley, A. N., Jr., \& Caldwell, D. S. (1997). Self-efficacy for arthritis pain: relationship to perception of thermal laboratory pain stimuli. Arthritis Care Research, 10(3), 177-184.

Lazarus, R.S., \& Folkman, S. (1984). Stress, Appraisal and Coping. New York: Springer.

Leeuw, M., Goossens, M. E., Linton, S. J., Crombez, G., Boersma, K., \& Vlaeyen, J. W. (2007). The fear-avoidance model of musculoskeletal pain: current state of scientific evidence. Journal of Behavioral Medicine, 30(1), 77-94.

Locke, E. A., \& Latham, G. P. (1990). A theory of goal setting \& task performance. Englewood Cliffs, NJ: Prentice Hall.

Locke, E. A., \& Latham, G. P. (2002). Building a practically useful theory of goal setting and task motivation. A 35-year odyssey. American Psychologist, 57(9), 705-717.

MacDonald, B., \& Davey, G. C. (2005). Inflated responsibility and perseverative checking: the effect of negative mood. Journal of Abnormal Psychology, 114(1), 176-182. 
MacDonald, B. A., \& Davey, G. C. L. (2005). A mood-as-input account of perserverative checking: the relationship between stop rules, mood and confidence in having ceheckd succesfully. Behavior Research and Therapy, 43, 69-91.

Martin, L., Ward, D. W., Achee, J. W., \& Wyer, R. S. (1993). Mood as input: people have to interpret the motivaitional implications of their Moods. Journal of Personality and Social Psychology, 64(3), 317-326.

Mayer, J. D., Gaschke, Y. N., Braverman, D. L., \& Evans, T. (1992). Mood Congruent Judgement Is a General Effect. Journal of Personality and Social Psychology, 63(1), 119-132.

McCracken, L. M., \& Samuel, V. M. (2007). The role of avoidance, pacing and other activity patterns in chronic pain. Pain, 130, 119-125.

McGowan, N., Sharpe, L., Refshauge, K., \& Nicholas, M. K. (2009). The effect of attentional retraining and threat expectancy in response to acute pain. Pain, 142(1-2), 101-107.

Meeten, F., \& Davey, G. C. (2011). Mood-as-input hypothesis and perseverative psychopathologies. Clinical Psychology Review, 31(8), 1259-1275.

Meredith, P. J., Strong, J., \& Feeney, J. A. (2006). The relationship of adult attachment to emotion, catastrophizing, control, threshold and tolerance, in experimentally-induced pain. Pain, $120(1-2), 44-52$

Moore, R. J. (2009). Biobehavioral Approaches to Pain. New York: Springer

Moors, A., \& De Houwer, J. (2006). Automaticity: a theoretical and conceptual analysis. Psychological Bulletin, 132(2), 297-326.

Moss-Morris, R., Sharon, C., Tobin, R. \& Baldi, J.C. (2005). A randomized controlled graded exercise trial for chronic fatigue syndrome: outcomes and mechanisms of change. Journal of Health Psychology, 10, 245-59.

Nielson, W. R., Jensen, M. P., \& Hill, M. L. (2001). An activity pacing scale for the chronic pain coping inventory: development in a sample of patients with fibromyalgia syndrome. Pain, 89(2-3), 111-115.

Philippot, P. (1993). Inducing and assessing differentiated emotion-feeling states in the laboratory. Cognition and Emotion, 7, 171-193.

Quartana, P. J., Campbell, C. M., \& Edwards, R. R. (2009). Pain catastrophizing: a critical review. Expert Review of Neurotherapeutics, 9(5), 745-758.

Radel, R., Sarrazin, P., \& Pelletier,L. (2009).Evidence of subliminally primed motivational orientations: the effects of unconscious motivational processes on the performance of a new motor task. Journal of Sport and Exercise Psychology, 31(5), 657-674.

Reeves, N.D. (2006). Adaptation of the tendon to mechanical usage. Journal of Musculoskeletal and Neuronal Interactions , 6, 174-180.

Rhudy, J. L., France, C. R., Bartley, E. J., Williams, A. E., McCabe, K. M., \& Russell, J. L. (2009). Does pain catastrophizing moderate the relationship between spinal nociceptive processes and pain sensitivity? Journal of Pain, 10(8), 860-869. 
Rottenberg, J., Ray, R. D., \& Gross, J. J. (2007). Emotion elicitation using films. In J. A. Coan \& J.J.B. Allen (Eds.), The handbook of emotion elicitation and assessment. New York: Oxford University Press.

Schrooten, M. G., \& Vlaeyen, J. W. (2010). Becoming active again? Further thoughts on goal pursuit in chronic pain. Pain, 149(3), 422-423.

Schwarz, N., \& Clore, G. L. (1983). Mood, misattribution, and judgements of well-being: Informative an directive functions of affective states. Journal of Personality and Social Psychology, 45, 513-523.

Severeijns, R., van den Hout, M. A., \& Vlaeyen, J. W. (2005). The causal status of pain catastrophizing: an experimental test with healthy participants. European Journal of Pain, 9(3), 257-265.

Siemer, M. (2005). Mood-congruent cognitions constitute mood experience. Emotion ,3, 96-308.

Skinner, B. F. (1953). Science and human behavior. New York: Macmillan.

Startup, H. M., \& Davey, G. C. (2001). Mood as input and catastrophic worrying. Journal of Abnormal Psychology, 110(1), 83-96.

Startup, H. M., \& Davey, G. C. (2003). Inflated responsibility and the use of stop rules for catastrophic worrying. Behavior Research and Therapy, 41(4), 495-503.

Stevenson, M. K., Kanfer, F. H., \& Higgins, J. M. (1984). Effects of goal specificity and time cues on pain tolerance. Cognitive Therapy and Research, 8, 415-426.

Strahan, E. J., Spencer, S. J., \& Zanna, M. P. (2002). Subliminal priming and persuasion: striking while the iron is hot. Journal of Experimental Social Psychology, 38, 556-568.

Sullivan, M. J., Bishop, S. R., \& Pivik, J. (1995). The Pain Catastrophizing Scale: Development and validation. . Psychological Assessment, 7(4), 524 - 532.

Sullivan, M.J.L. (2008). Toward a biopsychomotor conceptualization of pain: implications for research and intervention. Clinical Journal of Pain(24), 281-290.

Swinkels-Meewisse, I. E., Roelofs, J., Oostendorp, R. A. B., Verbeek, A. L. M., \& Vlaeyen, J.W.S. (2006). Acute low back pain: pain-related fear and pain catastrophizing influence physical performance and perceived disability. Pain, 120, 36-43.

Turk, D.C., Wack J.T, \& Kerns R.D. (1985). An empirical examination of the "painbehavior" construct. Journal of Behavioral Medicine, 8, 119-130.

Turner, L., \& Wilson, C. (2010). Worry, Mood and Stop Rules in Young Adolescents: Does the Moodas-Input Theory Apply? Journal of Experimental Psychopathology, 1(1), 34-51.

Van Damme, S., Crombez, G., \& Eccleston, C. (2008). Coping with pain: a motivational perspective. Pain, 139(1), 1-4.

van den Hout, J.H., Vlaeyen, J.W., Houben, R.M., Soeters, A.P., \& Peters, M.L. (2001). The effects of failure feedback and pain-related fear on pain report, pain tolerance, and pain avoidance in chronic low back pain patients. Pain, 92(1-2), 247-257.

van den Hout, J.H., Vlaeyen, J.W., Peters, M.L., Engelhard, I.M., \& van den Hout, M.A. (2000). Does failure hurt? The effects of failure feedback on pain report, pain tolerance and pain avoidance. European Journal of Pain, 4(4), 335-346. 
van den Hout, M., Kindt, M., Luigjes, J., \& Marck, C. (2007). Compulsive perseveration: empirical criticism on the mood-as-input model. Behavior Research and Therapy, 45(6), 1221-1230.

van der Giessen, R.N., Speksnijder, C.M. \& Helders, P.J. (2012).The effectiveness of graded activity in patients with non-specific low-back pain: a systematic review. Disability and Rehabilitation, 34, 107-1076.

Van Houdenhove, B., Onghena, P., Neerinckx, E., \& Hellin, J. (1995). Does high 'action-proneness' make people more vulnerable to chronic fatigue syndrome? A controlled psychometric study. Journal of Psychosomatic Research, 39, 633-40.

Van Houdenhove, B., \& Neerinckx, E. (1999). Is "ergomania" a predisposing factor to chronic pain and fatigue? Psychosomatics, 40, 529-530.

Van Houdenhoven, B., Neerinckx, E., Onghena, P., Lysens, R., \& Vertommen, H. (2001). Premorbid "overactive" lifestyle in chronic fatigue syndrome and fibromyalgia. An etiological factor or proof of good citizenship? Journal of Psychosomatic Research, 51, 571-576.

Van Wijhe, C. I., Peeters, M. C., \& Schaufeli, W. B. (2011). To stop or not to stop, that's the question: about persistence and mood of workaholics and work engaged employees. International Journal of Behavioral Medicine, 18(4), 361-372.

Veenhof, C., Köke, A.J.A., Dekker, J., Oostendorp, R.A., Bijlsma, J.W.J., Van Tulder, M.W., et al. ( 2006). Effectiveness of behavioral graded activity in patients with osteoarthritis of the hip and/or knee: a randomized clinical trial. Arthritis Care \& Research, 55, 925-934.

Vlaeyen, J. W., Crombez, G., \& Goubert, L. (2007). The psychology of chronic pain and its mangagement. Physical Therapy Reviews, 12(3), 179-188.

Vlaeyen, J. W., Kole-Snijders, A. M., Boeren, R. G., \& van Eek, H. (1995). Fear of movement/(re)injury in chronic low back pain and its relation to behavioral performance. Pain, 62(3), 363-372.

Vlaeyen, J. W., \& Linton, S. J. (2000). Fear-avoindance and its consequences in chronic muskoskeletal pain: a state of the art. Pain, 85, 317-332.

Vlaeyen, J. W., \& Morley, S. (2004). Active despite pain: the putative role of stop-rules and current mood. Pain, 110(3), 512-516.

Vonk, F., Verhagen, A.P., Twisk, J.W., Koke, A.J.A., Luiten, M.W.C.T., \& Koes, B.W. (2009). Effectiveness of a behavioural graded program versus conventional exercise for chronic neck pain patients. European Journal of Pain, 13, 533-541.

Watkins, E., \& Mason,A. (2002). Mood as input and rumination. Personality and Individual Differences, $32,577-587$

Wells, A., \& Papageorgiou, C. (2001). Social phobic interoception: effects of bodily information on anxiety, beliefs and self-processing. Behavior Research and Therapy, 39(1), 1-11.

White, P.D., Goldsmith, K.A., Johnson, A.L., Potts, L., Walwyn, R., et al. (2011) Comparison of adaptive pacing therapy, cognitive behaviour therapy, graded exercise therapy, and specialist medical care for chronic fatigue syndrome (PACE): a randomized trial. Lancet, 377, 823-836.

Willams, S. L., \& Kinney, P. J. (1991). Performance and nonperformance strategies for coping with acute pain: The role of perceived self-efficacy, expected outcomes, and attention. Cognitive Therapy and Research, 15, 1-19. 
Williams, A. C. C. (2002). Facial expression of pain: an evolutionary account. Behavioral and Brain Sciences, 25, 439-456.

Zale, E.L., Lange, K.L., Fields, S.A., \& Ditre, J.W. (2013). The relation between pain-related fear and disability: a meta-analysis. The journal of pain, 14, 1019-1030. 


\section{Chapter 2}

Distinct Combinations of Avoidance, Pacing and Persistence Behavior are Associated with Disability and Depression in Musculoskeletal Pain

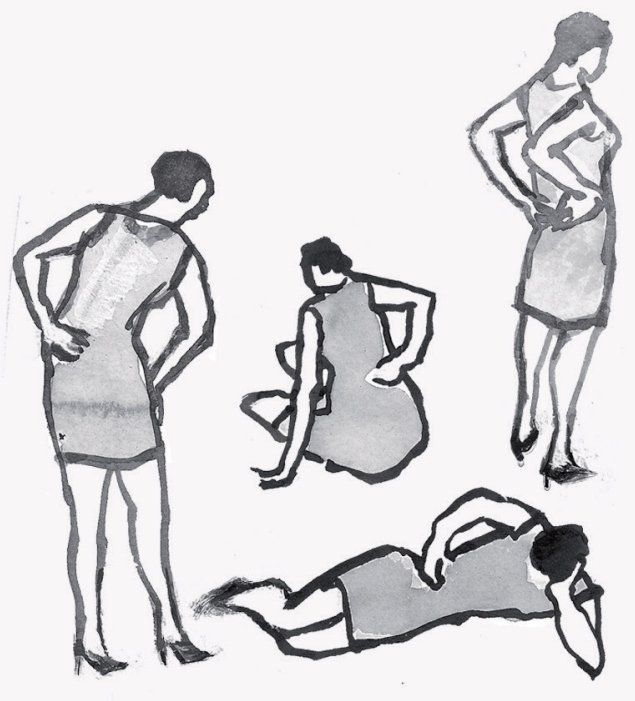




\begin{abstract}
The aims of this study were threefold: to replicate the factor structure of the Pain and Activity Relations Questionnaire in a sample of patients with musculoskeletal pain, to identify subgroups with distinct combinations of behavioral strategies (avoidance, pacing and persistence), and to assess differences amongst the subgroups on disability (Pain Disability Index), depression (Hospital Anxiety and Depression Scale) and pain (Multidimensional Pain Inventory). A sample of 299 participants completed questionnaires online. Exploratory principal factor analysis with oblique rotation was performed on the Pain and Activity Relations Questionnaire items. Subtypes of patients with similar behavioral strategies were identified with a cluster analysis using the mean scores of the Pain and Activity Relations Questionnaire subscales. Results supported the original three-factor structure of the Pain and Activity Relations Questionnaire (avoidance, pacing and persistence). Cluster analysis yielded four subgroups: Persisters, Persistent pacers, Avoidant pacers, and Cyclers. The Persisters reported less disability than the other subgroups, while the Cyclers (high in avoidance, pacing and persistence) reported more disability and depression than the Persistent pacers and more pain catastrophizing than any other cluster. The relationship of pacing with disability depended on its combination with increased avoidance or persistence. Pain report was independent of clusters membership. Findings of the present study indicate that the Dutch version of the Pain and Activity Relations Questionnaire is reliable and corroborates the original three-factor structure. Furthermore, not avoidance, pacing or persistence per se, but their combination is associated with more disability, more pain catastrophizing and more depression. The Persisters, scoring high on persistence and low on avoidance and pacing, reported the most favourable outcomes.
\end{abstract}




\section{Introduction}

Behavioral strategies such as avoidance (Philips, 1987), pacing (Nielson, Jensen, \& Hill, 2001), and persistence or confronting behavior (Hasenbring, Hallner, \& Rusu, 2009; McCracken \& Samuel, 2007) are suggested to be important determinants of disability and emotional functioning in chronic pain (Fordyce, 1976; McCracken \& Samuel, 2007). At present, there is compelling evidence indicating that avoidance behavior has a detrimental effect on disability (Asmundson, Norton, \& Allerdings, 1997; Vlaeyen \& Linton, 2000, 2012). Avoidance behaviour plays a key role in the effects of fear on disability, with avoidance leading to maintenance of fear of pain as it reduces disconfirmation of patients' catastrophic beliefs about pain. As a result, a vicious circle may develop of increasing fear, avoidance and disability (Asmundson, et al., 1997; Crombez, Vlaeyen, Heuts, \& Lysens, 1999; Geisser, Roth, Theisen, Robinson, \& Riley, 2000; Leeuw, et al., 2007; Philips, 1987).

Although the disabling effect of avoidance is well established, the evidence on the role of activity pacing and persistence in disability is limited and contradictory (Ersek, Turner, \& kemp, 2006; Feuerstein, et al., 2005; Garcia-Campayo, Pascual, Alda, \& Ramirez, 2007; Hadjistavropoulos, MacLeod, \& Asmundson, 1999; Jensen, Turner, Romano, \& Strom, 1995). Persistence behavior can be dysfunctional because individuals tend to ignore pain sensations and persist in activities despite severe pain, leading to physical overexertion and overuse (Hasenbring, Plaas, Fischbein, \& Willburger, 2006). However, research has demonstrated that task persistence is not unambiguously associated with disability. Some studies have shown that patients who tend to continue their activities despite increased pain, report more disability (Feuerstein, et al., 2005; Garcia-Campayo, et al., 2007), whereas other studies do not show any relationship (Engel, Schwartz, Jensen, \& Johnson, 2000; Truchon $\&$ Cote, 2005), or even show an inverse relationship (Ersek, et al., 2006; Hadjistavropoulos, et al., 1999; Hasenbring, et al., 2006; Jensen, et al., 1995; Kindermans, et al.; Truchon \& Cote, 2005). The same ambiguous findings hold for research on pacing behaviour. Pacing behaviour can be defined as efforts to modulate activity rate such as: dividing activities into pieces, going slower, maintaining a steady pace, taking breaks, etc... (Nielson, et al., 2001). A couple of recent studies reported that pacing was not significantly associated with physical disability in patients with chronic fatigue syndrome (White, et al., 2011) and fibromyalgia when controlling for pain intensity and pain catastrophizing (Karsdorp \& Vlaeyen, 2009a). Other studies revealed that increased use of pacing was associated both with higher disability in a heterogeneous sample of patients with chronic pain (McCracken \& Samuel, 2007), and with lower disability in patients with fibromyalgia (Nielson, et al., 2001).

One of the reasons for these conflicting results regarding pacing and persistence on disability may be that most studies have mainly focused on the effects of just one activity pattern in isolation, while the particular combination of different behavioral strategies might 
determine whether a certain behavioral response is functional or dysfunctional. Studies that have examined the association between the combination of two or more behavioral strategies and levels of disability, depression and pain are scarce at best. Such research is not only of theoretical importance, it may also have clinical implications as therapeutic interventions aimed at improving physical and emotional functioning that match certain activity profiles are likely to be more effective (Vlaeyen \& Morley, 2005). In a first attempt to do this, McCracken \& Samuel (2007) developed the Pain and Activity Relations Questionnaire, and showed that it contains three relatively independent behavioral strategies (pacing, avoidance and confronting or task persistence). Using cluster analysis techniques, these authors were able to identify distinctive subgroups of patients with different combinations of behavioural strategies in a heterogeneous sample of pain patients. The main conclusion was that especially avoidance and also pacing was related to higher levels of disability and that persistence was related to lower levels of disability, dependent on the degree to which it was combined with avoidance. The profiles with greater avoidance behaviour were associated with greater disability (McCracken \& Samuel, 2007).

The main purpose of the present study is to replicate the factor structure of the Pain and Activity Relation Questionnaire in a Dutch and heterogeneous sample of individuals with chronic pain, to identify subgroups with distinct combinations of behavioral strategies by means of a cluster analysis and to examine the relationship of specific combinations of behavioral strategies with pain catastrophizing, disability, depression, and pain.

\section{Methods}

\subsection{Participants}

The participants were recruited via newspaper advertisements and internet sites inviting people with low back and upper extremity pain to participate in a study that was aimed to examine the effects of pain on their daily functioning. Questionnaires were completed via an internet-based electronic environment named "Emium" (Janssen 2008), enabling completion of the battery of tests online. The inclusion criteria required participants to be between 18 and 65 years and experiencing pain symptoms in at least one of the following body sites: low back, neck, shoulder, upper arm, forearm, elbow, wrist, or hand. People with insufficient knowledge of the Dutch language were excluded. The research protocol was approved by the Medical Ethics Committee of the Faculty of Psychology and Neuroscience of the Maastricht University, and all participants provided written informed consent.

The total sample consisted of 301 participants with pain complaints in the upper extremities, or low back. Two participants were excluded from the analysis because they completed only 4 or less of the 15 questionnaires, leaving the sample size to a total of 299 participants. The dataset of the study contained 641 missing data $(0.64 \%)$ in 39 participants 
$(12.40 \%)$. The non-monotone missing data were imputed using data augmentation and imputation with the program NORM (Schafer, 1999). The program estimates values of missing data based on available data of the other variables in the same data set. Sample characteristics are described in Table 1.

Table 1 Descriptive statistics for the sample characteristics $(n=299)$

\begin{tabular}{|c|c|c|}
\hline Age in yrs & $M(S D)=41.08$ years $(12.71)$, range $18-64$ years & \\
\hline Gender & Men & $18.1 \%$ \\
\hline Level of education ${ }^{\text {a }}$ & $\begin{array}{l}M(S D)=2.06(1.01) \text {, range } 1-4 \\
\text { Primary and secondary education } \\
\text { Intermediate vocational education } \\
\text { Higher vocational education } \\
\text { Higher general education }\end{array}$ & $\begin{array}{l}38.5 \% \\
26.8 \% \\
25.1 \% \\
9.7 \%\end{array}$ \\
\hline Marital status & $\begin{array}{l}\text { Married } \\
\text { Unmarried, living together } \\
\text { Relationship, living apart } \\
\text { Single } \\
\text { Divorced } \\
\text { Widowed } \\
\text { Unmarried, living with parents }\end{array}$ & $\begin{array}{l}42.8 \% \\
21.4 \% \\
4.7 \% \\
15.7 \% \\
8.0 \% \\
1.3 \% \\
6.0 \%\end{array}$ \\
\hline Number of children & $M(S D)=1.11(1.36)$, range $1-9$ & \\
\hline $\begin{array}{l}\text { Number of years ago since first } \\
\text { pain complaints }\end{array}$ & $M(S D)=9.19$ years $(9.13)$, range $0-52$ years & \\
\hline Duration of present pain period & $M(S D)=6.21$ years $(7.97)$, range $0.01-37$ years & \\
\hline Diagnosis reported by the patient & $\begin{array}{l}\text { Upper extremity pain } \\
\text { Fibromyalgia } \\
\text { Rheumatic disorder } \\
\text { Back pain } \\
\text { Combination } 1-4 \\
\text { Other (cancer, whiplash, hypermobility, chronic fatigue } \\
\text { syndrome) } \\
\text { No diagnosis }\end{array}$ & $\begin{array}{l}16.4 \% \\
17.1 \% \\
7.9 \% \\
18.1 \% \\
10.3 \% \\
4.8 \% \\
25.3 \%\end{array}$ \\
\hline Site of pain & $\begin{array}{l}\text { Upper extremity pain } \\
\text { Back pain } \\
\text { Upper extremity pain and back pain } \\
\text { Upper extremity pain and lower extremity } \\
\text { Back pain and lower extremity } \\
\text { Upper extremity, back pain and lower extremity }\end{array}$ & $\begin{array}{l}13.4 \% \\
3.7 \% \\
17.1 \% \\
8.0 \% \\
5.7 \% \\
52.2 \%\end{array}$ \\
\hline Surgery on the painful body part & & $24.7 \%$ \\
\hline Job & $\begin{array}{l}\text { Working } \\
\text { Retired } \\
100 \% \text { disability pension } \\
\text { Partial disability pension }\end{array}$ & $\begin{array}{l}63.2 \% \\
3.7 \% \\
6.0 \% \\
38.5 \%\end{array}$ \\
\hline
\end{tabular}

a Level of education is based on the Dutch educational system ranging from primary and secondary school (score 1) to higher general education (score 4). 


\section{$2.2 \quad$ Measures}

2.2.1 Behavioral strategies. The Pain and Activity Relations Questionnaire (PARQ; McCracken \& Samuel, 2007) was the primary measure under investigation, and was designed to assess general tendencies for behavioural strategies. It was used to quantify the extent to which people in pain engage in three different behavioral strategies including avoidance ( 8 items), pacing (6 items), and persistence ( 7 items). The PARQ is a 21 -item questionnaire that is scored on a 6-point scale ranging from 0 (never) to 5 (always). Typical items are: "I avoid important activities when I am in pain" (Avoidance), "I split tasks into parts and do them one step at a time" (Pacing), "When my pain decreases, I try to be as active as possible" (Persistence). The development of the Dutch version involved its translation and back-translation, and a final review by the questionnaire developer (L. McCracken).

2.2.2 Pain catastrophizing. The Dutch version of the Pain Catastrophizing Scale (PCS; Sullivan, Bishop, \& Pivik, 1995) is a 13 item-questionnaire that assesses catastrophic thinking in response to pain. Ratings are made on a 5-point rating scale ranging from 0 (not at all) to 4 (always). The questionnaire consists of three subscales: helplessness, magnification, and rumination. The PCS total score, which was used in the present study, offers a good index of perceived threat value of pain. Total scores range from 0 to 52. Psychometric properties of the Dutch version of the PCS are satisfactory (Crombez, et al., 1999; Van Damme, et al., 2002). Cronbach's alpha in the current study was excellent $(\alpha=.90)$.

2.2.3 Pain. The location of self-rated musculoskeletal pain symptoms was assessed with a validated modified version of the Nordic Questionnaire (Kuorinka, et al., 1987). This questionnaire asks participants about their experience of musculoskeletal pain in nine body areas (neck, lower back, upper back, shoulders, elbows, wrist/hands, hips/ thighs, knees, ankles/feet). Pain severity in each region was measured with the two-item Pain Severity subscale of the Dutch version of the Multidimensional Pain Inventory (MPI; Lousberg, et al., 1999). The two items are: "Rate the level of your pain at the present moment" and "On average, how severe has your pain been during the last week." both rated on a 7-point scale, ranging from 0 (no pain) to 6 (the worst possible pain). Pain severity was calculated by summing the mean score of these two items, for each body area. Subsequently all the body areas were summed (Tait, Chibnall, \& Krause, 1990). The MPI has been shown to have good reliability and validity (Lousberg, et al., 1999). Cronbach's alpha of the pain measure in the current study was good $(\alpha=.87)$. In addition to pain severity, pain duration was also measured as the number of years suffering from pain. 
2.2.4 Pain disability. Pain disability was assessed with the Dutch version of the Pain Disability Index (PDI; Pollard, 1984; Tait, et al., 1990). PDI is a self-report measure designed to provide general and specific indices of disability related to pain. The questionnaire consists of 7 items, covering the following areas: sexual behavior, self care and life support activity. Participants have to rate their level of disability in each of the areas on a scale ranging from 0 (no disability) to 10 (total disability). The total score, ranging from 0 to 70 , is calculated by summing all the items. The psychometric quality of the Dutch version is good (Gheldof, et al., 2006). Cronbach's alpha in the current study was good $(\alpha=.89)$.

2.2.5 Depression. Depression was measured with the depression subscale of the Dutch version of the Hospital Anxiety and Depression Scale (HADS; Zigmond \& Snaith, 1983). The HADS is a 14-item self-report screening scale with two subscales, one for anxiety and one for depression, comprising seven items each. The measure was specifically designed to screen for distinct dimensions of anxiety and depression in nonpsychiatric hospital patients. It is scored on a 4-point scale ranging from 0 (not at all) to 3 (very often) and total scores range from 0 to 21 . The two-factor solution of the Dutch version has a good reliability and is stable across medical settings and groups (Spinhoven, et al., 1997). In the present study, only the depression subscale was used. Cronbach's alpha in the current study was good $(\alpha=.80)$.

\subsection{Procedure}

Participants completed the questionnaires measuring level of behavioural strategies, pain, depression, disability and pain catastrophizing. Besides the measures described above, patients also completed a set of other measures in the context of another study of which the results were published elsewhere (Karsdorp \& Vlaeyen, 2011).

\subsection{Statistical Analysis}

To test the factor structure of the Dutch version of the Pain and Activity Relations Questionnaire, an exploratory factor analysis was performed with SPSS 17.0 (SPSS Inc., Chicago, IL) using a Principal Factor Analysis (Costello \& Osborne, 2005). An oblique Rotation (Oblimin) was chosen as the factors were expected to intercorrelate somewhat. Internal consistency was assessed using Cronbach's alpha coefficients.

In order to examine combinations of behavioral strategies, homogenous subtypes of patients were identified by means of a cluster analysis using SPSS 17.0 (SPSS Inc., Chicago, IL), with Wards method as the clustering strategy and Squared Euclidean Distance as the distance measure. To distinguish the key features of each cluster regarding the specific combinations of behavioral strategies, differences on the Pain and Activity Relations Questionnaire subscales scores were compared by means of a series of ANOVAs. Next, the 
clusters were compared on gender, age, education, diagnosis, whether participants received surgery or not, pain duration, pain catastrophizing, disability, depression and pain by means of a series of $\chi^{2}$ tests and ANOVAs.

Due to outliers and skewness, depression and pain scores were log transformed. For ease of interpretation original mean scores were used in the figures.

\section{Results}

\subsection{Exploratory Factor Analysis and Reliability of Pain and Activity Relations Questionnaire}

An exploratory factor analysis of the 21-item Pain and Activity Relations Questionnaire was performed. According to the criterion Eigenvalues $>1$, an initial solution with five factors was found. However, as one subscale consisted of only two items (item number 2 and number 3) with 1 item (item number 2) also loading on another factor, and because another subscale consisted of 3 items only (item numbers 15, 20 and 21) with 1 item also loading on another factor, the five-factor solution was considered sub-optimal. Alternatively, inspection of the scree plot suggested a three- or a four-factor solution (Figure 1). Because in the four-factor model, one subscale consisted of only two items (item 20 and 21), the three-factor model was chosen as the most optimal solution. Three factors (with Eigenvalues $>1$ ) were extracted explaining $42.72 \%$ of the total variance. Eighteen of the twenty-one items had single salient loadings matching their scale assignment, confirming the factors reported by McCracken and Samuel (2007). However, one of the persistence items (item 3 "When my pain decreases, I try to be as active as possible") had low loadings both on confronting (.27) and on pacing (.30). In addition, a confronting item (item 15 "I alternate between doing nothing and pushing too hard"), had a double loading on persistence (.47) and avoidance (-.46), and an avoidance item (item 16 "I stop activities when my pain becomes intolerable") had a double loading on the avoidance (-.37) and the pacing scale (.36). When these three items were removed and factor analysis was repeated, a three-factor solution emerged which explained $44.9 \%$ of the total variance. All items showed a strong loading on just one of the three factors, which could be labeled "Pacing" (28.03\%), "Avoidance" (11.06\%), and "Persistence" (5.82\%). Table 2 shows the rotated factor loadings for the final three-factor solution, with the items 3,15 and 16 removed. All Cronbach's alpha coefficients were adequate $(>.70)$, suggesting that the three factors were internally consistent (see Table 3). 


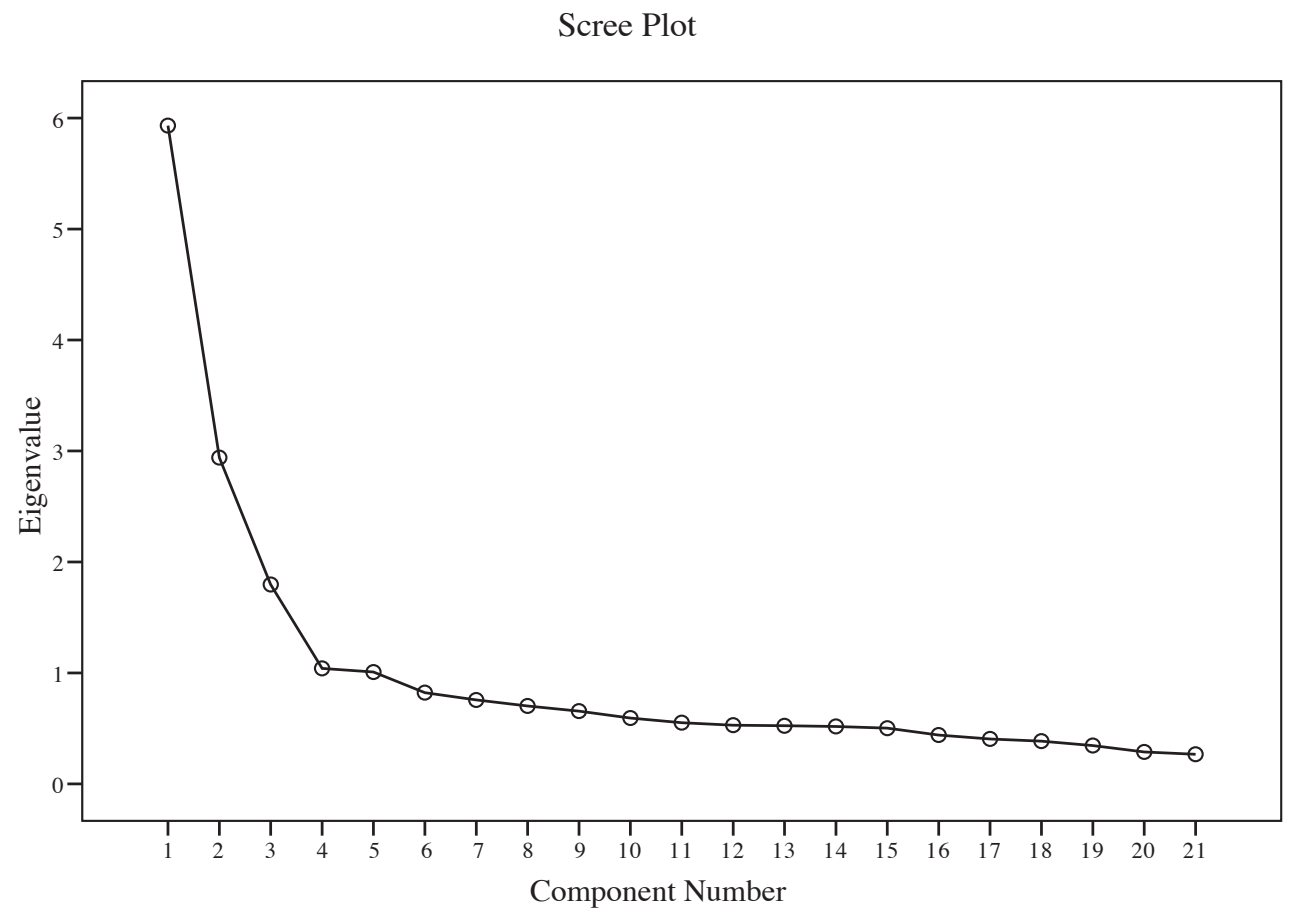

Figure 1. Scree plot. Each factor plotted against its eigenvalue $(\mathrm{n}=299)$

Table 2 Factor loadings of the Pain and Activity Relations Questionnaire 3-factor model (PFA) $(n=299)$.

Item description (original scale)

Factors

Mean $(S D)$ Av Pac Pers

8. I avoid important activities when I am in pain (Av)

$2.33(1.45) .72$

14. I am inactive because of pain (Av)

$2.22(1.44) .68$

1. I avoid activities that cause pain (Av)

$2.66(1.27) .67$

5. When I feel pain, I try to stay as still as possible (Av)

$1.80(1.36) .66$

9. I will stop any activity as soon as I sense pain coming on (Av)

$1.60(1.35) .61$

17. I don't even try to do some activities because I know they will hurt (Av)

$2.47(1.59) .59$

11. I do not engage in activities that cause my pain to increase (Av)

$2.25(1.44) .57$

4. I use repeated rest breaks to help me complete activities (Pac)

$2.89(1.39) \quad .75$

10. I split tasks into parts and do them one step at a time (Pac)

$2.56(1.45) \quad .75$

7. I pace myself so I don't overdo it during activities that tend to cause pain (Pac)

$3.19(1.30) \quad .69$

19. I pace myself to get things done (Pac)

$3.24(1.27) \quad .66$

18. I do tasks more slowly so that I can get them done with less pain (Pac)

$2.74(1.40)$

2. I stop activities before pain becomes too great and return to them later (Pac)

$2.73(1.38)$

.41

20. Considering my pain problem I do more than I should (Pers)

$3.28(1.39)$

21. I spend too much time on some activities and experience increased pain later (Pers) 3.00 (1.18)

6. I push myself to get things done despite my level of pain (pers)

$2.92(1.35)$

12. I do what I need to do regardless of the pain I feel (pers)

13. When my pain reduces I push to catch up on what I missed (pers)

$2.50(1.53)$

Note. Av: Avoidance; Pac: Pacing; Pers: Persistence. 
Table 3 Descriptive statistics of Pain and Activity Relations Questionnaire

\begin{tabular}{lllllllllll}
\hline Subscale & Items & $\alpha$ & $\mathrm{M}$ & $\mathrm{SD}$ & Subscale $\mathrm{r}$ & \multicolumn{4}{c}{$\begin{array}{c}\text { Zero-order correlations } \\
\text { PARQ and outcome measures }\end{array}$} \\
\hline & & & & & 1 & 2 & $\begin{array}{l}\text { Disability } \\
\text { (PDI) }\end{array}$ & $\begin{array}{l}\text { Depression } \\
\text { (HADS) }\end{array}$ & $\begin{array}{l}\text { Pain } \\
\text { (MPI) }\end{array}$ & $\begin{array}{l}\text { Catastrophizing } \\
\text { (PCS) }\end{array}$ \\
\hline 1. Avoidance & 7 & .84 & 2.2 & 1.0 & & & .40 & .24 & .18 & .42 \\
2. Pacing & 6 & .84 & 2.9 & 1.0 & .43 & & .25 & -.08 & .08 & .02 \\
3. Persistence & 5 & .71 & 2.9 & .92 & -.19 & -.40 & .12 & .16 & .13 & .15 \\
\hline
\end{tabular}

Note. All $r>\mathrm{I} .11 \mathrm{l}$ are significant at the $\alpha=.05$ level. All $r>\mathrm{l} .20 \mathrm{l}$ are significant at the $\alpha=.001$ level. PDI, Pain Disability Inventory; HADS: Hospital Anxiety and Depression Scale, depression subscale; MPI: Multidimensional Pain Inventory, pain severity subscale; PCS: Pain Catastrophizing Scale.

Table 3 also displays the Pearson correlation coefficients between the individual Pain and Activity Relations Questionnaire subscales. As expected, the avoidance scale is moderately correlated with the pacing scale (.43) and moderately but inversely related with the persistence scale (-.40), while the correlation between pacing and persistence was relatively small (-.19), suggesting that these two behavior patterns can occur independently. With respect to the zero-order correlations between the Pain and Activity Relations Questionnaire subscales and pain catastrophizing, disability, depression, and pain (see Table 3) it is of interest that greater avoidance is associated with greater disability, depression and pain catastrophizing. Persistence is only slightly associated with disability, depression, pain and pain catastrophizing. Greater pacing is associated with higher disability levels, but not with higher depression, higher pain or higher pain catastrophizing.

\subsection{Cluster Analyses of Patient Behavioral Strategies}

The Pain and Activity Relations Questionnaire subscale scores were subjected to a Cluster Analysis to create different activity pattern profiles. The agglomeration schedule and dendrogram were visually inspected and four clusters were selected. Based on the means of the constituent scale scores, the clusters were labeled "Persisters" ( $n=59)$, "Persistent pacers" ( $n=77)$, "Avoidant pacers" $(n=48)$, and the "Cyclers" $(n=115)$. The Avoidant pacers scored high on avoidance and pacing, but low on persistence. The Persisters scored high on persistence, and low on pacing and avoidance. The Persistent pacers scored both high on pacing and persistence, but low on avoidance. The Cyclers scored high on all three Pain and Activity Relations Questionnaire scales (avoidance, pacing and persistence). The four clusters are presented in Figure 2. 


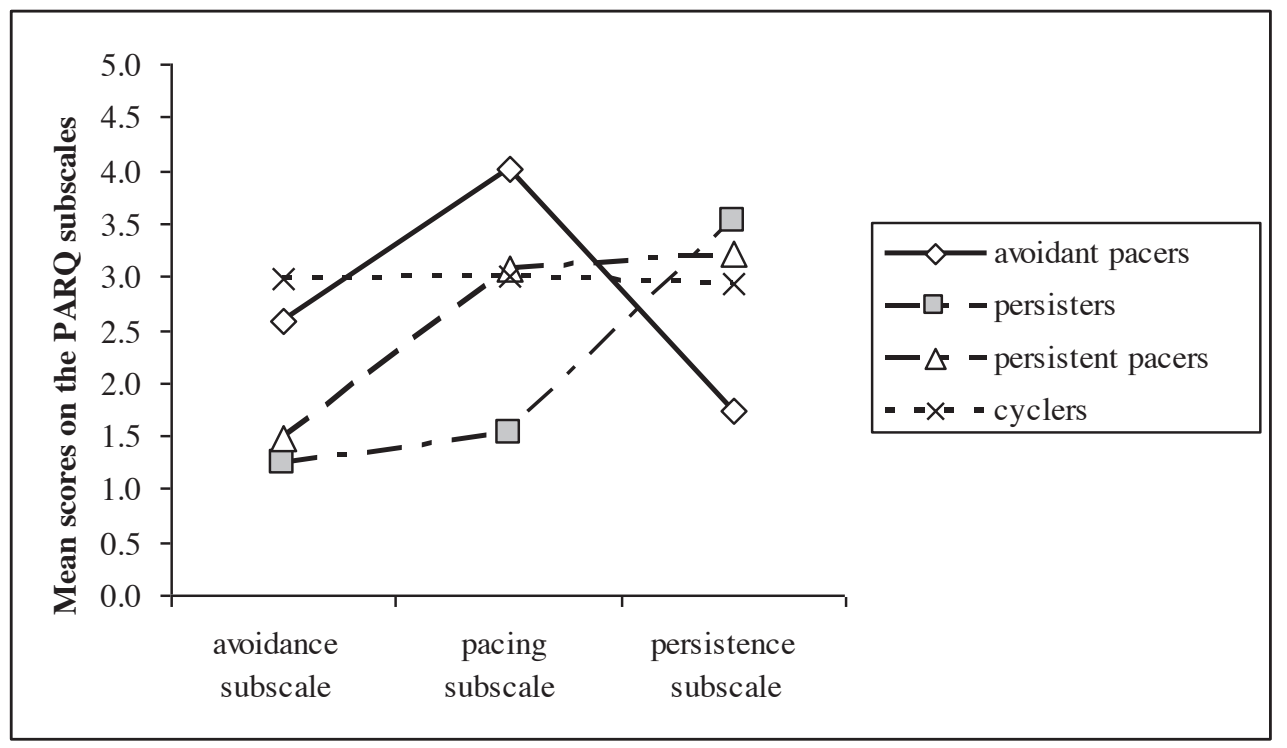

Figure 2. The scores of the four clusters on the Pain and Activity Relations Questionnaire subscales, the avoidance subscale, the pacing subscale and the persistence subscale. The four clusters are: "Avoidant pacers" ( $n=48)$, "Persisters" $(n=59)$, "Persistent pacers" $(n=77)$ and the "Cyclers" $(n=115)$. All differences are significant $(\mathrm{p}<.05)$ except for the difference between the Persistent pacers and the Cyclers on the pacing subscale

\subsection{Description of the Clusters}

A series of ANOVAs was performed to examine cluster differences on the subscales of the Pain and Activity Relations Questionnaire. This yielded overall significant effects for the avoidance subscale, $F(3,295)=124.59, p<.001, \eta^{2}=.56$, the persistence subscale $F(3$, $295)=59.71, p<.001, \eta^{2}=.38$, and the pacing subscale, $F(3,295)=134.09, p<.001, \eta^{2}$ $=.58$. Post hoc comparisons showed that all comparisons between the four clusters were statistically significant for the Avoidance subscale and the Persistence subscale (all $p<.05$ ). The Cyclers reported the greatest avoidance behavior followed by the Avoidant pacers, Persistent pacers and Persisters. The Persisters reported the greatest persistence behavior followed by the Persistent pacers, Cyclers and the Avoidant pacers. For the Pacing subscale, the difference between the Persistent pacers and the Cyclers was not significant. The Avoidant pacers reported the greatest pacing behavior, followed by the Persistent pacers, the Cyclers and the Persisters.

For descriptive purposes, a series of $\chi^{2}$ tests and ANOVAs compared the clusters on categorical and continuous variables related to patient characteristics, such as age, gender, education, diagnosis, operation, pain duration and pain catastrophizing (Table 4). The clusters differed in age $\left(F(3,295)=3.62, p<.05, \eta^{2}=.04\right)$, indicating that Persisters were younger 
than the other clusters (all $p<.01$ ). Results further showed that the clusters differed in pain catastrophizing, $F(3,295)=8.91, p<.001, \eta^{2}=.08$, indicating that participants in the Cyclers group reported more pain catastrophizing than participants in the other clusters (all $p$ 's $<.01$ ).

Table IV Means and standard deviations, and frequencies for comparisons between clusters on demographic variables and measures of disability, pain depression and catastrophizing

\begin{tabular}{|c|c|c|c|c|c|}
\hline & \multicolumn{5}{|c|}{ Activity pattern clusters } \\
\hline & $\begin{array}{l}\text { 1. Avoidant } \\
\text { pacers }\end{array}$ & 2. Persisters & $\begin{array}{l}\text { 3. Persistent } \\
\text { pacers }\end{array}$ & 4. Cyclers & $\begin{array}{l}\text { Significant } \\
\text { intercluster } \\
\text { differences } \\
(\mathrm{p}<.05) / \mathrm{c}^{2}\end{array}$ \\
\hline Gender ( $\%$ male $)$ & $14.6 \%(n=7)$ & $18.6 \%(n=11)$ & $19.5 \%(n=15)$ & $18.3 \%(n=21)$ & $.51(\mathrm{df}=3)$ \\
\hline Education & & & & & $14.12(\mathrm{df}=9)$ \\
\hline $\begin{array}{l}\text { Primary and } \\
\text { secondary }\end{array}$ & $33.3 \%(n=16)$ & $35.6 \%(n=21)$ & $37.7 \%(n=29)$ & $42.6 \%(n=49)$ & \\
\hline $\begin{array}{l}\text { Intermediate } \\
\text { vocational }\end{array}$ & $41.7 \%(n=20)$ & $20.3 \%(n=12)$ & $24.7 \%(n=19)$ & $25.2 \%(n=29)$ & \\
\hline $\begin{array}{l}\text { Higher } \\
\text { Vocational }\end{array}$ & $14.6 \%(n=7)$ & $32.2 \%(n=19)$ & $32.5 \%(n=25)$ & $20.9 \%(n=24)$ & \\
\hline Higher general & $10.4 \%(n=5)$ & $11.9 \%(n=7)$ & $5.2 \%(n=4)$ & $11.3 \%(n=13)$ & \\
\hline Diagnosis & & & & & $15.25(\mathrm{df}=15)$ \\
\hline No & $18.8 \%(n=9)$ & $33.3 \%(n=19)$ & $25.3 \%(n=19$ & $24.1 \%(n=27)$ & \\
\hline $\begin{array}{l}\text { Upper } \\
\text { extremity }\end{array}$ & $25 \%(n=12)$ & $10.5 \%(n=6)$ & $14.7 \%(n=11)$ & $17.0 \%(n=19)$ & \\
\hline Fibromyalgia & $20.9 \%(n=10)$ & $17.5 \%(n=10)$ & $18.7 \%(n=14)$ & $14.3 \%(n=16)$ & \\
\hline Back pain & $12.5 \%(n=6)$ & $22.8 \%(n=13)$ & $16 \%(n=12)$ & $19.6 \%(n=22)$ & \\
\hline Combination & $16.7 \%(n=8)$ & $5.3 \%(n=3)$ & $12 \%(n=9)$ & $8.9 \%(n=10)$ & \\
\hline Other & $6.3 \%(n=3)$ & $10.5 \%(n=6)$ & $13.3 \%(n=10)$ & $16.1 \%(n=18)$ & \\
\hline Operation (\% yes) & $22.9 \%(n=11)$ & $22 \%(n=13)$ & $27.3 \%(n=21)$ & $25.2 \%(n=29)$ & $.60(\mathrm{df}=3)$ \\
\hline Age & $42.58(12.04)$ & $36.27(13.73)$ & $42.26(11.97)$ & $42.14(12.71)$ & $\begin{array}{l}2<1 \\
2<3 \\
2<4\end{array}$ \\
\hline Pain duration & $8.64(9.35)$ & $8.02(8.82)$ & $10.47(9.51)$ & $9.17(8.93)$ & - \\
\hline Catastrophizing & $18.83(10.72)$ & $18.41(7.46)$ & $16.46(8.65)$ & $23.29(10.38)$ & $\begin{array}{l}4>1 \\
4>2 \\
4>3\end{array}$ \\
\hline
\end{tabular}

\subsection{Associations among Cluster Membership and Disability, Depression, and Pain}

ANOVA comparing the clusters at levels of disability, depression and pain revealed an effect of cluster membership on disability $\left(F(3,295)=8.93, p<.01, \eta^{2}=.08\right)$ and depression $(F(3$, $\left.295)=2.66, p<.05, \eta^{2}=.03\right)$. Follow-up analyses indicated that the Cyclers reported higher levels of disability than both the Persisters and Persistent pacers. The Persisters reported lower levels of disability than all the other clusters. The Cyclers also reported higher levels of depression than the Persistent pacers. No effect of cluster membership was found for pain, $F(3,295)=1.98, p>.05, \eta^{2}=.02$. Results are displayed in Figure 3. 

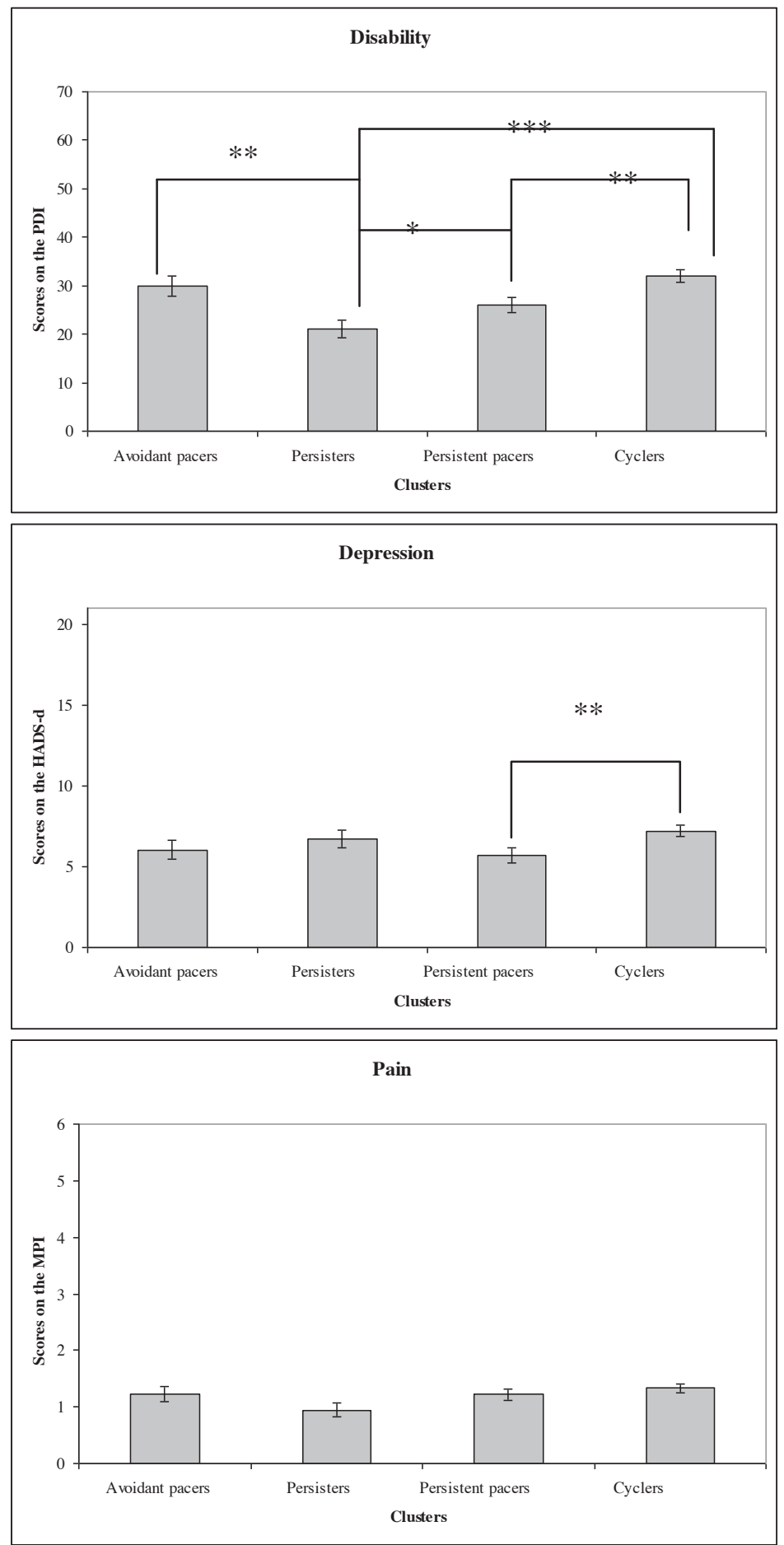

Figure 3. Comparison of the clusters on mean disability (PDI), depression (BDI), and pain (MPI), respectively. $*=$ significant at $\mathrm{p}<.05$ level, $* *=$ significant at $\mathrm{p}<.01, * * *=$ significant at $\mathrm{p}<.001$ 


\section{Discussion}

The main purpose of the present study was threefold: to replicate the factor structure of the Pain and Activity Relations Questionnaire in a Dutch heterogeneous sample of patients with current low back and upper extremity pain, to identify subgroups of patients with similar combinations of behavioral strategies, and to test whether cluster membership was associated with pain catastrophizing, current pain, disability and depression.

The factor structure of the Dutch version of the Pain and Activity Relations Questionnaire largely corroborated the original findings (McCracken \& Samuel, 2007), similarly yielding a three-factor solution with the factors pacing, avoidance, and persistence with excellent internal reliability. Correlations between individual Pain and Activity Relations Questionnaire subscales and outcome measures show that especially avoidance is associated with disability, depression, and pain catastrophizing, which is in line with other studies (Leeuw, et al., 2007; Turk \& Wilson, 2010; Vlaeyen \& Linton, 2000). The finding that higher pacing was associated with higher disability also corroborates previous findings with Pain and Activity Relations Questionnaire (McCracken \& Samuel, 2007) but contrasts those showing pacing to be associated with lower disability (Nielson, et al., 2001). The finding that greater task persistence is associated with less disability, is in line with results of Jensen and colleagues (Jensen, et al., 1995) but is in contrast with studies showing the opposite, namely that greater task persistence is associated with more disability (Feuerstein, et al., 2005; Garcia-Campayo, et al., 2007). Given the inconclusive findings regarding the role of pacing and task persistence, we were interested in the association of combinations of behavioral strategies with outcome measures, using clustering techniques.

The cluster analysis yielded the following four patient subgroups: Avoidant pacers, Persistent pacers, Persisters and Cyclers. Three of these subgroups are characterized by high scores on persistence, either in combination with high levels of pacing (Persistent pacers), high levels of both avoidance and pacing (Cyclers), or low levels of both pacing and avoidance (Persisters). A fourth group was characterized by high levels of both avoidance and pacing (Avoidant pacers). The profiles are largely in line with those found by McCracken and Samuel (2007), three of the four clusters are similar except that we found one group scoring high on both persistence and pacing, whereas McCracken and Samuel (2007) found a group of medium Cyclers.

Our results show that greater persistence was related to less disability, dependent on whether or not it was combined with high levels of avoidance. Persisters (those high on persistence and low on avoidance and pacing) reported lower levels of disability compared to all the other clusters, including the Persistent pacers and the Cyclers. This is in line with the results of McCracken and Samuel (2007) showing that the cluster with high levels of persistence and low levels of avoidance and pacing is the most functional group. 
Cyclers reported more disability compared to the Persistent pacers, which seems to suggest that especially the combination of persistence, pacing and avoidance behavior is detrimental. As avoidance behavior occurred in combination with high pacing or both high pacing and persistence in our study, it suggests that avoidance as a single strategy rarely occurs in patients with musculoskeletal pain. Note that also McCracken and Samuel (2007) did not find a pure avoidance cluster, as pacing levels were equally high as avoidance levels in the subgroup they labeled "Avoiders". Moreover, our study and the study of McCracken and Samuel (2007) both revealed that the (extreme) Cyclers constitute a relatively large group. This might indicate that this activity profile may be relevant, both clinically and scientifically, and probably deserves more attention than received so far. Not only are the Cyclers the largest subgroup in our sample, they also represent the most problematic group, reporting higher levels of disability, depression and pain catastrophizing. Similar findings were reported previously using activity monitoring in chronic low back pain patients (Huijnen, Verbunt, Roelofs, Goossens, \& Peters, 2009). These researchers showed that higher fluctuations in activity over time, i.e. high activity alternating with low activity levels, was associated with higher disability, whereas the mean activity level was not associated with perceived disability. Although more experimental work is needed, this cluster might reflect the typical goal conflicts that patients with enduring pain may encounter. The goal to persist despite pain, for example to satisfy others, may hold the risk of further reinjury and pain increase. In contrast, the goal to protect the body against injury may compromise other life goals such as the prevention of social rejection or isolation (Schrooten \& Vlaeyen, 2010; Vlaeyen, Kole-Snijders, Boeren, \& van Eek, 1995). This situation may result in indecision and oscillation between goals, which might constitute a key characteristic of the Cyclers (Schrooten \& Vlaeyen, 2010). Goal conflicts are shown to be associated with increased distress levels (Karoly, Okun, Ruehlman, \& Pugliese, 2008), and the finding that the Cyclers score higher than the other clusters on depression and pain catastrophizing is in line with this conjecture.

Of interest also is that elevated scores on the pacing subscale appeared in two different clusters, one in combination with high persistence scores and one with increased avoidance scores. This suggests that the way pacing is represented in the Pain and Activity Relations Questionnaire appears to be somewhat ambiguous. Throughout the literature, pacing is an ill-defined concept (Gill \& Brown, 2009), and our results indicate that pacing might be in fact an ambiguous concept that can be considered both a strategy to either increase or decrease activity, depending on existing levels of avoidance or persistence. For example, when pacing is used in a pain-contingent manner, pacing may actually reflect safety-seeking behavior that eventually prevents patients with increased pain-related fear from disconfirming their beliefs about the harmfulness of physical activity (Karsdorp \& Vlaeyen, 2009b). Furthermore, pacing could also be conceptualized as a time-contingent rather than a pain-contingent approach to 
try and increase activity levels in a graded fashion (Fordyce, 1976). Furthermore, pacing may be better conceptualized as non-pain but goal-contingent activity management. When considering the pacing subscale of Pain and Activity Relations Questionnaire, its constituent items are not clear as to whether pain, time or goal is used as a guide to pace or not. Currently, there is no instrument available that differentiates between these types of pacing.

In line with other studies (Huijnen, et al., 2009; Liszka-Hackzell \& Martin, 2004; Vendrig \& Lousberg, 1997), no relationship between clusters and level of self-reported pain intensity was found in our study. Studies using more objective assessment of activity levels also did not find associations between pain intensity and actual activity levels (Linton, 1985). These findings are in line with modern cognitive and behavioral models of pain proposing that not pain per se, but the meaning attached to pain in a certain context is more important in predicting behavioral responses to pain (Crombez, et al., 1999; Vlaeyen, et al., 1995).

The current study has a number of limitations. Given its correlational nature, it is not possible to draw causal conclusions. An additional limitation is the reliance on self-report measures only, targeting subjective reports about behavioural strategies rather their more objective observations. On the other hand, perceived decline in activity rather than the actual physical activity level has shown to predict disability in low back pain patients, indicating that especially self-reported activity levels are clinically important and relevant (Verbunt, et al., 2005). A last limitation is that the Pain and Activity Relations Questionnaire is a very broad measure of behavioral strategies. For example, the Pain and Activity Relations Questionnaire does not differentiate between passive (freezing e.g. resting) and active avoidance (fleeing e.g. asking for assistance) behavioural strategies. More subtle safetyseeking behaviours during performance of activities may also be quite disabling, and these have been shown to be strongly associated with negative outcomes (Tang, et al., 2007). For example, 'guarding' which is a subtle form of behaviour that is defined as active behavior that prevents or alleviates pain, and that includes stiffness, hesitation, limping, bracing, and flinching, has shown to be associated prospectively with a reduced likelihood of return to work, days lost and self-reported disability (Prkachin, Schultz, \& Hughes, 2007). As safety seeking behaviors can be very subtle and the Pain and Activity Relations Questionnaire does not identify these behaviors, more detailed information about the relationship between active avoidance behavior and outcome measures might be missed. Furthermore due to its broad general nature the Pain and Activity Relations Questionnaire is not situation specific. As contextual factors are deemed important with respect to the use of behavioral strategies, future research may benefit from the development of more situation-specific measures.

Notwithstanding these limitations, the present study demonstrates that persistence behaviour in combination with high levels of avoidance and pacing is dysfunctional, in terms of pain catastrophizing, disability and depression. Persistence in the absence of high levels of avoidance and pacing seems the most functional behaviour strategy. One advantage of 
using activity profiles of patients that cluster together, instead of just focusing on single behavioral strategies, is that it can provide us with clinically relevant information that is useful with respect to matching interventions to patients' risk profiles. The results of our study show that it is important not to rely solely on avoidance, pacing or persistence behavior per se but to consider the combinations of persistence with avoidance and pacing. Our study shows that not only avoidance per se seems dysfunctional but that also the combination of all three behavior patterns is associated with more disability, more pain catastrophizing as well as more depression. Our data indicate that treatment programs should not solely target avoidance behaviour by gradually increasing activity levels, or by teaching patients to pace their activities (Bradley, 1996; Gill, Ross, \& Keefe, 1988), but underscore the importance of considering the full pattern of activity behaviours. As Cyclers constitute the largest and the most problematic group of our sample, more clinical and scientific attention should be paid to this particular group of patients. In this perspective, an affective- motivational approach of pain, where pain and disability is considered in the context of goal pursuit, is receiving increasing scientific attention and may explain fluctuations in behaviour patterns (e.g. Christiansen, Oettingen, Dahme, \& Klinger, 2010; Goossens, et al., 2010; Karoly, et al., 2008; Van Damme, Crombez, \& Eccleston, 2008; Vlaeyen \& Morley, 2004; Vlaeyen, Crombez, \& Linton, 2009). An interesting avenue for future research is to investigate whether the extreme activity fluctuations of the Cyclers are associated with pain-related goal conflicts, and whether resolving these goal conflicts by flexibly adjusting goals could balance activity levels, and diminish levels of catastrophizing, disability and depression.

\section{Acknowledgements}

This study was supported by an innovation Grant (No. 453-04-003) provided by the NWO Social Sciences Research Council of The Netherlands. We thank Sita van Riet for her generous help in the data acquisition. We thank L. McCracken for the back-translation in developing the Dutch version of the Pain and Activity Relations Questionnaire and his valuable comments on an earlier version of this manuscript. 


\section{References}

Asmundson, G. J., Norton, G. R., \& Allerdings, M. D. (1997). Fear and avoidance in dysfunctional chronic back pain patients. Pain, 69, 231-236.

Bradley, L. A. (1996). Cognitive-behavioral therapy for chronic pain. In R. J. Gatchel \& D. C. Turk (Eds.), Psychological approaches to pain management: a practioner's handbook. (pp. 131147). New York, NY: Guilford Press.

Christiansen, S., Oettingen, G., Dahme, B., \& Klinger, R. (2010). A short goal-pursuit intervention to improve physical capacity: a randomized clinical trial in chronic back pain patients. Pain, $149,444-452$.

Costello,A.B., \& Osborne, J.(2005). Best practices in exploratory factor analysis: four recommendations for getting the most from your analysis. Practical assessment research and evaluation, 10, $1-9$.

Crombez, G., Vlaeyen, J. W., Heuts, P. H., \& Lysens, R. (1999). Pain-related fear is more disabling than pain itself: evidence on the role of pain-related fear in chronic back pain disability. Pain, 80, 329-339.

Engel, J. M., Schwartz, L., Jensen, M. P., \& Johnson, D. R. (2000). Pain in cerebral palsy: the relation of coping strategies to adjustment. Pain, 88, 225-230.

Ersek, M., Turner, J. A., \& kemp, C. A. (2006). Use of the chronic pain coping inventory to assess oder adults' pain coping strategies. The Journal of Pain, 7, 833-842.

Feuerstein, M., Nicholas, R. A., Huang, G. D., Haufler, A. J., Pransky, G., \& Robertson, M. (2005). Workstyle: development of a measure of response to work in those with upper extremity pain. Journal of Occupational Rehabilitation, 15, 87-104.

Fordyce, W. (1976). Behavioral methods for chronic pain and inllness. Saint Louis: The C.V. Mosby Company.

Garcia-Campayo, J., Pascual, A., Alda, M., \& Ramirez, M. T. (2007). Coping with fibromialgia: usefulness of the chronic pain coping inventory-42. Pain, 132, 68-76.

Geisser, M. E., Roth, R. S., Theisen, M. E., Robinson, M. E., \& Riley, J. L., 3rd (2000). Negative affect, self-report of depressive symptoms, and clinical depression: relation to the experience of chronic pain. The Clinical Journal of Pain, 16, 110-120.

Gheldof, E. L., Vinck, J., Van den Bussche, E., Vlaeyen, J. W., Hidding, A., \& Crombez, G. (2006). Pain and pain-related fear are associated with functional and social disability in an occupational setting: evidence of mediation by pain-related fear. European Journal of Pain, 10, 513-525.

Gill, J. R., \& Brown, C. A. (2009). A structured review of the evidence for pacing as a chronic pain intervention. European Journal of Pain, 13, 214-216.

Gill, K. M., Ross, S. L., \& Keefe, F. J. (1988). Behavioral treatement of chronic pain: four pain management protocols. In R. D. France \& R. Krishnan (Eds.), Chronic pain (pp. 376-413). Washington, D.C.: American Psychiatric Press.

Goossens, M. E., Kindermans, H. P., Morley, S. J., Roelofs, J., Verbunt, J., \& Vlaeyen, J. W. (2010). Self-discrepancies in work-related upper extremity pain: relation to emotions and flexiblegoal adjustment. European Journal of Pain, 14, 764-770. 
Hadjistavropoulos, H. D., MacLeod, F. K., \& Asmundson, G. J. (1999). Validation of the Chronic Pain Coping Inventory. Pain, 80, 471-481.

Hasenbring, M. I., Hallner, D., \& Rusu, A. C. (2009). Fear-avoidance- and endurance-related responses to pain: development and validation of the Avoidance-Endurance Questionnaire (AEQ). European Journal of Pain, 13, 620-628.

Hasenbring, M. I., Plaas, H., Fischbein, B., \& Willburger, R. (2006). The relationship between activity and pain in patients 6 months after lumbar disc surgery: do pain-related coping modes act as moderator variables? European Journal of Pain, 10, 701-709.

Huijnen, I. P., Verbunt, J. A., Roelofs, J., Goossens, M., \& Peters, M. (2009). The disabling role of fluctuations in physical activity in patients with chronic low back pain. European Journal of Pain, 13, 1076-1079.

Janssen, R. (2008). Emium; Effect Monitoring via Internet Universiteit Maastricht. Version 1.3. Maastricht: Research Institute of Experimental Psychopathology, Maastricht University.

Jensen, M. P., Turner, J. A., Romano, J. M., \& Strom, S. E. (1995). The Chronic Pain Coping Inventory: development and preliminary validation. Pain, 60, 203-216.

Karoly, P., Okun, M. A., Ruehlman, L. S., \& Pugliese, J. A. (2008). The Impact of Goal Cognition and Pain Severity on Disability and Depression in Adults with Chronic Pain: An Examination of Direct Effects and Mediated Effects via Pain-Induced Fear. Cognitive Therapy and Research, $32,418-433$.

Karsdorp, P. A., \& Vlaeyen, J. W. (2009a). Active avoidance but not activity pacing is associated with disability in fibromyalgia. Pain, 147, 29-35.

Karsdorp, P. A., \& Vlaeyen, J. W. (2009b). On the validity of 'activity pacing'. Comment on Jensen "research on coping with chronic pain: the importance of active avoidance of inappropriate conclusions" [Pain 2009;147:3-4]. Pain, 147(1-3), 305.

Karsdorp, P. A., \& Vlaeyen, J. W. (2011). Goals matter: both achievement and pain-avoidance goals are associate with pain severity and disability in patients with musculoskeletal pain. Pain, $152,1382-1390$.

Kindermans, H. P., Huijnen, I. P., Goossens, M. E., Roelofs, J., Verbunt, J. A., \& Vlaeyen, J. W. “Being” in pain: the role of self-discrepancies in the emotional experience and activity patterns of patients with chronic low back pain. Pain, 152, 403-409.

Kuorinka, I., Jonsson, B., Kilbom, A., Vinterberg, H., Biering-Sorensen, F., Andersson, G., et al. (1987). Standardised Nordic questionnaires for the analysis of musculoskeletal symptoms. Applied Ergonomics, 18, 233-237.

Leeuw, M., Goossens, M. E., Linton, S. J., Crombez, G., Boersma, K., \& Vlaeyen, J. W. (2007). The fear-avoidance model of musculoskeletal pain: current state of scientific evidence. Journal of Behavioral Medicine, 30, 77-94.

Linton, S. J. (1985). The relationship between activity and chronic back pain. Pain, 21, 289-294.

Liszka-Hackzell, J. J., \& Martin, D. P. (2004). An analysis of the relationship between activity and pain in chronic and acute low back pain. Anesthesia \& Analgesia, 99, 477-481. 
Lousberg, R., Van Breukelen, G. J., Groenman, N. H., Schmidt, A. J., Arntz, A., \& Winter, F. A. (1999). Psychometric properties of the Multidimensional Pain Inventory, Dutch language version (MPI-DLV). Behaviour Research and Therapy, 37, 167-182.

McCracken, L. M., \& Samuel, V. M. (2007). The role of avoidance, pacing and other activity patterns in chronic pain. Pain, 130, 119-125.

Nielson, W. R., Jensen, M. P., \& Hill, M. L. (2001). An activity pacing scale for the chronic pain coping inventory: development in a sample of patients with fibromyalgia syndrome. Pain, 89(2-3), 111-115.

Philips, H. C. (1987). Avoidance behaviour and its role in sustaining chronic pain. Behaviour Research and Therapy, 25(4), 273-279.

Pollard, C. A. (1984). Preliminary validity study of the pain disability index. Perceptual and Motor Skills, 59, 974.

Prkachin, K. M., Schultz, I.Z., \& Hughes, E. (2007). Pain behavior and the development of pain-related disability: the importance of guarding. The Clinical Journal of Pain, 23, 270-277.

Schrooten, M. G., \& Vlaeyen, J. W. (2010). Becoming active again? Further thoughts on goal pursuit in chronic pain. Pain, 149, 422-423.

Spinhoven, P., Ormel, J., Sloekers, P. P., Kempen, G. I., Speckens, A. E., \& Van Hemert, A. M. (1997). A validation study of the Hospital Anxiety and Depression Scale (HADS) in different groups of Dutch subjects. Psychological Medicine, 27, 363-370.

Sullivan, M. J., Bishop, S. R., \& Pivik, J. (1995). The Pain Catastrophizing Scale: Development and validation. Psychological Assessment, 7, 524 - 532.

Tait, R. C., Chibnall, J. T., \& Krause, S. (1990). The Pain Disability Index: psychometric properties. Pain, 40, 171-182.

Tang, N. K. Y., Salkovskisa, P. M., Poplavskayaa, E., Wrighta, K. J., Hannab, M., \& Hesterb, J. (2007). Increased use of safety-seeking behaviors in chronic back pain patients with high health anxiety. Behaviour Research and Therapy, 45, 2821-2835.

Truchon, M., \& Cote, D. (2005). Predictive validity of the Chronic Pain Coping Inventory in subacute low back pain. Pain, 116, 205-212.

Turk, D. C., \& Wilson, H. D. (2010). Fear of pain as a prognostic factor in chronic pain: conceptual models, assessment, and treatment implications. Current Pain and Headache Reports, 14, $88-95$.

Van Damme, S., Crombez, G., \& Eccleston, C. (2008). Coping with pain: a motivational perspective. Pain, 139, 1-4.

Van Damme, S., Crombez, G., Vlaeyen, J. W. S., Goubert, L., Van den Broeck, A., \& Van Houdenhove, B. (2002). De Pain Catastrophizing Scale: Psychometrische karakteristieken en normering. Gedragstherapie, 33, 209-220.

Vendrig, A. A., \& Lousberg, R. (1997). Within-person relationships among pain intensity, mood and physical activity in chronic pain: a naturalistic approach. Pain, 73, 71-76. 
Verbunt, J. A., Sieben, J. M., Seelen, H. A., Vlaeyen, J. W., Bousema, E. J., van der Heijden, G. J., et al. (2005). Decline in physical activity, disability and pain-related fear in sub-acute low back pain. European Journal of Pain, 9, 417-425.

Vlaeyen, J. W., Crombez, G., \& Linton, S. J. (2009). The fear-avoidance model of pain: We are not there yet. Comment on Wideman et al. "A prospective sequential analysis of the fear-avoidance model of pain" [Pain, 2009] and Nicholas "First things first: reduction in catastrophizing before fear of movement" [Pain, 2009]. Pain, 146, 222; author reply 222-223.

Vlaeyen, J. W., Kole-Snijders, A. M., Boeren, R. G., \& van Eek, H. (1995). Fear of movement/(re) injury in chronic low back pain and its relation to behavioral performance. Pain, 62, 363-372.

Vlaeyen, J. W., \& Linton, S. J. (2000). Fear-avoindance and its consequences in chronic muskoskeletal pain: a state of the art. Pain, 85, 317-332.

Vlaeyen, J. W., \& Linton, S. J. (2012). Fear-avoidance model of chronic musculoskeletal pain: 12 years on. Pain, 153, 1144-1147.

Vlaeyen, J. W., \& Morley, S. J.(2004). Active despite pain: the putative role of stop-rules and current mood. Pain, 110, 512-516.

Vlaeyen, J. W., \& Morley, S. J. (2005). Cognitive-behavioral treatments for chronic pain: what works for whom? The Clinical Journal of Pain, 21, 1-8.

White, P. D., Goldsmith, K. A., Johnson, A. L., Potts, L., Walwyn, R., DeCesare, J. C., et al. (2011). Comparison of adaptive pacing therapy, cognitive behaviour therapy, graded exercise therapy, and specialist medical care for chronic fatigue syndrome (PACE): a randomised trial. Lancet, $377,823-836$.

Zigmond, A. S., \& Snaith, R. P. (1983). The hospital anxiety and depression scale. Acta Psychiatrica Scandinavica, 67, 361-370. 


\section{Chapter 3}

No Mood-as-Input Effects for Primed Hedonic and Achievement Goals. Only Habitual Goal Preferences Predict Task Persistence
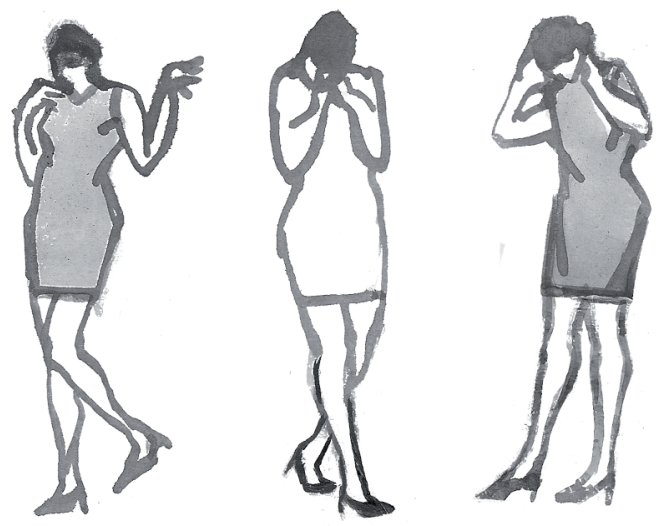


\begin{abstract}
According to the Mood-as-Input hypothesis (Martin, Ward, Achee, \& Wyer, 1993), task persistence is a function of the combined role of mood and processing goals. Two main processing goals are distinguished: achievement and hedonic goals. Achievement goals are predicted to produce greater task persistence when combined with negative mood compared to positive mood. Hedonic goals are predicted to produce the opposite pattern. As research has mainly tested the Mood-as-Input model with the use of momentary and explicit goal instructions, the main aim of this study was to investigate whether the Mood-as-Input model also applies when achievement and hedonic goals are induced without the use of explicit goal instructions, by means of supraliminal goal priming. Additionally, the moderating role of habitual goal preferences was investigated. Mood was manipulated with film fragments; goals were primed with a Scrambled Sentence Task, and habitual goals were measured with the Goal Pursuit Questionnaire (Karsdorp \& Vlaeyen, 2011). Task duration was measured with an impression-formation task. Results showed that, in contrast to the Mood-as-Input hypothesis, task persistence is predicted by habitual goals only. Participants, who preferred achievement goals over hedonic goals, persisted longer than those showing the opposite preference. Mood-as-Input effects are likely to be overruled by habitual goal preferences.
\end{abstract}




\section{Introduction}

The relationship between mood and task persistence (task duration) has been an important research topic in the last decades. In general, positive mood is suggested to improve performance, yielding mood congruent effects on behaviour (Bower, 1981; Isen, Shalker, Clark, \& Karp, 1978; Mayer, Gaschke, Braverman, \& Evans, 1992; Murray, Sujan, Hirt, \& Sujan, 1990). However, some studies also demonstrate incongruent mood effects (Forgas \& Bower, 1987; Martin, et al., 1993; Oaksford, Morris, Grainger, Williams, \& Mark, 1996). An affective-motivational model that offers a plausible explanation for both mood congruent as well as incongruent effects on behaviour is the Mood-as Input-model (Martin, et al., 1993). The Mood-as-Input postulates that mood, instead of having a stable motivational effect on behaviour, has different implications depending on the interpretation of the current mood state. According to Martin et al. (1993), the way in which people interpret their moods depends on so-called 'stop rules'. These stop rules can be considered processing goals people adopt when performing a task. Goals are generally defined as mental representations of desired end states or outcomes (Aarts \& Dijksterhuis, 2000). Two kinds of processing goals can be distinguished: achievement goals, adopted when people are guided by the question "Am I satisfied with the result of the task?", and hedonic goals, where individuals focus on the question "Am I enjoying this task?". When people adopt an achievement goal, a current positive mood signals that they have performed to the best of their ability, leading to task discontinuance, whereas a negative mood signals that they did not perform well enough, leading to task continuance. In contrast, when people adopt a hedonic goal, the opposite pattern arises: a positive mood signals that they are enjoying the task, leading to task continuance, whereas a negative mood signals that they are not enjoying the task anymore, leading to task termination. Supportive evidence for the Mood-as-Input hypothesis has been found in several domains including obsessive compulsive disorder (OCD) (Davey, Startup, Zara, MacDonald, \& Field, 2003); general anxiety disorder (GAD) (Davey, Startup, MacDonald, Jenkins, \& Patterson, 2005; Davey, et al., 2003; Startup \& Davey, 2001, 2003) and depression (Watkins $\&$ Mason, 2002) using explicit achievement and hedonic goal instructions (for review see Meeten \& Davey, 2011).

Current theories on goal pursuit postulate that in everyday life, people do not always follow explicit task instructions and are often not aware of the influence of goal activating stimuli in the environment on their behaviour (Blackmore, 2003; Nisbett \& Wilson, 1977; Nørretranders, 1991). The perception of goal-related cues in the environment can unconsciously activate goal representations in memory (Aarts \& Dijksterhuis, 2000; Bargh, Gollwitzer, Barndollar, \& Trotschel, 2001). In turn, these activated goals in memory can then

guide people's behaviour. In line with this conjecture it has been shown that the presentation of goal-related stimuli results in an increase in goal-related behaviour (Eitam, Hassin, \& 
Schul, 2008; Maio, Pakizeh, Cheung, \& Rees, 2009; Oikawa, 2004; Shantz \& Latham, 2009; Stajkovic, Locke, \& Blair, 2006). For example, in a study of Bargh and colleagues (2001), participants who were primed with words related to achievement subsequently performed better on a word search task. Additionally, it has been shown that goal-related stimuli activated goal-related behaviour particularly in people with a habitual preference for the specific goal (Aarts, et al., 2005; Fitzsimons \& Bargh, 2003; Karremans, Stroebe, \& Claus, 2006; Radel, Sarrazin, \& Pelletier, 2009; Strahan, Spencer, \& Zanna, 2002). For example, research demonstrated that the presentation of help-related stimuli increased helpful behaviour only in people with strong habitual goals of helping (Custers \& Aarts, 2005; Fitzsimons \& Bargh, 2003; Strahan, et al., 2002). Likewise, it was found that achievement-related stimuli promoted an achievement goal in individuals with chronically high achievement motivation, but not in individuals with chronically low achievement motivation (Hart \& Albarracin, 2009).

Based on the studies described above, it was hypothesized that the goals of the Mood-as-Input model (achievement and hedonic goals) can be activated outside of conscious awareness by presentation of goal-related stimuli, specifically in individuals with congruent habitual goal representations in memory. The aim of the present study was to investigate whether the Mood-as-Input model predictions hold when goals are activated outside of conscious awareness by means of supraliminal priming, and whether habitual goal pursuit strengthens this effect.

In line with the Mood-as-Input model it was predicted that participants who are primed with achievement goals, will show greater task duration when in a negative than a positive mood. Participants who are primed with hedonic goals will show greater task duration when in a positive mood than in a negative mood. Additionally, it was expected that if participants' habitual goals match the goals that they were primed with, this would strengthen the above-described Mood-as-Input effect.

\section{Method}

\subsection{Participants}

A sample of $N=160$ participants (30\% male; mean age $(S D)=29.97$ (12.53) years) participated in the experiment. In order to check for multivariate outliers, the leverage value per cell was calculated which yielded 3 multivariate outliers using the criterion $\chi<.01$. These outliers were excluded from the analysis leaving the sample at 157 participants $(29.9 \%$ male; Mean $(S D)$ age $=29.82$ (12.39) years). People were excluded when they had participated in a previous study of our research group using either a mood or goal induction procedure. 


\subsection{Research Design}

In this study, a 2 Mood (positive versus negative) X 3 Primed goal (neutral, achievement, versus hedonic) between-subject design was used. Habitual goal pursuit was measured with the Goal Pursuit Questionnaire as a continuous variable and entered as a covariate in the analysis. Task persistence (number of sentences read during the impression formation task) was the dependent variable. Scores on the dependent variable were log transformed in order to obtain a normal distribution. Participants were randomly assigned to one of the six conditions. The ethical committee of the Maastricht University approved the study.

\subsection{Materials}

2.3.1 Mood induction. Positive or negative mood states were induced by means of film fragments. To induce a positive mood, an excerpt of The Dead Poets Society (Weir, 1989) was presented; to induce a negative mood, a fragment from American History X (Kaye, 1998) was shown. Previous research demonstrated that watching these film fragments successfully induced mood states (Karsdorp, Ranson, Nijst, \& Vlaeyen, 2012; Schaefer, Nils, Sanchez, $\&$ Philippot, 2010). To neutralize baseline mood, subjects were first presented with a neutral horse riding scene form the movie Blue (Narizanno, 1968). To disguise the fact that the film fragments were used as a mood induction procedure, participants were told that the experiment was about rating movie fragments. After watching each fragment, participants were asked a series of questions. The questions were partially taken form the study of Martin et al. (1993); e.g. "Have you seen the movie, from which the film clip was taken, before?, Do you know the title of the movie?, Do you think you would be able to tell what the film is about, solely based on this film clip?". In addition some questions were added concerning perceptual features of the movie, because this is suggested to enhance the negative emotional valence in the negative mood condition (Ehlers \& Clark, 2000). Participants were asked to describe the situation, the surroundings and the clothing in the film clip. Furthermore they evaluated the clip as a whole, the quality of the sounds and colours used in the film on a 5-point scale, and they decided whether based on this fragment they would like to see the whole movie.

2.3.2 Mood manipulation check. The effectiveness of the mood manipulation was assessed with the Self-Assessment Manikin (SAM; Lang, 1980) and with the Positive and Negative Affectivity Schedule (PANAS; Watson, Clark, \& Tellegen, 1988). The SAM is a non-verbal, pictorial measure of affect consisting of three dimensions: valence, arousal, and dominance. In the present study, only the valence dimension was used. The valence scale depicts five manikins that range from a smiling, happy figure to a frowning, unhappy figure. Participants are asked to rate their valence level on a 9-point scale corresponding to the figures. The 
PANAS consists of a positive and a negative subscale, each containing 10 adjectives relating to positive affectivity (e.g. interested, excited, enthusiastic) or negative affectivity (e.g. distressed, upset, guilty). Participants have to indicate on a 5-point scale ranging from 1 (very slightly or not at all) to 5 (extremely) how they currently feel. The scales have been shown to be highly internally consistent, and have a good validity (Watson et al. 1988). Reliability for the PANAS in the present study is good (Cronbach's $\alpha=.79$ at baseline and $\alpha=.80$ after mood induction).

2.3.3 Goal induction. Achievement and hedonic goals were induced implicitly by means of a paper and pencil scrambled sentence task (Srull \& Wyver, 1979). To mask the real purpose of the task, the task was presented as a language ability test. Participants were presented with 15 sets of five words that were presented in a scrambled order. Participants were requested to form grammatically correct four-word sentences. The word that was left over served as the prime word. Depending on the goal condition, the prime word was meant to reflect the achievement goal, the hedonic goal, or no goal. The words that were used in the present study are presented in Table 1. In order to select the appropriate prime words, the words were rated on the extent to which they were related to the achievement or hedonic goals by a group of 15 experts (in the field of goal pursuit or general psychopathology), and a random group of 20 university students. This was done on a 10-point scale with 1 (not representing the goal at all) and 10 (representing the goal completely). In addition, words were rated on valence 1 (this word is very negative) or (this word is very common) respectively and 10 (this word is very positive). The mean scores of the achievement, hedonic and neutral words on these different scales are presented in the Table 2.

Table 1. Prime words used in the scrambled sentence task

\begin{tabular}{lll}
\hline Achievement $^{\text {a }}$ & Hedonic $^{\text {a }}$ & Neutral $^{\text {a }}$ \\
\hline Succeed (Slagen) & Enjoy (Geniet) & Spread (Spreid) \\
Complete (Voltooien) & Go through (beleven) & Digest (Verteer) \\
Win (Winnen) & Experience (Ervaar) & Sit (Zitten) \\
Ought to (Moeten) & Feel (Voelen) & Laydown (Leggen) \\
Accomplish (volbreng) & Amuse (Amuseren) & Shift (Schuiven) \\
Finish (Eindstreep) & Relax (Ontspannen) & Disappear (Verdwijnen) \\
Compete (Concurreren) & Comfortable (Comfortabel) & Staircase (Trappenhuis) \\
Thorough (Grondig) & Want (Verlang) & Enter (Betreed) \\
Achieve (Presteer) & Cosy (Gezellig) & Barrier (Slagboom) \\
Accurate (Accuraat) & Happy (Gelukkig) & Door handle (Deurknop) \\
Result (Resultaat) & Pleasant (Aangenaam) & Chairleg (Stoelpoot) \\
Perfection (Perfectie) & Enjoyable (Plezierig) & Lampshade (Lampenkap) \\
\hline
\end{tabular}

Note. ${ }^{a}$ Words between parentheses are the word used in the priming task translated in Dutch. 
Table 2. Mean ratings and standard deviation of prime words on the achievement, hedonic, and valence scales

\begin{tabular}{llll}
\hline & Achievement & Hedonic & Neutral \\
& words & words & words \\
& $M(S D)$ & $M(S D)$ & $M(S D)$ \\
\hline Achievement scale & $7.81(0.84)$ & $4.32(2.21)$ & $3.20(1.73)$ \\
Hedonic scale & $4.59(1.96)$ & $8.13(0.99)$ & $3.35(1.82)$ \\
Valence scale & $6.27(1.03)$ & $8.05(1.04)$ & $5.70(0.79)$ \\
\hline
\end{tabular}

2.3.4 Habitual goal pursuit. Habitual goals were measured with the Goal Pursuit Questionnaire (Karsdorp \& Vlaeyen, 2011), a 24-item questionnaire which was designed to measure the extent to which individuals have a preference for either hedonic goals (pain-avoidance goals or mood management goals) or achievement goals, when they are confronted with different situations in which both goals are conflicting (Karsdorp \& Vlaeyen, 2011). The questionnaire consists of 24 vignettes in which different situations are described and are followed by a certain thought a person could have in that situation. The thought represents either a hedonic goal or an achievement goal as being more important than the other. Participants are asked to rate to what extent they agree with the thought by indicating a number from 1 (totally disagree) to 6 (totally agree). Eight items are about a painful situation (e.g. "I think it is more important for the pain in my elbow to be reduced now, than for the meeting to be arranged"), eight items are about an unpleasant non-painful situation (e.g. "I think it is more important for me to reduce dullness, than for me to do well at the exam"), and eight items are about a pleasant non-painful situation (e.g. "I think it is more important to write a nice email reply than to finish the presentation"). Higher scores indicate preferences for hedonic goals over achievement goals. In a previous study, the goal pursuit questionnaire was validated in a sample of patients with chronic musculoskeletal pain (Karsdorp \& Vlaeyen, 2011). Therefore, we tested the psychometric properties in a sample of healthy subjects. A sample of 723 participants was included. Multivariate outlier detection with the Mahalanobis distance revealed 28 participants as multivariate outliers, which were removed from the dataset. The remaining sample consisted of 695 participants $(28.6 \%$ male; Mean $(S D)$ age $=23.75$ (7.53) years). To explore the factor structure of the Goal Pursuit Questionnaire, a principal component analysis with Oblique rotation was performed using SPSS 18 (SPSS, Chicago, IL). Missing data were imputed using data augmentation and imputation with the program NORM (Schafer, 1999). This program estimates values of missing data based on available data of the other variables in the same data set. The KMO measure was .90 , indicating that the items were appropriate for principal component analysis (Tabachnick \& Fidell, 2007). The scree plot suggested a two-factor solution (See Figure 1). The total variance explained was $41.16 \%$; the first and second factor explained $29.79 \%$ and $11.37 \%$ of the variance respectively. Some items were excluded: One item, item 16 loaded high on both factor 1 (.36) 
and factor 2 (.40); two items, item 1 and item 9, had a loading below .32, and one item, item 20 was the only non-pain item in the pain scale and was excluded in order to construct a pure subscale with solely pain items. Factor loadings are displayed in Table 1. Factor 1 (labelled the mood-management scale) consisted of 13 items concerning hedonic versus achievement goal conflicts in non-painful situations, with higher scores reflecting stronger preference for hedonic goals. Factor 2 (labelled pain-avoidance scale) consisted of 7 items concerning hedonic versus achievement goal conflicts in painful situations, with higher scores reflecting stronger preferences for pain-avoidance goals. Cronbach's $\alpha$ was $=.83$ and .84 respectively, suggesting excellent internal consistency. The correlation between the two subscales was $r$ $(695)=.54, p<.001$. In the experimental study only the mood-management subscale was used since it concerned a non-painful task with healthy participants.

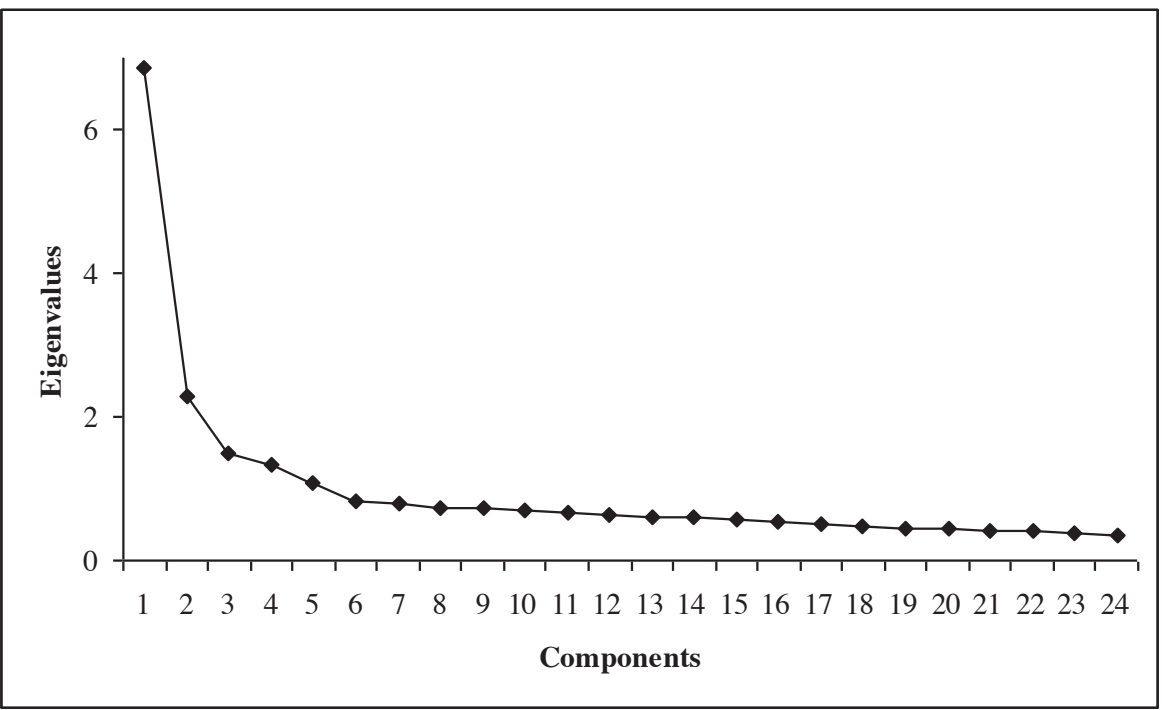

Figure 1. Scree plot. Each factor plotted against its eigenvalue $(\mathrm{N}=695)$ 
Table 1 Factor loadings of the goal pursuit questionnaire (PCA)

\begin{tabular}{|c|c|c|}
\hline I think it is more important. . . & $\begin{array}{l}\text { Factors } \\
\text { Factor I }\end{array}$ & Factor II \\
\hline 13: ...for me to write a nice e-mail reply than to finish the presentation & .73 & \\
\hline 4: ... for me to read the exciting book now than to write a good report & .71 & \\
\hline 2: ... for me to tell my holiday stories than to finish my work & 69 & \\
\hline $12:$...for me to decrease my boredom, than for me to finish the assembly line work & .60 & \\
\hline $11: \ldots$ for me to reduce dullness, than for me to do well at the exam & .59 & \\
\hline 19: ....for me to have interesting conversations now, than to have the decisions made & .55 & \\
\hline 23: ...for me to enjoy my work now, than to finish the other obligations & .55 & \\
\hline $15: \ldots$ for me to reduce my tiredness now, than to take the minutes & .48 & \\
\hline 10: ...for my frustration to be reduced now than to repair the bike & .46 & \\
\hline 17: ...for my irritation to reduce than for me to get the leakage repaired & .45 & \\
\hline 22: ...for me to enjoy the summery weather than to get the floor floored & .45 & \\
\hline 8: ...for me to finish watching the movie than to arrange the garden & .44 & \\
\hline 5: ...for me to for me to prevent despair now, than to succeed in obtaining a correct calculation & .42 & \\
\hline $14: . .$. for the pain in my wrists to be reduced now, than for the album to be completed & & .80 \\
\hline 6: ...for the pain in my upper back to be reduced now, than for the boxes to be moved outside & & .75 \\
\hline 21: ....for the pain in my forearm to be reduced now, than for the car to be repaired & & .74 \\
\hline 7: ...for the pain in my back to be reduced now, than for the house to be clean & & .73 \\
\hline 3: ...for the pain in my shoulder to be reduced now, than for the paintwork to be completed. & & .67 \\
\hline 18: ...for the pain in my hands to be reduced now, than to rehearse the compositions & & .63 \\
\hline 24: ...for the pain in my elbow to be reduced now, than for the meeting to be arranged & & .39 \\
\hline
\end{tabular}

2.3.5 Goal pursuit during the experiment. Participants' goal pursuit during the impression formation task was measured retrospectively with the following statement: "During the impression formation task I thought it was more important to enjoy doing the task than to form a good impression". The rating scale was a 6-point scale ranging from 1 (totally agree) to 6 (totally disagree).

2.3.6 Awareness check. In order to check whether participants were unaware of the purpose of the experiment, a short open-ended questionnaire measuring participants' ideas about the hypothesis of the experiment (Bargh et al., 2001) was administered at the end of the experiment. The questions were: "What do you think is the purpose of the study?"; "Do you think that there is a relationship between the different tasks? If yes, how?", "Has anything that you were doing on one task, affected your performance on another task?"

2.3.7 Task persistence. Task persistence was measured with a computerized version of the impression formation task used by Martin et al., (1993). In this task participants are instructed to form an impression of a target person $\mathrm{X}$, by reading a number of behaviours describing that target person ' $\mathrm{X}$ '. The descriptions were presented, one by one, for five seconds each, on the computer screen. Participants were instructed that they could decide for 
themselves when to stop with the task. After each description, a blank screen was presented and participants decided whether they wanted to continue and read the next description. If so, they pressed the space bar and the next description appeared on the screen; if they wanted to stop with the task, participants pressed the stop-button. The impression formation task provided ambiguous information about person $\mathrm{X}$, as it consisted of positive, as well as negative and neutral behaviours. Example descriptions are "locked himself out of his own house", "got a balloon flight as a birthday present", "wouldn't talk to the secretaries except to ask for favours". Unknown to the participants, 100 of these descriptions were available. The number of descriptions read was automatically registered by the computer, and taken as a measure of task persistence.

\section{$2.4 \quad$ Procedure}

After informed consent, participants' baseline mood was measured with the SAM and the PANAS. Subsequently all participants watched the neutral film clip and completed the film clip questions and the SAM. After this, either the positive or negative movie fragment was shown, again followed by film rating questions and the SAM and the PANAS. Subsequently the scrambled sentence task was presented. Immediately after participants finished the scrambled sentence task, the impression-formation task was started. After participants finished with the impression-formation task, they filled out the questions concerning the purpose of the experiment. The Goal Pursuit Questionnaire was administered afterwards, at home.

\section{Results}

\subsection{Mood Manipulation Check}

To check whether the mood manipulation was successful, a 3 Time (baseline, after neutral film, versus after mood induction) x 2 Mood (positive versus negative) ANOVA for repeated measures was performed on the valence scale of the SAM. Results showed a main effect of Time $F(2,310)=23.94, p<.001, \eta^{2}=.13$ and an interaction effect of Mood X Time $F(2$, $310)=26.21, p<.001, \eta^{2}=.15$. As expected, follow-up tests demonstrated that the mood conditions did not differ at baseline, $F(1,155)=.28, p=.60, \eta^{2}<.01$ and after the neutral film fragment, $F(1,155)=.19, p=0.66, \eta^{2}<.01$. After the mood induction, participants in the negative mood condition reported more negative mood than participants in the positive mood condition, $F(1,155)=18.78, p<.001, \eta^{2}=.11$. Within the negative mood condition, participants reported more negative mood after the mood induction compared to baseline, $F$ $(1,76)=52.56, p<.001, \eta^{2}=.41$, and after the neutral film, $F(1,76)=51.41, p<.001, \eta^{2}$ $=.40$. Within the positive mood condition, mood reports after the mood induction did not 
differ significantly from the other time points (See Figure 2). Note that a similar pattern was obtained when mood analyses were done on the PANAS scores.

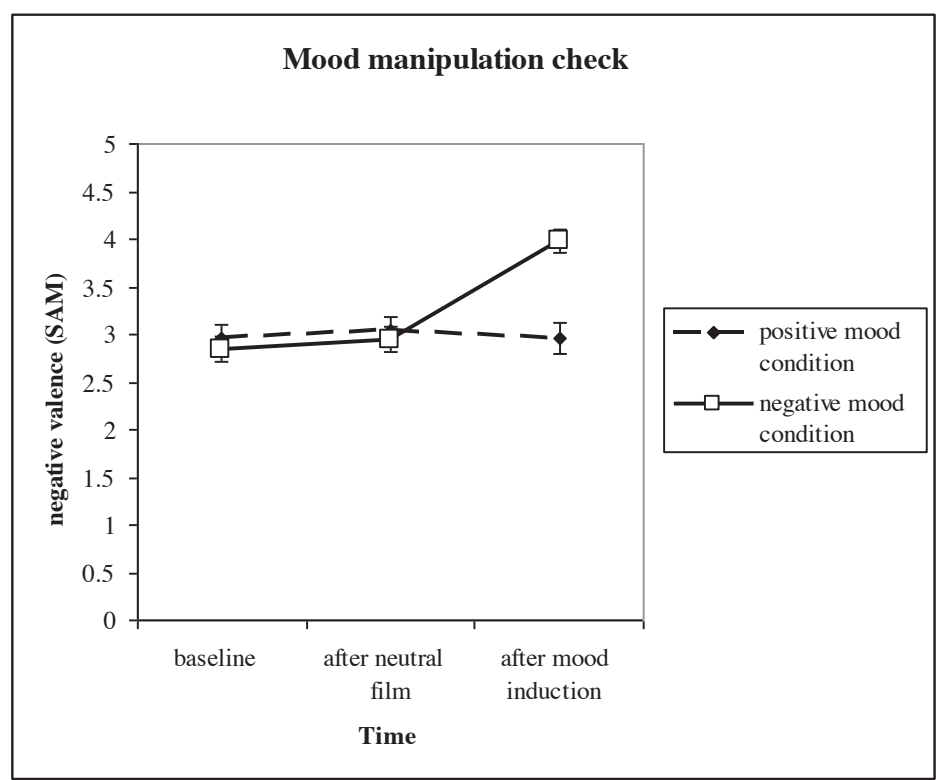

Figure 2. Average scores and standard errors of the mean on the SAM valence scale for the positive and negative mood condition at baseline, after the neutral film fragment, and after mood induction.

\subsection{Goal Pursuit During the Experiment}

To establish whether the explicitly reported goal pursuit during the impression formation task was related to habitual goals and differed between the three goal conditions, a 3 Primed Goal (achievement, hedonic, versus neutral) ANOVA was performed with scores on the mood-management scale as covariate and self-reported goal pursuit during the impression formation task as dependent variable. Results showed that self-reported goal pursuit during the experiment was related to habitual goal pursuit $F(1,153)=10.01, p<.01, \eta^{2}=.06$. As expected, participants who habitually showed a stronger preference for hedonic goals over achievement goals also reported that it was more important to enjoy the impression formation task than to perform well on the task. No differences were obtained between the three prime conditions on self-reported goal pursuit $F(2,153)=0.72, p=.48, \eta^{2}<.01$ indicating that goal priming did not influence self-reported goal pursuit during the task. Means for the hedonic, achievement and neutral condition were $\mathrm{M}(S D)=2.62(1.33) ; \mathrm{M}(S D)=2.38(1.27)$; and $\mathrm{M}$ $(S D)=2.32(1.25)$, respectively. 


\subsection{Awareness Check}

Inspection of the open-ended questions demonstrated that none of the participants guessed either the purpose of the experiment, or the nature of the relationship between the different tasks during the experiment.

\subsection{Task Persistence}

To test the Mood-as-Input hypothesis and the moderating role of habitual goals a 2 Mood (positive versus negative) X 3 Primed goal (achievement, hedonic, versus none) ANCOVA was conducted with the log transformed scores of number of sentences read as dependent variable, and the centred scores of the mood management subscale of the goal pursuit questionnaire as a covariate. Non-significant interactions were stepwise deleted from the model, with higher order interactions first. Unexpectedly, results yielded no three-way interaction between mood, primed goals, and habitual goals, $F(4,145)=2.22, p>.05, \eta^{2}$ $=.06$. Also no two-way interactions between primed goals and mood, $F(2,145)=0.07, p>$ $.05, \eta^{2}<.01$ and between hedonic goals and mood were found, $F(1,145)=0.18, p>.05, \eta^{2}$ $<.01$. Subsequently, the non-significant three-way interaction and two-way interaction terms were deleted step by step from the model resulting in a main effect of habitual goal pursuit, $F(1,152)=5.94, p=.02, \eta^{2}=.04,(\beta=-1.9)$ indicating that participants with strong habitual achievement goals read more sentences than participants with strong habitual hedonic goals (see Figure 3). For ease of interpretation the outcome variable (number of sentences read) displayed in Figure 3 is not log transformed. No other effects were found (all $p \mathrm{~s}>.05)^{1}$. habitual goals from the model, also did not yield a significant main or interaction effect of mood and primed goals (all $p \mathrm{~s}>.05$ ). 


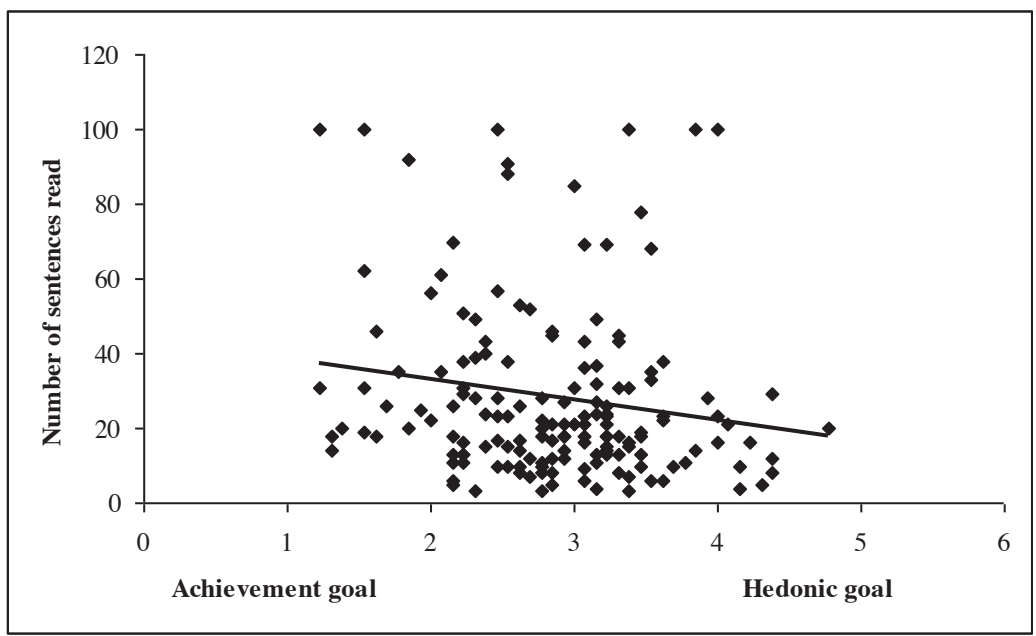

Figure 3. Participants with stronger preferences for achievement goals as compared to hedonic goals demonstrated greater task persistence than those who showed the opposite pattern.

\section{Discussion}

The aim of the present study was twofold: the primary aim was to test whether the Moodas-Input Mood x Goal interaction hypothesis also applies when, instead of using explicit goal instructions, goals were activated by means of supraliminal priming, in a healthy population. A second aim was to test whether habitual goals, as measured with the Goal Pursuit Questionnaire, moderated the relationship between primed goals and mood on the one hand and task persistence on the other. In order to do this, the psychometric properties of the Goal Pursuit Questionnaire (Karsdorp \& Vlaeyen, 2011) were tested first in a sample of healthy participants. The results supported the validity and internal reliability of Goal Pursuit Questionnaire in a healthy population, previously established in a population with pain symptoms.

Concerning the first aim, unexpectedly, results of the present study failed to demonstrate that task persistence on the impression formation task was predicted by a statistical interaction between mood and primed goals. Concerning the second aim, no moderation effect of habitual goals was found. Instead, results of the present study showed a main effect of habitual goals, with participants showing a habitual preference for achievement goals over hedonic goals persisting longer (reading more sentences) on a task without clear performance standards.

The absence of a Mood $x$ Goal interaction effect in the present study is in contrast with previous research that tested the Mood-as-Input hypothesis using explicit goal instructions. For example, in the study of Martin et al. (1993) the Mood-as-Input model was tested with explicit goal instructions using the same impression formation task as was used in the present 
study, and in contrast to the present findings, interaction effects between mood and goals were found. Furthermore interaction effects were found in a number of other studies testing the Mood-as-Input model with explicit goal instructions using different kinds of persistence tasks (Hirt, Melton, McDonald, \& Harackiewicz, 1996; Martin, Abend, Sedikides, \& Green, 1997; Meeten \& Davey, 2011; Sanna, Parks, \& Chang, 2003; Sanna, Turley, \& Mark, 1996; Wright, Startup, \& Mathews, 2005; for a review see Meeten \& Davey, 2011).

The finding that habitual goals did not moderate the effect of goal primes on task persistence is in contrast to Person $\mathrm{x}$ Situation models assuming chronic levels of achievement motivation to interact with situational achievement primes in producing motivational responses (Bargh, Lombardi, \& Higgins, 1988; Hart \& Albarracin, 2009). For example, Hart and Albarracin (2009) showed that situational achievement cues can elicit achievement or fun goals depending on habitual differences in achievement motivation. That is, achievement priming activated a goal to achieve and inhibited a goal to have fun in individuals with chronically high achievement motivation. The opposite pattern was found in participants with chronically low achievement motivation.

There are several explanations for the absence of a Mood x Goals interaction effect and a moderating role of habitual goals in the present study. Firstly, the priming procedure seemed to be successful, in the sense that none of the participants indicated to be aware of the aim of the priming procedure. However, it is possible that the priming manipulation was not strong enough to increase goal accessibility and in turn produce Mood-as-Input effects. The results of the present study showed that the three goal conditions did not differ on their self-reported goal pursuit during the impression formation task. Although, research showed that goal-related stimuli can influence behavior even when people are unaware of their goals during task performance (Bargh, Gollwitzer, Lee-Chai, Barndollar, \& Trötschel, 2001), it is possible that Mood-as-Input effects only occur when people are aware of their current goals. A second explanation for the absence of Mood-as-Input effects and a moderating role of habitual goals is that habitual goals overruled the activation of the primed goal. It is possible, that a ceiling effect occurred in which the habitual goals resulted in chronically accessible goals in memory, leaving no room for improvement by the primed goals. The finding that habitual goal preferences, but not goal priming, was associated with goal preferences during the experimental task is in line with this suggestion. Future, research is required to unravel this issue.

Results of the present study demonstrated a main effect of habitual goals, with participants showing a strong preference for achievement goals over hedonic goals reading more sentences. These results are in line with studies in the domain of worrying, and pain, demonstrating greater task persistence when experimentally manipulated achievement goals are high (Davey, et al., 2005; Karsdorp, Nijst, Goossens, \& Vlaeyen, 2010; Karsdorp, et al., 2012; Ceulemans, Karsdorp, \& Vlaeyen, 2013, Turner \& Wilson, 2010). Moreover, the 
present study is in line with research demonstrating that self-reported habitual achievement goals are related to greater self-reported task persistence (Van Wijhe, Peeters \& Schaufeli, 2011). These findings are in line with goal setting theory (Locke \& Latham, 1990), stating that task performance is a function of individual differences in motivation, with more challenging goals (such as achievement goals) leading to higher levels of performance than easier goals (hedonic goals or no goals). The present study adds to previous research by demonstrating that the relative strength of habitual achievement goals over habitual hedonic goals predicts actual (not self-reported) behavior.

Caution should be drawn to the present findings as habitual goals were not experimentally manipulated. Therefore, no causal conclusions can be made concerning the direction of the relationship between preferences for achievement over hedonic goals and the degree of task persistence. To conclude, the results of the present study do not provide support for the applicability of the Mood-as-Input model (Martin, et al., 1993; Vlaeyen \& Morley, 2004) to habitual goals or goals that are induced by means of supraliminal priming, in healthy individuals. The findings indicate that the robustness of the Mood-as-Input model is still to be tested in a variety of different situations. The present results for the first time demonstrate that habitual goal pursuit as measured with the Goal Pursuit Questionnaire is related to behavioral task persistence. Greater task persistence is predicted by a stronger habitual endorsement of achievement goals over hedonic goals, as hypothesized by goal setting theory. 


\section{References}

Aarts, H., Chartrand, T. L., Custers, R., Danner, U., Giel, D., Jefferies, V. E., et al. (2005). Social stereotypes and automatic goal pursuit. Social Cognition, 23, 465-490.

Aarts, H., \& Dijksterhuis, A. (2000). Habits as knowledge structures: automaticity of goal-directed behavior. Journal of Personality and Social Psychology, 78, 53-63.

Bargh, J. A. (1984). Automatic and conscious processing of social information. . In R. S. Wyer \& T. K. Scrull (Eds.), Handbook of social cognition (Vol. 3, pp. 1-43). Hillsdale, NJ: Erlbaum.

Bargh, J. A., Gollwitzer, P. M., Barndollar, A. L., \& Trotschel, R. (2001). The automated will: Nonconsious Activation and Pursuit of Behavioral Goals. Journal of Personality and Social Psychology, 81, 1014-1027.

Bargh, J. A., Lombardi, W. J., \& Higgins, E. T. (1988). Automaticity of chronically accessible constructs in person $\mathrm{x}$ situation effects on person perception: it's just a matter of time. Journal of Personality and Social Psychology, 55, 599-605.

Blackmore, S. (2003). Consciousness: An introduction. New York: Oxford University Press.

Bower, G. H. (1981). Mood and Memory. American Psychologist, 36(2), 129-148.

Ceulemans, K., Karsdorp, P. A., \& Vlaeyen, J. W. (2013). Mood, stop-rules and task persistence: No Mood-as-Input effects in the context of pain. Journal of Behaviour Therapy and Experimental Psychiatry, 44, 463-468.

Custers, R., \& Aarts, H. (2005). Beyond priming effects: the role of positve affect and discrepancies in implicit processes of motivation and goal pursuit. European Review of Social Psychology, $16,257-300$

Davey, G. C., Startup, H. M., MacDonald, B. A., Jenkins, D., \& Patterson, K. (2005). The use of 'as many as can' versus 'feel like continuing' stop rules during worrying. Cognitive Therapy and Research, 29, 155-169.

Davey, G. C., Startup, H. M., Zara, A., MacDonald, C. B., \& Field, A. P. (2003). The perseveration of checking thoughts and mood-as-input hypothesis. Journal of Behavior Therapy and Experimental Psychiatry, 34, 141-160.

Ehlers, A., \& Clark, D. M. (2000). A cognitive model of posttraumatic stress disorder. Behaviour Research and Therapy, 38, 319-345.

Eitam, B., Hassin, R. R., \& Schul, Y. (2008). Nonconscious goal pursuit in novel environments: the case of implicit learning. Psychologival Science, 19, 261-267.

Fitzsimons, G. M., \& Bargh, J. A. (2003). Thinking of you: nonconscious pursuit of interpersonal goals associated with relationship partners. Journal of Personality and Socical Psychology, 84, 148-164.

Forgas, J. P., \& Bower, G. H. (1987). Mood Effects on Person-Perception Judgements. Journal of Personality and Social Psychology, 53, 53-60.

Hart, W., \& Albarracin, D. (2009). The effects of chronic achievement motivation and achievement primes on the activation of achievement and fun goals. Journal of Personality and Social Psychology, 97, 1129-1141. 
Higgins, E. T., \& King, G. (1981). Accesibility of social constructs: Information-processing consequences of individual and contextual variability In N. Cantor \& J. F. Kihlstrom (Eds.), Personality, cognition, and social interaction (pp. 69-121). Hilsdale, NJ: Erlbaum.

Hirt, E. R., Melton, J. R. R., McDonald, H. E., \& Harackiewicz, J. M. (1996). Processing goals, task interest, and the mood - performance relationship: a mediational analysis. Journal of Personality and Social Psychology, 71, 245-261.

Isen, A. M., Shalker, T. E., Clark, M., \& Karp, L. (1978). Affect, Accessibility of Material in Memory, and Behaviour: A Cognitive Loop? . Personality and Social Psychology, 36, 1-12.

Karremans, J. C., Stroebe, W., \& Claus, J. (2006). Beyond Vicary's fantasies: The impact of subliminal priming and brand choice. Journal of Experimental Social Psychology, 42(6), 792-798.

Karsdorp, P. A., Nijst, S. E., Goossens, M. E., \& Vlaeyen, J. W. (2010). The role of current mood and stop rules on physical task performance: An experimental investigation in patients with workrelated upper extremity pain. European Journal of Pain, 14, 434-440.

Karsdorp, P. A., Ranson, S., Nijst, S. E., \& Vlaeyen, J. W. S. (2012). Goals, mood and performance duration on cognitive tasks during experimentally induced mechanical pressure pain. Journal of Behavior Therapy and Experimental Psychiatry, 44, 240-247.

Karsdorp, P. A., \& Vlaeyen, J. W. (2011). Goals matter: both achievement and pain-avoidance goals are associate with pain severity and disability in patients with musculoskeletal pain, Pain, 152, 1382-1390.

Lang, P. J. (1980). Behavioral treatment and behavioral assessment: computer applications. In J. Sidowski, J. Johnson \& T. Williams (Eds.), Technology in mental health care delivery systems (pp. 119-137). Norwood: Ablex.

Locke, E. A., \& Latham, G. P. (1990). A theory of goal setting \& task performance. Englewood Cliffs, NJ: Prentice Hall.

Maio, G. R., Pakizeh, A., Cheung, W. Y., \& Rees, K. J. (2009). Changing, priming, and acting on values: effects via motivational relations in a circular model. Journal of Personality and Social Psychology, 97, 699-715.

Martin, L., Abend, T., Sedikides, C., \& Green, J. D. (1997). How Would I Feel If...? Mood as Input to a Role Fulfillment Evaluation Process. Journal of Personality and Social Psychology, 73, 242-253.

Martin, L., Ward, D. W., Achee, J. W., \& Wyer, R. S. (1993). Mood as input: people have to interpret the motivaitional implications of their Moods. Journal of Personality and Social Psychology, 64, 317-326.

Mayer, J. D., Gaschke, Y. N., Braverman, D. L., \& Evans, T. (1992). Mood Congruent Judgement Is a General Effect. Journal of Personality and Social Psychology, 63, 119-132.

Meeten, F., \& Davey, G. C. (2011). Mood-as-input hypothesis and perseverative psychopathologies. Clinical Psychology Review, 31, 1259-1275.

Moors, A., \& De Houwer, J. (2006). Automaticity: a theoretical and conceptual analysis. Psychological Bulletin, 132, 297-326. 
Murray, N., Sujan, H., Hirt, E. R., \& Sujan, M. (1990). The Influence of Mood on Categorization: A Cognitive Flexibility Interpretation. Journal of Personality and Social Psychology, 59, 411425 .

Nisbett, R. E., \& Wilson, T. D. (1977). Telling more than we can know: verbal reports on mental processes. Psychological Review, 84, 231-259.

Nørretranders, T. (1991). The user illusion: Cutting consciousness down to size. New York: Penguin.

Oaksford, M., Morris, F., Grainger, B., Williams, J., \& Mark, G. (1996). Mood, reasoning, and central executive processes. Journal of Experimental Psychology: Learning, Memory, and Cognition, $22,476-492$.

Oikawa,M. (2004). Moderation of automatic achievement goals by conscious monitoring. Psychological Reports, 95, 975-980.

Radel, R., Sarrazin, P., \& Pelletier,L. (2009).Evidence of subliminally primed motivational orientations: the effects of unconscious motivational processes on the performance of a new motor task. Journal of Sports and Exercise Psychology, 31(5), 657-674.

Ramanathan, S., \& Menon, G. (2006). Time-varying Effects of Chronic Hedonic Goals on Impulsive Behavior. Journal of Marketing Research, 18, 628-641

Sanna, L. J., Parks, C. D., \& Chang, E. C. (2003). Mixed-motive conflict in social dilemmas: Mood as input to competitive and cooperative goals. Group Dynamics: Theory, Research, and Practice, 71, 26-40.

Sanna, L. J., Turley, K. J., \& Mark, M. M. (1996). Expected evaluation, goals, and performance: Mood as input. Personality and Social Psychology Bulletin, 22, 223-235.

Schaefer, A., Nils, F., Sanchez, X., \& Philippot,P. (2010). Assessing the effectiveness of a large database of emotion-eliciting films: A new tool for emotion researchers'. Cognition \& Emotion, 24, $1153-1172$.

Shantz, A., \& Latham, G. P. (2009). An exploratory field experiment of the effect of subconscious and conscious goals on employee performance. Orgainzational behavior and human decision processes, 109, 9-17.

Srull, T. K., \& Wyver, R. S. (1979). The role of category accessibility in the interpretation of information about persons: some determinants and implications. Journal of Personality and Social Psychology, 37, 1660-1672.

Stajkovic, A. D., Locke, E. A., \& Blair, E. S. (2006). A first examination of the relationships between primed subconscious goals, assigned conscious goals, and task performance. Journal of Applied Psychology, 91, 1172-1180.

Startup, H. M., \& Davey, G. C. (2001). Mood as input and catastrophic worrying. Journal of Abnormal Psychology, 110, 83-96.

Startup, H. M., \& Davey, G. C. (2003). Inflated responsibility and the use of stop rules for catastrophic worrying. Behaviour Research and Therapy, 41, 495-503.

Strahan, E. J., Spencer, S. J., \& Zanna, M. P. (2002). Subliminal priming and persuasion: striking while the iron is hot. Journal of Experimental Social Psychology, 38, 556-568. 
Turner, L., \& Wilson, C. (2010). Worry, Mood and Stop Rules in Young Adolescents: Does the Moodas-Input Theory Apply? Journal of Experimental Psychopathology, 1, 34-51.

Van Wijhe, C. I., Peeters, M. C., \& Schaufeli, W. B. (2011). To Stop or Not to Stop, That's the Question: About Persistence and Mood of Workaholics and Work Engaged Employees. International Journal of Behavioral Medicine, 18, 361-372.

Vlaeyen, J. W., \& Morley, S. (2004). Active despite pain: the putative role of stop-rules and current mood. Pain, 110, 512-516.

Watkins, E., \& Mason,A. (2002). Mood as input and rumination. Personality and Individual Differences, $32,577-587$.

Watson, D., Clark, L. A., \& Tellegen, A. (1988). Development and validation of brief measures of positive and negative affect: the PANAS scales. Journal of Personality and Social Psychology, 54, 1063-1070.

Wright, D. B., Startup, H. M., \& Mathews, S. A. (2005). Mood, dissociation and false memories using the Deese-Roediger-McDermott procedure. Brittish Journal of Psychology, 96, 283-293. 


\section{Chapter 4}

\section{Testing the Activation of Primed Hedonic and Achievement Goals}

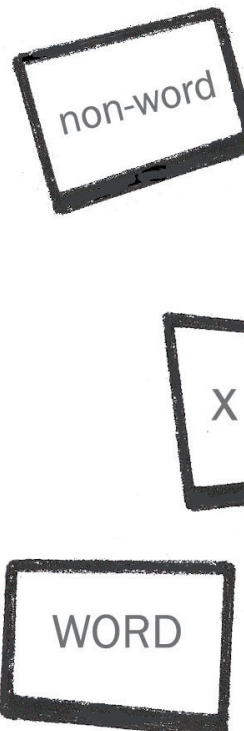




\begin{abstract}
Models on goal pursuit, such as the Mood-as-Input model, postulate that persistence behaviour is determined by two broad classes of 'stop rules' or goals: hedonic and achievement goals. Although previous goal priming studies found goal priming effects on behavior, only a few studies tested the actual accessibility of the primed goals. The aim of the present study was to test whether these goals can be activated by supra- and subliminal presentation of goal stimuli. One hundred twenty participants were primed with either supraliminal or subliminal presented goal or no-goal words by means of a scrambled sentence task or a dot detection task respectively. Subsequently, goal activation was measured with a lexical decision task. Both priming techniques did not influence responses on the lexical decision task, suggesting that supraliminal and subliminal presentation of goal stimuli failed to activate hedonic and achievement goals. In contrast to other goal priming studies, our study controlled for lexical differences which could potentially explain previously found goal priming effects.
\end{abstract}




\section{Introduction}

Human behaviour is determined by goals (Aarts, Custers, \& Holland, 2007). Goals are defined as mental representations of desired states or outcomes (Aarts \& Dijksterhuis, 2000). Motivational models of persistence behaviour, such as the Mood-as Input-model, postulate that two broad classes of goals (or so called 'stop rules') may be important in influencing persistence behaviour: hedonic and achievement goals (Hirt, Melton, McDonald, \& Harackiewicz, 1996; Martin, Ward, Achee, \& Wyer, 1993). Indeed, research has repeatedly demonstrated that achievement goals relative to hedonic goals facilitate persistence behaviour in a context of negative mood or pain (Davey, Startup, Zara, MacDonald, \& Field, 2003; Karsdorp, Nijst, Goossens \& Vlaeyen, 2010; MacDonald \& Davey, 2005; Martin, Ward, Achee, \& Wyer, 1993; Startup \& Davey, 2001, 2003; Watkins \& Mason, 2002). These studies have activated goal pursuit with explicit verbal instructions activating the goals within conscious awareness. Recently, it has been questioned whether goal pursuit is always accompanied by conscious processes. In everyday life people are often unconscious of the processes underlying their thoughts and goal dependent behaviours (Blackmore, 2003; Nisbett \& Wilson, 1977; Nørretranders, 1991). An unresolved question is whether Mood-asInput predictions also hold within the context of unconscious goal pursuit.

Research from the area of social psychology has shown that goals can be activated by means of unconscious goal priming (Custers \& Aarts, 2010). The mechanism underlying unconscious goal priming is based on the idea that contextual cues can activate a mental goal representation, which in turn influences behaviour (Bargh, 1990, 2006). A distinction is made between subliminal and supraliminal priming. In the case of supraliminal goal priming the subject is aware of the presented stimuli but not of the relation between the stimuli and the following task (Bargh \& Chartrand, 2000). An example of a supraliminal goal priming technique is the scrambled sentence task (Srull \& Wyver, 1979). In this task participants are requested to construct a grammatically correct four-word sentence from a set of five words that are presented in a scrambled order. Dependent on the specific variation of the task, either the four-word sentence as a whole or the remaining fifth word is the priming stimulus. In the case of subliminal goal priming, the subject is both unaware of both the presented stimuli and the link between the stimuli and the following task. The prime stimuli are presented unconsciously by presenting the stimuli for a very short duration and by masking the primes (Bargh \& Chartrand, 2000).

There is supportive evidence that achievement goals can be activated by means of subliminal (Custers et al. 2009, Hart \& Albaracin, 2009) or supraliminal (Bargh, Gollwitzer, Barndollar, \& Trotschel, 2001; Bargh \& Ferguson, 2000; Eitam, Hassin, \& Schul, 2008; Oikawa, 2004; Stajkovic, Locke, \& Blair, 2006, Shanz \& Latham, 2009) priming, and in turn may affect behaviours such as performance on word search puzzle, the subconscious need 
for achievement, self-agency and goal prioritization. The unconscious activation of hedonic goals has received far less attention so far. There have been attempts to unconsciously activate hedonic goals with supraliminal priming methods but not with subliminal priming methods (Fishbach, Friedman, \& Kruglanski, 2003, Laran, Janiszweki, \& Cunha, 2008). Supraliminal hedonic goal priming has been shown to influence physical endurance on a self-control task (Fishbach et al., 2003), goal accessibility (Laran et al, 2008), and choice preference (Laran et al, 2008).

Although several studies have examined the effects of goal priming on behavior, only a few have tested the actual accessibility of the primed goals. The aim of the present study was to investigate whether it is possible to unconsciously activate the goals of the Mood-as-Input model, hedonic and achievement goals, by testing goal accessibility after subliminal and supraliminal priming techniques. The study consisted of three different goal priming conditions: the hedonic goal condition, the achievement goal condition and a nogoal control condition. These goals were primed either by means of a scrambled sentence task (supraliminal priming), or by masking and briefly $(33 \mathrm{~ms})$ presenting goal words (subliminal priming). Accessibility of the goals was tested using a lexical decision task that was administered at baseline and after the priming procedure. In the lexical decision task, participants decided whether a presented letter string represented a word or a non-word. The main idea behind the lexical decision task is that a lexical decision to a (goal-related) target word is facilitated when it is preceded by a (goal-) related prime word, compared to a goalunrelated prime word. Four different word types were used to measure goal activation in the lexical decision task: achievement words, hedonic words, positive words and neutral words. A category of positive words was included, because the hedonic words were significantly more positive in valence than achievement words and to ensure that the priming effect was not due to positive valence irrespective of the content of the hedonic goal.

It was expected that the primed goal (i.e., achievement or hedonic) would become more accessible, and that this would yield faster responses on the subsequent presentation of related goal words (i.e., achievement or hedonic respectively) relative to no-goal words (positively or neutral valenced words) and the unrelated goal words in a lexical decision task.

\section{Method}

\subsection{Participants}

A total of 120 psychology students participated in the experiment [87\% women, mean age $(S D)=21.20$ (3.92) years]. Only participants who had normal or corrected to normal vision and had Dutch as their mother tongue were included. Compliance with these criteria was verbally checked prior to inclusion in the study. Participants were recruited by means of advertisements in and around the university. They received course credits or $€ 7.50$ as a 
reward for their participation. They were randomly assigned to the experimental conditions: 60 participants took part in the supraliminal condition and 60 in the subliminal condition. The experiment was approved by the ethical committee of the Faculty of Psychology and Neuroscience of Maastricht University.

In the supraliminal analysis of the experiment, one participant was excluded from the analysis because she made more than $80 \%$ errors in the lexical decision task $(96 \%$ for the baseline task and $86 \%$ for the second task), due to technical errors. The final sample of the supraliminal analysis therefore consisted of 59 participants [75 \% female, mean age $(S D)=21.64$ years, (3.86)]. In the subliminal analysis, one participant was excluded because data from the second lexical decision task were not recorded. Thus 59 participants remained [70\% female, mean age $(S D)=20.80$ (3.99) years]. All participants indicated that they were unaware of the aim of the study.

\subsection{Research Design}

The design of both the supraliminal and the subliminal experiment was a 3 Prime (no-goal, hedonic, versus achievement) X 4 Target (hedonic, achievement, positive, versus neutral) mixed factorial design, with prime as between-subjects factor and target as within-subjects factor, and reaction time as dependent variable. The research design is visually depicted in Figure 1.

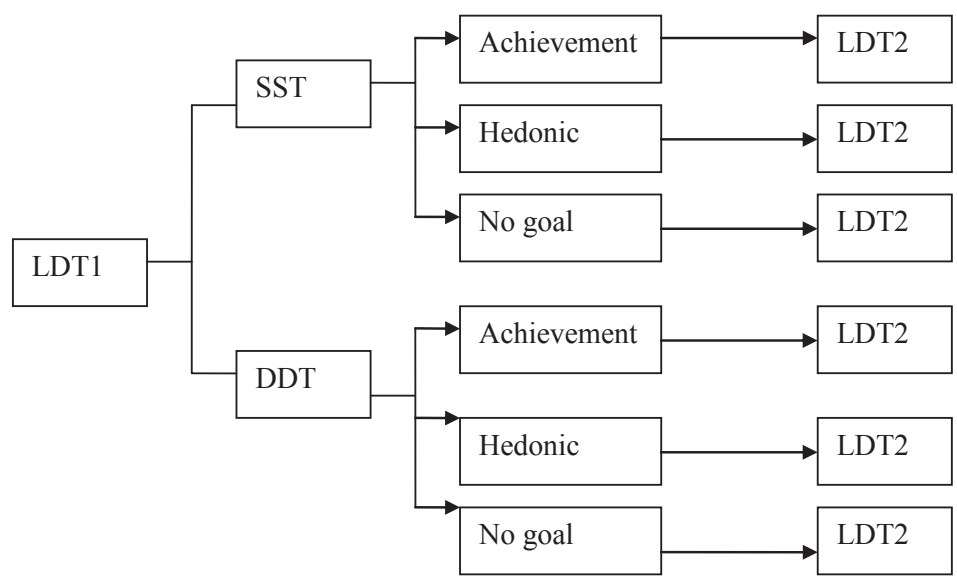

Figure 1. Visual presentation of the research design. After participants received the baseline lexical decision task, they where either supraliminally primed by means of the scrambled sentence task (either the achievement version, the hedonic version, or the no-goal version) or subliminally primed by means of the dot detection task (either the achievement version, the hedonic version, or the no-goal version). After the priming task, participants received a second lexical decision task. The baseline version and the second version of the lexical decision task were counterbalanced across participants.

Note. SST, scrambled sentence task; LDT1, baseline lexical decision task; LDT2, second lexical decision task. 


\section{$2.3 \quad$ Measures}

2.3.1 Mood. Research suggests that primes can also influence mood (Rholes, Riskind \& Lane, 1987). Therefore, the Self-Assessment Manikin (SAM; Lang, 1980) was administered to control for possible mood differences between goal priming conditions, in the present experiment. The SAM is a nonverbal questionnaire that measures affective reactions on three dimensions: valence, arousal and dominance. It uses a 9-point scale with graphical characters. For pleasure, the figures range from a smiling happy figure to a frowning unhappy figure. For arousal, the figures range from excited open eyes to sleepy closed eyes and for dominance, figures range from a small figure (no control over the situation) to a large figure (maximum control over the situation). In the present study, only the valence scale was used. The SAM has been used effectively to measure affective reactions to a wide variety of stimuli such as pictures, images, sounds, advertisements and painful stimuli (Bradley \& Lang, 1994).

2.3.2 Lexical decision task. To test whether the primed goal was activated, a lexical decision task was used. Two lexical decision tasks were created, one lexical decision task was used to measure baseline accessibility of the goals; the other task was used to measure accessibility after the priming procedure. The two lexical decision tasks were counterbalanced across participants. Each lexical decision task consisted of the following events. After a fixation cross was presented for $500 \mathrm{~ms}$, a letter string appeared on the screen. Participants were to decide whether the presented letter string was a word or a non-word, by pressing the button p (right) or q (left). The labels 'yes' and 'no' were attached to the buttons and indicated either 'yes, this is a word' or 'no, this is not a word'. The placement of the button labels was counterbalanced across participants (see Figure 2). Stimuli remained on the screen until a response was given. Participants were not explicitly instructed to react as fast and as accurately as possible. The reason for this was that an explicit instruction to react as fast and accurately as possible may have induced an achievement goal. Instead, participants were instructed to react as soon as the stimuli were presented on the screen.

Each lexical decision task consisted of 48 different stimuli of which half were word stimuli ( 24 words) and the other half were non-word stimuli ( 24 non-words). The word stimuli consisted of 4 categories: hedonic, achievement, positive and neutral words. The non-word stimuli were created with the software WordGen (Duyck, Desmet, Verbeke, \& Brysbaert, 2004). The 48 different stimuli were repeated 4 times (192 trials).

The selection of the hedonic, achievement, neutral, and positive word stimuli was based on a pilot study with 13 experts (4 experts in the field of goal pursuit and 9 experts in the field of psychopathology). These experts rated a total of 347 word stimuli on valence and on the extent to which the words reflected an achievement or hedonic goal. Response categories of the achievement and hedonic scales varied from 1 (this word does not reflect 
the achievement/hedonic goal at all) to 10 (this word totally reflects the achievement/hedonic goal). Response categories of the valence scale varied from 1 (this word is very negative) to 10 (this word is very positive).

The words that scored highest on the achievement scale and lowest on the hedonic scale were selected as achievement words. The opposite was true for words that were selected as hedonic words. Words were categorized as neutral if they scored low on both the achievement scale and the hedonic scale and if their valence was between 4 and 6 . Words were categorized as positive if they scored low both on the achievement and hedonic scale and high in valence. Moreover, words were selected such that the 4 word categories (achievement, hedonic, neutral, versus positive) matched on the number of letters (ranging from 3 to 12) and on word frequency (log frequencies ranging from 0 to 2.99). Word frequency was determined with the CELEX database in Wordgen (Duyck et al., 2004). Non-words were matched on number of letters. To ensure that the priming effect was not due to an orthographic overlap between the prime words and the target (lexical decision) words, the first two letters of the prime and target words were never the same (for example the Dutch words 'volhouden' as a prime and 'voltooien' as a target would be a case of orthographic overlap between prime and target). From the 347 words that were rated in the pilot study, a total of 24 word stimuli were selected for each lexical decision task. The 24 word stimuli encompassed 4 different word categories, six words were related to the hedonic goal, six words were related to the achievement goal, six words were neutral and thus unrelated to either goal and six words were positive and also unrelated to either goal. An example of an achievement word is the word: 'result', an example of a hedonic word is the word 'enjoy' and an example of a neutral word is 'carpet'. (For a complete list of stimuli, see Appendix I).

At the end of the experimental session, participants rated the valence of the 24 selected word stimuli as well as the extent to which they reflected achievement and hedonic goals. The latter was done to check whether the words still reflected the intended goal. 


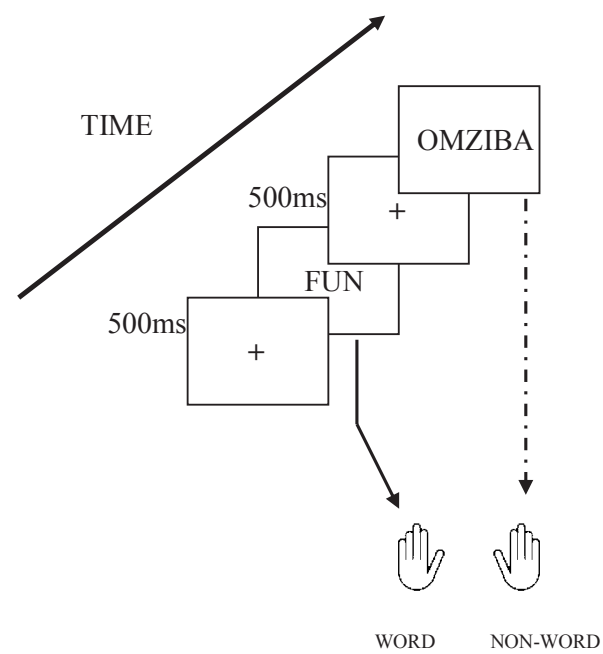

Figure 2. In the lexical decision task, participants were requested to indicate whether the presented stimulus is a word or a non-word by pressing the P - key or the Q - key.

2.3.3 Dot detection task. Subliminal priming of goals was done by means of a dot detection task (Aarts et al., 2007) which consisted of the following events: First a fixation cross appeared for $500 \mathrm{~ms}$. Then a forward mask, which was a random letter string printed in black capital letters, font Ariel, letter size 14 (XQFBZRMQWGBX; Chartrand \& Bargh, 1996), was presented in white on a black background for $500 \mathrm{~ms}$. After this, a prime word was presented in black capitals, letter size 14 for $33 \mathrm{~ms}$. This prime was immediately followed by a backward mask, which again was a random string of letters (XQFBZRMQWGBX) for $200 \mathrm{~ms}$. Then, after a blank screen of $50 \mathrm{~ms}$ a dot either appeared or not. The dot consisted of a small white letter 'o' (letter size 14) on a black screen. If the dot was present (50\% of the trials), it appeared either above or below the middle of the screen. In this way participants were encouraged to focus on the middle of the screen and thus to pay attention to the location of the prime stimulus (Aarts et al. 2007). If a dot appeared it was presented for $33 \mathrm{~ms}$, either above or below a '=' sign that was presented in the middle of the screen. After $33 \mathrm{~ms}$ the dot disappeared and the ' $=$ ' sign reappeared and stayed on the screen until the participant responded. Participants had to indicate whether a dot was presented or not, by pressing the p key or the q key. Answering options ("yes" or "no") were counterbalanced across the two keys. After 500 ms a new trial started (see Figure 3)

Three different between-subjects versions of the task were created: a neutral task, a hedonic task and an achievement task. Each task consisted of 12 different prime words (See Appendix I), which were repeated 10 times (= 120 trials). These words were selected based on the pilot study described above. Before the actual start of the task, participants received 12 practice 
trials. In order to prevent priming effects from practice trials, no primes were presented in the practice trials and a black screen was presented instead.

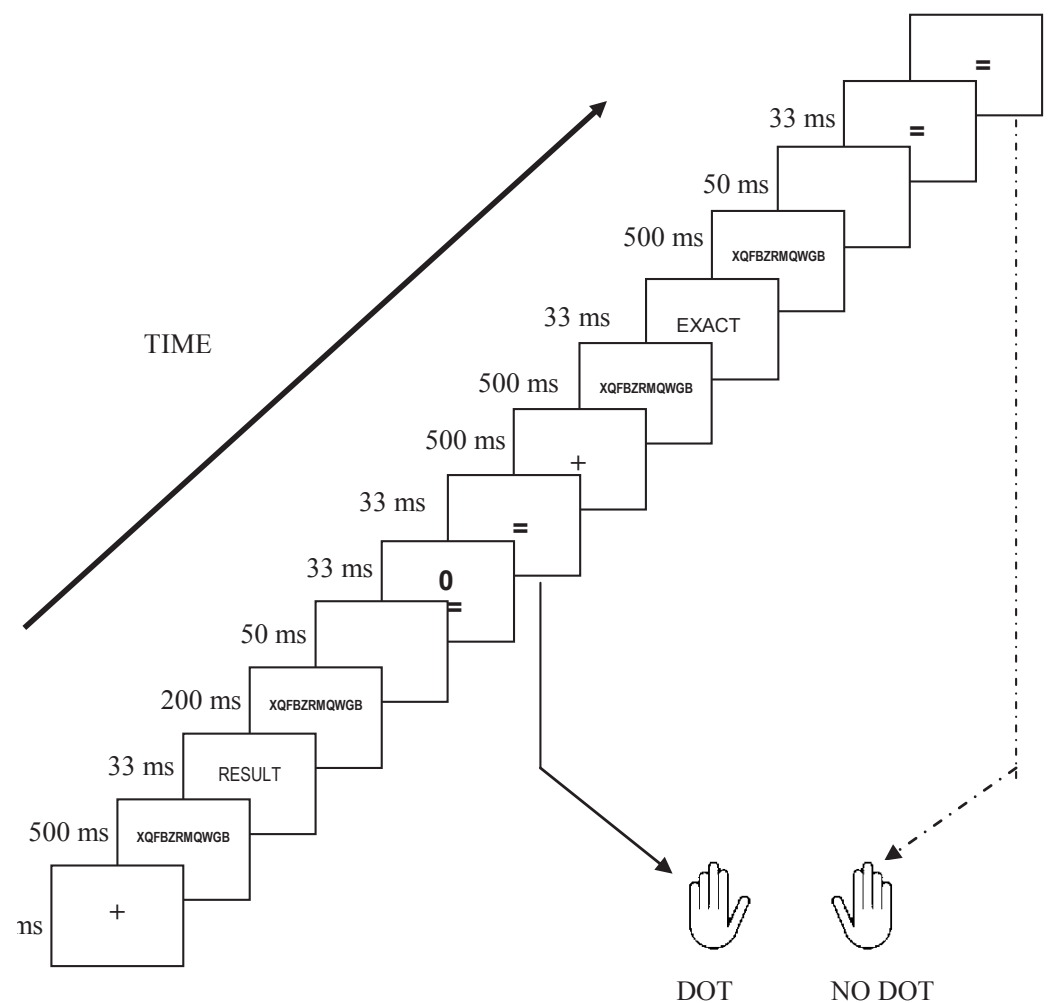

Figure 3. In the dot detection task, participants have to indicate whether or not a dot is present by pressing the $\mathrm{P}$ - key (Yes) or the $\mathrm{Q}-$ key $(\mathrm{No})$. If the dot is present, it appears either above or below the '=' sign in the middle of the screen.

2.3.4 Supraliminal priming task (scrambled sentence task). The supraliminal goal priming manipulation was induced by means of a paper and pencil scrambled sentence task (Srull \& Wyver, 1979). In this task, participants formed a grammatically correct four-word sentence from a series of five words that were presented in a scrambled order. The four-word sentence was meant to reflect the specific goal. The fifth word was a neutral word. An example of a four-word sentence that reflects the achievement goal is: 'Saskia wants to achieve results' (in Dutch: 'Saskia wil resultaat behalen'). The task comprised 15 sentences in total. In the achievement goal or hedonic goal condition twelve sentences served to activate either an achievement or hedonic goal and three sentences served as neutral fillers to mask the actual purpose of the task. In the no goal condition the task consisted of 15 neutral sentences. 
2.3.5 Awareness check. To test participants' awareness of the priming procedure, two different awareness checks were used dependent on type of priming procedure (subliminal or supraliminal). In the subliminal priming condition a post experimental recognition task was used to test whether participants were able to consciously perceive the priming words (Van den Bussche, Segers, \& Reynvoet, 2008). In the recognition task, participants performed a subliminal lexical decision task in which they were asked to decide whether a subliminally presented stimulus was a word or a non-word. Prime word stimuli were mixed with nonwords and were presented subliminally for $33 \mathrm{~ms}$. Masking conditions were the same as in the dot detection task. The same 12 prime words that were previously used in the dot detection task were matched on number of letters with 12 non-words and these 24 stimuli were repeated 3 times which yielded a total of 72 trials.

In the subliminal and supraliminal priming condition the awareness check also consisted of a short open-ended questionnaire measuring participants' ideas about the hypothesis of the experiment (Bargh et al., 2001). The questions were: 'What do you think is the purpose of the study?', 'Do you think that there is a relationship between the different tasks?', 'Has anything that you were doing on one task, affected your performance on another task?'

\subsection{Procedure}

Participants were told that they took part in several short, unrelated studies about language ability and/or visual perception of different research teams. After they had read the subject information sheet and filled out the informed consent form, participants completed the SAM and started with the baseline lexical decision task. Next, they performed either the scrambled sentence task $(N=59)$ or the dot detection task $(N=59)$ dependent on priming condition. Immediately after the priming task participants completed respectively the SAM, the second lexical decision task, the SAM and the awareness questionnaire. Participants in the subliminal priming condition also performed the recognition task, after they completed the awareness questionnaire. Finally, participants rated the stimulus words on an achievement scale, a hedonic scale, and a valence scale (1-10). All participants were debriefed about the purpose of the experiment.

\section{Results}

\subsection{Goal and Valence Rating of the Word Stimuli}

To check whether the words used in the priming task reflected the appropriate goals, three separate repeated measures ANOVA were conducted with Prime (achievement, hedonic, versus neutral) as within-subjects factor and the scores on the achievement scale, the hedonic 
scale or the valence scale as dependent variables. To establish whether the target words used in the lexical decision tasks reflected the appropriate goals the same analyses were performed as for the prime words, but now with Target as within-subjects factor (achievement, hedonic, neutral, versus positive). Tables 1 and 2 show the mean hedonic, achievement and valence scores of each word type that was used in the lexical decision task and the priming task respectively. Results showed that words were selected appropriately both in the priming task and the lexical decision tasks, with the achievement words scoring higher on the achievement scale compared to all the other word types and the hedonic words scoring higher on the hedonic scale compared to all the other word types. The neutral words were rated less positive in valence compared to all the other word types in both the priming task and the lexical decision tasks. Hedonic words were rated more positively than the achievement words and unexpectedly hedonic words were also rated more positively than the positive words, in the lexical decision tasks. (For a detailed analysis see Appendix II)

Table 1 Mean rating scores for the words that were used in the lexical decision tasks

\begin{tabular}{llll}
\hline & $\begin{array}{l}\text { Achievement scale } \\
M(S D)\end{array}$ & $\begin{array}{l}\text { Hedonic scale } \\
M(S D)\end{array}$ & $\begin{array}{l}\text { Valence scale } \\
M(S D)\end{array}$ \\
\hline Enough words & $8.0(1.35)$ & $3.75(1.74)$ & $6.4(0.88)$ \\
Enjoy words & $3.60(1.74)$ & $7.74(1.39)$ & $8.69(0.68)$ \\
Neutral words & $2.69(1.67)$ & $2.49(1.60)$ & $4.98(0.91)$ \\
Positive words & $3.56(1.51)$ & $5.13(1.79)$ & $7.73(0.78)$ \\
\hline
\end{tabular}

Table 2 Mean rating scores for the words that were used in the priming task

\begin{tabular}{llll}
\hline & $\begin{array}{l}\text { Achievement scale } \\
M(S D)\end{array}$ & $\begin{array}{l}\text { Hedonic scale } \\
M(S D)\end{array}$ & $\begin{array}{l}\text { Valence scale } \\
M(S D)\end{array}$ \\
\hline Enough words & $7.99(1.45)$ & $3.90(1.68)$ & $6.5(0.91)$ \\
Enjoy words & $3.16(1.81)$ & $8.31(1.36)$ & $8.8(0.65)$ \\
Neutral words & $2.76(1.54)$ & $2.51(1.59)$ & $5.04(0.88)$ \\
\hline
\end{tabular}

\subsection{Mood}

To check whether priming condition had an influence on mood state, a 3 Prime condition X 4 Time (baseline, after lexical decision task 1, after priming, after lexical decision task 2) repeated measures ANOVA was conducted with the pleasure subscale of the SAM as dependent variable.

The influence of priming condition on mood did not reach statistical significance, $F(2,115)=0.88, p>.05 \eta^{2}=.02$. No interaction between time and prime was found, $F(6,345)$ $=0.35, p>.05, \eta^{2}<.01$. Unexpectedly, there was a significant main effect of time, $F(3,345)$ $=39.59, p<.001, \eta^{2}=.26$, showing that participants experienced less pleasure after priming than at baseline, independent of priming condition, $F(1,115)=32.65, p<.001, \eta^{2}=.22$. 


\subsection{Awareness Check}

To check for prime awareness in the subliminal priming condition, the percentage of correct classifications on the awareness test was subjected to a one sample $t$-test. The awareness check showed that participants in the subliminal priming condition, on average, could only classify $51 \%$ of the primes correctly, indicating that primes could not be classified above chance $(50 \%), t(58)=1.52, p>.05$.

To check whether level of awareness influenced the priming effects, a 3 Prime (achievement, hedonic, versus neutral) x 4 Target (achievement, hedonic, positive, versus neutral) ANCOVA was conducted with prime as between-subjects factor, target as withinsubjects factor, the centred awareness scores as a covariate and reaction time as dependent variable. Results yielded no significant awareness effects (all $p s>.05$ ). Review of the answers on the open-ended question concerning awareness of the prime manipulation indicated that none of the participants was aware of the priming manipulation.

\subsection{Supraliminal Priming Condition}

Incorrect responses on the lexical decision tasks were excluded from the analyses $(1.8 \%$ of the responses in the baseline lexical decision task and $2.7 \%$ of the responses for the second lexical decision task). Next, response latencies lower than $300 \mathrm{~ms}$ and higher than $1200 \mathrm{~ms}$ were excluded, to lessen the influence of outliers (Aarts et al., 2007). (Note that the data were also analysed with median reaction time scores instead of mean reaction time scores. The results were not reported here as the direction of effects was similar). In total, $6.3 \%$ of the trials were excluded for the baseline lexical decision task and $7.4 \%$ for the lexical decision task after the priming procedure. There was no difference in number of incorrect responses, between prime conditions, all $p \mathrm{~s}>.05$. In the lexical decision task after the priming procedure, significantly more mistakes were made than in the first lexical decision task, $t(56)=-2.76, p<.01$.

To test the hypothesis whether goal priming resulted in a faster categorization of goal-related words in the lexical decision task after priming, a 3 Prime (achievement, hedonic, versus no-goal) x 4 Target (achievement, hedonic, positive, versus neutral) x 2 Task (lexical decision task 1, lexical decision task 2) ANOVA was conducted with prime condition as between-subjects factor and target as within-subjects factor, the mean reaction time as dependent variable. In contrast to the predictions this yielded no three-way interaction between prime, target and task $F(4.6,129.8)=0.38, p>.05, \eta^{2}=.01$, indicating that response times on the second lexical decision task did not differ as a function of priming condition, relative to the first lexical decision task. A main effect of target was found, $F(2.5$, $140.3)=5.2, p<.01, \eta^{2}=.09$. Participants reacted faster on hedonic words compared to all the other word types (neutral words, $F(1,56)=11.7, p<.01, \eta^{2}=.17$; achievement words, 
$F(1,56)=9.2, p<.01, \eta^{2}=.14$ and positive words, $\left.F(1,56)=14.9, p<.001, \eta^{2}=.21\right)$. No effect of prime condition was found, $F(2,56)=0.45, p>.05, \eta^{2}=.02$.

\subsection{Subliminal priming condition}

In the subliminal priming experiment, $1.9 \%$ of the responses in the baseline lexical decision task and $3 \%$ of the responses in the second lexical decision task were incorrect. Additionally, $3.7 \%$ of the responses in the baseline task and $3.4 \%$ of the responses in the second lexical decision task were excluded due to exceeding the reaction time filter of 300-1200 ms. The number of excluded responses did not differ between prime conditions (all $p \mathrm{~s}>.05$ ).

A 3 Prime x 4 Target x 2 Task ANOVA with reaction time as dependent variable yielded no three-way interaction between prime, target and task, $F(6,168)=0.76, p>.05$, $\eta^{2}=.03$, indicating that response times on the second lexical decision task did not differ as a function of priming condition, relative to the first lexical decision task. There was a main effect of target, $F(3,168)=3.91, p<.01 \eta^{2}=.07$. Participants reacted faster on hedonic words compared to all the other word types (neutral words, $F(1,56)=4.41, p<.05, \eta^{2}=.07$; achievement words, $F(1,56)=5.60, p<.05, \eta^{2}=.09$, and positive words, $F(1,56)=9.75$, $\left.p<.01, \eta^{2}=.15\right)$. Moreover, participants reacted faster on the second lexical decision task compared to the first, $F(3,168)=6.50 p<.05 ; \eta^{2}=.10$. No effect of prime condition was found, $F(2,56)=0.07, p>.05, \eta^{2}<.01$.

\section{Discussion}

The aim of the present study was to investigate whether achievement and hedonic goals could be activated by means of priming. Goals were primed either subliminally through the dot detection task, or supraliminally by means of a scrambled sentence task. A lexical decision task was used to measure the accessibility of the goals, both before and after priming. It was expected that participants would respond faster to achievement words in the second lexical decision task as compared to the baseline task, when they were primed with achievement goal words in the preceding priming task. Likewise, it was expected that participants would respond faster to hedonic words when they were primed with hedonic words. The present findings do not support these hypotheses. Contrary to the results of other goal priming studies, goal priming did not have an influence on accessibility of the goal- related words in the lexical decision task (Aarts et al., 2007; Forster, Liberman, \& Higgins, 2005; Shah, 2003; Shah \& Kruglanski, 2003). The question can be raised why goal priming did not affect the speed of categorization of goal-related words in the present study, while there is a vast literature of studies that successfully induced unconscious goal pursuit, including achievement goals (Bargh et al., 2001, Custers et al., 2009; Engeser, 2009; Etiam et al, 2008, Hart \& Albarracin, 
2009, Oikawa et al, 2004; Stajkovic et al., 2006) and hedonic goals (Fishbach, 2007, Laran et al. 2008).

The goal and non-goal related words were rated in accordance with their selected categories; achievement words scored higher on the achievement scale than the other word types and hedonic words scored higher on the hedonic scale than the other word types. This indicates that the null findings of the present study are not explained by the words not representing the specified goal.

There are several possible explanations for the differences between the findings of the present study and those of previous research. Firstly, although some prime words were the same as those used in previous achievement and hedonic priming research (the words: 'win, competition, strive, accomplish, achievement and ambition' for achievement priming and 'happy, enjoy, entertainment, fun' for hedonic priming, were also used in previous studies (Bargh 2001, Custers et al., 2009;Engeser, 2009; Etiam 2008, Fishbach et al., 2007, Hart \& Albarracin, 2009, Laran et al. 2008), the remaining words differed from those used in previous research. Different words were used in the present study to ensure that priming effects were not due to differences in word length, word frequency or orthographic overlap. Previous studies did not report on matching words on word length, word frequency and orthographic overlap (Bargh 2001, Custers et al., 2009; Engeser, 2009; Etiam 2008, Hart \& Albarracin, 2009, Laran, 2008, Oikawa et al, 2004, Stajkovic et al., 2006), not even when a word search puzzle or a lexical decision task was used as outcome measure (Bargh et al. 2001, Laran, 2008). Therefore, it cannot be ruled out that, in these studies priming effects were found, because of differences in word frequency and orthographic overlap instead of differences in goal content. Additionally, these studies did not rate word category as an additional manipulation check.

An overview of the goal priming literature shows that goal activation depends on several factors, such as: the strength of motivation to strive for the goal, the value that is attached to the goal, the expectancy to reach that goal, the goal context, the presence of competing goals, and individuals differences such as pre-existing goals in memory (Aarts, 2005, Aarts, 2007, Ferguson, 2008, Forster et al., 2005, Shah, 2005). In order to try to comprehend the null findings, these factors will be discussed in the light of the present experiment.

It is possible that in the present experiment, the priming procedure did not trigger motivational activity. Aarts et al. (2007) suggested that concept priming leads to motivational activity in cognition and behaviour only if the concept represents a desired state in the perceiver's mind and is attached to positive affect. In line with this reasoning, Ferguson (2008) showed that implicit activation of an achievement goal leads to evaluative readiness to pursue the goal and that this is most strongly for those who are motivated to pursue that goal. Goal concepts that are neutral or do not represent desired states do not trigger 
motivational activity (Custers \& Aarts, 2005). More specifically, Aarts and colleagues (2007) demonstrated that the accessibility of a goal as measured with a lexical decision task diminishes when that goal is co-activated with negative affect. Results of the present study showed that participants experienced significantly lower mood scores after the second lexical decision task as compared to the baseline task. Although we did not consequently co- activate the priming stimuli with negative mood, it is possible that the negative mood at the end of the second lexical decision task is a sign of diminished activation of the goals due to negative mood.

Ramanathan and Menon (2006) showed that context is important in goal priming. When the behavioural context is relevant and has been experienced frequently, the goal is likely to be pursued. However, when the goal has not been experienced frequently in a certain context or the context is irrelevant for goal pursuit, the goal may not become active because the context does not afford an opportunity for goal pursuit. In the present study there was no task other then the (second) lexical decision task where participants could use the achievement or hedonic goal. The lexical decision task is not a performance task that leads to the fulfilment of hedonic or achievement goals, and therefore does not trigger participants to apply these goals to the task. In other words, the expectancy to reach the goal and the strength of motivation to pursue the goal may have been low, leaving the speed of categorization of achievement or hedonic words in a lexical decision task unaffected by the priming manipulation. Additionally, it should be noted that, in order to prevent an explicit achievement goal instruction, we did not explicitly instruct participants to react as fast and as accurate as possible, in contrast to standard lexical decision task procedures. This could have influenced the measurement of goal accessibility. It is possible that goal accessibility is only reliably measured when response latencies are in a certain response window. However, mean response latencies in the present study were in the same range as those in the study of Foster et al. (2005).

Another explanation for the null findings with respect to the priming of hedonic and achievement goals could be the exposure to competing goals. Shah et al. (2005) have shown that priming an additional goal that is unrelated to the focal, primed goal, has a detrimental effect on goal activation and commitment because they pull resources away from the focal, primed goal. In the baseline task of the present study, participants were presented with both achievement and hedonic goal words. More specifically, individuals in the achievement priming condition were also explicitly exposed to hedonic goal words, before the priming procedure, during the baseline lexical decision task. This may have neutralized the priming effect of the achievement goal they were subsequently primed with. However, this does not mean that the use of a baseline lexical decision task should always be avoided. The study of Forster et al. (2005) also used a baseline lexical decision task and several follow-up lexical decision tasks to measure goal activation, and these authors did find goal priming effects. 
However, they used explicit goal instructions instead of unconscious goal manipulation, and they only used one goal condition instead of two, so that participants were never exposed to alternative goal words at baseline.

Some priming studies demonstrated that the effect of goal-related stimuli is moderated by pre-existing goals in memory (Aarts, 2005; Fitzimons\& Bargh, 2003; Strahan et al.2002; Karremans et al., 2006; Radel et. al. 2009, Ferguson, 2008, Hart \& Albarracin, 2009). For example, the presentation of help-related stimuli increased helpful behaviour only in people with strong pre-existing goals of helping (Aarts, 2005; Fitzimons\& Bargh, 2003; Strahan et al.2002). Likewise, it was found that achievement-related stimuli promoted an achievement goal and the inhibition of a fun goal in individuals with chronically high achievement motivation only (Hart \& Albarracin, 2009). Strahan et al. (2002) showed that thirst primes are effective for people that are thirsty, but not for people that are hydrated. In the present study we used a baseline lexical decision task to measure accessibility of pre-existing goals at baseline. Moreover we did not find moderating effects of baseline achievement or hedonic accessibility on the accessibility of these goals after priming. Nevertheless, it is possible that individual characteristics, such as perfectionism, fear of failure, delay of gratification played a role.

Another explanation for the absence of a priming effect in the present study is that, instead of the disrupting effect of competing goals at baseline, the hedonic goal concept may have been so strongly activated at baseline, that it may have overruled the priming effect of the hedonic and achievement primes. Results from the present experiment showed that participants reacted faster on hedonic words irrespective of priming condition and this effect was found at baseline as well as in the lexical decision task after the priming. The fact that the hedonic goal was more accessible at baseline (and after the priming task) could suggest that this goal represents a particularly strong desired state in this sample of university students. This is also reflected in the high positive valence of the hedonic words. This could be a ceiling effect, in that this desired state was so strong that it overruled the priming from the alternative achievement goal condition and the no-goal condition and that it did not improve the already high accessibility of the hedonic goal concept by means of hedonic priming. However, caution is warranted as there may be an alternative explanation for the faster categorization of hedonic words. The hedonic words were rated as more positive than the other goal and non-goal words. As a result, it cannot be determined from our data whether it was the specific hedonic quality or merely the positive value, or a combination of both, that caused the overall faster responses. Furthermore, research has shown that individuals pay more attention to emotionally valenced information in comparison to neutral stimuli, the so-called emotion salience effect (Buchanan \& Adolphs, 2002). As hedonic words were by definition more emotional than the other word categories, their emotional salience instead of their increased accessibility could be an explanation for the overall faster responses. 
To conclude, the absence of achievement and hedonic goal priming effects in the present study is likely not due to the specific goal priming method, nor to the specific stimuli used. Several factors could play a role such as: the presence or absence of a goal-relevant context, the role of conflicting goals, the possible overruling effect of baseline goals, the absence of an explicit instruction to respond as fast and accurately as possible, and the control for lexical differences.

The present interpretation of the data suggests that the unconsciously induced hedonic and achievement goals were not activated due to the priming procedure. This is in contrast with the vast majority of studies that induced achievement and hedonic goals by means of supraliminal or subliminal priming methods (Bargh et al., 1996; Bargh et al., 2001; Bargh \& Ferguson, 2000; Custers et al. 2009, Chartrand \& Bargh, 1996; Eitam, Hassin, \& Schul, 2008; Hart \& Albaracin, 2009; Oikawa, 2004, Shah \& kruglanski, 2002; Stajkovic et al., 2006; Shanz \& Latham, 2009). However, in the domain of achievement priming, recently a few studies have been published that failed to replicate the achievement goal priming results (Doyen, Klein, Pichon, \& Cleeremans, 2012; Eder, Leipert, Musch, \& Klauer, 2012; Engeser, 2009; Harris, Coburn, Rohrer, \& Pashler, 2013; Shanks, et al., 2013), suggesting that goal priming evidence might not be that robust as initially thought.

For future research it is recommended to unconsciously induce hedonic and achievement goals within a goal context and by means of a task that equally triggers achievement and hedonic goals and assesses not only the primed behavior but also measures goal accessibility at the same time. It seems also important to make sure that the goals are represented as desirable states, and that no competing goals are primed. Furthermore, the assessment of baseline goal accessibility and individual differences that can moderate the priming effects might be considered in future studies on goal priming. Finally, when using a lexical decision task, it is important to control for lexical factors (e.g. number of letters, word frequency and orthographic overlap) to make sure that possible priming effects are due to goal content rather than lexical differences.

\section{Acknowledgements}

This study was supported by an innovation Grant (No. 453-04- 003) provided by the NWO Social Sciences Research Council of The Netherlands. 


\section{APPENDIX I}

Words in lexical decision task 1

\begin{tabular}{lllll}
\hline Achievement words & Hedonic words & Positive words & Neutral words & number of letters \\
\hline Grondig & Vreugde & Eerlijk & Snuiten & 7 \\
Streven & Boeiend & Tactvol & Schaduw & 7 \\
Compleet & Vakantie & Populair & Schuiven & 8 \\
Voltooien & Plezierig & Voorspoed & Hetzelfde & 9 \\
Volhouden & Zorgeloos & Melodieus & Opklapbed & 9 \\
Systematisch & Enthousiasme & Rechtvaardig & Doorscheuren & 12 \\
\hline
\end{tabular}

\section{Words in lexical decision task 2}

\begin{tabular}{lllll}
\hline Achievement words & Hedonic words & Positive words & Neutral words & Number of letters \\
\hline Taak & Pret & Dons & Naam & 4 \\
Score & Zalig & Hemel & Veter & 5 \\
Adequaat & Amuseren & Charmant & Slagboom & 8 \\
Prestatie & Verlangen & Bijzonder & Tafelblad & 9 \\
Verbetering & Comfortabel & Verfrissend & Handschrift & 11 \\
Verplichting & Tevredenheid & Zomerkleding & Maatschappij & 12 \\
\hline
\end{tabular}

Words in the priming task

\begin{tabular}{llll}
\hline Achievement words & Hedonic words & Neutral words & Number of letters \\
\hline Eis & Lol & Rug & 3 \\
Doel & Fijn & Kast, & 4 \\
Leren & Geluk & Ivoor & 5 \\
Winst & Genot & Rogge & 5 \\
Winnen & Gevoel & Karton & 6 \\
Inzet & Graag & Draad & 5 \\
Precies & Feesten & Gebruik & 7 \\
Deadline & Genieten & Elastiek & 8 \\
Resultaat & Aangenaam & Wegrollen & 9 \\
Accuraat & Gelukkig & Deurknop & 8 \\
Eindstreep & Blijdschap & Observator & 10 \\
Competitie & Ontspannen & Universeel & 10 \\
\hline
\end{tabular}




\section{APPENDIX I ENGLISCH TRANSLATION OF THE WORDS}

Words in lexical decision task 1

\begin{tabular}{llll}
\hline Achievement words & Hedonic words & Positive words & Neutral words \\
\hline Thorough & Joy & Honest & To blow one's nose \\
Strive & Interesting & Discrete & Shadow \\
Complete & Holiday & Popular & To shove \\
To complete & Pleasant & Wealth & Idem \\
To endure & Carefree & Melodic & Foldaway bed \\
Systematic & Enthusiasm & Just & To tear \\
\hline
\end{tabular}

Words in lexical decision task 2

\begin{tabular}{llll}
\hline Achievement words & Hedonic words & Positive words & Neutral words \\
\hline Task & Fun & Fuzz fibre & Name \\
Score & Delightful & Heaven & Shoe lace \\
Adequate & To entertain & Charming & Barrier \\
Effort & To long for & Special & Tabletop \\
Improvement & Comfortable & Refreshing & Handwriting \\
Obligation & Contentment & Summer clothing & Society \\
\hline
\end{tabular}

Words in the priming task

\begin{tabular}{lll}
\hline Achievement words & Hedonic words & Neutral words \\
\hline Demand & Fun & Back \\
Goal & Nice & Closet \\
Learn & Happiness & Ivory \\
Victory & Enjoyment & Rye \\
To win & feeling & Cardboard \\
Effort & Gladly & Thread \\
Exact & To party & Use \\
Deadline & To enjoy & Rubber band \\
Result & Cosy & Roll off \\
Accurate & Happy & Doorknob \\
Finish line & Gladness & Observer \\
Competition & Relaxing & Universal \\
\hline
\end{tabular}




\section{APPENDIX II}

Results for the prime words showed a main effect of prime on the achievement scale, $F(1.88$, $220.44)=475.44, p<.001, \eta^{2}=.80$, and the hedonic scale, $F(1.98,231.96)=577.24, p<$ $.001, \eta^{2}=.83$. As expected posthoc tests showed that achievement words were rated higher on the achievement scale than hedonic words, $F(1,117)=539.37, p<.001, \eta^{2}=.82$, and neutral words, $F(1,117)=850.63, p<.001, \eta^{2}=.88$. Moreover, hedonic words were rated higher on the hedonic scale than neutral words, $F(1,117)=1026.70, p<.001, \eta^{2}=.90$ and achievement words $F(1,117)=576.63, p<.001, \eta^{2}=.83$. Neutral words scored lower on the achievement and hedonic scale as compared to the achievement words, $F(1,117)=850.63, p$ $<.001, \eta^{2}=.88$ and $F(1,117)=576.63, p<.001, \eta^{2}=.83$ respectively, and the hedonic words, $F(1,117)=4.51, p<.05$, and $F(1,117)=1026.70, p<.001, \eta^{2}=.90$, respectively.

Additionally a main effect of prime was found for the valence scale, $F(1.99,232.41)$ $=854.50, \eta^{2}=.83$. Post hoc tests demonstrated that hedonic words were rated as more positive than achievement words, $F(1,117)=662.56, p<.001, \eta^{2}=.85$. Neutral words were rated as less positive as compared to both the achievement words $F(1,117)=259.35, p<$ $.001, \eta^{2}=.69$ and hedonic words $F(1,117)=1551.17, p<.001, \eta^{2}=.93$

Results for the target words that were used in the two lexical decision tasks, showed a main effect of target on the achievement scale, $F(2.34,274.18)=453.67, p<.001, \eta^{2}=$ .80 and hedonic scale, $F(3,351)=385.65, p<.001, \eta^{2}=.77$. Follow-up tests showed that achievement words scored higher on the achievement scale as compared to the hedonic words, $F(1,117)=566.01, p<.001, \eta^{2}=.83$, the neutral words, $F(1,117)=849.63, p<.001$, $\eta^{2}=.88$, and the positive words, $F(1,117)=837.10, p<.001, \eta^{2}=.88$. Moreover, followup tests showed that hedonic words scored higher on the hedonic scale as compared to the achievement words, $F(1,117)=457.50, p<.001, \eta^{2}=.80$, neutral words, $F(1,117)=907.91$, $p<.001, \eta^{2}=.89$, and positive words, $F(1,117)=373.72, p<.001, \eta^{2}=.76$. The neutral words scored lower on the hedonic scale as compared to the achievement words, $F(1,117)$ $=56.23, p<.001, \eta^{2}=.33$, and the positive words, $F(1,117)=433.16, p<.001, \eta^{2}=.79$. In addition, for the valence scale a main effect of target was found $F(2.25,262.79)=717.15, p$ $<.001, \eta^{2}=.86$, showing that hedonic words were rated more positively than neutral words, $F(1,117)=1388.50, p<.001, \eta^{2}=.92$, achievement words, $F(1,117)=633.60, p<.001, \eta^{2}$ $=.84$, and positive words, $F(1,117)=365.97, p<.001, \eta^{2}=.76$. Neutral words were rated less positive than the achievement, $F(1,117)=286.99, p<.001, \eta^{2}=.71$ and positive words, $F(1,117)=815.22, p<.001, \eta^{2}=.87$. 


\section{References}

Aarts, H., Chartrand, T. L., Custers, R., Danner, U., Giel, D., Jefferies, V. E., et al. (2005). Social stereotypes and automatic goal pursuit. Social Cognition, 23, 465-490.

Aarts, H., Custers, R., \& Holland, R. W. (2007). The nonconscious cessation of goal pursuit: when goals and negative affect are coactivated. Journal of Personality and Social Psychology, 92, 165-178.

Aarts, H., \& Dijksterhuis, A. (2000). Habits as knowledge structures: automaticity of goal-directed behavior. Journal of Personality and Social Psychology, 78, 53-63.

Bargh, J. A. (1990). Auto-motives: Preconscious determinants of social interaction. In E. T. Higgins \& R. M. Sorrentino (Eds.), Handbook of motivation and cognition (Vol. 2, pp. 93- 130). New York: Guilford.

Bargh, J. A. (2006). What have we been priming all these years? On the development, mechanisms, and ecology of nonconscious social behavior. European Journal of Social Psychology, 36, $147-168$.

Bargh, J. A., \& Chartrand, T. L. (2000). The mind in the middle: A practical guide to priming and automaticity research. In H. T. Reis \& C. M. Judd (Eds.), Handbook of research methods in social and personality psychology. (pp. 253-285). New York: Camebridge University Press.

Bargh, J. A., Chen, M., \& Burrows, L. (1996). Automaticity of social behavior: direct effects of trait construct and stereotype-activation on action. Journal of Personality and Social Psychology, $71,230-244$.

Bargh, J. A., \& Ferguson, M. J. (2000). Beyond behaviorism: on the automaticity of higher mental processes. Psychological Bulletin, 126, 925-945.

Bargh, J. A., Gollwitzer, P. M., Barndollar, A. L., \& Trotschel, R. (2001). The automated will: Nonconsious Activation and Pursuit of Behavioral Goals. Journal of Personality and Social Psychology, 81, 1014-1027.

Blackmore, S. (2003). Consciousness: An introduction. New York: Oxford University Press.

Bradley, M. M., \& Lang, P. J. (1994). Measuring emotion: the Self-Assessment Manikin and the Semantic Differential. Journal of Behaviour Therapy and Experimental Psychiatry, 25, 4959 .

Buchanan, T.W., \& Adolphs, R. (2002).The role of the human amygdala in emotional modulation of long-term declarative memory. In S.C. Moore \& M. Oaksford (Eds). Emotional cognition: From brain to behaviour (pp. 9- 34). Amsterdam: Benjamins.

Chartrand, T.L., \& Bargh, J.A. (1996). Automatic activation of impression formation and memorization of goals: nonconscious goal priming reproduces effects of explicit task instructions. Journal of Personality and Social Psychology, 71, 464-478.

Custers, R., \& Aarts, H. (2005). Beyond priming effects: the role of positive affect and discrepancies in implicit processes of motivation and goal pursuit. European Review of Social Psychology, $16,257-300$. 
Custers, R., \& Aarts, H., Oikawa, M.,\& Elliot, A. (2009).The nonconscious road to perceptions of performance: Achievement priming augments outcome expectancies and experienced selfagency. Journal of Experimental Social Psychology, 45, 1200-1208.

Custers, R., \& Aarts, H. (2010). The Unconscious Will: How the Pursuit of Goals Operates Outside of Conscious Awareness. Science, 329, 47-50.

Davey, G. C., Startup, H. M., Zara, A., MacDonald, C. B., \& Field, A. P. (2003). The perseveration of checking thoughts and mood-as-input hypothesis. Journal of Behaviour Therapy and Experimental Psychiatry, 34, 141-160.

Doyen, S., Klein, O., Pichon, C. L., \& Cleeremans, A. (2012). Behavioral priming: it's all in the mind, but whose mind? PLoS One, 7(1), e29081.

Duyck, W., Desmet, T., Verbeke, L. P., \& Brysbaert, M. (2004). WordGen: a tool for word selection and nonword generation in Dutch, English, German, and French. Behavior Research Methods, Instruments and Computers, 36, 488-499.

Eder, A., Leipert, C., Musch, J., \& Klauer, K.-C. (2012). Failed replication to prime intelligent behavior. Available: http://www.PsychFileDrawer.org/replication.php?attempt=MTI0 ， Retrieved October 07, 2012

Engeser, S. (2009). Nonconscious activation of achievement goals: moderated by word class and the explicit achievement Motive? Swiss Journal of Psychology, 68, 193-200.

Eitam, B., Hassin, R. R., \& Schul, Y. (2008). Nonconscious goal pursuit in novel environments. Psychological Science, 19, 261-267.

Fishbach, A., Friedman, R. S., \& Kruglanski, A. W. (2003). Leading us not into temptation: momentary allurements elicit overriding goal activation. Journal of Personality and Social Psychology, 84, 296-309.

Fishbach, A., Aparna A. L. (2007). Be Better or Be Merry: How Mood Affects Self-Control. Journal of Personality and Social Psychology, 93, 158-173.

Fitzsimons, G. M., \& Bargh, J. A. (2003). Thinking of you: Nonconscious pursuit of interpersonal goals associated with relationship partners. Journal of Personality and Social Psychology, $84,148-164$.

Forster, J., Liberman, N., \& Higgins, E. T. (2005). Accessibility from active and fulfilled goals. Journal of Experimental Psychology, 41, 220-239.

Harris, C. R., Coburn, N., Rohrer, D., \& Pashler, H. (2013). Two failures to replicate high-performancegoal priming effects. PLoS One, 8(8), e72467.

Hart, W. \& Albaracin, D. (2009).The Effects of Chronic Achievement motivation and Achievement Primes on the Activation of Achievement and Fun Goals. Journal of Personality and Social Psychology , 97, 1129-1141.

Karremans, J. C., Stroebe, W., \& Claus, J. (2006). Beyond Vicary's fantasies: The impact of subliminal priming and brand choice. Journal of Experimental Social Psychology, 42(6), 792-798.

Karsdorp, P. A., Nijst, S. E., Goossens, M. \& Vlaeyen, J. W. (2010). The role of current mood and stop rules on physical task performance: An experimental investigation in patients with workrelated upper extremity pain. European Journal of Pain, 14, 434-440. 
Laran, J., Jansizewski, C., \& Cunha, J. R. (2008). Context-dependent effects of goal primes. Journal of consumer research, 35, 653-667.

MacDonald, B. A., \& Davey, G. C. L. (2005). A mood-as-input account of perseverative checking: the relationship between stop rules, mood and confidence in having checked successfully. Behaviour Research and Therapy, 43, 69-91.

Martin, L., Ward, D. W., Achee, J. W., \& Wyer, R. S. (1993). Mood as input: people have to interpret the motivational implications of their Moods. Journal of Personality and Social Psychology, 64(3), 317-326.

Meyer, D. E., \& Schvaneveldt, R. W. (1971). Facilitation in recognizing pairs of words: Evidence of a dependence between retrieval operations. Journal of Experimental Psychology, 90, 227-234.

Nisbett, R. E., \& Wilson, T. D. (1977). Telling more than we can know: verbal reports on mental processes. Psychological Review, 84, 231-259.

Nørretranders, T. (1991). The user illusion: Cutting consciousness down to size. New York: Penguin.

Oikawa, M. (2004). Moderation of automatic achievement goals by conscious monitoring. Psychological Reports, 95, 975-980.

Radel, R., Sarrazin, P.,Legrain, P., \& Gobance,L. (2009). Subliminal priming of motivational orientation in educational settings: Effect on academic performance moderated by mindfulness. Journal of Research in Personality, 43, 695-698.

Ramanathan, S., \& Menon, G. (2006). Time-Varying Effects of Chronic Hedonic Goals on Impulsive Behavior. Journal of Marketing Research, 63, 628-641.

Rholes, W.S., Riskind, J.H. \& Lane, J.W. (1987). Emotional states and memory biases: effects of cognitive priming and mood. Journal of personality and social psychology, 52, 91-99.

Shah, J. (2003). Automatic for the people; How Representations of Significant Others Implicitly Affect Goal Pursuit. Journal of Personality and Social Psychology, 84, 661-681.

Shah, J., \& kruglanski, A. W. (2002). Priming against your will: How accessible alternatives affect goal pursuit. Journal of Experimental Social Psychology, 38, 368-383.

Shah, J., \& Kruglanski, A. W. (2003). When opportunity knocks: bottom-up priming of goals by means and its effects on self-regulation. Journal of Personality and Social Psychology, 84, 11091122 .

Shanks, D. R., Newell, B. R., Lee, E. H., Balakrishnan, D., Ekelund, L., Cenac, Z., et al. (2013). Priming intelligent behavior: an elusive phenomenon. PLoS One, 8(4), e56515.

Shantz, A., \&Latham, G.P.(2009). An exploratory field experiment of the effect of subconscious and conscious goals on employee performance. Organizational Behavior and Human Decision Processes, 109, 9-17.

Srull, T.K., \& Wyver, R. S. (1979). The role of category accessibility in the interpretation of information about persons: some determinants and implications. Journal of Personality and Social Psychology, 37, 1660-1672.

Stajkovic, A. D., Locke, E. A., \& Blair, E. S. (2006). A first examination of the relationships between primed subconscious goals, assigned conscious goals, and task performance. Journal of Applied Psychology, 91, 1172-1180. 
Startup, H. M., \& Davey, G. C. (2001). Mood as input and catastrophic worrying. Journal of Abnormal Psychology, 110, 83-96.

Startup, H. M., \& Davey, G. C. (2003). Inflated responsibility and the use of stop rules for catastrophic worrying. Behaviour Research and Therapy, 41, 495-503.

Van den Bussche, E., Segers, G., \& Reynvoet, B. (2008). Conscious and unconscious proportion effects in masked priming. Consciousness and Cognition, 17, 1345-1358.

Watkins, E., \& Mason,A. (2002). Mood as input and rumination. Personality and Individual Differences, $32,577-587$. 


\section{Chapter 5}

Pain Catastrophizing, Threat, and the Informational Value of Mood: Task Persistence During a Painful

Finger Pressing Task

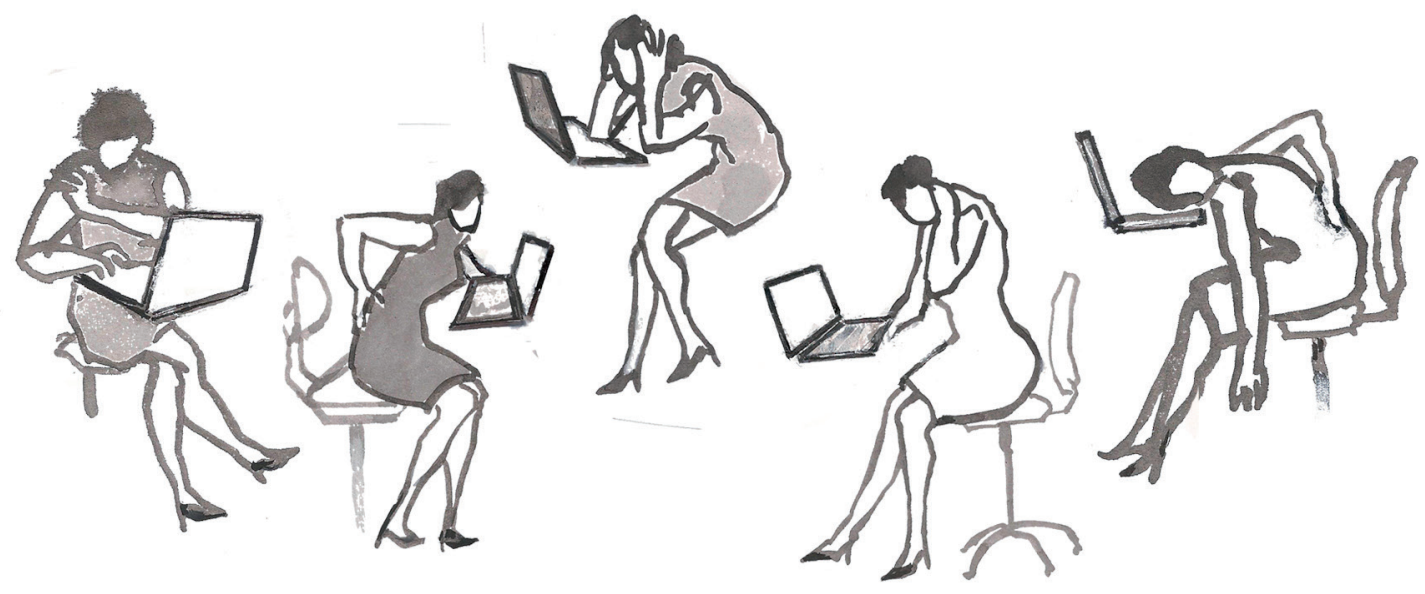




\begin{abstract}
Pain catastrophizing has shown to predict avoidance behavior in acute and chronic pain, but the literature is inconsistent. The present study tested the hypothesis that current mood and threat context moderate the relationship between pain catastrophizing and performance duration. Affective-motivational models postulate that negative and positive moods provide information about whether an activity is respectively threatening or safe. Moreover, it has been proposed that stable cognitive schemas about threat influence behavior particularly in threat-relevant contexts. The present study aimed to establish whether pain catastrophizing is related to less or greater performance duration, when participants experience respectively negative or positive moods, particularly in a high threatening pain context. A $2 \operatorname{mood} \times 2$ threat context between-subjects factorial design was applied in 89 healthy participants with pain catastrophizing as covariate and performance duration during a painful finger pressing task as dependent variables. As predicted, higher pain catastrophizing was associated with less performance duration when participants experienced negative moods. The opposite was found when participants experienced positive moods. Moreover, these relationships were most pronounced in a high threatening pain context. This study suggests that the relationship between pain catastrophizing and performance duration during painful activities is moderated by situational factors such as current mood and threat context.
\end{abstract}

Based on:

Petra A. Karsdorp, Saskia M.G. Ranson, Martien G.S. Schrooten, Johan W.S. Vlaeyen (2012). Pain catastrophizing, threat, and the informational value of mood: Task persistence during a painful finger pressing task. Pain, 153(7), 1410-1417. 


\section{Introduction}

A prevailing model that provides an explanation for the development of chronic pain is the Fear-Avoidance model (Vlaeyen \& Linton, 2000). Central to this model is the role of catastrophic (mis)interpretations of pain. Pain catastrophizing involves an exaggerated negative orientation towards pain and its possible consequences (Sullivan, Bishop, \& Pivik, 1995 ) and may give rise to pain-related fear and avoidance, and eventually to more pain and disability (Vlaeyen \& Linton, 2000). There is accumulating evidence in favor of the FearAvoidance model (Vlaeyen, Kole-Snijders, Boeren, \& van Eek, 1995; Vlaeyen \& Linton, 2000). Moreover, cognitive behaviour treatments targeting catastrophic (mis)interpretations have shown to be successful in chronic pain (Eccleston, Williams, \& Morley, 2009). However, the effect sizes are relatively small (Eccleston, Williams, \& Morley, 2009). Additionally, there are studies that failed to demonstrate a catastrophizing-avoidance relationship (George, Dannecker, \& Robinson, 2006; McGowan, Sharpe, Refshauge, \& Nicholas, 2009; Meredith, Strong, \& Feeney, 2006; Rhudy et al., 2009; Severeijns, van den Hout, \& Vlaeyen, 2005). A possible explanation is that the Fear-Avoidance model does not take into account the context in which the pain is experienced. It has been argued that contextual factors may moderate the catastrophizing-avoidance relationship (George, Dannecker, \& Robinson, 2006; Severeijns, van den Hout, \& Vlaeyen, 2005; Vlaeyen, \& Morley, 2004).

Affective-motivational models (Martin, Ward, Achee, \& Wyer, 1993; Vlaeyen, \& Morley, 2004) postulate that moods signal goal attainment and may influence task persistence (measured as task duration). Research has demonstrated that when people pursue hedonic goals, negative moods signal that the task is unpleasant, whereas positive moods signal that the task is pleasant, leading to respectively task disengagement or continuance. When the goal is to perform well, the same moods have opposing effects on performance duration (Davey, Eldridge, Drost, \& MacDonald, 2007; Davey, Startup, MacDonald, Jenkins, \& Patterson, 2005; Davey, Startup, Zara, MacDonald, \& Field, 2003; MacDonald, \& Davey, 2005a; MacDonald, \& Davey, 2005b; Martin, Abend, Sedikides, \& Green, 1997; Martin, Ward, Achee, \& Wyer, 1993; Sanna, Meier, \& Wegner, 2001; Sanna, Parks, \& Chang, 2003; Startup, \& Davey, 2001, 2003; Watkins, \& Mason, 2002). Individuals who catastrophize about pain may primarily adopt hedonic goals aimed at avoiding the threat of pain, rather than performing well. Research outside the pain field has demonstrated that individuals who tend to catastrophize infer danger on the basis of their negative moods (Arnzt, Rauner, \& van den Hout, 1995; Gangemi, Mancini, \& van den Hout, 2007; Wells, \& Papageorgiou, 2001). It could be hypothesized that individuals who catastrophize about pain also infer danger on the basis of their negative moods and safety on the basis of their positive mood leading to respectively reduced or increased task persistence during painful tasks. 
Besides the role of mood, also the degree to which the context is threatening may influence the catastrophizing-avoidance relationship (Severeijns, van den Hout, \& Vlaeyen, 2005; Vlaeyen, \& Morley, 2004). It has been demonstrated that stable cognitive schemas about threat influence behaviour particularly in threat-relevant contexts (Bower, 1981; Bradley, Mogg, \& Millar, 2000; Gray, \& McNaughton, 2000; Mathews, \& MacLeod, 1994). Therefore, we hypothesized that the catastrophizing-avoidance relationship would be most pronounced when the pain stimulus is highly threatening. The proposed theoretical model is illustrated schematically in Figure 1.

The aim of the present study was to test whether mood and threat context moderate the relationship between pain catastrophizing and task persistence during a painful task. It was predicted that pain catastrophizing would be related to less performance duration when participants experience negative moods, but to greater task persistence when participants experience positive moods. Moreover, it was predicted that this effect would be most pronounced in a high threatening pain context.

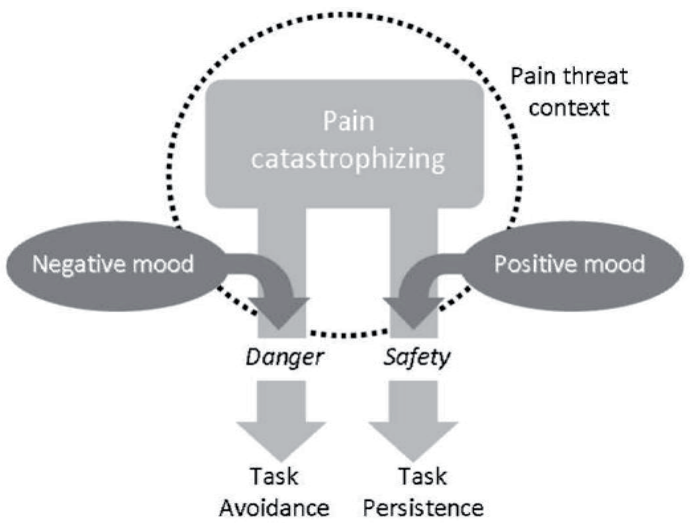

Figure 1. Schematic representation of an affective-motivational model of the relationship between pain catastrophizing and pain behaviour. 


\section{Methods}

\subsection{Participants}

Eighty-nine first-year students from Maastricht University (faculties of Health Science, Psychology, or Medicine) participated in the experiment [68 women; $M_{\text {age }}(S D)=21.06$ (2.88)]. Exclusion criteria were: 1) pain complaints in the upper extremities, neck or shoulder during the last week (measured with the question: "Did you have any pain complaints in the neck, shoulder, arm, wrist or hand during the last week?). One participant was excluded because of technical errors, and two participants (from the negative mood, low threat condition and the high threat, positive mood condition) were excluded because their task duration (28 and $39 \mathrm{~min})$ deviated more than $3 S D(S D=5.50)$ from the mean $(M=4.33 \mathrm{~min})$. The final sample size consisted of 86 participants [65 women; $M_{\text {age }}(S D)=21.10$ (2.90)]. None of the participants indicated that they were aware of the hypothesis of the experiment. The ethical committee of the Maastricht University approved the study.

Participants were randomly assigned to one of two experimental threat conditions (low threat / high threat). Subsequently participants were re-randomized to another of two experimental mood conditions (positive / negative mood). This resulted in four experimental groups.

\subsection{Task Persistence}

To measure task persistence during a finger pressing task, participants performed a Martians task. This is an adapted version of the Martians task used in previous research (Arcediano, Ortega, \& Matute, 1996; Meulders, Vervliet, Vansteenwegen, Hermans, \& Baeyens, 2010). Participants were instructed that the goal of this computer game was to save the planet from a Martians invasion by shooting alien invaders. Invaders appeared on the screen one by one in rows of 10 aliens with a regular speed of 5 invaders per second. Once an alien appeared on the screen the participant was instructed to shoot the alien by a button press. When the button press was given within $100 \mathrm{~ms}$ after the appearance of the alien, the alien was hit and the picture of the alien was replaced by a picture of an explosion. When the participant missed the alien, its picture remained on the screen. Participants were instructed to press the button and shoot aliens with their index finger of their dominant hand while their wrist was attached to the table with a wristband to avoid extensive movements with their dominant arm. A pilot study $\left[N=94,22\right.$ male, $M_{\text {age }}(S D)=21.35$ (2.17) $]$ demonstrated that button pressing in response to circles appearing on the screen one by one with a speed of 5 presses per second for a fixed duration of 5 minutes resulted in painful sensations in the arm, $F(1$, $93)=155.98, p<.001, \eta^{2}=.63$, (with pain ratings of $M_{\text {before }}(S D)=1.43(1.01)$ and $M_{\text {after }}$ $(S D)=3.47(1.76)$ on a 10-point Likert scale). Participants were instructed that there was no 
right or wrong time to stop the Martians task. They decided for themselves when to end the task by pushing the stop-button. Unknown to the participant, the maximal duration of the Martians task was 45 minutes in total. Participants were instructed that at the end of the task they would receive feedback on their total number of hits. Task persistence was registered as the total time spent on the task in minutes. Additionally, to check whether mood, threat context, and pain catastrophizing were associated with physical load and task performance, respectively the number of space-bar presses per second and proportion of hits and false positives were registered.

\subsection{Threat Instruction}

To create a pain-threatening context two threat messages were used. The first message was about the potential risk of getting repetitive strain injury symptoms. In order to further increase the threat value, the second message was false feedback of muscle electromyography measurement (EMG) in the arm.

The first message was modelled on the threat message developed by Jackson and colleagues (2005) and Boston and Sharpe (2005). In the present study, those in the threat condition received information about the Martians task as 'the Repetitive Strain Injury task (RSI-task)', while the low threat group received information referring to 'the Martians task.' All information given to the participants was accurate, however, participants in the threat group received information which highlighted some of the physical mechanisms using biomedical terminology and which contained examples of fear-inducing physical responses to repetitive movements with the finger (e.g. inflammated tendon sheet). In contrast, the low threat group received information containing common terminology and reassuring examples that the task was harmless (see Appendix).

The second message was adapted from previous research in which false blood pressure feedback was used to increase the threat value (Van Damme, Crombez, van Nieuwenborgh-De Wever, \& Goubert, 2008; Vlaeyen et. al, 2009). In the present study, false arm muscle EMG feedback was used as it was deemed more suitable in a context of a painful finger pressing task (Martians task). Before starting the Martians task, but after the first low or high threat message, participants received a message requesting to sit still for a couple of seconds in order to measure their arm muscle tension. After 10 seconds, those in the threat condition received false feedback of their arm muscle EMG: "According to the electromyography measurement your muscle tension is rather high but just within the limits to allow participation to the RSI-task." The participants in the low threat condition did not receive any message about their muscle tension. 


\subsection{Mood Induction}

To induce the appropriate moods, participants were presented with either a positive ('Le Fabuleux Destin d'Amélie Poulain,' directed by J. Jeunet, 2001; 4:12 minutes) or negative video excerpt ('Il y'a longtemps que je t'aime,' directed by P. Claudel, 2008; 5:05 minutes). Participants were told that the experimenter was interested in the way people evaluate several film fragments (Martin, Abend, Sedikides, \& Green, 1997; Martin, Ward, Achee, \& Wyer, 1993). Before presentation of the positive or negative excerpt all participants watched a neutral excerpt. The neutral excerpt was a Belgian weather forecast (4:29 minutes). The excerpt was used to bring the participants in relatively neutral moods at the start of the experiment. Moreover, the excerpt was used to draw participants' attention away from the overall emotional tone of the film clips and thus lessen the chance that the subjects would guess that the film clips were used to influence their moods (Martin, Ward, Achee, \& Wyer, 1993). After each excerpt, participants completed several questions about the movies to mask the actual purpose of the video excerpts (mood induction) and to give participants the impression that the experiment was about rating movies. The questions were: "Have you seen the fragment of this movie before?", "Can you tell what this movie is about on the basis of this fragment?", "How much attention did you pay to the film fragment?", and "How interesting was the film fragment?"

All three excerpts were selected based on a recent study in our lab demonstrating that participants $\left[\left(N=98,22\right.\right.$ male, $M_{\text {age }}(S D)=22.37$ (5.38) $]$ experienced more negative moods on a 9-point Likert valence scale ranging from 1 (a smiling, happy figure) to 9 (a frowning, unhappy figure), after watching the negative video excerpt $\left[M_{\text {negative }}(S D)=4.33\right.$ (1.52)] than after the neutral excerpt $\left[M_{\text {neutral }}(S D)=3.38(1.20)\right], F(1,47)=26.59 p<.001$, $\eta^{2}=.36$. Likewise participants experienced more positive moods after watching a positive excerpt $\left[M_{\text {positive }}(S D)=2.72(1.01)\right]$ than after a neutral excerpt, $F(1,52)=41.46 p<.001$, $\eta^{2}=.44$.

\subsection{Pain Catastrophizing}

The Dutch version of the Pain Catastrophizing Scale (PCS) (Sullivan, Bishop, \& Pivik, 1995; Van Damme et al., 2000) was used to assess catastrophic thinking about pain in general. This is a 13-item questionnaire consisting of three subscales: helplessness, magnification, and rumination. The PCS total score, which was used in the present research, offers a good index of the catastrophic construct, because the three subscales are highly correlated. An example of an item is: "I become afraid that the pain will get worse." Ratings are made on a 5-point scale ranging from 0 (not at all) to 4 (always). High mean total scores indicate high levels of pain catastrophizing. Psychometric properties of the Dutch version of the PCS are satisfactory (Crombez, Vlaeyen, Heuts, \& Lysens, 1999; Van Damme, Crombez, Bijttebier, 
Goubert, \& Van Houdenhove, 2002; Vancleef, Peters, Roelofs, \& Asmundson, 2006). In the present study, the internal consistency was adequate (Cronbach's alpha $=.85$ ).

\subsection{Threat Manipulation Check}

In order to test whether the threat manipulation was successful, catastrophic thinking about pain before and after the Martians task was assessed with two adapted versions of the 8-item perceived threat of pain questionnaires (PTP) (Vlaeyen et. al, 2009). One version measured perceived threat before (PTP-A) and the other measured perceived threat during a coldpressor task retrospectively (PTP-B). For the purpose of the present study the questionnaires were adapted such that they referred to 'the Martians task' as opposed to 'the cold pressor task'. Examples of the questionnaire before the Martians task were "I wonder whether this test can be harmful for my hand", and "I worry that something serious can happen." For the questionnaire after the Martians task the items were written in the past tense. Participants were asked to indicate to what extent every statement applied to them on an 11-point scale ranging from 0 (not at all) to 10 (very $m u c h$ ). Previous research has shown an adequate internal consistency for both versions (Vlaeyen et. al, 2009). The internal consistency of the present study was also satisfactory for both versions with a Cronbach's alpha of .63 and .68 for the STP-A and B respectively.

\subsection{Mood Manipulation Check}

The Self Assessment Manikin (Bradley, \& Lang, 1994; Lang, 1980) was used to measure mood valence. The SAM is a nonverbal pictorial assessment technique measuring the three major affective dimensions: valence, arousal, and dominance. In the present study only the valence dimension was used, which consists of one 9-point Likert scale ranging from 1 (a smiling, happy figure) to 9 (a frowning, unhappy figure). Participants were instructed to rate how they felt. The SAM has been used effectively to measure affective reactions to a wide variety of stimuli such as pictures, images, sounds, advertisements, and painful stimuli (Bradley, \& Lang, 1994).

In addition to the SAM valence scale, current levels of sadness, anxiety, and happiness were rated on a 5-point scale. The possible range of scores varied between 1 (not at all) to 5 (very much) (MacDonald, \& Davey, 2005b).

\subsection{Pain Intensity and Pain Unpleasantness}

Experienced pain and pain unpleasantness in the dominant arm was measured before and after the Martians task. Ratings were made on an 11-point Likert scale ranging from 0 (no pain at all) to 10 (the most intense pain imaginable) for pain intensity, and from 0 (not unpleasant 
at all) to 10 (the most unpleasant pain imaginable) for pain unpleasantness (Edwards, \& Fillingim, 1999; Price, Bush, Long, \& Harkins; 1994).

\subsection{Procedure}

Participants were told that the experiment consisted of two separate experiments. One experiment was about evaluating situations with minimal information and the other was about validating a computer task, the so-called Martians task. After signing informed consent, participants completed the PCS and some biographical questions on the internet at home using the electronic environment EMIUM (Janssen, 2008). Next, they were invited to the lab and seated in front of a computer. The experimenter attached three electromyography (EMG) electrodes to the dominant arm and told that participants' muscle tension would be recorded during the second experiment. Subsequently, participants were told that the first experiment was about rating movies. Participants watched a neutral film followed by the film, the mood and pain questions. Next, participants watched one of two mood films dependent on the mood condition followed by the film and mood questions. During the so-called second experiment participants received information about the Martians task including the first low or high threat message about the potential risk of RSI symptoms. Next, an EMG recording took place and false feedback of muscle tension was provided to the participant dependent on the threat condition. Subsequently, participants completed the PTP-A, the pain questions and the Martians task. After the Martians task participants completed the pain questions, the mood questions and the PTP-B. All participants were debriefed about the design and purpose of the study and the false feedback of the EMG recordings immediately after the experiment. Participants received course credits for their participation or $€ 7.50$.

\subsection{Statistics}

To check whether the mood manipulation was successful a 2 Threat (low versus high threat) $\mathrm{x}$ 2 Mood (positive versus negative) x 3 Time (before mood film, after mood film, versus after Martians task) MANCOVAs was conducted with pain catastrophizing as (centered) covariate and the SAM valence scale, happiness, sadness and anxiety as dependent variables.

Next, to establish whether the threat manipulation was successful two 2 Threat (low versus high threat) x 2 Mood (positive versus negative) ANCOVAs were performed with pain catastrophizing as (centered) covariate and either the STP-A or the STP-B as the dependent variable.

To establish whether the task was painful two 2 Threat (low versus high threat) x 2 Mood (positive versus negative) x 2 Time (before versus after the Martians task) MANCOVAs were performed with pain catastrophizing as (centered) covariate and with either pain intensity or unpleasantness as the dependent variable. 
Next a series of 2 Threat (low versus high threat) x 2 Mood (positive versus negative) ANCOVAs were performed with pain catastrophizing as (centered) covariate. Firstly, to establish whether overall physical load (operationalized by the number of button presses per second) and task performance (proportion of hits or false positives) differed between the four experimental conditions and were related to pain catastrophizing. Secondly, to establish whether the relationship between pain catastrophizing and task persistence on the Martians task was moderated by mood and threat context.

Note that the analysis of task persistence, number of button presses per second, proportion of hits and false positives were also conducted with the centred variable pain intensity at baseline as covariate. These results were not reported here because they yielded the same significant findings as the analyses without pain intensity as a covariate. Moreover, pain intensity at baseline was not significantly related to number of presses per minute, hits, false positives, and task persistence (all $F \mathrm{~s}<1.00$ and all $p \mathrm{~s}>.05$ ).

For all analyses, pain catastrophizing was initially included as a continuous variable and not as a dichotomized between-subjects factor, because dichotomization leads to reduced statistical power and less accurate statistical tests (DeCoster, Iselin, \& Gallucci, 2009; MacCallum, Zhang, Preacher, \& Rucker, 2002). In case of a significant interaction between pain catastrophizing and the between- or within-subjects factors follow-up analyses were performed. Firstly, the effect of pain catastrophizing was tested at each level of the within or between subjects factor by means of an ANCOVA and by calculating a Pearson productmoment correlation between pain catastrophizing and the dependent variable. Secondly, subgroups were created scoring high or low on pain catastrophizing based on median split of the PCS $(M e=13)$. Subsequently, the $(\mathrm{M})$ ANCOVAs were repeated for the two subgroups separately.

\section{Results}

\subsection{Manipulation Check}

3.1.1 Mood manipulation. Table 1 displays mean mood scores and standard deviations for each mood condition. A 2 Threat x 2 Mood x 3 Time MANCOVA with the PCS as covariate demonstrated a main effect of time, $F(8,74)=2.92, p=.01, \eta^{2}=.24$, that was superseded by the expected interaction Time $\mathrm{x}$ Mood, $F(8,74)=7.15, p<.001, \eta^{2}=.44$. As expected, posthoc tests ${ }^{1}$ analysing the Time $x$ Mood interaction, demonstrated that participants in the positive mood condition experienced more positive moods after the mood film than at baseline, (SAM valence, $F(1,37)=28.12, p<.001, \eta^{2}=.43$; happiness, $F(1,37)=13.95, p$ $\left.<.001, \eta^{2}=.27\right)$. Participants in the negative mood condition experienced greater negative 
moods after the mood film than at baseline (SAM valence, $F(1,42)=13.80, p<.001, \eta^{2}=$ .25 ; sadness, $\left.F(1,42)=17.67, p<.001, \eta^{2}=.30\right)$. Overall no significant mood differences emerged between baseline and at the end of the Martians task (all $p s>.05$ ).

Finally, an overall main effect of pain catastrophizing was demonstrated, $F(4,78)=3.25, p=$ $.02, \eta^{2}=.14$, indicating that higher pain catastrophizing was associated with higher negative moods $\left(\right.$ SAM valence, $F(1,81)=6.15, p=.02, \eta^{2}=.07, r(86)=.21$; sadness, $F(1,81)=$ $\left.11.51, p=.001, \eta^{2}=.12, r(86)=.30\right)$. There were no other significant main or interaction effects of pain catastrophizing, mood, threat, and time (all $p \mathrm{~s}>.05$ ). These findings suggest that the mood manipulation was successful and was not significantly influenced by threat condition and pain catastrophizing.

Table 1 Means and standard deviation of experienced mood and threat for each mood and threat condition separately

\begin{tabular}{|c|c|c|c|c|}
\hline & \multicolumn{2}{|c|}{ High threat condition } & \multicolumn{2}{|c|}{ Low threat condition } \\
\hline & $\begin{array}{l}\text { Positive } \\
\text { mood condition }\end{array}$ & $\begin{array}{l}\text { Negative mood } \\
\text { condition }\end{array}$ & $\begin{array}{l}\text { Positive mood } \\
\text { condition }\end{array}$ & $\begin{array}{l}\text { Negative mood } \\
\text { condition }\end{array}$ \\
\hline & $M(S D)$ & $M(S D)$ & $M(S D)$ & $M(S D)$ \\
\hline \multicolumn{5}{|l|}{ Valence scale a } \\
\hline baseline & $3.50(1.10)$ & $3.33(1.20)$ & $3.64(1.36)$ & $3.23(1.04)$ \\
\hline after mood induction & $2.67(0.77)$ & $3.79(1.32)$ & $2.95(1.32)$ & $3.86(1.11)$ \\
\hline after task & $3.89(1.28)$ & $3.75(1.42)$ & $3.64(1.14)$ & $3.19(1.03)$ \\
\hline \multicolumn{5}{|l|}{ Happiness } \\
\hline baseline & $4.00(0.59)$ & $4.29(0.69)$ & $4.00(0.69)$ & $4.00(0.59)$ \\
\hline after mood induction & $4.56(0.62)$ & $4.13(0.74)$ & $4.18(0.80)$ & $4.00(0.84)$ \\
\hline after task & $3.72(0.89)$ & $4.17(0.64)$ & $3.95(0.95)$ & $4.24(0.62)$ \\
\hline \multicolumn{5}{|l|}{ Sadness } \\
\hline baseline & $2.33(0.69)$ & $2.42(0.72)$ & $2.91(1.01)$ & $2.48(0.87)$ \\
\hline after mood induction & $2.22(0.55)$ & $2.88(0.90)$ & $2.55(0.80)$ & $2.81(0.98)$ \\
\hline after task & $2.50(0.79)$ & $2.54(0.88)$ & $2.50(0.80)$ & $2.48(0.81)$ \\
\hline \multicolumn{5}{|l|}{ Anxiety } \\
\hline baseline & $2.06(0.24)$ & $2.04(0.20)$ & $2.14(0.47)$ & $1.86(0.36)$ \\
\hline after mood induction & $2.11(0.76)$ & $2.08(0.65)$ & $2.18(0.73)$ & $1.90(0.30)$ \\
\hline after task & $2.06(0.24)$ & $1.96(0.20)$ & $2.00(0.44)$ & $1.90(0.30)$ \\
\hline \multicolumn{5}{|l|}{ Threat } \\
\hline $\begin{array}{l}\text { after threat induction, but } \\
\text { before task (PTP-A) }\end{array}$ & $3.01(1.00)$ & $2.99(1.04)$ & $2.76(1.10)$ & $2.32(0.98)$ \\
\hline after task (PTP-B) & $3.56(1.60)$ & $3.61(1.36)$ & $3.42(1.40)$ & $3.34(1.31)$ \\
\hline
\end{tabular}

Note. PTP, perceived threat of pain questionnaire. ${ }^{\text {a }}$ Low scores indicate positive moods and high scores indicate negative moods. 
3.1.2 Threat manipulation. In Table 1 mean threat scores and standard deviations are presented for each threat condition. As expected, a 2 Threat x 2 Mood ANCOVA with the PCS as covariate demonstrated that experienced threat directly after the threat manipulation was higher in the high than in the low threat condition, $F(1,81)=6.16, p=.02, \eta^{2}=.07$. Moreover, overall higher pain catastrophizing was associated with higher perceived threat directly after the threat manipulation and the Martians task (respectively $F(1,81)=7.49$, $p<.01, \eta^{2}=.09, r(86)=.27$, and $\left.F(1,81)=7.96, p<.01, \eta^{2}=.09, r(86)=.29\right)$. No other main or interaction effects were demonstrated of threat, mood, and pain catastrophizing (all $p$ s $>.05$ ). This indicated that the threat manipulation was successful and was not significantly influenced by mood condition and pain catastrophizing.

3.1.3 Task manipulation. As expected, a 2 Threat x 2 Mood x 2 Time MANCOVA with the PCS as covariate, demonstrated a significant main effect of time, $F(1,81)=95.45, p$ $<.001, \eta^{2}=.54$, indicating that participants experienced more pain after the Martians task than before the task (see Figure 2). Moreover, a significant interaction was obtained between the PCS and time, $F(1,81)=5.42, p=.02, \eta^{2}=.06$. Follow-up analyses of this interaction demonstrated that higher pain catastrophizing was associated with higher pain levels after the Martians task, but not before the Martians task (respectively $F(1,81)=5.64, p=.02, \eta^{2}=.07$, $r(86)=.25$, and $\left.F(1,81)=0.21, p=.65, \eta^{2}<.01, r(86)<.01\right)$.

The analysis of pain unpleasantness demonstrated, as expected, a main effect of time, $F(1,81)=92.61, p<.001, \eta^{2}=.53$, indicating that pain was rated as more unpleasant after the Martians task than before. Moreover, the analysis demonstrated that higher pain catastrophizing was overall associated with higher pain unpleasantness ratings, $F(1,81)=$ 4.92, $p=.03, \eta^{2}=.06, r(86)=.17$. Finally, a significant interaction effect of Time $\mathrm{x}$ Mood, $F(1,81)=4.01, p<.05, \eta^{2}=.05$, was found. However, follow-up tests testing the effect of mood before and after the Martians task separately did not yield significant mood effects (all $p \mathrm{~s}>$.05). No other significant main or interaction effects were obtained for time, mood, threat, and pain catastrophizing on pain intensity and unpleasantness (all $p \mathrm{~s}>.05$ ). These findings indicate that pain intensity and unpleasantness increased during the task, and that the increase in intensity was stronger for those scoring high on pain catastrophizing. The increase in pain was not significantly influenced by mood and threat condition. 


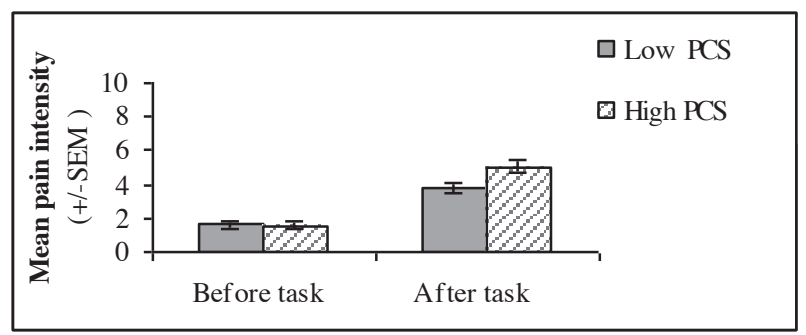

Figure 2. Mean pain intensity for individuals with high and low pain catastrophizing before and after the Martians task.

\subsection{Physical Load and Task Performance}

Means and standard deviations of number of responses per seconds, hits, and false positives are presented in Table 2. As expected a 2 Threat x 2 Mood ANCOVA with the PCS as covariate did not yield a significant effect of mood, threat, and pain catastrophizing on number of responses per seconds (all $p \mathrm{~s}>.05$ ). This indicated that physical load did not differ between the mood and threat conditions and was unrelated to pain catastrophizing.

When the total number of button presses was divided into hits (button presses when an alien was presented on the screen) and false positives (button presses without the presence of an alien), a marginally significant larger proportion of hits were found among participants with positive than negative moods, $F(1,78)=3.96, p=.05, \eta^{2}=.05$. No other main or interaction effects were obtained for mood, threat, and pain catastrophizing on proportion of hits and false positives (all $p \mathrm{~s}>.05$ ). 


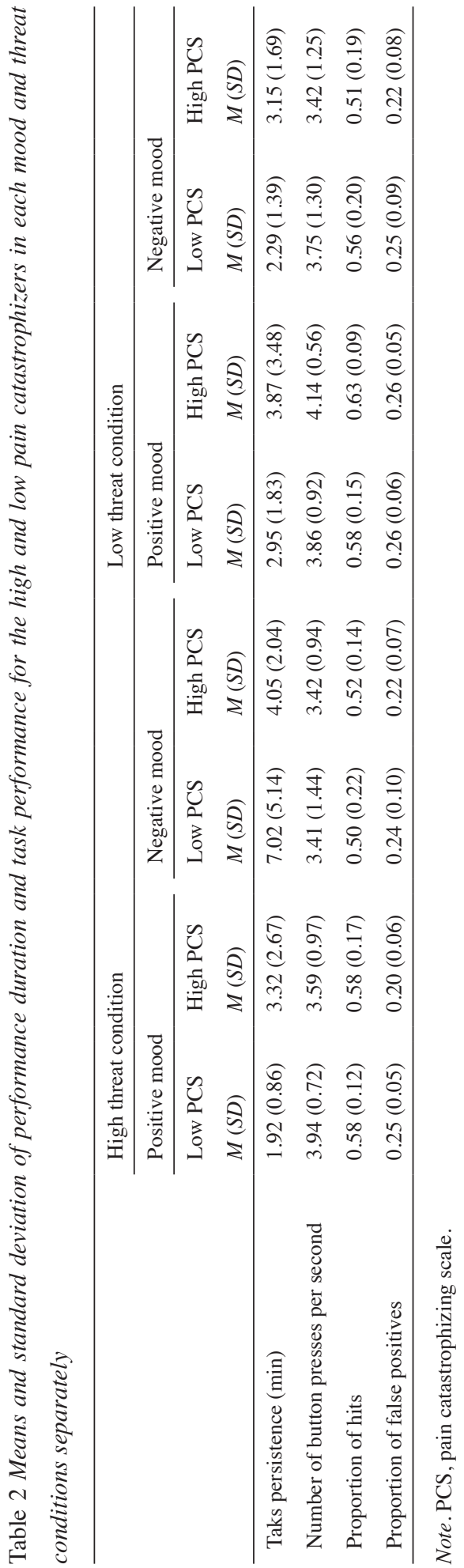




\subsection{Task Persistence}

Means and standard deviations of task persistence are presented in Table 2. As expected, a 2 Threat $x 2$ Mood ANCOVA with the PCS as covariate demonstrated a significant three-way interaction between threat, mood, and pain catastrophizing, $F(1,78)=7.81, p=.007, \eta^{2}=$ .09 (see Figure 3). This three-way interaction consisted of a significant two-way interaction between mood and pain catastrophizing in the high threat condition, $F(1,38)=9.17, p=.004$, $\eta^{2}=.19$, but not in the low threat condition, $F(1,40)=0.33, p=.57, \eta^{2}=.01$. Follow-up tests of the two-way interaction in the high threat condition demonstrated that, as expected, high pain catastrophizing was related to greater task persistence in the positive mood condition, $F(1,16)=5.12, p=.04, \eta^{2}=.24, r(18)=.49$, but to less task persistence in the negative mood condition, $F(1,22)=6.31, p=.02, \eta^{2}=.22, r(24)=-.47$. Additionally, unexpectedly, participants with low pain catastrophizing (based on median split) showed greater task persistence when in a positive than a negative mood, $F(1,23)=11.51, p=.003, \eta^{2}=.33$. No such a mood effect was demonstrated for the participants with high pain catastrophizing, $F(1$, $15)=0.40, p=.54, \eta^{2}=.03$. No other main or interaction effects were obtained for mood, threat, and pain catastrophizing, (all $p \mathrm{~s}>.05$ ).
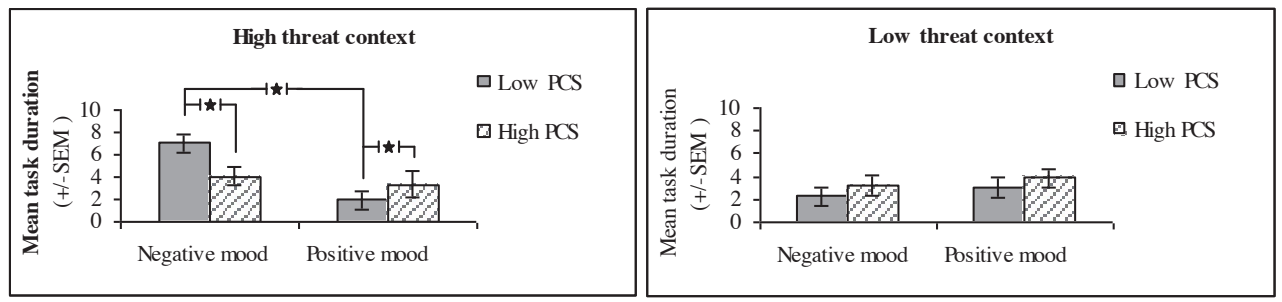

Figure 3. The relationship between pain catastrophizing and task persistence (min) dependent on mood and threat condition.

\section{Discussion}

The findings of the present study support the conjecture that the relationship between pain catastrophizing and task persistence during painful tasks is moderated by situational factors, such as current mood and threat context. In line with the predictions, the results on task persistence demonstrated that higher pain catastrophizing was associated with less duration during a painful finger pressing task when participants experienced negative moods. In contrast, when participants experienced positive moods, higher pain catastrophizing was associated with greater task persistence. This corroborates research demonstrating that mood may have opposing effects on behaviour depending on goal pursuit (Davey, Eldridge, Drost, \& MacDonald, 2007; Davey, Startup, MacDonald, Jenkins, \& Patterson, 2005; Davey, Startup, Zara, MacDonald, \& Field, 2003; MacDonald, \& Davey, 2005b; Mathews, 
\& MacLeod, 1994; Martin, Abend, Sedikides, \& Green, 1997; Sanna, Meier, \& Wegner, 2001; Sanna, Parks, \& Chang, 2003; Startup, \& Davey, 2001, 2003; Watkins, \& Mason, 2002), and supports affective-motivational models, such as the mood-as-input and moodas-information models (Martin, Ward, Achee, \& Wyer, 1993; Schwarz, \& Clore, 2003). These models put forward that current mood is informational on the presence of threat or safety during the performance of a task. The present findings indicate that, relative to low pain catastrophizers, individuals with high pain catastrophizing tend to infer danger from their negative mood and relative safety from their positive mood, which in turn leads to respectively less or greater task persistence during painful activities. Moreover, as predicted, the present study demonstrates that the relationship between pain catastrophizing and task persistence and the modulating effect of mood was most pronounced when the pain stimulus was highly threatening. This finding is in line with theories emphasizing that stable cognitive schemas about threat influence behaviour when activated by threat-relevant contextual cues (Bower, 1981; Edwards, Burt, \& Lipp, 2010; Gray, \& McNaughton, 2000; MacLeod, \& Rutherford, 1992).

An unpredicted finding was that mood and threat context did not influence task persistence within the relatively high catastrophizing group in the present study. High catastrophizing participants did not show less task persistence in a negative than a positive mood, particularly in a high threatening context. A possible explanation is that individuals with high pain catastrophizing developed stable cognitive schemas about pain and less flexibly adapt to changing contexts (Moriarty, McGuire, \& Finn, 2011), diminishing their sensitivity to situational factors, such as mood and threat manipulations. In line with this suggestion, the present study demonstrated that high catastrophizing individuals overall experienced higher negative moods, threat, and pain unpleasantness than low catastrophizing individuals, irrespective of mood and threat context. Nonetheless, both the mood and threat manipulations were equally successful in both the low and high catastrophizing groups. Moreover, pain catastrophizing was measured in a pain-free sample with lower levels of catastrophizing as compared to patients with chronic pain. For example, a mean PCS score of $M=12.52$ ( $S D=6.62$; range $0-32$ ) was obtained in the present study, which was similar to other pain-free samples (Severeijns, van den Hout, \& Vlaeyen, 2005). However, a mean PCS score of $M(S D)=25.5$ (11.3) - 33.9 (11.9) was obtained in patients with chronic musculoskeletal pain (Thibault, Loisel, Durand, Catchlove, \& Sullivan, 2008). Therefore, an alternative explanation is that not stable cognitive schemas, but the absence of individuals with heightened levels of pain catastrophizing resulted in the non-significant mood and threat effects in the high catastrophizing group. Future research is required replicating the present study in patients with chronic pain as these patients may have relatively high levels of pain catastrophizing. Note that the present paradigm may be particularly relevant for patients with 
computer-related upper extremity pain as the Martians task evokes painful sensations due to prolonged computer use.

Although no specific hypotheses were formulated with respect to the low pain catastrophizing group, an intriguing finding was that mood and threat context influenced task persistence particularly in relatively low catastrophizing individuals. Individuals with low levels of pain catastrophizing in a high threat context showed greater task persistence when in a negative than a positive mood. No such a mood effect was demonstrated in a low threat context. Although to the best of our knowledge this is the first study demonstrating a mood effect in low catastrophizing people there is one study that showed similar findings. Researchers (Van den Hout, Vlaeyen, Houben, Soeters, \& Peters, 2001) found that patients with low back pain demonstrated greater task persistence on a physical exercise task in a negative than positive mood. Moreover, they found that this effect was most pronounced in patients with low negative affect. Given that negative affectivity is highly correlated with pain catastrophizing (Lee, Watson, \& Law, 2010; Mounce, Keogh, \& Eccleston, 2010) these results (Van den Hout, Vlaeyen, Houben, Soeters, \& Peters, 2001) may be in line with the present findings. The Mood-as-input model may cautiously provide an explanation for these findings (Vlaeyen, \& Morley, 2004). Research has demonstrated that participants with low pain catastrophizing are more inclined to adopt achievement goals (Karsdorp, \& Vlaeyen, 2011). Therefore, a negative as opposed to a positive mood may have informed the low catastrophizing participants in the present study that they had not performed well enough on the task leading to greater task persistence. However, the reason why low and high catastrophizing individuals adopted respectively achievement or pain-avoidance goals particularly in a high threatening context remains unknown. An explanation may be that low and high catastrophizing individuals process threatening information differently influencing their goal activation. Research on anxiety disorders has suggested that low anxious individuals tend to avoid consciously perceived threatening information, whereas high anxious individuals tend to focus on threatening information and show difficulty disengaging from it (Edwards, Burt, \& Lipp, 2010). It is possible that in the present study, the low catastrophizing individuals drew their attention away from pain-avoidance goals elicited by the threat instruction, and in turn focused on the opposing achievement goals (i.e. save the planet from a Martians invasion), whereas the high catastrophizing individuals focused on pain-avoidance goals in response to the threat instruction (i.e. avoid harm to the arm muscle). As a result, mood may have informed low catastrophizing individuals about their performance and high pain catastrophizing individuals about the possible threat of the task. Note, that no achievement goals were measured in the present study. Therefore, we can only speculate about the possible mechanisms explaining task persistence in the low pain catastrophizing individuals. Future research is required in which activation of achievement goals is measured in low catastrophizing individuals in a threatening context. 
The results of the present study demonstrated that the Martians task was a painful task. However, the task was particularly painful for individuals with high pain catastrophizing. This finding corroborates studies demonstrating that individuals with high levels of catastrophizing selectively attend to painful sensations and interpret ambiguous sensations as painful (Van Damme, Crombez, \& Eccleston, 2002, 2004; Vancleef, Peters, \& De Jong, 2009).

Task persistence could not be explained by physical load as participants did not differ on number of button presses per second during the Martians task. However, participants with a positive mood showed a greater proportion of hits, i.e. fast button press in response to the appearance of a Martian, than participants with negative moods. Indeed, positive moods can engender more quick and efficient information processing (Isen, 2001) than negative moods (Hirt, McDonald, \& Melton, 1996; Schwarz, \& Bless, 1991). This suggests that a positive mood elicited faster information processing and responding to Martian pictures in the present study leading to a greater number of hits when participants experienced positive than negative moods.

Some caution is warranted about the generalization of the present findings to patients with chronic pain as the sample consisted of only pain-free students. It is possible that in the academic context students are inclined to adopt achievement goals which in turn may have influenced their task persistence. In turn, patients with chronic pain may respond differentially to threat and mood manipulations because of their acquired cognitive pain schemes. Note, however, that the inclusion of pain-free individuals may provide insight into the mechanisms that contribute to the onset of chronic pain complaints.

In sum, the present study indicates that the relationship between pain catastrophizing and task persistence during painful activities is influenced by situational factors such as mood and threat context. In line with modern affective motivational-models of pain, these findings provide support for the assumption that stable cognitive schemas about pain and threat are activated by threat contexts and that mood may serve as an informational source about whether a task should be avoided or not. 


\section{Appendix}

\subsection{High Threat Orienting Passage}

Before we begin, carefully read the following information about the Repetitive strain injury (RSI)-task. You will be requested to perform one similar movement with your forefinger repeatedly. Repetitive movement with the same muscle in the arm, in this case the musculus extensor digitorum, can lead to RSI. RSI is caused by a swollen or inflammated tendon sheath, caused by long-standing rubbing of the tendon against bones and ligaments. RSI causes a constant pain in neck, arms, and hands, which can even continue at night. Warning signs include sensations of tingling, weakness or loss of grab ability, a deaf feeling, and sometimes turning pale. A victim is often unaware of the development of RSI. However, RSI can permanently damage your body tissue. Severe cases can lead to the incapacity of loading the muscle, wearing a holding brace permanently and the inability to perform daily activities. Keep this warning in mind during the RSI-task.

\subsection{Low Threat Orienting Passage}

Before we begin, carefully read the following information about the Martians task. You will be requested to perform one similar movement with your forefinger repeatedly. The Martians task is a safe and effective experimental procedure. A review of the literature showed that over 50 experiments have used the Martians task with various populations including young children, pregnant women, elderly people, college students, and persons with chronic medical conditions. Hereby, it turns out that this task is a popular and safe method for scientific research. The Martians task is harmless. You may experience short-term discomfort or tiredness in the muscles in the arm during and shortly after the experiment. However, these sensations will disappear soon. The procedure is safe because the loading of the muscles is low and speed of movement is controlled. Keep this reassurance in mind during the Martians task. 


\section{References}

Arcediano, F., Ortega, N., \& Matute, H. (1996). A behavioural preparation for the study of human Pavlovian conditioning. Quarterly Journal of Experimental Psychology, 49, 270-283.

Arnzt, A., Rauner, M., van den Hout, M. (1995). "If I feel anxious, there must be danger": Exconsequentia reasoning in inferring danger in anxiety disorders. Behaviour Research and Therapy, 33, 917-925.

Boston, A., \& Sharpe, L. (2005). The role of threat-expectancy in acute pain: effects on attentional bias, coping strategy effectiveness and response to pain. Pain, 119, 168-175.

Bower, G.H. (1981). Mood and memory. American Psychologist, 36, 129-148.

Bradley, M.M., \& Lang,P.J. (1994). Measuring emotion: The self-assessment manikin and the semantic differential. Journal of Behavior Therapy and Experimental Psychiatry, 25, 49-59.

Bradley, B.P., Mogg, K., \& Millar, N. (2000). Biases in overt and covert orienting to emotional facial expressions. Cognition and Emotion, 14, 798-808.

Crombez, G., Vlaeyen, J.W.S., Heuts, P.H.T.G., \& Lysens, R. (1999). Pain-related fear is more disabling than pain itself: evidence on the role of pain-related fear in chronic low back pain disability. Pain, 80, 329-339.

Davey, G.C.L., Eldridge, F., Drost, J., \& MacDonald, B.A. (2007). What ends a worry bout? An analysis of changes in mood and stop rule use across the catastrophizing interview task. Behaviour Research and Therapy, 45, 1231-1243.

Davey, G.C.L., Startup, H.M., MacDonald, C.B., Jenkins, D., \& Patterson, K. (2005). The use of "as many as can" versus "feel like continuing" stop rules during worrying. Cognitive Therapy and Research, 29, 155-169.

Davey, G.C.L., Startup, H.M., Zara, A., MacDonald, C.B., \& Field, A.P. (2003). The perseveration of checking thoughts and mood-as-input hypothesis. Journal of Behavior Therapy and Experimental Psychiatry, 34, 141-160.

DeCoster, J., Iselin, A.M., Gallucci, M. (2009). A conceptual and empirical examination of justifications for dichotomization. Psychological Methods, 14, 349-366.

Eccleston, C., Williams, A.C.D.C., Morley, S. (2009). Psychological therapies for the management of chronic pain (excluding headache) in adults. Cochrane Database of Systematic Reviews. 2.

Edwards, M.S., Burt, J.S., \& Lipp, O.V. (2010). Selective attention for masked and unmasked emotionally toned stimuli: Effects of trait anxiety, state anxiety, and test order. British Journal of Psychology, 101, 325-343.

Edwards, R.R., Fillingim, R.B. (1999). Ethnic differences in thermal pain responses. Psychosomatic Medicine,61, 346-354.

Gangemi, A., Mancini, F., van den Hout, M. (2007). Feeling guilty as a source of information about threat and performance. Behaviour Research and Therapy, 45, 2387-2396.

George, S.Z., Dannecker, E.A., Robinson, M.E. (2006). Fear of pain, not pain catastrophizing, predicts acute pain intensity, but neither factor predicts tolerance or blood pressure reactivity: An experimental investigation in pain-free individuals. European Journal of Pain, 10, 457-465. 
Gray, J.A., \& McNaughton, N. (2000). The neuropsychology of anxiety ( $2^{\text {nd }}$ Ed.). NY: Oxford University Press Inc.

Hirt, E.R., McDonald, H.E., Melton, R.J. (1996). Processing goals and the affect-performance link: Mood as main effect or mood as input? In: Martin, L.L., Tesser, A., (Eds.). Striving and feeling: Interactions among goals, affect and self-regulation. (pp. 303-328). Mahwah, NJ: Erlbaum,

Isen, A.M. (2001). An influence of positive affect on decision making in complex situations: theoretical issues with practical implications. Journal of Consumer Psychology, 11, 75-85.

Jackson, T., Pope, L., Nagasaka, T., Fritch, A., Lezzy, T., \& Chen, H. (2005). The impact of threatening information about pain on coping and pain tolerance. Britisch Health Journal of Psychology, $10,441-451$.

Janssen, R. (2008). EMIUM; Effect Monitoring via Internet Universiteit Maastricht. Version 1.3. Maastricht: Research Institute of Experimental Psychopathology, Maastricht University.

Karsdorp, P.A., Vlaeyen, J.W.S. (2011). Goals matter: Both achievement and pain-avoidance goals are associated with pain severity and disability in patients with low back and upper extremity pain. Pain, 152, 1382-1390

Lang, P.J. (1980). Behavioral treatment and bio-behavioral assessment: computer applications. In: Sidowski, J. B., Johnson, J H, Williams T A, (Eds.), Technology in mental health care delivery systems. (pp. 119-137). Ablex: Norwood NJ.

Lee, J.E., Watson, D., \& Law, L.A.F. (2010). Lower-order pain-related constructs are more predictive of cold pressor pain ratings than higher-order personality traits. Journal of Pain, 11, 681-691.

MacCallum, R.C., Zhang, S., Preacher, K.J., \& Rucker, D.D. (2002). On the practice of dichotomization of quantitative variables. Psychological Methods, 7, 19-40.

MacDonald, B., \& Davey, G.C.L. (2005a). A mood-as-input account of perseverative checking: The relationship between stop rules, mood and confidence in having checked successfully. Behaviour Research and Therapy, 43, 69-91.

MacDonald, B., \& Davey GCL.(2005b). Inflated responsibility and perseverative checking: The effect of negative mood. Journal of Abnormal Psychology, 114, 176-182.

MacLeod, C., Rutherford, E.M. (1992). Anxiety and the selective processing of emotional information: mediating roles of awareness, trait and state variables, and personal relevance of stimulus materials. Behaviour Research and Therapy, 30, 479-491.

Mathews, A., \& MacLeod, C. (1994). Cognitive approaches to emotion and emotional disorders. Annual Review of Psychology, 45, 25-50.

Martin, L.L., Abend, T., Sedikides, C., \& Green, J.D. (1997). How would I feel if ...? Mood as input to a role fulfilment evaluation process. Journal of Personality and Social Psychology, 73, 242-253.

Martin, L.L., Ward, W., Achee, J.W., \& Wyer, R.S. (1993). Mood as input: people have to interpret the motivational implications of their moods. Journal of Personality and Social Psychology, 64, 317-326. 
McGowan, N., Sharpe, L., Refshauge, K., \& Nicholas, M.K. (2009). The effects of attentional retraining and threat expectancy in response to acute pain. Pain, 142, 101-107.

Meredith, P.J., Strong, J., \& Feeney, J.A. (2006). The relationship of adult attachment to emotion, catastrophizing, control, threshold and tolerance, in experimentally-induced pain. Pain, 120, 44-52.

Meulders, A., Vervliet, B., Vansteenwegen, D., Hermans, D., \& Baeyens, F. (2010). A new tool for assessing context conditioning induced by US-unpredictability in humans: The Martians task restyled. Learning and Motivation, 42, 1-12.

Moriarty, O., McGuire, B.E., Finn DP. (2011). The effect of pain on cognitive function: a review of clinical and preclinical research. Progress in Neurobiology, 93, 385-404.

Mounce C., Keogh E, Eccleston, C. A (2010). Principal components analysis of negative affect-related constructs relevant to pain: evidence for a three component structure. Journal of Pain, 11, 710-717.

Price, D.D., Bush, F.M., Long, S., \& Harkins, S.W. (1994). A comparison of pain measurement characteristics of mechanical visual analogue and simple numerical rating scales. Pain, 56, 217- 226.

Rhudy, J.L., France, C.R., Bartley, E.J., Williams, A.E., McCabe, K.M., \& Russell, J.L. (2009). Does pain catastrophizing moderate the relationship between spinal nociceptive processes and pain sensitivity? Journal of Pain, 10, 860-869.

Sanna, L.J., Meier, S., \& Wegner, E.A. (2001). Counterfactuals and motivation: Mood as input to affective enjoyment and preparation. British Journal of Social Psychology, 40, 235-256.

Sanna, L.J., Parks, C.D., \& Chang, E.C. (2003). Mixed-motive conflict in social dilemmas: Mood as input to competitive and cooperative goals. Group Dynamics: Theory, Research and Practice, 7, 26-40.

Schwarz, N., \& Bless, H. (1991). Happy and mindless, but sad and smart. The impact of affective states on analytic reasoning. In Forgas, J.P., Editor. Emotion and social judgment. (pp. 55-71). Oxford, England: Pergamon.

Schwarz, N., \& Clore, G.L. (2003). Mood as information: 20 years later. Psychological Inquiry, 14, 196-303.

Severeijns, R., van den Hout M.A., \& Vlaeyen, J.W.S. (2005). The causal status of pain catastrophizing: an experimental test with healthy participants. European Journal of Pain, 9, 257-265.

Startup, H.M., \& Davey, G.C.L. (2003). Inflated responsibility and the use of stop rules for catastrophic worrying. Behaviour Research and Therapy, 41, 495-503.

Startup H.M., \& Davey, G.C.L. (2001). Mood as input and catastrophic worrying. Journal of Abnormal Psychology, 110, 83-96.

Sullivan, M.L.J., Bishop, S.R., \& Pivik, J. (1995). The Pain Catastrophizing Scale: Development and Validation. Psychological Assessment, 1995, 524-532.

Thibault, P., Loisel, P., Durand, M., Catchlove, R., \& Sullivan, M.J.L. (2008). Psychological predictors of pain expression and activity intolerance in chronic pain patients. Pain, 139, 47-54. 
Van Damme, S., Crombez, G., Vlaeyen, J.W.S., Goubert, L., Van den Broeck, A., \& Van Houdenhove, B. (2000). De Pain Catastrophizing Scale: Psychometrische karakteristieken en normering. Gedragstherapie, 33, 209-220.

Van Damme, S., Crombez, G., Bijttebier, P., Goubert, L., \& Van Houdenhove, B.A. (2002). Confirmatory factor analysis of the pain catastrophizing scale: Invariant factor structure across clinical and non-clinical populations. Pain, 96, 319-324.

Van Damme, S., Crombez, G., \& Eccleston, C. (2002). Retarded disengagement from pain cues: The effects of pain catastrophizing and pain expectancy. Pain, 100, 111-118.

Van Damme, S., Crombez, G., Eccleston, C. (2004). Disengagement from pain: The role of catastrophic thinking about pain. Pain,107, 70-76.

Van Damme, S., Crombez, G., van Nieuwenborgh-De Wever, K., \& Goubert, L. (2008). Is distraction less effective when pain is threatening? An experimental investigation with the cold pressor task. European Journal of Pain,12, 60-67.

Van den Hout, J.H.C., Vlaeyen, J.W.S., \& Houben, R.M.A., Soeters, A.P.M., \& Peters, M.L. (2001). The effect of failure feedback and pain-related fear on pain report, pain tolerance, and pain avoidance in chronic low back pain patients. Pain, 92, 247-257.

Vancleef, L.M., Peters, M.L., \& De Jong, P.J. (2009). Interpreting ambiguous health and bodily threat: are individual differences in pain-related vulnerability constructs associated with a non-line negative interpretation bias? Journal of Behavior Therapy and Experimental Psychiatry, 40, 59-69.

Vancleef, L.M., Peters, M.L., Roelofs, J., \& Asmundson, G.J. (2006). Do fundamental fears differentially contribute to pain-related fear and pain catastrophizing? An evaluation of the sensitivity index. European Journal of Pain, 10, 527-536.

Vlaeyen, J.W.S., Hanssen, M., Goubert, L., Vervoort, T., Peters, M., van Breukelen, G., Sullivan, M.J.L., \& Morley, S. (2009). Threat of pain influences social context effects on verbal report and facial expression. Behaviour Research and Therapy, 47, 774-782.

Vlaeyen, J.W.S., Kole-Snijders, A.M.J., Boeren, R.G.B., \& van Eek, H. (1995). Fear of movement / (re) injury in chronic low back pain and its relation to behavioral performance. Pain, 62, 363-372.

Vlaeyen. J.W.S., \& Linton, S.J. (2000). Fear-avoidance and its consequences in chronic musculoskeletal pain: A state of the art. Pain, 85, 317-332.

Vlaeyen, J.W.S., \& Morley, S. (2004). Active despite pain: The putative role of stop-rules and current mood. Pain, 110, 512-516.

Watkins, E., \& Mason,A. (2002). Mood as input and rumination. Personality and Individual Differences, $32,577-587$.

Wells, A., \& Papageorgiou, C. (2001). Social phobic interoception: effects of bodily information on anxiety, beliefs and self-processing. Behaviour Research and Therapy, 39, 1-11. 


\section{Chapter 6}

Goal Preferences Predict Physical Task Persistence in Patients with Chronic Back Pain

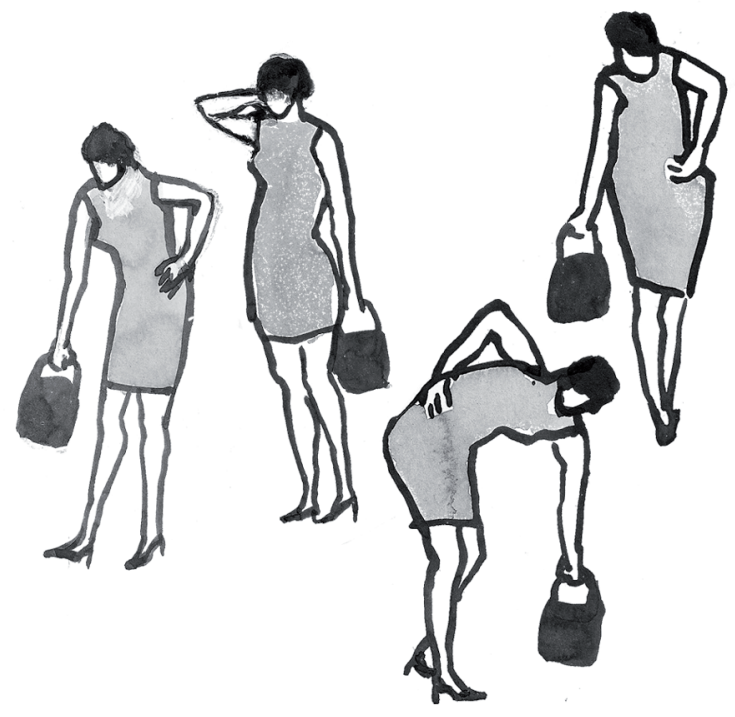




\begin{abstract}
Chronic back pain patients often experience impaired task performance, either in the form of increased or decreased physical task persistence. Recently, affective-motivational approaches have been proposed predicting that goals and current mood influence the extent to which patients persist in a painful task. The aim of the present study was to examine the role of habitual pain-avoidance and achievement goals and current mood on physical task persistence during a painful weightlifting task in patients with chronic back pain. A total of 57 patients with back pain lasting longer than 3 months, were tested. Mood was manipulated with positive or negative film fragments; habitual goals were measured with the Goal Pursuit Questionnaire. The performance task consisted of lifting a bag of $5.5 \mathrm{~kg}$. The dependent measure was the total lifting time. Patients with stronger habitual preferences for pain-avoidance goals displayed lower task persistence than those who preferred achievement goals. Unexpectedly, neither an effect of mood nor an interaction between goal preferences and mood were found. Interestingly, neither pain catastrophizing nor pain-related fear was related to task persistence. The present results support the predictive validity of habitual goal preferences as measured with Goal Pursuit Questionnaire in explaining physical task persistence in chronic back pain patients. The results suggest that not the perceived threat value of pain per se, but the decision making process as to whether to achieve a non-pain goal versus to avoid further pain is related to behavioral outcomes.
\end{abstract}




\section{Introduction}

Chronic back pain presents a major health problem (Mehlum, Kjuus, Veiersted, \& Wergeland, 2006; Silverstein, Welp, Nelson, \& Kalat, 1998), and pain-related fear has been proposed as a key variable in its development and maintenance (Crombez, Vlaeyen, Heuts, \& Lysens, 1999; Vlaeyen \& Linton, 2000, 2012; Vlaeyen, et al., 1999, Zale et al. 2013). The FearAvoidance model proposes that avoidance behaviour may be functional in the short term but that in the long run, it may become dysfunctional, starting with catastrophic (mis) interpretations of pain and leading into a vicious circle of fear of pain, avoidance behaviour, and disability. Despite the accumulating evidence supporting the role of pain-related fear, there are still some inconsistent results that are not fully understood (van den Hout, Vlaeyen, Houben, Soeters, \& Peters, 2001). For example, some studies observed increased instead of decreased task persistence under experimentally induced negative mood (Severeijns, van den Hout, \& Vlaeyen, 2005; van den Hout, et al., 2001), while other studies failed to observe a relationship between pain-related fear and task persistence (de Gier, Peters, \& Vlaeyen, 2003). These results suggest that pathways to disability other than those described in the current Fear-Avoidance models may exist.

Recently, affective-motivational approaches have been proposed that predict both increased and decreased task persistence, depending on the contextual factors: goal pursuit and mood. The Mood-as-Input model (Martin, Ward,Achee, \& Wyer, 1993) distinguishes between achievement and hedonic goals, each associated with two different questions individuals ask themselves during the performance of a task: "Am I satisfied with the result of the task?" (achievement goal) versus "Am I still enjoying this task?" (hedonic goal). The Mood-asInput model predicts that the effect of these goals on behaviour depend on mood, having informational value. That is, when pursuing an achievement goal, negative mood signals that not enough progress has been made, leading to increased task persistence. In contrast, positive mood signals that results have been reached, leading to early task disengagement. On the other hand, when a hedonic goal is adopted, the opposite effects of mood on task persistence are expected (Vlaeyen \& Morley, 2004). The Mood-as-Input model has been successful in predicting perseverative behaviors of individuals with obsessive-compulsive disorder (Davey, Startup, Zara, MacDonald, \& Field, 2003; MacDonald \& Davey, 2005; MacDonald \& Davey, 2005), general anxiety disorder (Davey, Startup, MacDonald, Jenkins, \& Patterson, 2005; Davey, Eldridge, Drost, \& MacDonald, 2007; Startup \& Davey, 2001, 2003) and depression (Watkins \& Mason, 2002, for review see Meeten \& Davey, 2011). In the domain of pain however, a limited number of experimental studies have been performed, and studies so far have shown main effects of mood and goals rather than the typical mood $\mathrm{x}$ goal interaction in the prediction of task performance (Ceulemans, Karsdorp, \& Vlaeyen, 2013; Karsdorp, Nijst, Goossens, \& Vlaeyen, 2010). However, a limitation of these studies 
is that participants were instructed to adopt a specific goal, which does not necessarily mean that participants actually adopted these goals during task performance. Alternatively, measuring habitual goal pursuit might provide a more valid way to test the effects of goals on task performance.

The Goal Pursuit Questionnaire was developed as a measure of the decisions patients make in various situations when confronted with two conflicting goals. The Goal Pursuit Questionnaire distinguishes choices between non-pain hedonic versus achievement goals, and pain-avoidance hedonic versus achievement goals. In a recent study, goal preferences were shown to be related to self-reported disability (Karsdorp \& Vlaeyen, 2011). Participants who strongly endorsed either achievement or pain-avoidance goals reported higher disability levels. Although this study was one of the first to support an affective-motivational account of disability in chronic pain patients, it was limited by the absence of a measure of actual physical task performance (Crombez, Eccleston, Van Damme, Vlaeyen, \& Karoly, 2012; Van Damme, Legrain, Vogt, \& Crombez, 2010).

Therefore, the aim of the present study is to test whether current mood in combination with habitual goal preferences for achievement or hedonic goals predict actual task performance. In line with the Mood-as-Input model, we expect that individuals with stronger habitual preferences for pain-avoidance goals as compared to achievement goals would display shorter weight lifting times when they are in a negative mood than when they are in a positive mood. Individuals with stronger habitual preferences for achievement goals as compared to pain-avoidance goals are expected to display longer weight lifting times when in a negative mood than when in a positive mood.

\section{Methods}

\subsection{Participants}

A total of 58 patients with chronic musculoskeletal pain were tested. Patients reportedly suffered back pain for longer than three months. The inclusion criteria required participants to be between 18 and 60 years old. Participants were excluded when they were pregnant or when they had insufficient knowledge of the Dutch language. Participants were recruited via rehabilitation physicians of the Multidisciplinary Pain Centre, Ziekenhuis Oost Limburg, Belgium, and department of rehabilitation medicine of Maastricht University Hospital, The Netherlands), patient organisations and advertisements. Participants were paid for their participation (7.50 Euros) and received a compensation for travel costs. The Medical Ethics Committee of Maastricht University approved the study. One participant was detected as an outlier, scoring more than 3 standard deviations from the mean on the outcome measure, and was excluded from the analysis. The remaining sample consisted of 57 participants $(24.5 \%$ 
men; mean age $(S D)=47.72$ (10.64) years). Participants were randomly assigned to one of two experimental mood conditions. Demographic data of the sample are displayed in Table 1.

Table 1 Demographic characteristics of the patient sample $(n=57)$

\begin{tabular}{|c|c|}
\hline Characteristics & Value \\
\hline \multicolumn{2}{|l|}{ Age, $y$} \\
\hline Mean (SD) & $47.72(10.64)$ \\
\hline Range & $18-60$ \\
\hline Male sex & $24.6 \%$ \\
\hline \multicolumn{2}{|l|}{ Level of education } \\
\hline Primary education & $5.3 \%$ \\
\hline Secondary education & $54.4 \%$ \\
\hline Intermediate vocational education & $17.5 \%$ \\
\hline Higher vocational education & $15.8 \%$ \\
\hline Higher general education & $7 \%$ \\
\hline \multicolumn{2}{|l|}{ Marital status } \\
\hline Married & $61.4 \%$ \\
\hline Unmarried, living together & $10.5 \%$ \\
\hline Relationship, living apart & $7.0 \%$ \\
\hline Single & $10.5 \%$ \\
\hline Divorced & $3.5 \%$ \\
\hline Widowed & $1.8 \%$ \\
\hline Unmarried, living with parents & $5.3 \%$ \\
\hline \multicolumn{2}{|l|}{ Number of children } \\
\hline Mean (SD) & $1.23(1.07)$ \\
\hline Range & $0-4$ \\
\hline \multicolumn{2}{|l|}{ Job } \\
\hline Working & $42.1 \%$ \\
\hline Student & $7 \%$ \\
\hline $100 \%$ disability pension & $8.8 \%$ \\
\hline Partial disability pension & $14.0 \%$ \\
\hline Partial sickness benefit & $3.5 \%$ \\
\hline Full sickness benefit & $10.5 \%$ \\
\hline Disability pension + sickness benefit & $5.3 \%$ \\
\hline Unemployment benefit & $8.8 \%$ \\
\hline \multicolumn{2}{|l|}{ Recruitment } \\
\hline Rehabilitation physicians & $21 \%$ \\
\hline Patient organizations & $61.4 \%$ \\
\hline Advertisements & $17.5 \%$ \\
\hline \multicolumn{2}{|l|}{ Number of years since first pain complaints } \\
\hline Mean (SD) & $13.81(10.89)$ \\
\hline Range & $1-47$ \\
\hline
\end{tabular}


Table 1 continued

\begin{tabular}{ll}
\hline Characteristics & Value \\
\hline Diagnosis made by a physician (according to the patient) & \\
Herniated disk & $10.5 \%$ \\
Fibromyalgia & $21.1 \%$ \\
Rheumatic disorder & $1.8 \%$ \\
Combination of 1-3 & $26.3 \%$ \\
Wear and tear & $5.3 \%$ \\
Other (whiplash, hyper mobility, & $8.8 \%$ \\
nonspecific back pain, tendonitis) & $10.5 \%$ \\
No diagnosis & $40.4 \%$ \\
Surgery performed on the painful body & \\
part & \\
Treatment for pain & $19.3 \%$ \\
No treatment & $21.1 \%$ \\
Physician & $1.8 \%$ \\
Psychologist & $24.6 \%$ \\
Physiotherapist & $14.0 \%$ \\
Physician + psychologist & $10.5 \%$ \\
Physician + physiotherapist & $1.8 \%$ \\
Physiotherapist + psychologist & $7 \%$ \\
Physician + psychologist + physiotherapist & $64.9 \%$ \\
Use of pain medication &
\end{tabular}

\subsection{Tasks and Measurements}

2.2.1 Biographical and medical questions. The following sample characteristics were measured: gender, level of education, marital status, job situation, duration of pain complaints, whether or not surgery for back pain complaints was performed, diagnosis, treatment for back pain, and use of pain medication.

2.2.2 Mood induction. In order to induce positive or negative mood short film fragments were used. Because it is suggested that Mood-as-Input effects especially arise when it is not clear to the participant that mood is manipulated (Meeten \& Davey, 2011), the film fragments were presented as short cognitive tasks that were meant to measure skin conductance at rest. The mood induction procedure started with a short relaxation period of 1 minute. Then, to equalize mood at baseline, a short episode of a weather report (duration: 4:20 min) was shown. After this fragment, the following three questions were asked: "Have you already seen this fragment before?", "How concentrated were you when watching this fragment?", "How interesting did you think the fragment was?" To induce a positive mood, a fragment of "Le fabuleux destin de Amelie Poulain (2001, by Jean-Pierre Jeunet)." (duration: 4:12 min) was shown; to induce a negative mood, a fragment of "Il y a longtemps que je t'aime (2008, by Philippe Claudel)" (duration: $5.05 \mathrm{~min}$ ) was shown. The positive and negative mood 
fragments were followed by the following questions: "Did you ever see this fragment before? If yes how often?", "Do you know the title of this film? If yes, what is the title?", "Do you think that, based of this fragment alone, you could tell what is the film about?" These questions served to disguise the mood manipulation and to enhance the attention that was paid to the fragments. The above described mood induction procedure has been successfully used in previous research (Karsdorp, Ranson, Schrooten, \& Vlaeyen, 2012; Schrooten, Karsdorp, \& Vlaeyen, 2013).

2.2.3 Mood manipulation check. The effect of the mood manipulation was checked with the valence scale of the Self Assessment Manikin (SAM; Lang, 1980). The SAM is a nonverbal measure, using a 9-point scale with 5 graphical characters, and has been used successfully to measure affective reactions to a wide variety of stimuli such as pictures, images, sounds, advertisements and painful stimuli (Bradley \& Lang, 1994). In the current study, SAM was administered before and after each film fragment. At the end of the experiment, some openended questions were asked to check whether participants knew that the film fragments were used to manipulate their mood.

2.2.4 Task persistence. To assess task persistence, participants were asked to perform a weight lifting task (Vlaeyen, Kole-Snijders, Boeren, \& van Eek, 1995). They were requested to stand upright with their arms loosely alongside their body and to lift a $5.5 \mathrm{~kg}$ weight with their dominant hand. The following instruction was given: "You can choose for yourself how long you will lift the weight. There is no right or wrong time to stop with the task. When you feel that you want to end the task, say 'stop' and put the weight on the ground." Unknown to the participants, the maximum duration of the task was $300 \mathrm{sec}$. Note that participants were not instructed to perform the task until they no longer could tolerate the pain (pain tolerance) but instead could decide for themselves when to stop with the task, in order to prevent the induction of an explicit achievement goal. In order to avoid the fact that participants would end the task because they experienced it as a meaningless activity, they were told that the researchers were interested in skin conductance during the lifting task.

2.2.5 Habitual goal preferences. To assess participants' habitual goal preferences a 16item Goal Pursuit Questionnaire (Karsdorp \& Vlaeyen, 2011) was used. This questionnaire measures the extent to which a person has a preference for either a hedonic goal or an achievement goal, when confronted with two conflicting goals. The Goal Pursuit Questionnaire comprises two subscales: the mood-management scale (8 items) measuring a preference for hedonic goals over achievement goals, and the pain-avoidance scale ( 8 items), measuring a preference for hedonic pain-avoidance goals over achievement goals. A total of 16 situational contexts are described, each followed by a thought a person could have in that situation. The 
thought reflects the result of a decision making process in terms of one of the goals (either the hedonic / pain-avoidance goal or the achievement goal) as being more important than the other. An example of an item of the pain-avoidance subscale is: Context: "While typing a report, your neck becomes increasingly painful. Your boss expects the report to be finished that day". Thought: "I think it is more important for the pain in my neck to be reduced now, than for the report to be finished on time". An example of an item of the hedonic subscale (mood-management subscale) is; Context: "You have received some funny e-mail messages. Since you want to reply to the messages, there is less time available to prepare a presentation. You are expected to finish the presentation today". Thought: "I think it is more important to write a nice e-mail reply than to finish the presentation".

Participants are asked to imagine the situation, and to rate to what extent they agree with the thought by choosing a number from 1 (totally disagree) to 6 (totally agree). Higher scores indicate a stronger preference for hedonic or pain-avoidance goals over achievement goals. Note that this questionnaire is designed to measure goal preferences, and not actual behavior. Participants were instructed to rate what they would think in the described situation, not what they would actually do. Previous research on patients with pain complaints supported the construct validity of the questionnaire and showed adequate reliability for both subscales, pain-avoidance (Cronbach's $\alpha=.88$ ) and hedonic subscale (Cronbach's $\alpha=.76$ ) (Karsdorp \& Vlaeyen, 2011). Reliability for the present study for the pain-avoidance subscale was excellent (Cronbach's $\alpha=.87$ ), and for the hedonic subscale was good (Cronbach's $\alpha=.77$ ).

2.2.6 Pain and pain unpleasantness. Before and after the weightlifting task, experienced pain intensity and pain unpleasantness were measured on an 11-point scale. The endpoints of the scale for pain intensity were as follows: 0 corresponded to "no pain at all," and 10 was equivalent to "the most intense pain imaginable"; for pain unpleasantness, 0 was "not unpleasant at all", and 10 was "the most unpleasant pain imaginable" (Edwards \& Fillingim, 1999; Price, Bush, Long, \& Harkins, 1994).

2.2.7 Pain catastrophizing. The Dutch version of the Pain Catastrophizing Scale (PCS; Crombez \& Vlaeyen, 1996; Sullivan, Bishop, \& Pivik, 1995) was used to asses the exaggerated negative orientation towards painful stimuli. The PCS is a 13-item questionnaire that consists of three subscales: helplessness (6 items), magnification (3 items) and rumination (4 items). A sample item is: 'If I am in pain, I feel as if I can't take this anymore'. In the present study, the total score was used (theoretical range: 0 to 52). Psychometric properties of the Dutch version of the PCS are satisfactory (Van Damme et. al., 2000). Reliability of the PCS total score in the current sample was excellent (Cronbach's $\alpha=.92$ ). 
2.2.8 Pain-related fear. The Dutch version (Vlaeyen, Haazen, Schuerman, Kole-Snijders, \& van Eek, 1995) of the Tampa Scale of Kinesiophobia (TSK; Miller, Kori, \& Todd, 1991) was used to assess pain-related fear. The items are rated on a 4-point scale ranging from 1 (strongly disagree) to 4 (strongly agree). Total scores range from 11 to 44 . The two factor-model of the TSK-11 shows good psychometric properties and has an invariant factor structure across patients with various musculoskeletal pain diagnoses (Roelofs, et al., 2007). TSK has shown to predict behavioral performance in pain patients, including lifting tasks (SwinkelsMeewisse, Roelofs, Oostendorp, Verbeek, \& Vlaeyen, 2006; Vlaeyen, Kole-Snijders, et al., 1995). Reliability of TSK in the current sample was sufficient to good. (TSK: Cronbach's $\alpha$ $=.77)$.

2.2.9 Back pain disability. Back pain disability was measured with the Owestry Disability Index (ODI; Fairbank \& Pynsent, 2000). ODI assesses back pain disability in 10 areas of daily life (pain intensity, personal care, lifting, walking, sitting, standing, sleeping, sex life, social life and travelling). Six statements cover each area, and participants have to indicate which statement best fits their current situation. An example of the statements in the travel area is: 1) I can travel anywhere without pain, 2) I can travel anywhere but it gives me extra pain, 3) Pain is bad but I manage journeys over two hours, 4) Pain restricts me to journeys of less than one hour, 5) Pain restricts me to short necessary journeys under 30 minutes, 6) Pain prevents me from travelling except to receive treatment. Total scores can range from 0 (highest level of function) to 50 (lowest level of function). The ODI has a good validity (Fairbank \& Pynsent, 2000). The internal consistency in the current sample was good (Cronbach's $\alpha=.76$ )

2.2.10 Threat value of the weightlifting task. To determine the subjective threat value of the weightlifting task, 2 visual analogue scales were used, measuring perceived threat and perceived harmfulness of the task respectively. The scales were anchored by "not at all threatening" or "not all harmful" (score of 0 ) and "very threatening" or "very harmful" (score of 100 [100-mm scale]).

2.2.11 Reasons for stopping with the task. To assess the reasons participants used to decide to stop with the weightlifting task, the following questions were asked after termination of the weight lifting task. The first question asked for the reason why participants stopped with the task and consisted of three answering options: 1) I did not enjoy the task anymore (hedonic reason) 2) I thought I delivered a sufficiently good performance (achievement reason) 3) I thought the task was too painful (pain reason) 4) I terminated the task for other reasons.

Additionally, participants were asked to rate the degree to which they agreed with the following two statements on a 6 -point Likert scale $(1=$ totally disagree and $6=$ totally 
agree): "During the weightlifting task it was more important for me to reduce the pain than to get a good performance" and "During weightlifting task it was more important for me to enjoy the task than to reach a good performance".

\subsection{Procedure}

Before entering the lab, participants completed the following questionnaires at home either on paper or electronically via the internet: biographical questions, Goal Pursuit Questionnaire, TSK, and PCS. Upon arrival at the laboratory, participants were told that the experiment consisted of several tasks (film fragments and a weightlifting task). A cover story was designed to cover up the mood induction, to increase the credibility of the weightlifting task, and to prevent participants from stopping with the task because they felt it was a useless activity. Participants were led to believe that the experiment was about the role of skin conductance during lifting tasks in patients with chronic pain. The actual purpose of the study was communicated to the participants after termination.

Instructions for the weightlifting task were given and the electrodes were attached to the ring and middle finger of the non-dominant hand in order to give participants the impression that skin conductance was measured. Participants completed SAM, and after a short period of relaxation, they watched a neutral film clip (an episode of the Belgian weather report), which was followed by a number of questions about this fragment and the administration of the second SAM. Subsequently, participants watched either a positive or a negative film fragment, dependent on the results of the randomization, and completed questions about this film fragment, completed SAM once more, and rated their baseline pain level. Then, participants performed the weightlifting task, which was immediately followed by the completion of the pain items, VAS-threat, and the reasons for stopping with the task. Participants who watched the negative film fragment received a positive mood film at the end of the experiment in order to abolish any negative consequents of the negative mood induction. During debriefing, participants were asked about their ideas of the aims of the experiment

\subsection{Statistical analyses}

All analyses were conducted using the Statistical Package for the Social Sciences (SPSS) for Windows version 17.0. 


\section{Results}

\subsection{Mood Manipulation Check}

In order to test whether the mood manipulation was successful, a 2 Mood (positive versus negative) x 3 Time (baseline, after neutral film, versus after mood induction) ANOVA for repeated measures was conducted with the SAM as dependent variable. A significant Mood $\mathrm{x}$ Time interaction was found $\left(F(2,110)=15.68, p<.001, \eta^{2}=.22\right)$. After the mood induction, participants in the negative mood condition reported feeling less happy compared to those in the positive mood condition $\left(F(1,55)=11.60, p<.01, \eta^{2}=.18\right)$. Within the negative mood condition, participants reported more negative mood states after mood induction compared to baseline, $F(1,24)=19.60, p<.001, \eta^{2}=.45$, and to the neutral film, $F(1,24)=15.13, p$ $<.01, \eta^{2}=.39$. Within the positive mood condition, participants reported less negative mood states after mood induction compared to baseline, $F(1,31)=5.74, p<.05, \eta^{2}=.16$, and to the neutral film, $F(1,31)=9.03, p<.05, \eta^{2}=.12$ (See figure 1$)$. These results suggest that the mood manipulation was successful.

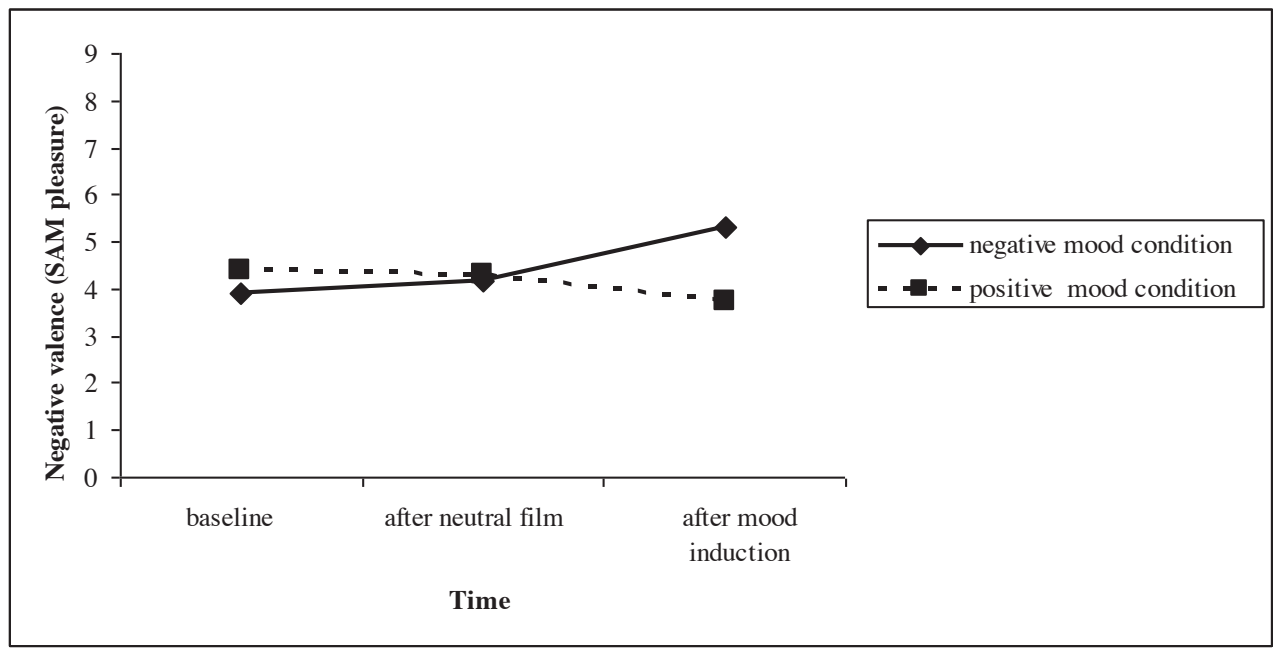

Figure 1. Mean scores on the SAM pleasure scale, at baseline, after the neutral film and after mood induction, split up by mood condition (positive versus negative).

\subsection{Goal Pursuit During the Experiment}

To check whether goal preferences specific for the weightlifting task were associated with participants' general habitual goal preferences for hedonic versus achievement goals, two separate ANCOVAs were conducted with mood condition as between-subjects factor, with either the pain-avoidance subscale or the mood-management subscale of the Goal Pursuit Questionnaire as covariates and one of the two goal statements ("During the weightlifting 
task it was more important for me to reduce the pain than to deliver a good performance" and "During weightlifting task it was more important for me to enjoy the task than to get a good performance") as dependent variables. Interestingly, participants who reported a general preference for mood-management (hedonic) goals relative to achievement goals did not explicitly report that enjoyment was more important than delivering a good performance during the weightlifting task $\left(F(1,53)=0.93, p>.05, \eta^{2}<.001\right)$. Similarly, participants who showed a habitual preference for pain-avoidance goals relative to achievement goals did not explicitly report that it was more important to diminish pain than to deliver a good performance during the weightlifting task $\left(F(1,53)=0.12, p>.05, \eta^{2}=.04\right)$. These findings may suggest that participants may not have been aware of their habitual goals during task performance. Furthermore, inspection of the multiple choice question concerning reasons for stopping with the task revealed that the majority of the patients reported stopping with the task because of the pain (see table 2). Chi-square tests with a median split on the scores of the pain-avoidance subscale of the Goal Pursuit Questionnaire revealed that the reasons for stopping with the task (pain versus achievement) were not associated with habitual preferences for achievement versus pain-avoidance goals $\left(\chi^{2}=2.38, p>.05\right)$ providing further support that participants were not aware of their habitual goals. (Note that because the 'hedonic reason' and 'other reason' category had not enough observations per cell, these categories were excluded from the analysis).

Table 2 Absolute scores and frequencies of the different answering options concerning the question about reasons for stopping with the task, split up by Habitual Goal Pursuit

\begin{tabular}{llll}
\hline $\begin{array}{l}\text { Reasons for stopping } \\
\text { with the task }\end{array}$ & $\begin{array}{l}\text { Stronger habitual preferences } \\
\text { for achievement versus pain- } \\
\text { avoidance goals }{ }^{\text {a }}\end{array}$ & $\begin{array}{l}\text { Stronger habitual preferences } \\
\text { for pain-avoidance versus } \\
\text { achievement goals }\end{array}$ & Total \\
$n($ percent) & $n$ (percent) & $5(45.5 \%)$ & $n($ percent) \\
\hline Achievement & $6(54,5 \%)$ & $20(55,6 \%)$ & $36(67,6 \%)$ \\
Pain & $16(44,4 \%)$ & $23,4 \%)$ \\
\hline
\end{tabular}

Note: ${ }^{a}$ Based on the median split of the Goal Pursuit Questionnaire (Me: 4) the sample was spilt in a group with stronger habitual achievement preferences relative to pain-avoidance preferences and a group with stronger pain-avoidance preferences relative to achievement preferences. 


\subsection{Pain Intensity and Pain Unpleasantness}

To check whether the weightlifting task increased experienced pain, and whether mood and habitual goal pursuit were associated with pain, two separate 2 Time x 2 Mood ANCOVAs were performed on the pain intensity and pain unpleasantness scores (Table 3). As expected, results showed a significant main effect of time for pain intensity, $F(1,52)=30.22, p$ $<.001, \eta^{2}=.37$, and pain unpleasantness, $F(1,52)=24.55, p<.001, \eta^{2}=.32$, indicating that participants reported higher pain intensity and unpleasantness after task execution than before. Neither pain intensity nor pain unpleasantness was found to be affected by mood condition, (pain intensity: $F(1,52)=1.81, p>.05$; and pain unpleasantness: $F(1,52)=$ $.47, p>.05$ ), by habitual pain-avoidance goal preferences (pain intensity: $F(1,52)=.30, p$ $>.05$; pain unpleasantness: $F(1,52)=.39, p>.05)$ or by habitual mood-management goal preferences (pain intensity: $F(1,52)=1.12, p>.05$; pain unpleasantness: $F(1,52)=.38, p>$ .05 . No other interaction effects were found (all $p$ 's $>.05$ ).

Table 3 Mean scores and (standard errors) for pain intensity and pain unpleasantness before and after the lifting task

\begin{tabular}{lll}
\hline & $\begin{array}{l}\text { Time } \\
\text { Before lifting task }\end{array}$ & After lifting task \\
\cline { 2 - 3 } & $M(S E)$ & $M(S E)$ \\
\hline Pain intensity & $4.18(1.96)$ & $5.41(2.16)$ \\
Pain unpleasantness & $4.14(1.97)$ & $5.18(2.23)$ \\
\hline
\end{tabular}

\subsection{Task Characteristics and Potential Confounders}

Table 4 displays mean scores and Pearson's product-moment correlations between the time spent on the weightlifting task, gender, pain intensity, pain catastrophizing, pain-related fear, disability, perceived harmfulness, perceived threat value of the task, and the two subscales of the Goal Pursuit Questionnaire. Perceived threat value and harmfulness of the weightlifting task were positively correlated with pain catastrophizing, indicating that individuals who catastrophized more also found the weightlifting task more threatening and harmful. However, pain catastrophizing, perceived threat value, perceived harmfulness and disability level were not significantly correlated with time spent on the task. Also pain intensity and pain-related fear were not related to the lifting time ( $p s>.05$ ). The two subscales of the Goal Pursuit Questionnaire were not related to pain catastrophizing $(p s>.05)$. The pain-avoidance subscale was marginally associated with time spent on the task, $r(57)=-.24, p=.08$. Male participants spent significantly more time on the task than female participants $(r(57)=.40$, $p<.01)$. As gender was related to task persistence, it was included as a predictor in the regression analysis. 
Table 4 Means and standard deviations and Pearson's correlations between objective lifting time and gender, pain catastrophizing, pain-related fear, pain intensity, disability, perceived threat and harmfulness, and the two subscales of the Goal Pursuit Questionnaire

\begin{tabular}{lllll}
\hline & Mean (SD) & & PCS & Lifting time \\
\hline Objective lifting time & 77.16 & $(75.98)$ & - & - \\
Gender & - & - & .21 & $.40^{* *}$ \\
Pain catastrophizing (PCS) & 17.58 & $(9.74)$ & & -.11 \\
Pain intensity before the task & 4.18 & $(1.96)$ & .11 & -.24 \\
Disability (OID) & 34.50 & $(16.92)$ & $.37^{* *}$ & -.10 \\
Pain-related fear (TSK) & 24.19 & $(6.05)$ & $.51^{* *}$ & $<.01$ \\
Perceived harmfulness & 20.51 & $(24.32)$ & $.35^{* *}$ & .16 \\
Perceived threat value & 17.05 & $(20.82)$ & $.43^{* *}$ & .03 \\
Hedonic subscale GPQ & 2.37 & 2.36 & .22 & .11 \\
Pain-avoidance subscale GPQ & 3.87 & 1.26 & .05 & -.24 \\
\hline
\end{tabular}

Note: gender: (female: -1, male: 1); PCS, Pain Catastrophizing Scale; OID, Owestry Disability Index; TSK, Tampa Scale of Kinesiophobia; GPQ, Goal Pursuit Questionnaire

$* p<.05$

$* * p<.01$

\subsection{Task Persistence}

To test whether mood, habitual goals and their interactions are related to time spent on the weightlifting task, a linear regression was conducted (Table 5) with time spent on the weightlifting task as dependent variable and gender, pain-related fear, mood, the two subscales of the Goal Pursuit Questionnaire and the two interaction terms "mood x pain-avoidance" and "mood x mood-management" as predictors. Both gender and the pain avoidance subscale of the Goal Pursuit Questionnaire explained a significant amount of variance in task persistence with $R^{2}=.26, F(6,50)=2.98, p<.05$. Being male and having a stronger preference for achievement goals over pain-avoidance goals was associated with greater task persistence (Figure 2). 
Table 5 Linear regression analysis with task persistence as dependent variable

\begin{tabular}{llll}
\hline Predictors & B (SE) & Standardized $\beta$ & $\mathrm{R}^{2}$ \\
\hline Gender & $39.13(11.83)^{* *}$ & $.45^{* *}$ & $.30^{*}$ \\
Pain-related fear (TSK) & $-30.92(19.20)$ & -.22 & \\
Mood & $-9.61(9.23)$ & -.13 & \\
Pain-avoidance goal & $-24.37(11.88) *$ & $-.40^{*}$ & \\
Hedonic goal (mood-management subscale) & $10.98(16.85)$ & .13 & \\
Mood x pain-avoidance goal & $11.48(16.32)$ & .14 & \\
Mood x hedonic goal & $12.78(23.21)$ & .12 & \\
\hline
\end{tabular}

Note: gender (female: -1, male: 1); $\operatorname{mood}($ negative:-1, positive: 1 )

$* p<.05$

$* * p<.01$

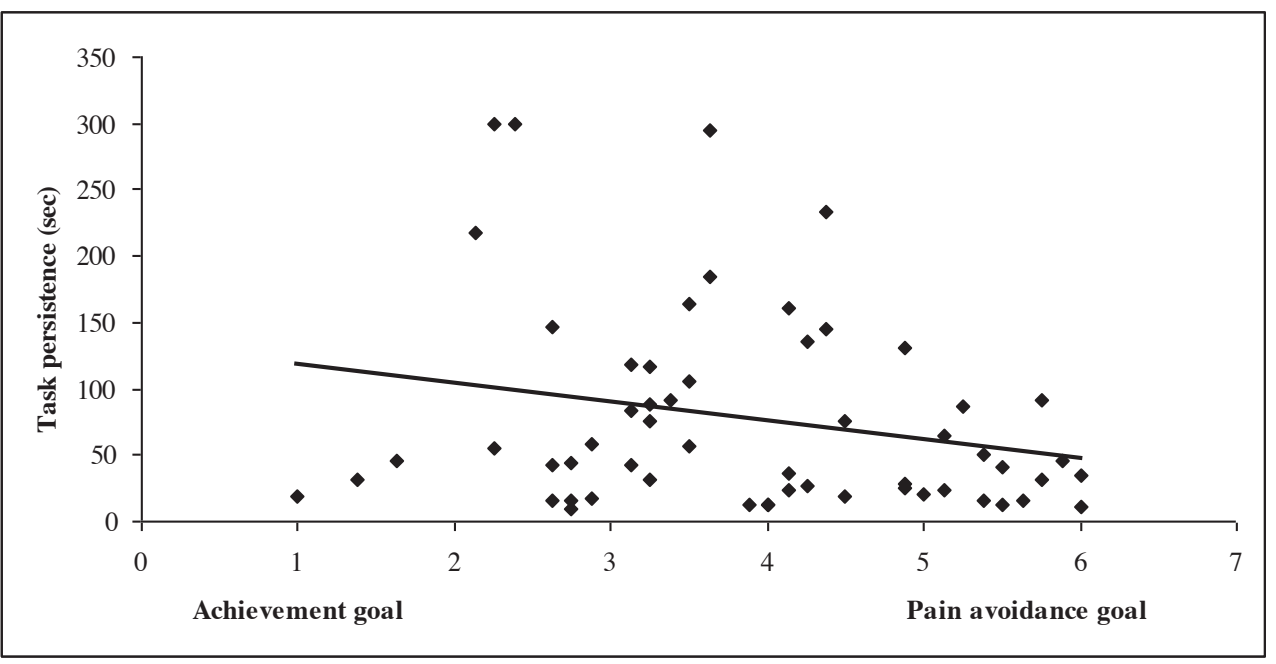

Figure 2. Participants with stronger preferences for pain-avoidance goals as compared to achievement goals demonstrated lower task persistence than those who showed the opposite pattern.

\section{Discussion}

The aim of the present study was to test whether habitual goal pursuit, and its interaction with current mood predicts physical task persistence in chronic pain. Earlier findings suggested that habitual goal pursuit was associated with self-reported disability, and the current study tested whether this finding generalized towards actual behavioural performance. In contrast with the Mood-as-Input predictions, actual performance was not predicted by the interaction effect between habitual goals and current mood states. However, scores on the pain-avoidance subscale of the Goal Pursuit Questionnaire were significantly and uniquely associated with 
lifting time, over and beyond the influence of gender, pain catastrophizing and the moodmanagement scale. That is, patients who reported a stronger preference for pain-avoidance goals over achievement goals showed lesser task persistence on a painful weightlifting task. The results corroborate findings showing that hedonic goals relative to achievement goals reduce task persistence in patients with upper extremity pain (Karsdorp, et al., 2010) as well as in healthy participants (Ceulemans, Karsdorp, \& Vlaeyen, 2013). In healthy participants habitual goal preferences as measured with the Goal Pursuit Questionnaire were demonstrated to predict task persistence in a non-painful cognitive task, with participants having stronger habitual preferences for achievement over hedonic goals showing greater task persistence. This finding and the finding of the present study support the construct validity of Goal Pursuit Questionnaire (Ranson, Karsdorp and Vlaeyen, unpublished manuscript).

The present results contribute to further understanding of the role of goals and decision-making in painful task persistence. First, they demonstrate that not only verbal goal instructions but also habitual goal preferences influence painful task persistence in individuals with chronic pain complaints. Furthermore, the finding that the pain-avoidance subscale and not the mood-management subscale of the Goal Pursuit Questionnaire predicted task persistence may indicate that the role of habitual goals is content-specific.

Interestingly, participants' reasons for stopping with the weightlifting task did not show any association with their habitual goal preferences, with the majority of the participants reporting pain as the reason for stopping with the weightlifting task. This suggests that participants were not aware of the influence of their habitual goals on their behaviour, which is in line with the literature of unconscious goal pursuit (Bargh, 2006).

The present results do not provide evidence for the Mood-as-Input model but are supported by goal pursuit theory, predicting that task performance is a function of individual differences in motivation, with more challenging goals such as achievement goals, leading to higher levels of performance than easier goals (hedonic goals) or no goals (Locke \& Latham, 2002). Furthermore, results also partially support the Fear-Avoidance model, demonstrating a negative association between high pain-avoidance goals and the degree of physical task persistence. Paradoxically, and in contrast with previous studies examining behavioural performance (and weightlifting tasks in particular) (Crombez, et al., 1999; Smeets, van Geel, Kester, \& Knottnerus, 2007; Vlaeyen, Kole-Snijders, et al., 1995), fear of movement/(re) injury and pain catastrophizing were not associated with time spent on the lifting task. There may be several explanations for this. Firstly, although these results show that the lifting task was painful, it is possible that the threat value was not high enough. Indeed, mean pain catastrophizing values and VAS ratings of harmfulness and threat value of the task $[M=17.58$ (9.74), $M=17.05$ (20.81) and $M=20.51$ (24.32), respectively] are relatively low for a patient sample (Sullivan, 1995). In order to prevent the induction of an achievement or hedonic goal, participants were told they could decide for themselves when to stop with the weightlifting 
task, which might have increased feelings of safety. Second, the literature shows that context factors such as mood and threat can moderate the relation between pain catastrophizing and task persistence. It was found that the influence of pain catastrophizing on pain perception is weakened when low threat stimuli are used (Gracely, et al., 2004). Furthermore, the results are in line with a recent study demonstrating that both threat context and mood moderated the relationship between pain catastrophizing and task persistence (Karsdorp, Ranson, Schrooten, et al., 2012). In that study, pain catastrophizing was associated with lower task persistence but only in a high threatening pain context. The absence of a high threat context in the present study could possibly explain the absence of an association between pain catastrophizing and task persistence.

Although mood induction was successful with participants reporting more negative mood states in the negative mood condition than those in the positive mood condition, and also reporting mood changes after mood induction compared to baseline within each mood condition, the present study did not find mood effects on task persistence. This is in contrast with previous studies demonstrating mood effects on painful task persistence in patients with chronic pain (Karsdorp, et al., 2010) and pain tolerance (Tang, et al., 2008; Zelman, Howland, Nichols, \& Cleeland, 1991). Although most studies show that negative affect and pain catastrophizing lead to shorter tolerance times, the literature is not unequivocal on this point with some studies showing longer tolerance times under negative mood conditions (Severeijns, et al., 2005; van den Hout, et al., 2001).

In contrast to the Mood-as-Input hypothesis, no interaction effects between mood and goals were found. There are a number of factors that could explain the absence of Moodas-Input effects in the present study. For example, it has been shown that mood is not used as information when it is attributed to an obvious source, or when it is seen as irrelevant to the judgement at hand (Meeten \& Davey, 2011; Schwarz \& Clore, 1983). A plausible explanation is that chronic pain patients who have a history of pain, have learnt that physical performance is often associated with mood changes (Connelly et al., 2007) and for this reason do not consider mood as relevant information for deciding whether to stop or continue with an activity. Another factor that could play a role is cognitive load. Increased cognitive load has shown to increase the likelihood that mood is used as information (Schwarz, Strack, Kommer, \& Wagner, 1987; Siemer \& Reisenzein, 1998; van den Hout, Kindt, Luigjes, \& Marck, 2007). For example, one study showed that Mood-as-Input effects diminish when the degree of complexity of the task is decreased (van den Hout, et al., 2007). As the present study uses a physical rather than a cognitive task, and the task is a particularly simple one, this could explain why no Mood-as-Input effects were found. Furthermore, it has been suggested that Mood-as-Input effects are more commonly observed when there is little or no other subjective evidence than mood, such as task instructions or other relevant information, on which to base judgements concerning continuing or stopping with the task (Meeten \& 
Davey, 2011). As most participants explicitly reported using pain increase as a reason for stopping with the task, it could be that pain was also partly used as information to decide when to stop with the task, which diminished the influence of mood. Furthermore, habitual goals are by definition more stable and therefore, in contrast to induced goals, are less likely to be influenced by context elements such as mood.

Finally, it has been demonstrated that mood is more likely to be used as information when the individual is in a negative mood because of a motivation to understand, and repair that mood (Clark \& Isen, 1982). In many psychopathologies where Mood-as-Input effects have been shown, such as depressive rumination and anxiety, task persistence under negative mood conditions is associated with a decrease of worry symptoms and anxiety and an increase of confidence, and mood repair. However in chronic pain, in contrast to OCD and depressive rumination, the opposite process seems to take place, in the sense that task persistence is often associated with more pain and does not lead to mood repair but to more negative mood (Gaskin, Greene, Robinson, \& Geisser, 1992). It is possible that pain is an exception, compared to the other domains were Mood-as-Input effects were demonstrated (e.g. Ceulemans, Karsdorp, \& Vlaeyen, 2012; Ceulemans, et al., 2013; Karsdorp, Nijst, Goossens, \& Vlaeyen, 2010; Karsdorp, Ranson, Nijst, \& Vlaeyen, 2012). However, further research is needed to test this assumption.

There are some limitations to this study, which may be addressed in future studies. The study sample is relatively small, and future studies might replicate this design with larger samples. As habitual goals are measured and not manipulated, only conclusions could be drawn about associations and not about causal relations. Furthermore, the zero order correlation between the pain-avoidance subscale of the Goal Pursuit Questionnaire and the outcome measure was only marginally significant while it was a significant predictor in the regression model. This might indicate that one of the variables in the regression model might act as suppression variable.

In conclusion, the present study does not provide evidence for the Mood-as-Input model as an appropriate explanatory framework for physical task persistence in patients with chronic back pain. Instead, habitual goal preferences were shown to predict physical task persistence. More specifically, it was shown that in pain patients, preferences for painavoidance goals relative to achievement goals are associated with shorter task persistence than opposite goal preferences. Interestingly, although the task was painful, results showed no association between task persistence and pain catastrophizing or pain-related fear. In this way results only partly support the Fear-Avoidance model. The present results suggest that pain-avoidance goals are not necessarily related to fear-avoidance beliefs, but nevertheless can be associated with task persistence in pain patients. As in the present study voluntary task performance instead of pain tolerance was measured, the results shed light to a different and particularly relevant category of activity than those usually studied in fear-avoidance 
studies. After all, in daily activities, pain patients not always perform activities until levels of pain tolerance but they may use rules other than pain increases in deciding when to end daily activities. In addition, results further support the predictive validity of the Goal Pursuit Questionnaire in explaining physical task persistence.

\section{Acknowledgements}

This study was supported by an innovation Grant (No. 453-04-003) provided by the NWO Social Sciences Research Council of The Netherlands. We thank Sita Van Riet and Marionne Vaessen for their generous help in the data acquisition. 


\section{References}

Bargh, J. A. (2006). What have we been priming all these years? On the development, mechanisms, and ecology of nonconscious social behavior. European Journal of Social Psychology, 36, $147-168$.

Bradley, M. M., \& Lang, P. J. (1994). Measuring emotion: the Self-Assessment Manikin and the Semantic Differential. Journal of Behavior Therapy and Experimental Psychiatry, 25, 49-59.

Ceulemans, K., Karsdorp, P. A., \& Vlaeyen, J. W. (2012). Effects of responsibility and mood on painful task persistence. Journal of Behavior Therapy and Experimental Psychiatry, 44, 186-193.

Ceulemans, K., Karsdorp, P. A., \& Vlaeyen, J. W. (2013). Mood, stop-rules and task persistence: No Mood-as-Input effects in the context of pain. Journal of Behavior Therapy and Experimental Psychiatry, 44, 463-468.

Clark, M. S., \& Isen, A. M. (1982). Toward understanding the relationship between feeling states and social behavior In A. Hastorf \& A. M. Isen (Eds.), Cognitive Social Psychology (pp. 73-108). New York: Elsevier.

Connelly, M., Keefe, F. J., Affleck, G., Lumley, M., Anderson, T., \& Waters, S. (2007). Effects of dayto-day affect regulation on the pain experience of patients with rheumatoid arthritis. Pain $131,162-170$.

Crombez, G., Eccleston, C., Van Damme, S., Vlaeyen, J. W., \& Karoly, P. (2012). Fear-avoidance model of chronic pain: the next generation. Clinical Journal of Pain, 28, 475-483.

Crombez, G., \& Vlaeyen, J. W. (1996). De pain catastrophizing scale (PCS). Ongepubliseerde geautoriseerde bewerking.

Crombez, G., Vlaeyen, J. W., Heuts, P. H., \& Lysens, R. (1999). Pain-related fear is more disabling than pain itself: evidence on the role of pain-related fear in chronic back pain disability. Pain, 80 , 329-339.

Davey, G. C., Startup, H. M., MacDonald, B. A., Jenkins, D., \& Patterson, K. (2005). The use of 'as many as can' versus 'feel like continuing' stop rules during worrying. Cognitive Therapy and Research, 29, 155-169.

Davey, G. C., Startup, H. M., Zara, A., MacDonald, C. B., \& Field, A. P. (2003). The perseveration of checking thoughts and mood-as-input hypothesis. Journal of Behavior Therapy and Experimental Psychiatry, 34, 141-160.

Davey, G. C. L., Eldridge, F., Drost, J., \& MacDonald, B. A. (2007). What ends a worry bout? An analysis of changes in mood and stop rule use across the catastrophising interview task. Behaviour Research and Therapy, 45, 1231-1243.

de Gier, M., Peters, M. L., \& Vlaeyen, J. W. (2003). Fear of pain, physical performance, and attentional processes in patients with fibromyalgia. Pain, 104(1-2), 121-130.

Edwards, R. R., \& Fillingim, R. B. (1999). Ethnic differences in thermal pain responses. Psychosomatic Medicin, 61, 346-354.

Fairbank, J. C., \& Pynsent, P. B. (2000). The Oswestry Disability Index. Spine (Phila Pa 1976), 25(22), 2940-2952; discussion 2952. 
Gaskin, M. E., Greene, A. F., Robinson, M. E., \& Geisser, M. E. (1992). Negative affect and the experience of chronic pain. Journal of Psychosomatic Research, 36, 707-713.

Gracely, R. H., Geisser, M. E., Giesecke, T., Grant, M. A. B., Petzke, F., Williams, D. A., et al. (2004). Pain catastrophizing and neural responses to pain in persons with fibromyalgia. Brain 127, 835-843

Karsdorp, P. A., Nijst, S. E., Goossens, M. E., \& Vlaeyen, J. W. (2010). The role of current mood and stop rules on physical task performance: An experimental investigation in patients with workrelated upper extremity pain. European Journal of Pain, 14, 434-440.

Karsdorp, P. A., Ranson, S., Nijst, S. E., \& Vlaeyen, J. W. S. (2012). Goals, mood and performance duration on cognitive tasks during experimentally induced mechanical pressure pain. Journal of Behavior Therapy and Experimental Psychiatry, 44, 240-247.

Karsdorp, P. A., Ranson, S., Schrooten, M. G., \& Vlaeyen, J. W. (2012). Pain catastrophizing, threat, and the informational value of mood: task persistence during a painful finger pressing task. Pain, 153, 1410-1417.

Karsdorp, P. A., \& Vlaeyen, J. W. (2011). Goals matter: both achievement and pain-avoidance goals are associate with pain severity and disability in patients with musculoskeletal pain. Pain, $152,1382-1390$.

Locke, E. A., \& Latham, G. P. (2002). Building a practically useful theory of goal setting and task motivation. A 35-year odyssey. American Psychologist, 57, 705-717.

MacDonald, B., \& Davey, G. C. (2005). Inflated responsibility and perseverative checking: the effect of negative mood. Journal of Abnormal Psychology, 114, 176-182.

MacDonald, B. A., \& Davey, G. C. L. (2005). A mood-as-input account of perserverative checking: the relationship between stop rules, mood and confidence in having ceheckd succesfully. Behaviour Research and Therapy, 43, 69-91.

Martin, L., Ward, D. W., Achee, J. W., \& Wyer, R. S. (1993). Mood as input: people have to interpret the motivaitional implications of their Moods. Journal of Personality and Social Psychology, 64, 317-326.

Meeten, F., \& Davey, G. C. (2011). Mood-as-input hypothesis and perseverative psychopathologies. Clinical Psychological Review, 31, 1259-1275.

Mehlum, I. S., Kjuus, H., Veiersted, K. B., \& Wergeland, E. (2006). Self-reported work-related health problems from the Oslo Health Study. Occupational Medicne (London), 56, 371-379.

Miller, R. P., Kori, S. H., \& Todd, D. D. (1991). Unpublished report.

Price, D. D., Bush, F. M., Long, S., \& Harkins, S. W. (1994). A comparison of pain measurement characteristics of mechanical visual analogue and simple numerical rating scales. Pain, 56, 217-226.

Ranson, S., Karsdorp, P. A., \& Vlaeyen, J. W. Unpublished manuscript.

Roelofs, J., Sluiter, J. K., Frings-Dresen, M. H., Goossens, M., Thibault, P., Boersma, K., et al. (2007). Fear of movement and (re)injury in chronic musculoskeletal pain: Evidence for an invariant two-factor model of the Tampa Scale for Kinesiophobia across pain diagnoses and Dutch, Swedish, and Canadian samples. Pain, 131, 181-190. 
Schrooten, M. G., Karsdorp, P. A., \& Vlaeyen, J. W. (2013). Pain catastrophizing moderates the effects of pain-contingent task interruptions. European Journal of Pain, 17, 1082-1092.

Schwarz, N., \& Clore, G. L. (1983). Mood, misattribution, and judgments of well-being. Informative and directive functions of affective states. Journal of Personality and Social Psychology, 45, 513-523.

Schwarz, N., Strack, F., Kommer, D., \& Wagner, D. (1987). Soccer, rooms, and the quality of your life: Mood effects on judgments of satisfaction with life in general and with specific domains. European Journal of Social Psychology, 17, 69-79.

Severeijns, R., van den Hout, M. A., \& Vlaeyen, J. W. (2005). The causal status of pain catastrophizing: an experimental test with healthy participants. European Journal of Pain, 9, 257-265.

Siemer, M., \& Reisenzein, R. (1998). Effects of mood on evaluative judgements: Influence of reduced processing capacity and mood salience. Cognition and Emotion, 12, 783-805.

Silverstein, B., Welp, E., Nelson, N., \& Kalat, J. (1998). Claims incidence of work-related disorders of the upper extremities: Washington state, 1987 through 1995. American Journal of Public Health, 88, 1827-1833.

Smeets, R. J. E. M., van Geel, A. C. M., Kester, A. D. M., \& Knottnerus, J. A. (2007). Physical capacity tasks in chronic low back pain: What is the contributing role of cardiovascular capacity, pain and psychological factors? Disability and Rehabilitation, 29, 577-586.

Startup, H. M., \& Davey, G. C. (2001). Mood as input and catastrophic worrying. Journal of Abnormal Psychology, 110, 83-96.

Startup, H. M., \& Davey, G. C. (2003). Inflated responsibility and the use of stop rules for catastrophic worrying. Behaviour Research and Therapy, 41, 495-503.

Sullivan, M. J. (1995). Pain Catastrophizing Scale: user manual

Sullivan, M. J., Bishop, S. R., \& Pivik, J. (1995). The Pain Catastrophizing Scale: Development and validation. Psychological Assessment, 7, 524 - 532.

Swinkels-Meewisse, I. E., Roelofs, J., Oostendorp, R. A. B., Verbeek, A. L. M., \& Vlaeyen, J. W. S. (2006). Acute low back pain: pain-related fear and pain catastrophizing influence physical performance and perceived disability. Pain, 120, 36-43.

Tang, N. K., Salkovskis, P. M., Hodges, A., Wright, K. J., Hanna, M., \& Hester, J. (2008). Effects of mood on pain responses and pain tolerance: an experimental study in chronic back pain patients. Pain, 138, 392-401.

Van Damme, S., Crombez, G., Vlaeyen, J.W.S., Goubert, L., Van den Broeck, A., \& Van Houdenhove, B. (2000). De Pain Catastrophizing Scale: Psychometrische karakteristieken en normering. Gedragstherapie, 33, 209-220.

Van Damme, S., Legrain, V., Vogt, J., \& Crombez, G. (2010). Keeping pain in mind: a motivational account of attention to pain. Neuroscience and Biobehavioral Reviews, 34, 204-213.

van den Hout, J. H., Vlaeyen, J. W., Houben, R. M., Soeters, A. P., \& Peters, M. L. (2001). The effects of failure feedback and pain-related fear on pain report, pain tolerance, and pain avoidance in chronic low back pain patients. Pain, 92, 247-257. 
van den Hout, M., Kindt, M., Luigjes, J., \& Marck, C. (2007). Compulsive perseveration: empirical criticism on the mood-as-input model. Behaviour Research and Therapy, 45, 1221-1230.

Vlaeyen, J. W., Haazen, I. W., Schuerman, J. A., Kole-Snijders, A. M., \& van Eek, H. (1995). Behavioural rehabilitation of chronic low back pain: comparison of an operant treatment, an operant-cognitive treatment and an operant-respondent treatment. Brittisch Journal of Clinical Psychology, 34, 95-118.

Vlaeyen, J. W., Kole-Snijders, A. M., Boeren, R. G., \& van Eek, H. (1995). Fear of movement/(re) injury in chronic low back pain and its relation to behavioral performance. Pain, 62, 363-372.

Vlaeyen, J. W., \& Linton, S. J. (2000). Fear-avoindance and its consequences in chronic muskoskeletal pain: a state of the art. Pain, 85, 317-332.

Vlaeyen, J. W., \& Linton, S. J. (2012). Fear-avoidance model of chronic musculoskeletal pain: 12 years on. Pain, 153, 1144-1147.

Vlaeyen, J. W. S., \& Morley, S. (2004). Active despite pain: the putative role of stop - rules and current mood. Pain, 110, 512-516.

Vlaeyen, J. W. S., Seelen, H. A. M., Peters, M., de Jong, P., Aretz, E., Beisiegel, E., et al. (1999). Fear of movement/(re)injury and muscular reactivity in chronic low back patients: an experimental investigation. Pain, 82, 297-304.

Watkins, E., \& Mason,A. (2002). Mood as input and rumination. Personality and Individual Differences, $32,577-587$.

Zale, E.L., Lange, K.L., Fields, S.A., \& Ditre, J.W. (2013). The relation between pain-related fear and disability: a meta-analysis. The journal of pain, 14, 1019-1030.

Zelman, D. C., Howland, E. W., Nichols, S. N., \& Cleeland, C. S. (1991). The effects of induced mood on laboratory pain. Pain, 46, 105-111. 


\section{Chapter 7}

General Discussion

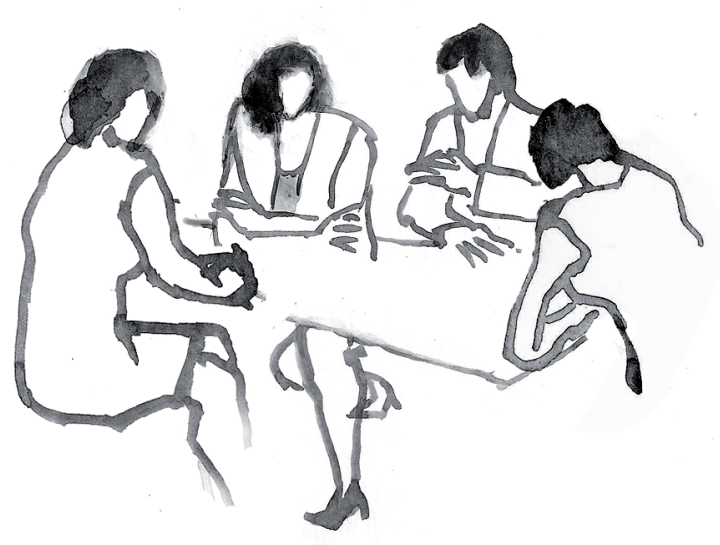




\section{Introduction}

In daily life patients with chronic pain are often faced with the difficult choice between two competing goals: whether to avoid pain and potential harm or to persist in valued activities despite pain. While a lot of research has focused on the mechanisms underlying avoidance behavior (e.g. Vlaeyen \& Linton, 2000, 2012), the mechanisms underlying persistence behavior have been largely neglected in pain research (Andersen, Haahr \& Frost, 2007; Feuerstein, et al., 2005; Garcia-Campayo, Pascual, Alda, \& Ramirez, 2007, Van Houdenhove, Neerinckx, Onghena, Lysens \& Vertommen, 2001). The Fear-Avoidance model explains disability as the result of the following cascade of reactions: catastrophic interpretations of pain, resulting from misconceptions about pain, usually lead to pain-related fear that is associated with the avoidance of daily activities, with disuse, depression, and disability as a consequence (Vlaeyen \& Linton, 2000). However, the Fear-Avoidance model does not provide an explanation for the supposed dysfunctional effects of persistence behavior on disability and pain (Andersen et al., 2007; Garcia-Campayo et al., 2007; Van Houdenhove et al., 2001). Some studies seem to suggest that persistence behavior and the resulting overuse syndrome are key variables in the etiology and maintenance of non-specific pain syndromes such as fibromyalgia (e.g. van Houdenhove, 2004, Hasenbring, 2012). These findings suggest that both excessive avoidance ánd excessive persistence behaviors may underlie chronic pain and disability. A new promising model that provides an explanatory framework for both persistence and avoidance behavior associated with pain disability is the Mood-asInput Model (Martin, Ward, Achee, \& Wyer, 1993). The Mood-as-Input model seemed a particularly promising model because it offers, in contrast to the Fear-Avoidance model, an explanation for both increased and decreased levels of activity. The central Mood-as-Input assumption is that the same mood state can have differential effects on task persistence, dependent on the goal context in which it appears, being either an achievement or a hedonic context. In an achievement context, a positive mood state signals that one has achieved the goals of the task, leading to task discontinuance, while in a hedonic context, the same positive mood means that participants are still enjoying the task, leading to task continuance. In the course of the years, evidence for the Mood-as-Input account has been found within different clinical domains: obsessive compulsive disorder (OCD) (Davey, Startup, Zara, MacDonald, \& Field, 2003; MacDonald \& Davey, 2005a; MacDonald \& Davey, 2005b; Van den Hout, Kindt, Luigjes, \& Marck, 2007), general anxiety disorder (GAD) (Startup \& Davey, 2001, 2003) and depression (Hawksley \& Davey, 2010; Watkins \& Mason, 2002), and across different tasks. However, evidence for the applicability of the Mood-as-Input model to the domain of pain is scarce. Furthermore, the model has mainly been tested using explicit goal instructions. As in everyday life numerous activities are performed without following explicit verbal instructions, an unresolved question is whether the Mood-as-Input model still applies 
when other than explicit goal instructions are used. Therefore, the main purpose of the present dissertation was to investigate whether the Mood-as-Input model could serve as an explanatory framework for task persistence in the domain of pain, without using explicit goal instructions, using goal priming and habitual goal pursuit instead.

\section{Summary of main findings}

In a first study the relationship between activity-related behavioral strategies (e.g. avoidance behavior, persistence behavior and pacing) and functioning in chronic pain was explored. As a particular strength of applying the Mood-as-Input model to the domain of pain is that it offers, in contrast to the Fear-Avoidance model, an explanation for both increased and decreased levels of activity, we wanted to test our basic assumption that both increased and decreased activity levels are associated with more disability (Chapter 2). The study investigated the association between activity strategies (e.g. avoidance behavior, persistence behavior, and pacing) and functioning (disability, depression, pain severity, and pain catastrophizing) in a heterogeneous group of patients with musculoskeletal pain. Activity strategies were measured with the Patients Activity Relations Questionnaire (McCracken \& Samuel, 2007) and associations between different combinations of activity strategies and functional outcomes were examined. The findings showed that not avoidance, pacing or persistence per se, but especially the combination of elevated levels in all three activity strategies (which we called the cycler group) was associated with more disability, more pain catastrophizing, and more depression. Unexpectedly, the group of patients with high levels of persistence and low levels of pacing and avoidance reported the best outcomes.

Because to date the Mood-as-Input model has mainly been tested with explicit goal instructions, that is explicitly instructing participants to pursue either a hedonic goal or an achievement goal while doing a task, the study in chapter 3 tested whether the predictions of the Mood-as-Input model would also hold without the use of explicit goal instructions, using goal priming and habitual goal assessment instead. Habitual goal preferences are defined as preferences that people naturally adopt for one particular goal in favour of another conflicting goal. Achievement and hedonic goals were manipulated by means of supraliminal priming with the Scrambled Sentence Task and habitual goal preferences for achievement versus hedonic goals were assessed with the Goal Pursuit Questionnaire (GPQ; Karsdorp \& Vlaeyen, 2011). Similar to the study of Martin, Ward, Achee \& Wyer (1993), mood was induced with video clips, and task persistence was measured with the impression formation task. Unexpectedly, the results did not yield any Mood-as-Input interaction effects. Instead, a main effect of habitual goal preferences was found with participants reporting greater preferences for achievement goals as compared to hedonic goals showing greater task persistence. 
A major assumption of the goal priming procedure is that goals are made more accessible and in turn influence behavior (Bargh, 1990, 2006). The study described above did not yield any significant effects of primed goals on behavior. It was however unclear whether this was due to 1) insufficient accessibility of goals, 2) the inability of these goals to influence behavior or 3) the absence of explicit goal instructions. Therefore, it was further tested whether the chosen priming procedure in fact made the primed hedonic or achievement goals more accessible using a lexical decision task (Chapter 4). In contrast to our expectations, there was no evidence that the primed goals were made more accessible by means of the goal priming procedure.

Furthermore, the generalizability of the Mood-as-Input model to the domain of pain was investigated in two additional studies, one study involving healthy participants (Chapter 5) and a study with patients with chronic pain (Chapter 6). The study using healthy participants focused on a Mood-as-Input account of painful task persistence using pain catastrophizing as a proxy for a specific pain-avoidance goal. The study addressed the question whether contextual factors such as mood and threat context could moderate the relationship between pain catastrophizing and task persistence in healthy participants. In the context of pain, negative and positive mood may give different information about whether an activity is threatening or safe, with positive moods signalling that an activity is safe and negative moods signalling that an activity might be dangerous. It was predicted that pain catastrophizing would be related to less task persistence when participants experience negative moods, but to greater task persistence when participants experience positive moods; particularly in a high threatening context. Pain catastrophizing was measured with the Pain Catastrophizing Scale (PCS), mood was manipulated by means of film fragments, and participants were asked to perform a painful finger-pressing task in either a high or a low threat context. Results confirmed the hypothesis, demonstrating a significant interaction between mood and pain catastrophizing, only in the high threat context and not in the low threat context. Pain catastrophizing was related to less task persistence when participants experience negative moods, but to greater task persistence when participants experience positive moods. In study $\mathrm{V}$ (described in chapter 6), physical task persistence was measured using a weight-lifting task in a sample of patients with chronic back pain (suffering pain $>3$ months). Mood was manipulated with film fragments, and habitual goals were measured with the Goal Pursuit Questionnaire (GPQ). Similar to the results of study II (presented in chapter 3), these results did not provide evidence for the Mood-as-Input hypothesis but instead showed a main effect of goal preferences. More specifically, pain patients with stronger habitual preferences for pain-avoidance goals relative to achievement goals showed lower task persistence than those with the opposite preference.

Overall, results from our studies did not provide strong evidence for the validity of the Mood-as-Input model when using goal priming and habitual goal pursuit instead of 
explicit goal instructions. First of all, study I did not provide unequivocal evidence for the idea that increased levels of activity are associated with more disability. Second, from the three Mood-as-Input studies, a Mood-as-Input interaction effect was found in one study only, when pain catastrophizing was used as a specific pain-avoidance goal (study IV). An interaction effect between mood and pain catastrophizing predicted task persistence within a threatening context, such that high pain catastrophizing was related to less task persistence when participants experienced negative moods, but related to greater task persistence when participants experienced positive moods. No Mood-as-Input effects were found in the other two studies (II and V). Instead, main effects of habitual goal preferences were found. In healthy participants, stronger goal preferences for achievement goals compared to nonpain hedonic goals were associated with greater task persistence. Similarly, in pain patients, stronger goal preferences for pain-avoidance goals compared to achievement goals were related to lesser task persistence.

\section{The association between activity patterns and disability}

A particular strength of applying the Mood-as-Input approach to the domain of pain is that it can explain disability related to both decreased as well as increased levels of activity. So, as a first step we explored the relationship between activity-related behavioral strategies (e.g. avoidance behavior, persistence behavior and pacing) and functioning in chronic pain, focusing on the question whether it is really the case that both increased and decreased activity levels are associated with dysfunctional outcomes. Instead of studying activity related strategies in isolation, combinations of activity related strategies (avoidance, pacing, and persistence) were investigated, creating subgroups of patients. The relationship of these combinations of activity related strategies with measures of pain catastrophizing, pain, depression and disability was studied (Study I). In line with the evidence for the FearAvoidance model, subgroups of patients displaying avoidance behavior reported the poorest outcomes. However, results did not provide unequivocal evidence that increased levels of activity are associated with less or more disability (Feuerstein et al. 2005; Garcia-Campayo et al., 2007). Results demonstrated that the relation between persistence and disability depended on its combination with other activity levels. When combined with low levels of pacing and avoidance behavior, elevated levels of persistence behavior were associated with more favorable outcomes. However, when combined with high levels of both pacing and avoidance, increased levels of persistence were associated with the least favorable outcomes. A recent meta-analysis on the adaptivity of different activity strategies (Andrews, Strong, \& Meredith, 2012) gives more insight into the conflicting results described in the literature concerning the functionality of persistence behavior. These authors suggest that there might be two types of persistence behavior, an adaptive and a maladaptive type. The maladaptive type is suggested 
to be related to overactivity, persisting in activities to the point of severe pain aggravation. The question is, what is meant by "overactivity" and "persistence. The existence of different types of persistence behavior (maladaptive and adaptive) is also corroborated by our results showing that persistence was related to less disability, dependent on whether or not it was combined with high levels of avoidance. Patients groups who reported persistence behavior in combination with avoidance behavior reported more disability than those reporting persistence behavior without avoidance. A more fine-grained and functional definition of persistence behavior referring to the reasons behind the persistence behavior would perhaps help to differentiate between adaptive and maladaptive kinds of persistence behavior. For example, one may persist in a certain behavior either in order to avoid certain consequences (e.g. avoid negative evaluations from others) or in order to approach consequences (reach satisfaction). A further differentiation was proposed by Kindermans and colleagues (2011) who differentiate between task-contingent persistence, pain-contingent persistence, and excessive persistence. Task-contingent persistence refers to finishing activities despite pain, while the determinant of behavior of pain-contingent persistence is the level of experienced pain. Excessive persistence is defined as the absence of breaks with, as a consequence rebound effects of pain and inactivity. The results of that study suggest that excessive persistence might be a maladaptive form of persistence behavior as it was shown to be related to higher levels of disability and depressive symptomatology, while task-contingent persistence might be a more adaptive form of persistence behavior as it was related to lower levels of disability and depressive symptomatology.

Results from Study I further showed that elevated scores on all three activity strategies (persistence behavior, avoidance behavior and pacing) were shown to be associated with more disability, pain catastrophizing and depression. This might indicate that it is not so much the increased level of activity per se but rather the switching between different activity strategies leading to extreme fluctuations in activity that is particularly dysfunctional. However, these results should be interpreted cautiously given the correlational and crosssectional nature precluding any causal inferences regarding the direction of the relationship between the activity related strategies and disability. Furthermore, the Patients Activity Relations Questionnaire does not explicitly measure switching between activity-related strategies. Nevertheless, this interpretation of the results is in line with a study by Huijnen et al. (2009) using activity monitoring in chronic low back pain patients. These researchers showed that higher fluctuations in activity over time, i.e. high activity alternating with low activity levels, was associated with higher disability, whereas the mean activity level was not associated with perceived disability. Further research should address the mechanisms behind these activity fluctuations. It might be that this switching between activity related strategies reflects the typical goal conflicts that patients with enduring pain may encounter (Schrooten, Wiech \& Vlaeyen, manuscript submitted for publication) 
To summarize, results from Study I indicate that it might not be avoidance or persistence per se that is associated with disability but the combination of elevated levels of all three activity related strategies. This might have implications concerning the dependent variable that is most relevant to be studied in Mood-as-Input studies in the domain of pain.

\section{Evidence of Mood-as-Input effects in task persistence}

An overview of the Mood-as-Input literature showed that the vast majority of the studies used explicit goal instructions to induce achievement or hedonic goals (Meeten \& Davey, 2011; also see Chapter 1). However, as in daily life most of our activities are not guided by explicit task instructions, the question was raised whether the predictions of the Mood-as-Input model also hold when explicit goal instructions are not used, but habitual goal assessment and supraliminal goal priming are used instead. Similar to the study of Martin et al. (1993), which serves as a classical example in the Mood-as-Input literature, film fragments were used as mood manipulation and the impression formation task was used to measure task persistence. In contrast to the Mood-as-Input hypothesis, results showed neither an interaction between mood and primed goals nor between mood and habitual goals. Instead, a main effect of habitual goal preferences was found, indicating that stronger goal preferences for achievement goals over hedonic goals are associated with higher task persistence. This result is in line with other studies within the Mood-as-Input literature testing the role of naturally adopted achievement and hedonic goals (Davey, Startup, MacDonald, Jenkins, \& Patterson, 2005; Van Wijhe, Peeters, \& Schaufeli, 2011a; Van Wijhe, Peeters, \& Schaufeli, 2011b). Van Wijhe and colleagues (2011a, 2011b) failed to find a Mood-as-Input interaction effect but demonstrated that naturally adopted goals could explain the difference in work motivation between workaholics (a maladaptive form of working hard) and work engaged employees (an adaptive form of working hard); the former being related to achievement goals and the latter to hedonic goals. In the domain of general anxiety, Davey and colleagues (2005) showed that in healthy participants, naturally adopted achievement goals were related to greater task persistence during a catastrophizing interview. Our findings not only corroborate the existing evidence, but also give further insight into the influence of goals on behavior. In contrast to the other studies, our study measured the relative strength of goal preferences instead of measuring the independent influence of achievement goals and hedonic goals. The advantage of the GPQ over other questionnaires that have been developed to measure goals in the context of workaholism (Work Persistence Rules checklist; Van Wijhe et al. 2011) and worrying (Worry Stop Rule checklist; Davey et al., 2005) is twofold. First, as already mentioned, instead of measuring hedonic and achievement goals separately on different scales, GPQ measures the relative importance of achievement over hedonic goals, avoiding problems of comparing two different separate goal scales post hoc. Second, and 
more importantly, instead of measuring actual behavior, GPQ measures the importance or preference of achievement versus hedonic goals and in this way better conceptualizes the goal concept. As mentioned before, goals can best be conceptualized as closely related to values and are differentiated from actual behavior. When studying the influence of goals on behavior, measuring behavior when assessing goal preferences holds the risk of confounding goals with their behavioral outcomes.

While accumulating evidence is found for the Mood-as-Input-hypothesis using explicit goal instructions (Meeten \& Davey, 2011), the present findings do not provide evidence for the Mood-as-Input-hypothesis when goals are non-explicitly induced. In trying to understand the absence of Mood-as-Input effects in the study using primed and habitual goals in healthy participants (Study II), a number of factors could be considered. First, not all published studies found effects that are in line with Mood-as-Input hypothesis. For instance, Turner \& Wilson (2010) failed to demonstrate Mood-as-Input effects in the domain of worrying, in young adolescents. In this study mood was manipulated and hedonic or achievement goal instructions were given. Results showed no impact of mood and /or goal (stop-rule) instructions on perseveration of worry as measured with a catastrophizing interview. Furthermore, in two studies using implicit instead of explicit goals, in the domain of workaholism, no interaction effects between mood and naturally adopted goals were found (Wijhe 2011a; 2011b). Second, the question remains whether the primed hedonic and achievement goals were activated strongly enough to influence behaviour. Results of the study III suggests that the primed achievement and hedonic goals were not made more accessible as measured with a lexical decision task, which might indicate that the goals were not activated strongly enough to influence task persistence. However, these results should be interpreted cautiously because other factors could play a role in the failure to find heightened accessibility of the primed goals. In our study, in contrast to other goal priming studies (Bargh, 2001; Custers et al., 2009; Engeser, 2009; Eitam, 2008; Hart \& Albarracin, 2009; Laran, 2008; Oikawa et al, 2004; Stajkovic et al., 2006), word stimuli were matched on word length, word frequency and controlled for orthographic overlap. Therefore, it cannot be completely ruled out that priming effects that were found in previous studies were not due to differences in goal content but could be explained by lexical differences instead. A third factor that seems relevant when using goal priming is the presence of a goal relevant context. In the studies II and III the goal context was not manipulated, and hence relatively neutral. The absence of a context in which the (achievement or hedonic) goals could be considered as relevant could explain why goals were not made more accessible and did not influence behavior respectively. In both studies II and III, the features of the task do not particularly trigger participants to apply the achievement or hedonic goals to the task. For example, in study III, the lexical decision task was used which is not a task that leads to the fulfilment of hedonic or achievement goals. Similarly, the impression formation task that was used in 
study II was not framed as a hedonic or achievement oriented task, and mood but not goal context was manipulated. In the absence of a relevant goal context manipulation, the tasks might have been perceived as irrelevant for achievement or hedonic goal pursuit and goals might not have been activated. For example, a study of Laran et al. (2008) provides evidence that goal priming effects are context dependent, showing that goal primes encourage primeconsistent behavior when the behavioral context is well-known and prime-inconsistent behavior when the behavioral context is unknown or irrelevant. Supraliminal hedonic goal priming influenced restaurant choice and accessibility in a lexical decision task, but only in a common context (making a restaurant reservation for tonight), and not in an uncommon context (making a restaurant reservation for a month from now).

Another issue to consider is that other achievement goal priming studies, instead of studying the influence of priming on task duration, investigated the influence of priming on task performance within a given time frame. For example, performance tasks that were used are the number of words that are found in a word search puzzle, a free recall task, or a word listing task within a given time period (Bargh, Gollwitzer, Barndollar, \& Trotschel, 2001; Chartrand \& Bargh, 1996; Eitam, Hassin, \& Schul, 2008; Engeser, 2009; Hart \& Albarracin, 2009; Maio, Pakizeh, Cheung, \& Rees, 2009; Oikawa, 2004; Shantz \& Latham, 2009; Stajkovic, Locke, \& Blair, 2006). In contrast to our studies, the dependent variable that is used in the achievement goal priming literature is not task persistence measured as task duration in an open-ended task, but task performance within a given time period. It is possible that achievement priming does not so much influence task duration, but that it rather influences the effort that is spend. Alternatively, achievement goal priming may have an effect on both task duration and effort, resulting in an effort/duration trade-off. From a Mood-as-Input perspective this would mean that current mood would provide information about goal progress, influencing both task effort and task duration. As a consequence, when only task duration and not task effort is measured, possible Mood-as-Input effects might be overlooked.

Recently, some general concerns have been expressed about the replicability of priming experiments, and doubts have been raised on the robustness of priming effects (Kahneman, 2012). An important issue is the publication bias. Within the overview of the Mood-as-Input literature the ratio of positive to negative findings is 29 to 4 (for an overview see Table 1, chapter 1). It is striking that within the sciences, the tendency to publish only positive results is greatest in the domain of psychology and psychiatry (Fanelli, 2010). In this way, the published literature could provide an incomplete picture of the total body of the research that has been conducted, biasing the results and increasing the chance on publications of studies suffering from type 1 error. However, recognition for the problem is rapidly growing, and the need for replication studies is recognized. In the domain of achievement priming, recently a few studies have been published that failed to replicate 
the achievement goal priming results (Doyen, Klein, Pichon, \& Cleeremans, 2012; Engeser, 2009; Harris, Coburn, Rohrer, \& Pashler, 2013; Shanks, et al., 2013), suggesting that goal priming evidence might not be that robust as initially thought. Harris et al. (2013) failed to replicate results in two direct replications of Bargh et al. (2001), in which participants were primed with achievement related or neutral words, and performance on a word search puzzle task was measured. Recently, another achievement priming study by Dijksterhuis and van Knippenberg (1998) in which priming the stereotype of professors increased performance in a general knowledge test (Trivial Pursuit Game), whereas priming the stereotype of soccer hooligans reduced performance in the knowledge test, could not be replicated (Eder, Leipert, Musch, \& Klauer, 2012; Shanks, et al., 2013).

Priming effects are often subtle, and could be undermined by small experimental changes. It is important to carefully think about and to systematically investigate which factors influence the presence or absence of priming effects. Forster, Liberman, and Friedman, (2007), propose some principles that are important in goal priming and could help to make a distinction between goal priming effects and priming effects that do not involve goals. Goal priming a) is sensitive to the value of the prime, b) involves gradients as a function of distance to the goal, c) is proportional to the product of the expectancy and value, d) results in post- attainment decrements in motivation, e) involves inhibition of conflicting goals. How can we apply these principles to the priming of hedonic and achievement goals in a Mood-asInput context?

In a typical Mood-as-Input study, an open-ended task is used and the criteria of reaching the goals of the task are deliberately left ambiguous and unclear. These circumstances are thought to increase the likelihood that mood is used as information to disambiguate the situation. As the hedonic and achievement goals are very general processing goals and criteria to reach the goals are vague, the strength of motivation to pursue these goals and expectancy to reach them may be low, making it more difficult to prime these goals in a Mood-asInput context. Furthermore, it might be problematic to activate goals in combination with negative mood. Aarts and colleagues (2007) demonstrated that the accessibility of a goal as measured with a lexical decision task diminishes when that goal was co-activated with negative affect. Results of the study III revealed that participants experienced significantly lower mood scores after the second lexical decision task as compared to the baseline task. Although we did not consequently co-activate the priming stimuli with negative mood, it is possible that the negative mood at the end of the second lexical decision task is a sign of diminished activation of the goals. Another issue of importance is the time frame in which the goal activation is measured. Measurement should preferably occur after the goal has been activated within a relevant goal context, but before goal fulfilment, due to post-attainments decreases in motivation. As already mentioned above, it is possible that in study III, goals were not activated because of a lack of a goal relevant context. Furthermore it might be 
more difficult to measure goal activation in a Mood-as-Input context because there are no predetermined, and specific criteria for goal fulfillment. Another factor is the exposure to competing goals. Shah (2005) showed that priming an additional goal that is unrelated to the focal, primed goal, has a detrimental effect on goal activation and commitment because it pulls resources away from the focal, primed goal. In the baseline lexical decision task of study III, participants were presented with both achievement and hedonic goal words. More specifically, individuals in the achievement priming condition were also explicitly exposed to hedonic goal words, before the priming procedure, during the baseline lexical decision task. This may have neutralized the priming effect of the achievement goal they were subsequently primed with.

To summarize, the majority of evidence for Mood-as-Input interaction effects comes from studies that tested the Mood-as-Input model using explicit goal instructions outside the pain field. The present data do not allow any firm conclusions about the validity of Moodas-Input model using primed and habitual goals instead of explicit goals. It is not a simple matter of 'either the model does not apply to primed goals or the goals are not induced strongly enough'; there may be other variables to consider: the difference between primed goals and measured goal preferences, the presence or absence of a goal context, the dependent measure that is used (task duration and/or task effort), the possible interaction between mood manipulation and goal manipulation, the role of an ambiguous, open-ended goal context and its influence on goal activation, the role of conflicting goals, and the difficulties to measure goal activation in a context where goal fulfillment is unclear.

\section{Applying the Mood-as-Input model in the domain of pain}

In their review Meeten \& Davey, (2011) argue that the Mood-as-Input model can serve as a transdiagnostic framework that could be applied to several clinical domains in which repetitive behavior is problematic such as obsessive-compulsive disorder, generalized anxiety disorder, and depression. Despite the accumulating evidence for the Mood-as-Input model across different domains, their overview of the literature seems to paint a rosier picture than might be justified. First, the authors did not include the few published studies that failed to find Mood-as-Input effects (Turner \& Wilson, 2010; Van Wijhe, et al., 2011a; Van Wijhe, et al., 2011b). Second, the few recently published studies carried out in the in the domain of pain in which no mood-goal interaction effects were found, (Ceulemans, Karsdorp, \& Vlaeyen, 2013b; Karsdorp, Ranson, Nijst, \& Vlaeyen, 2012), combined with the studies described in this dissertation, suggest that Mood-as-Input effects might not be as robust as initially thought. In the domain of pain, the evidence for the applicability of the Moodas-Input model is still scarce. Only a handful of studies have been published. Overall, no Mood-as-Input effects but only main effects of goals and mood have been found. In two 
studies, Karsdorp and colleagues (Karsdorp, Nijst, Goossens, \& Vlaeyen, 2010; Karsdorp, et al., 2012) tested the applicability of the Mood-as-Input model to painful task persistence using explicit goal instructions in a sample of patients with upper extremity pain and in sample of healthy participants, respectively. Both studies did not yield any Mood-as-Input effects; instead independent main effects of mood and goals were found with participants in a positive mood displaying greater task persistence than participants in a negative mood; and participants who received achievement goal instructions displaying longer task persistence than participants receiving hedonic goal instructions. In another study, Ceulemans and colleagues, (2013b) failed to replicate the study of Martin et al. (1993) with a painful task. Again, no Mood-as-Input effects were found and greater task persistence was related with hedonic goals as compared to achievement goals. In another study using healthy volunteers, the combined influence of sense of responsibility and mood on painful task persistence, was tested (Ceulemans, et al., 2013a). It was hypothesized that mood is differentially interpreted depending on the responsibility context. In a context of high responsibility, negative mood is suggested to inform people that they have not yet fully addressed their responsibility concerns, leading to task continuance; whereas positive mood informs them they have done enough, leading to task disengagement. In a low responsibility context the opposite pattern of results was expected. Results showed no interaction effect but a main effect of responsibility. A higher sense of responsibility was related to greater painful task persistence. These results are in line with results from study $\mathrm{V}$, also yielding a main effect of habitual goal preferences. Pain patients reporting stronger habitual goal preferences for pain-avoidance goals over achievement goals displayed greater task persistence than those who showed the opposite pattern of goal preferences.

Remarkably, study IV, investigating the role of pain catastrophizing and mood on painful task persistence in a healthy population, is to the best of our knowledge the only pain study without the use of explicit goals, in which results were found that are somewhat in line with Mood-as-Input hypotheses. In this study, current (induced) mood moderated the relationship between pain catastrophizing and task persistence but only in a high painthreatening and not in a low threat context.

An important question to consider is why Mood-as-Input effects were not found in patient study V and the other pain studies described above (Ceulemans et al, 2013a,2013b; Karsdorp, et al., 2010; Karsdorp, et al., 2012), while such effects were found in study IV investigating the role of pain catastrophizing and mood on painful task persistence in a healthy population. Given the differences between the studies (see Table 2), there might be several explanations. First, study V included patients with chronic back pain complaints, while study IV was an analogue study with healthy participants. Also, in the only other Moodas-Input study using pain patients (with upper extremity pain), no Mood-as-Input interaction effects were found (Karsdorp et al. 2009). It is possible that chronic pain patients who 
have a history of pain have learnt that physical performance is often associated with mood changes (Connelly, Keefe et al. 2007), and for this reason do not consider mood as relevant information for deciding whether to stop or to continue with an activity. Moreover, research has shown that affect is used as information unless it is attributed to an obvious source (Scott \& Cervone, 2002; Shwartz \& Clore, 1983). This effect is referred to as the discounting effect. In future studies, the question should be addressed whether it is an inherent feature of chronic pain patients that they attribute their mood fluctuations to physical performance or pain, and therefore consider mood as irrelevant. This could be investigated, for example, in a study directly comparing Mood-as-Input effects in chronic pain patients, acute pain patients and healthy participants, while particularly assessing their mood attributions. Second, the pain catastrophizing goal that was used in the study IV is a more specific, pain-relevant goal than the more general goal preferences for pain-avoidance over achievement goals targeted in study V. More importantly, in contrast to study V, the goal context was also manipulated, with a high pain-threatening context as a context that is particularly relevant for the pain- avoidance goal to become active and a low threat context as a context which is not that relevant for a pain-avoidance goal to become active. Results showed Mood-as-Input effects only in the high threat context and not in the reassuring context, indicating that a goal relevant context might be particularly important in yielding Mood-as-Input effects. The possible importance of a relevant goal context for Mood-as-Input effects to arise is further supported by another negative study failing to manipulate goal context (Ceulemans et al., 2012). It might be that if a goal is not seen as relevant within the context, this might negatively affect the likelihood that mood is used as information to determine goal progress. However further research is needed to explicitly test this assertion within different goal contexts. 


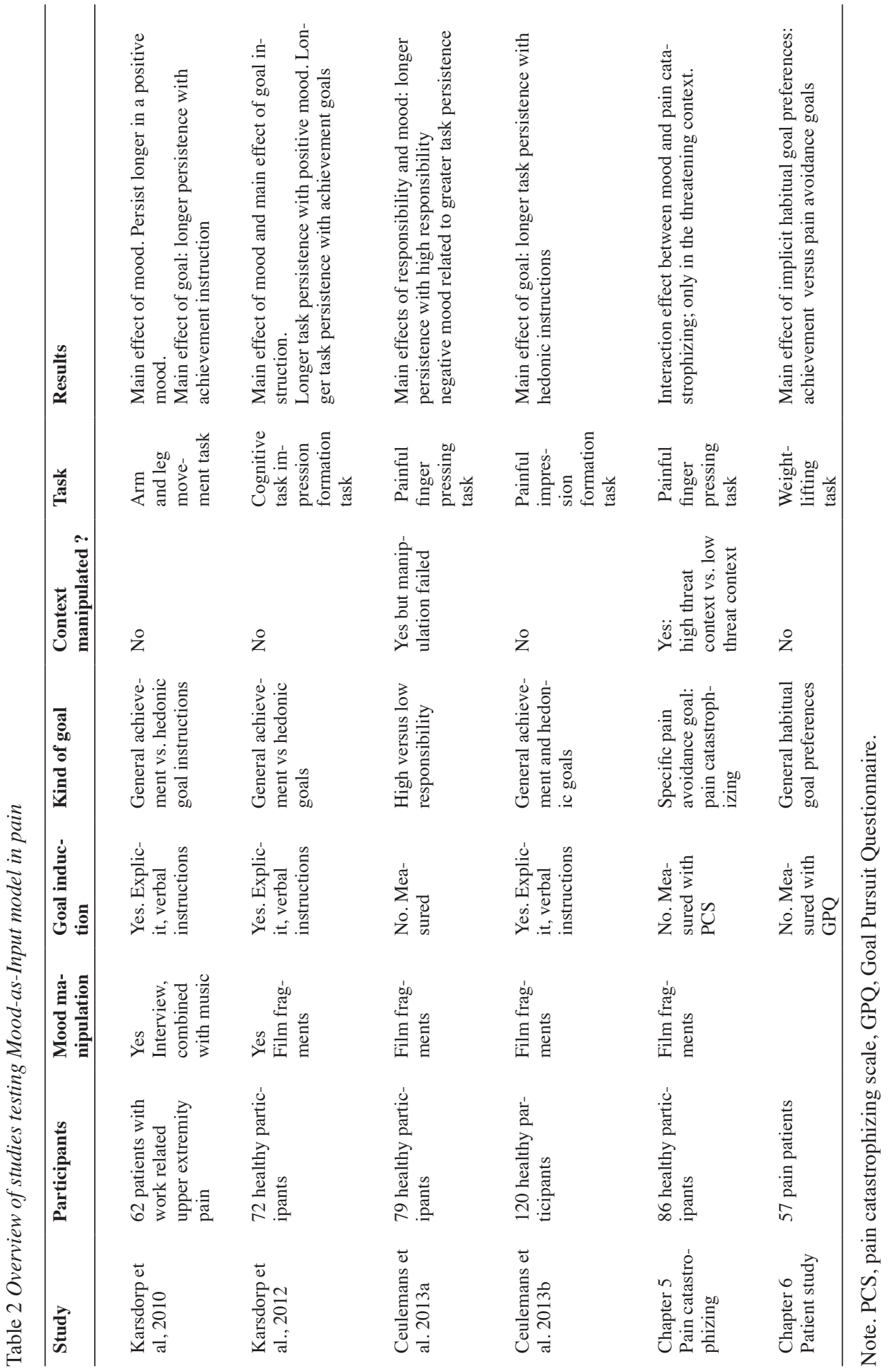


Apart from the presence of a specific and relevant goal context, several other factors seem to influence the presence or absence of Mood-as-Input effects (Meeten and Davey, 2011). A detailed analysis of these factors and how they apply to pain can help to direct future studies and to give insight in the particular circumstances in which Mood-as-Input effects can be expected, also in the domain of pain. In the following paragraph, these factors are discussed and their relevance for studying Mood-as-Input effects in the domain of pain is addressed.

A first factor that could play a role is cognitive load. High cognitive load has shown to increase the likelihood that mood is used as information (Shwartz et al. 1987, Seimer en Reisenzein, 1998, van den Hout et al. 2007). For example, a study of Van den Hout et al. (2007) showed that the strength of Mood-as-Input effects diminishes when the degree of complexity of the task was decreased. Besides the complexity of the task, also certain information processing strategies can inflict a high cognitive load. For instance anxious, depressed and obsessive-compulsive patients have shown to adopt particularly complex information processing strategies, which make it more likely that they use current mood as information (Meeten \& Davey, 2011). In pain, high pain catastrophizing may be especially relevant in this respect because it has been shown to be related to hypervigilance, an information processing strategy that inflicts a high cognitive load and that emerges when the threat value of pain is high and the fear system is activated (Crombez, Van Damme, Eccleston, 2005). However, results from study IV do not support the idea that high levels of pain catastrophizing improve the likelihood that mood is used as information. On the contrary, the results showed that mood and threat context influenced performance duration particularly in relatively low catastrophizing individuals, within a threatening context. Individuals with low levels of pain catastrophizing in a high threat context showed greater performance duration when in a negative than a positive mood. However, Mood-as-Input effects in relatively high catastrophizing group, within a high threatening context, were not found. Although speculative, a possible explanation for these findings may be that low and high catastrophizing individuals process threatening information differently, influencing their goal activation. Within a threat context it might be that low catastrophizing individuals draw their attention away from pain-avoidance goals and focus on opposing achievement goals, whereas the high catastrophizing individuals focus on pain-avoidance goals in response to the threat. As a result, mood may inform low catastrophizing individuals about their performance and high pain catastrophizing individuals about the possible threat of the task. As to the role of cognitive load, it could be that Mood-as-Input effects in the domain of pain are more difficult to find when using simple physical tasks. The influence of information processing strategies such as the degree of pain catastrophizing seems to be more complex than simply the degree of cognitive load. The difference between information processing strategies in high and low catastrophizers, their influence on goal activation, and the use of mood as information should be addressed more systematically in future research with pain patients. 
Furthermore, it has been suggested that Mood-as-Input effects are more commonly observed when there is little or no subjective evidence other than mood, such as task instructions or other relevant information, on which to base judgements concerning continuing or stopping with the task (Meeten \& Davey, 2011). It is possible, that in the domain of pain, patients to some degree use pain as information in deciding when to stop with the task, which would diminish the likelihood that mood is used as information in this particular patient group. As demonstrated in the patient study $\mathrm{V}$, the majority of the participants $(67.6 \%)$ explicitly reported using pain increase as a reason for stopping with the task.

Furthermore it has been suggested that when the task is well-known, or the criteria for reaching the goals of the task are very clear, it is less likely to rely on informational properties of the task. Meeten \& Davey (2011) argue that high worriers possess poorer problem solving confidence than non-worriers, making it less clear when the goals of the task are reached, and in turn making it more likely to find Mood-as-Input effects in this patient group. In comparison, it could be less likely to find Mood-as-Input effects in pain patients, due to the above described pain-as-information, overriding principle.

The main conclusions concerning the factors that might affect the presence or absence of Mood-as-Input effects in the domain of pain can be summarized as follows:

1. In order to increase the likelihood that mood is used as information, it may be necessary to, apart from inducing a goal, also to induce a goal relevant context. Within a pain threatening context, pain catastrophizing might be a particularly relevant pain-avoidance goal compared to a general hedonic or achievement goal.

2. Similarly, current mood needs to be perceived as a relevant source of information. Chronic pain patients have learned that mood fluctuations are naturally related to pain or physical activity and therefore do not perceive mood as a source of relevant information about goal progress. It is not likely that mood is used as information in the domain of pain.

3. Increased cognitive load has shown to increase the likelihood that mood is used as information. Within the domain of pain, more complex physical activities inducing a greater cognitive load than a simple weight lifting task might increase the likelihood that context factors such as mood are used as information.

4. Within the domain of pain, the degree that patients use pain as information could influence the likelihood that mood is used as information. It could be interesting to investigate under which circumstances the 'pain-as-information' rule would be overridden by other context effects. 


\section{Discussing the results in light of models explaining task persistence}

Besides our main finding that the present results do not support the Mood-as-Input model, questions can be raised as to whether the Mood-as-Input model is in fact an extension of the Fear-Avoidance model. As Vlaeyen \& Morley (2004) suggested in their review, at first sight it seems very plausible and promising to apply the Mood-as-Input model to the domain of pain. They present the model as a promising alternative for the prevailing Fear-Avoidance model because, as they state, it incorporates the predictions of the Fear-Avoidance model but also extends its scope to pain experiences associated with persistence behaviour. As they argue, the Mood-as-Input model can both account for avoidance behavior as well as persistence behavior in the presences of pain. However, a closer look might reveal some (conceptual) problems. First, although the Mood-as-Input is a model that tries to explain task persistence defined as task duration, it strictly spoken does not say anything about avoidance behavior. Decreased levels of activity do not necessarily reflect avoidance behavior due to fear. According to Dannecker \& George (2009), escape and avoidance behavior can be operationalzed as task duration only when pain is the reason to stop with the task (using a pain-stop rule). In this respect, pain tolerance tasks can be considered a measure of escaping the onset of pain or avoidance of pain exacerbations. In a study comparing possible laboratory measures of escape and avoidance in healthy participants, Dannecker \& George (2009) compared task duration while using a pain tolerance instruction with task duration without using a 'stop rule' (participants could decide for themselves when to stop with the task). Results showed that task duration with a pain tolerance stop rule was a valid measure of escape from pain or avoidance of pain exacerbation and was predicted by pain catastrophizing. However, task duration with the unrestricted stop rule was not related to self-reported escape/avoidance measures and was not predicted by fear, anxiety, or catastrophizing. As in the present dissertation, we measured task duration using an unrestricted stop rule instruction; the question could be raised whether we in fact measured escape or avoidance behavior. In study V, patients reported pain as the main reason for stopping with the task, which might indicate that pain was used as a stop rule and hence avoidance was in fact measured. However, explicitly reported reasons for stopping with the task were not associated with habitual preferences for achievement versus painavoidance goals, leaving the question whether avoidance behaviour was measured or not, unresolved. Overall, it might be too premature to say that the Mood-as-Input incorporates the predictions of the Fear-Avoidance model, and the question remains whether the informational properties of mood and goals could influence decisions to avoid activities. In order to test this, a different outcome measure than task duration using an unrestricted stop rule, is needed.

Second, the key idea behind applying the Mood-as-Input to pain is that not only avoidance behavior per se, but also persistence behavior per se, is related to disability. 
Unfortunately, the results of study I do not provide evidence for this basic assumption. As results from study I suggest that fluctuations between different activity patterns are associated with more disability, it would be more interesting for future research to target the switching between activity levels instead of task persistence per se.

Results from study $\mathrm{V}$ show that in pain patients, preferences for pain-avoidance goals relative to achievement goals are associated with shorter task persistence than opposite goal preferences. Interestingly, although the task was painful, task persistence was not correlated with pain catastrophizing or pain related fear. In this way, results only partly support the Fear-Avoidance model. The present results make clear that pain-avoidance goals are not necessarily related to fear-avoidance beliefs, but nevertheless can be associated with task persistence in pain patients. As in the present study voluntary task performance instead of pain tolerance was measured, the results shed light to a different and particularly relevant category of activity than those usually studied in fear-avoidance studies. After all, in daily activities, pain patients not always perform activities until levels of pain tolerance but they may use certain rules other than pain increases for deciding when to end daily activities.

Overall, results of the present dissertation demonstrate that habitual goal preferences are associated with task persistence. Pain-free individuals with stronger habitual achievement goals than hedonic goals showed greater task persistence on a non painful task. Similarly, pain patients with stronger achievement goals than pain avoidance goals showed greater task persistence in a painful physical task. As only main effects of goals were found and mood effects on task persistence were absent, the present findings can be framed within goal setting theories, which do not refer to mood, but state that pursuing difficult goals as compared to easy goals prolong effort and positively affects task persistence (Locke \& Latham, 1990).

\section{Clinical Implications}

Given the scope of this thesis and the relative lack of supportive evidence for the Moodas-Input model, it is not possible to derive any direct clinical implications from the present results. Nevertheless it is interesting to speculate about future directions for clinical practice. First of all, the results from study I, as well as those from previous studies (McCracken \& Samuel, 2007; Huijnen, Verbunt, Roelofs, Goossens, \& Peters, 2009), indicate that treatment programs targeting activity-related dysfunction should not look solely at single behavioral strategies (e.g. avoidance, pacing or persistence) but should consider the full pattern of activity related strategies. As not only avoidance per se but also switching between these behavioral patterns seems to represent a particularly problematic clinical group, assessing these patterns might contribute to the development of a customized treatment. Also, more information is needed about the mechanisms behind the switching behavior as well as a more fine-grained analysis as to when switching between activity patterns is adaptive and 
when it is not. Speculating on this matter, it might be that switching between activity patterns based on indecision and incompetence to resolve goal conflicts is particularly maladaptive. In this case learning to resolve goal conflicts in a flexible way would be a possible treatment approach (e.g. Van Den Hout, Vlaeyen, Heuts, Zijlema, \& Wijnen, 2003).

As the present results stress the importance of goal preferences in influencing activity levels, clinical interventions might focus on the adoption of a flexible goal pursuit style in which goals are accommodated to the characteristics of the situation. When a preference of pain-avoidance goals in combination with dysfunctional decreased activity levels dominates, patients could be encouraged to adopt achievement goals instead, and to persist with these goals despite the pain. This could be done within an 'exposure in vivo' framework (Barlow, 2002; De Jong et al., 2005; Vlaeyen, Morley, Linton, Boersma, \& De Jong, 2012). If patients on the other hand show maladaptive persistence behavior, the strategy could be to encourage them to prevent persistence behavior when exposed to situations or contexts that elicit an achievement goal. Furthermore, the efficacy of activity exposure might be further optimized by embedding it in a broader motivational approach. In this respect Relational Framing Theory (RFT) and Acceptance and Commitment Therapy (ACT) can be relevant (Barnes Holmes, Barnes Holmes, McHugh, \& Hayes, 2004; Hayes \& Duckworth, 2006). RFT focuses on rule governed behavior. Rules are often adaptive, but can also lead to maladaptive responses. For example, people can persevere in following socially imposed rules that are no longer effective. Relational framing can lead to cognitive fusion, a process in which ones thoughts and rules are fused with reality. For example, a pain patient can be fused with an enough stop rule 'I always have to do my best', which in the long run could lead to overuse, more disability, and more pain. Those maladaptive influences can be subjugated by ACT interventions (McCracken, Mackichan, \& Eccleston, 2007). One intervention within ACT is learning how to see ones thoughts for what they really are, just thoughts; a process called 'cognitive diffusion'. This process teaches the client to adopt a different perspective on their thoughts, changing its context and its influence on behavior. Having more insight into one's rules and values can lead to more psychological flexibility and on its turn to more adaptive responses.

\section{Limitations}

The present body of research has a number of limitations that should be considered. First, as mentioned above, it is not clear whether the priming manipulation that was used in studies II and III was sufficient to implicitly induce achievement or hedonic goals. In general, results of this thesis showed that task persistence is related to habitual goal preferences, with greater task persistence being associated with the adoption of achievement goals in favour of hedonic goals, both in healthy participants as well as in pain patients. However, as habitual goal preferences were not experimentally manipulated (Studies II and IV), no causal inferences 
can be made concerning the direction of the relationship between preferences for achievement over hedonic goals and the degree of task persistence. This lack of causal direction also holds for the relationship between the combinations of activity patterns and disability in study I. Second, another limitation of this study is the reliance on self-report measures only, targeting subjective reports about behavioral strategies rather their more objective observations. Additionally, in retrospect, the Patients Activity Relations Questionnaire might not be an ideal measure to assess activity patterns due to its broad general nature and lack of situation specificity. As the role of contextual factors in the adaptiveness of behavioral strategies is deemed important, future research may benefit from the development of more situationspecific measures. Furthermore, as the Patients Activity Relations Questionnaire does not explicitly measure switching between behavior patterns, no strong claims can be made about the cycling cluster representing an oscillation between activity patterns.

Third, some studies might be underpowered. Because of lack of power, only a minimum of predictors could be included in the regression model in study V. Hence, a number of variables that might influence lift duration (e.g. BMI) were not controlled for, and therefore results should be interpreted with caution. Furthermore, zero-order correlations between the pain-avoidance subscale of the GPQ and the outcome measure were only marginally significant while it was a significant predictor in the regression model. This might indicate that one of the variables in the regression model might act as a suppression variable, enhancing the relationship between goal pursuit and task persistence.

\section{Conclusions}

In the introduction, the following research questions were formulated:

1. What is the relationship between the different activity-related behavioural strategies (avoidance, persistence and pacing) and levels of functioning? Are there particular combinations of behavioural strategies that are more dysfunctional than others?

2. Can achievement and hedonic goals be primed by means of supraliminal or subliminal priming?

3. Do the predictions based on the Mood-as-Input model hold when primed goals or habitual goals are used instead of explicit goal instructions?

4. Do the predictions based on the Mood-as-Input model hold within a high and low pain threatening context?

5. Do the predictions based on the Mood-as-Input model hold in patients with chronic back pain, when habitual goal preferences are used instead of explicit goal instructions?

With respect to research question 1 , findings demonstrated that the relation between persistence and disability depended on its combination with other activity levels. When combined with 
low levels of pacing and avoidance behavior, elevated levels of persistence behavior were associated with more favorable outcomes. However, when combined with high levels of both pacing and avoidance, increased levels of persistence were associated with the least favorable outcomes. With respect to research questions 3 and 5, the data presented in this dissertation do not provide evidence for the validity of the Mood-as-Input when habitual goals are used in healthy participants or in patients with chronic back pain. Concerning research question 2, the present results did not provide evidence that achievement and hedonic goals were activated by means of supraliminal or subliminal priming. Hence, the question remains whether predictions based on the Mood-as-Input model hold when primed goals are used instead of explicit goal instructions. As to research question 4, a Mood-as-Input interaction effect was found in a study that successfully manipulated goal context. Mood-as-Input effects were only found in the threat context, a context matching the specific pain-avoidance goal.

Overall, a number of factors seem to affect the presence or absence of Mood-asInput interaction effects, and a careful analysis of these factors and their applicability to the domain of pain is necessary to ensure future success in investigating the Mood-as-Input in the context of pain. Although the Mood-as-Input model was not confirmed throughout this dissertation, goals were demonstrated to be important, both in non-painful and painful task persistence. Results of goal effects on task persistence concern naturally adopted goal preferences. Pain- free individuals with stronger habitual achievement goals than hedonic goals showed greater task persistence on a non-painful task. Similarly, pain patients with stronger achievement goals than pain-avoidance goals showed greater task persistence in a painful physical task.

Finally, the question can be raised whether the absence of clear evidence that persistence behavior per se is associated with disability does make a theoretical model that is able to explain both increased and decreased activity levels unnecessary. First, a recent meta-analysis of activity patterns suggests that there might be different types of persistence behavior, and that some kinds are associated with more disability (Andrews, Strong, \& Meredith, 2012). Second, as escape behavior and decreased levels of activity are demonstrated to be dysfunctional, the model can give information about the factors that play a role in trying to increase activity levels. As results from study I suggest that especially fluctuations between different activity patterns is associated with more disability, an interesting avenue for future research is to target switching behavior and the mechanisms behind that instead of task persistence per se. 


\section{References}

Andersen, J.H., Haahr, J.P., Frost, P. (2007). Risk for more severe regional musculoskeletal symptoms: a two-year prospective study of a general working population. Arthritis \& Rheumatism, 56, $1355-1364$.

Andrews, N. E., Strong, J., \& Meredith, P. J. (2012). Activity pacing, avoidance, endurance, and associations with patient functioning in chronic pain: a systematic review and meta-analysis. Archives of Physical Medicine and Rehabilitation, 93, 2109-2121.

Bargh, J. A. (1990). Auto-motives: Preconscious determinants of social interaction. In E. T. Higgins \& R. M. Sorrentino (Eds.), Handbook of motivation and cognition (Vol. 2, pp. 93- 130). New York: Guilford.

Bargh, J. A. (2006). What have we been priming all these years? On the development, mechanisms, and ecology of nonconscious social behavior. European Journal of Social Psychology, 36, 147-168.

Bargh, J. A., Gollwitzer, P. M., Barndollar, A. L., \& Trotschel, R. (2001). The automated will: Nonconsious Activation and Pursuit of Behavioral Goals. Journal of Personality and Social Psychology, 81, 1014-1027.

Barlow, D.H. Anxiety and Its Disorders: The Nature and Treatment of Anxiety and Panic. New York, NY: The Guilford Press; 2002.

Barnes Holmes, Y., Barnes Holmes, D., McHugh, L., \& Hayes, S.C. (2004). Relational frame theory: some implications for understanding and treating human psychopathology, International Journal of Psychology and Psychological Therapy, 4, 355-375.

Ceulemans, K., Karsdorp, P. A., \& Vlaeyen, J. W. (2013a). Effects of responsibility and mood on painful task persistence. Journal of Behaviour Therapy and Experimental Psychiatry, 44, 186-193.

Ceulemans, K., Karsdorp, P. A., \& Vlaeyen, J. W. (2013b). Mood, stop-rules and task persistence: No Mood-as-Input effects in the context of pain. Journal of Behaviour Therapy and Experimental Psychiatry, 44, 463-468.

Chartrand, T. L., \& Bargh, J.A. (1996). Automatic activation of impression formation and memorization of goals: nonconscious goal priming reproduces effects of explicit task instructions. Journal of Personality and Social Psychology, 71, 464-478.

Cipher, D. J., \& Fernandez, E. (1997). Expectancy variables predicting tolerance and avoidance of pain in chronic pain patients. Behaviour Research and Therapy, 35, 437-444.

Davey, G. C., Startup, H. M., MacDonald, B. A., Jenkins, D., \& Patterson, K. (2005). The use of 'as many as can' versus 'feel like continuing' stop rules during worrying. Cognitive Therapy and Research, 29, 155-169.

Davey, G. C., Startup, H. M., Zara, A., MacDonald, C. B., \& Field, A. P. (2003). The perseveration of checking thoughts and mood-as-input hypothesis. Journal of Behavior Therapy and Experimental Psychiatry, 34, 141-160.

de Jong, J.R., Vlaeyen, J.W., Onghena, P., Cuypers, C., den Hollander,M., \& Ruijgrok, J. (2005). Reduction of pain-related fear in complex regional pain syndrome type I: the application of graded exposure in vivo. Pain, 116, 264-75. 
Dijksterhuis, A., \& van Knippenberg, A. (1998). The relation between perception and behavior, or how to win a game of trivial pursuit. Journal of Personality and Social Psychology, 74, 865-877.

Doyen, S., Klein, O., Pichon, C. L., \& Cleeremans, A. (2012). Behavioral priming: it's all in the mind, but whose mind? PLoS One, 7(1), e29081.

Eder, A., Leipert, C., Musch, J., \& Klauer, K.-C. (2012). Failed replication to prime intelligent behavior. Available: http://www.PsychFileDrawer.org/replication.php?attempt=MTI0 ， Retrieved October 07, 2012

Eitam, B., Hassin, R. R., \& Schul, Y. (2008). Nonconscious goal pursuit in novel environments: the case of implicit learning. Psychological Science, 19(3), 261-267.

Engeser, S. (2009). Nonconscious Activation of Achievement Goals: Moderated by Word Class and the Explicit Achievement Motive? Swiss Journal of Psychology, 68, 193-200.

Fanelli, D. (2010). "Positive" results increase down the Hierarchy of the Sciences. PLoS One, 5(4), e10068.

Forster, J., Liberman, N., \& Friedman, R. S. (2007). Seven principles of goal activation: a systematic approach to distinguishing goal priming from priming of non-goal constructs. Personality and Social Psychology Review, 11, 211-233.

Garcia-Campayo, J., Pascual, A., Alda, M., \& Ramirez, M. T. (2007). Coping with fibromialgia: usefulness of the chronic pain coping inventory-42. Pain, 132, 68-76.

Harris, C. R., Coburn, N., Rohrer, D., \& Pashler, H. (2013). Two failures to replicate high-performancegoal priming effects. PLoS One, 8(8), e72467.

Hart, W., \& Albarracin, D. (2009). The effects of chronic achievement motivation and achievement primes on the activation of achievement and fun goals. Journal of Personality and Social Psychology, 97, 1129-1141.

Hasenbring, M.I., Hallner, D., Klasen, B, Streitlein-Böhme, I., Willburger, R., \& Rusche, H. (2012). Pain-related avoidance versus endurance in primary care patients with subacute back pain: psychological characteristics and outcome at a 6-month follow-up. Pain, 153, 211-217.

Hawksley, J., \& Davey, G. C. (2010). Mood-as-input and depressive rumination. Behaviour Research and Therapy, 48, 134-140.

Hayes, S.C., \& Duckworth, M.P., (2006). Acceptance and commitment therapy and traditional cognitive behavior therapy approaches to pain. Cognitive and Behavioral Practice, 13, 185-187.

Huijnen, I. P., Verbunt, J. A., Roelofs, J., Goossens, M., \& Peters, M. (2009). The disabling role of fluctuations in physical activity in patients with chronic low back pain. European Journal of Pain, 13, 1076-1079.

Kahneman, D. (2012). A proposal to deal with questions about priming effects. Nature.

Karsdorp, P. A., Nijst, S. E., Goossens, M. E., \& Vlaeyen, J. W. (2010). The role of current mood and stop rules on physical task performance: An experimental investigation in patients with workrelated upper extremity pain. European Journal of Pain, 14, 434-440.

Karsdorp, P.A., Ranson, S., Nijst, S. E., \& Vlaeyen, J. W. S. (2012). Goals, mood and performance duration on cognitive tasks during experimentally induced mechanical pressure pain. Journal of Behaviour Therapy and Experimental Psychiatry. 
Karsdorp, P.A., \& Vlaeyen, J. W. (2011). Goals matter: both achievement and pain-avoidance goals are associate with pain severity and disability in patients with musculoskeletal pain. Pain, 152, 1382-1390.

Kindermans, H.P., Roelofs, J., Goossens, M.E., Huijnen, I.P., Verbunt, J.A., Vlaeyen, J.W. (2011). Activity patterns in chronic pain: underlying dimensions and associations with disability and depressed mood. Journal of Pain, 12, 1049-1058.

Locke, E.A., \& Latham, G. P. (1990). A theory of goal setting \& task performance. Englewood Cliffs, NJ: Prentice Hall.

MacDonald, B., \& Davey, G.C.L. (2005a). Inflated responsibility and perseverative checking: the effect of negative mood. Journal of abnormal psychology, 114, 176-182.

MacDonald, B. A., \& Davey, G.C.L. (2005b). A mood-as-input account of perserverative checking: the relationship between stop rules, mood and confidence in having ceheckd succesfully. Behaviour Research and Therapy, 43, 69-91.

McCracken, L.M., Mackichan, F., \& Eccleston, C. (2007). Contextual cognitive-behavioral therapy for severely disabled chronic pain sufferers: Effectiveness and clinically significant change. European Journal of Pain, 11,314-322.

Maio, G. R., Pakizeh, A., Cheung, W. Y., \& Rees, K. J. (2009). Changing, priming, and acting on values: effects via motivational relations in a circular model. Journal of Personality and Social Psychology, 97, 699-715.

Martin, L., Ward, D. W., Achee, J. W., \& Wyer, R. S. (1993). Mood as input: people have to interpret the motivaitional implications of their Moods. Journal of Personality and Social Psychology, 64, 317-326.

Martin, L., Abend, T., Sedikides, C., \& Green, J. D. (1997). How Would I Feel If...? Mood as Input to a Role Fulfillment Evaluation Process. Journal of Personality and Social Psychology, 73, 242-253.

McCracken, L. M., \& Samuel, V. M. (2007). The role of avoidance, pacing and other activity patterns in chronic pain. Pain, 130, 119-125.

Meeten, F., \& Davey, G. C. (2011). Mood-as-input hypothesis and perseverative psychopathologies. Clinical Psychology Review, 31, 1259-1275.

Norem, J. K., \& Illingworth, K. S. (2003). Mood and performance among defensive pessimists and strategic optimists. Journal of Research in Personality, 38, 351-366

Oikawa,M. (2004). Moderation of automatic achievement goals by conscious monitoring. Psychological Reports, 95(3 Pt 1), 975-980.

Sanna, L. J., Turley, K. J., \& Mark, M. M. (1996). Expected evaluation, goals, and performance: Mood as input. . Personality and Social Psychology Bulletin, 22, 223-235.

Sanna, L. J., Meier, S., \& Wegner, E. A. (2001). Counterfactuals and motivation: mood as input to affective enjoyment and preparation. British Journal of Social Psychology, 40, 235-256.

Sanna, L. J., Parks, C. D., \& Chang, E. C. (2003). Mixed-motive conflict in social dilemmas: Mood as input to competitive and cooperative goals. . Group Dynamics: Theory, Research, and Practice, 71, 26-40. 
Schrooten, M.G. S., Wiech, K., \& Vlaeyen, J. W. S. (2013) When pain meets...Pain-related choice behaviour and pain perception in different goal conflict situations. Manuscript submitted for publication.

Shah, J. (2005). The automatic pursuit and management of goals. Curr Dir Psychol Sci, 14, 10-13.

Shanks, D. R., Newell, B. R., Lee, E. H., Balakrishnan, D., Ekelund, L., Cenac, Z., et al. (2013). Priming intelligent behavior: an elusive phenomenon. PLoS One, 8(4), e56515.

Shantz, A., \& Latham, G. P. (2009). An exploratory field experiment of the effect of subconscious and conscious goals on employee performance. Orgainzational behavior and human decision processes, 10, 9-17.

Stajkovic, A. D., Locke, E. A., \& Blair, E. S. (2006). A first examination of the relationships between primed subconscious goals, assigned conscious goals, and task performance. Journal of Applied Psychology, 91, 1172-1180.

Startup, H. M., \& Davey, G. C. (2001). Mood as input and catastrophic worrying. Journal of Abnormal Psychology, 110, 83-96.

Startup, H. M., \& Davey, G. C. (2003). Inflated responsibility and the use of stop rules for catastrophic worrying. Behaviour Research and Therapy, 41(4), 495-503.

Turner, L., \& Wilson, C. (2010). Worry, Mood and Stop Rules in Young Adolescents: Does the Moodas-Input Theory Apply? Journal of Experimental Psychopathology, 1, 34-51.

van den Hout, J. H., Vlaeyen, J. W., Houben, R. M., Soeters, A. P., \& Peters, M. L. (2001). The effects of failure feedback and pain-related fear on pain report, pain tolerance, and pain avoidance in chronic low back pain patients. Pain, 92, 247-257.

Van Den Hout, J.H., Vlaeyen, J.W., Heuts, P.H., Zijlema, J.H.,\& Wijnen, J.A. (2003). Secondary prevention of work-related disability in nonspecific low back pain: does problem-solving therapy help? A randomized clinical trial. Clinical Journal of Pain, 19, 87-96.

van den Hout, M., Kindt, M., Luigjes, J., \& Marck, C. (2007). Compulsive perseveration: empirical criticism on the mood-as-input model. Behaviour Research Therapy, 45, 1221-1230.

van Houdenhoven, B., Neerinckx, E., Onghena, P., Lysens, R., \& Vertommen, H. (2001). Premorbid "overactive" lifestyle in chronic fatigue syndrome and fibromyalgia. An etiological factor or proof of good citizenship? Journal of Psychosomatic Research, 51, 571-576.

van Houdenhove, B., Egle, U.T. (2004). Fibromyalgia: a stress disorder? Piecing the biopsychosocial puzzle together. Psychotherapy and Psychosomatics, 73, 267-75.

Van Wijhe, C. I., Peeters, M. C., \& Schaufeli, W. B. (2011a). To Stop or Not to Stop, That's the Question: About Persistence and Mood of Workaholics and Work Engaged Employees. International Journal of Behavioral Medicine. 18, 361-372.

Van Wijhe, C. I., Peeters, M. C., \& Schaufeli, W. B. (2011b). Understanding workaholism and work engagement: the role of mood and stop rules. Career Development International, 16, 254270 .

Vlaeyen, J. W. S., \& Linton, S. J. (2000). Fear-avoindance and its consequences in chronic muskoskeletal pain: a state of the art. Pain, 85, 317-332. 
Vlaeyen, J. W. S. \& Linton, S.J. (2012). Fear-avoidance model of chronic musculoskeletal pain: 12 years on. Pain, 153, 1144-1147.

Vlaeyen, J. W. S., \& Morley, S. (2004). Active despite pain: the putative role of stop - rules and current mood. Pain, 110, 512-516.

Vlaeyen, J.W., Morley, S., Linton, S., Boersma, K., \& De Jong, J. (2012). Pain-Related Fear: ExposureBased Treatment for Chronic Pain. Seattle: IASP Press.

Watkins, E., \& Mason,A. (2002). Mood as input and rumination. Personality and Individual Differences, $32,577-587$. 
Summary

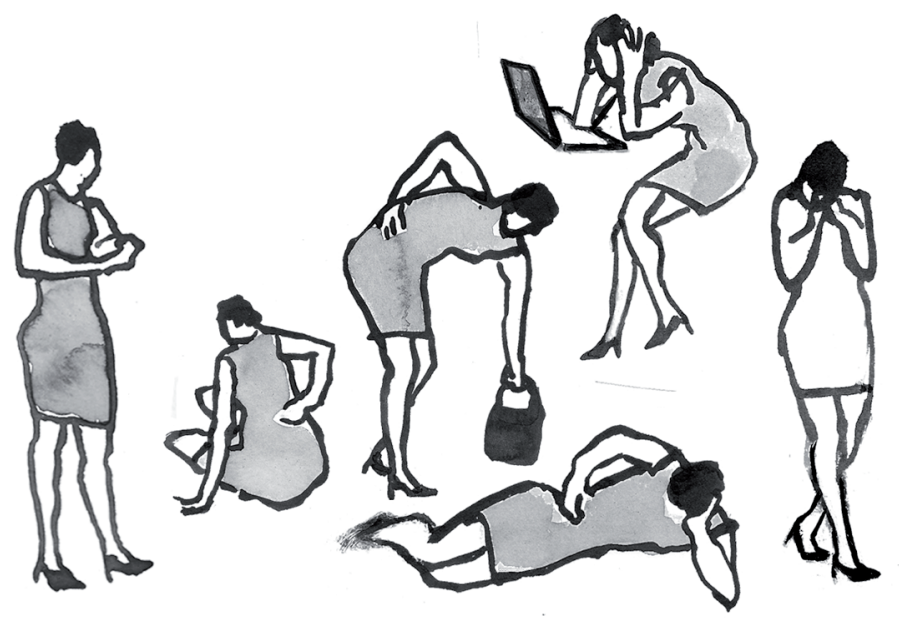


Chronic pain and its associated disability is a huge societal problem with a prevalence of $18 \%$ in the Netherlands (Breivik, Collett, Ventafridda, Cohen, \& Gallacher, 2006). In the past decade, the Fear-Avoidance model has been one of the prevailing models when it comes to explaining pain-related disability. Despite the accumulating evidence in favor of the model, it seems less applicable to pain syndromes where increased levels of activity (persistence behavior) rather than decreased levels of activity (avoidance behavior) play a prominent role. Recently, a novel model stemming from social psychology has been proposed as an alternative explanation that could explain both pain disability associated with increased and decreased levels of activity: the Mood-as-Input model (Martin, Ward, Achee, \& Wyer, 1993). The Mood-as-Input model states that the amount of time that is spent on an activity is predicted by a statistical interaction between mood and goals. Two goals are particularly important: achievement goals and hedonic goals. The key idea behind the Mood-as-Input model is that mood serves as information to interpret the progress one has made on the goals that one is pursuing. Positive mood in combination with a hedonic goal signals that the task is still enjoyable, leading to task continuance, while positive mood in combination with an achievement goal signals that a good performance has been delivered, leading to task termination. Negative mood in combination with hedonic or achievement goals is predicted to display the opposite pattern of results. So far, the Mood-as-Input model has mainly been tested using explicit goal instructions. In a typical experiment, participants perform an openended task while being either in a positive or a negative mood state and are explicitly instructed to either continue with the task until they delivered a good performance (achievement goal) or until they no longer enjoyed the task (hedonic goal). As in everyday life, people often do not follow explicit task instructions when performing activities it seems particularly relevant to test whether the predictions of the Mood-as-Input model also hold when primed goals and/ or habitual goals are used instead of explicit task instructions.

The main purpose of the present dissertation was to investigate whether the Moodas-Input model could serve as an explanatory framework for task persistence (measured as task duration) in the domain of pain, without using explicit goal instructions, using goal priming and habitual goal preferences instead. Habitual goal preferences are defined as preferences that people naturally adopt for one particular goal in favour of another conflicting goal (Karsdorp \& Vlaeyen, 2011).

As the Mood-as-Input model tries to explain pain disability associated with both increased and decreased levels of activity, Study I (chapter 2) explored whether activityrelated strategies, such as avoidance, pacing or persistence behavior, are associated with levels of disability, depression, and pain in patients with musculoskeletal pain. Instead of studying these activity-related strategies in isolation, subgroups of patients displaying different combinations of levels of avoidance, pacing and persistence, were investigated. Activity-related strategies were measured with the Pain and Activity Relations Questionnaire 
(McCracken \& Samuel, 2007) and subgroups were created by means of a cluster analysis. A sample of 299 participants completed questionnaires measuring disability (Pain Disability Index; Tait, Chibnall, \& Krause, 1990), depression (Hospital Anxiety and Depression Scale; Zigmond \& Snaith, 1983) pain (Multidimensional Pain Inventory; Lousberg, et al., 1999) and activity related strategies (Pain and Activity Relations Questionnaire; McCracken \& Samuel, 2007) on the internet. The Pain and Activity Relations Questionnaire was translated into Dutch and an exploratory principal factor analysis with oblique rotation was performed. Results showed that the Dutch version of the Pain and Activity Relations Questionnaire supported the original three-factor structure of the Pain and Activity Relations Questionnaire (avoidance, pacing and persistence). Cluster analysis yielded four clusters: One cluster labeled 'the persisters' (high in persistence behavior and low in both pacing and avoidance behavior) and two clusters with elevated scores on pacing: one in combination with elevated scores on avoidance, labeled the 'avoidant pacers' and the other in combination with elevated scores on persistence which was labeled the 'persistent pacers'. A fourth cluster showed high scores on all activity patterns and was labeled 'the cyclers'. A comparison of these clusters on measures of pain catastrophizing, disability, depression and pain demonstrated that not avoidance, pacing or persistence per se, but especially elevated levels of all three activity patterns (the cycler group) was associated with more disability, more pain catastrophizing and more depression. Unexpectedly, the persisters reported the best outcomes. In this way the results of study I do not provide evidence for the fact that persistence behavior or increased levels of activity per se are associated with more disability. Results suggest that activity fluctuations rather than increased activity levels per se are associated with worse outcomes.

The goal of Study II (chapter 3) was threefold: 1) to investigate whether the Moodas-Input model also applies when achievement and hedonic goals are activated by means of supraliminal priming; 2) to investigate the moderating role of people's habitual hedonic and achievement goals as measured with the Goal Pursuit Questionnaire; and 3) to validate the Goal Pursuit Questionnaire in a sample of healthy participants. In line with the Mood-as-Input model, task persistence was expected to be a function of the interaction between primed goals and mood. Additionally it was expected that participants' habitual goals would moderate the effect of goal primes on task persistence, so that the Mood-as-Input effect would be stronger when primed goals and habitual goals were congruent.

The Goal Pursuit Questionnaire (Karsdorp \& Vlaeyen, 2011) is a newly developed questionnaire measuring habitual goal preferences. It measures the extent to which a person has a preference for hedonic goals over achievement goals when confronted with a situation where both goals are conflicting. The Goal Pursuit Questionnaire was submitted to an exploratory factor analysis in sample of 700 healthy participants. The factor analysis yielded a two-factor solution, with a pain-avoidance subscale and a non-pain subscale (mood-management subscale). Higher scores on the pain-avoidance subscale, reflect stronger 
preference for pain-avoidance goals relative to achievement goals. Higher scores on the nonpain subscale (mood-management subscale) reflect stronger preferences for hedonic goals relative to achievement goals.

A subsample of 160 participants participated in the experimental study, using a 2 Mood (positive versus negative) X 3 Primed goal (hedonic. achievement, neutral) betweensubjects design. Habitual goal was included as covariate. The experimental study was based on the original study of Martin et al. (1993), using the same type of mood manipulation and impression formation task with the only difference that goals were not explicitly instructed but manipulated using a Scrambled Sentence Task. However results did not provide evidence for the validity of the Mood-as-Input model without the use of explicit goal instructions. No interaction effects were found between mood and primed goals or between mood and habitual goal preferences. Furthermore, habitual goal preferences did not moderate the goal priming effect. Instead, results demonstrated that task persistence was predicted by habitual goal preferences. Participants, who preferred achievement goals over hedonic goals, persisted longer than those who showed the opposite preference.Additionally, results demonstrated that the Goal Pursuit Questionnaire is a reliable and valid measure that predicts task persistence in healthy participants.

Because the study described in chapter 3 failed to demonstrate an interaction between primed goals and mood, Study III (chapter 4) investigated whether the goals of the Mood-as-Input model could in fact be made more accessible by means of supraliminal or subliminal priming.

One hundred and twenty participants were either primed with subliminal or with supraliminal presented goal words by means of a scrambled sentence task or a dot detection task in which goal words were presented for $33 \mathrm{~ms}$, respectively. Goal accessibility was measured with a lexical decision task in which subjects had to decide whether a presented letter string was either a word or a non-word. The lexical decision task was administered both before and after priming. The word stimuli included in the lexical decision task consisted of four categories: hedonic words, achievement words, positive but non-hedonic words or neutral words. So for both the supra- and subliminal priming tasks, a 3 Prime (no-goal, hedonic versus achievement) X 4 Target (hedonic, achievement, positive versus neutral) mixed factorial design was used, with prime as between-subjects factor and target as withinsubjects factor and reaction time as dependent variable. It was hypothezised that participants would respond faster to achievement words in the second lexical decision task as compared to the baseline task, when they were primed with achievement goal words in the preceding priming task. Accordingly, it was expected that participants would respond faster to hedonic words in the second lexical decision task as compared to the baseline task when they were primed with hedonic words in the priming task. For both the supraliminal and the subliminal priming, results did not show faster responses on hedonic goal words in a lexical decision 
task after being primed with hedonic goal words; or faster responses on achievement goal words after being primed with achievement goal words. These findings suggest that the priming method did not significantly increase accessibility of goal-related achievement and hedonic words.

Study IV (chapter 5) investigated the applicability of the Mood-as-Input model to pain using pain catastrophizing as a very specific pain-avoidance goal. In line with the Mood-asInput model it was predicted that pain catastrophizing would be related to less task persistence when participants experience negative moods, and related to greater task persistence when participants experience positive moods, particularly in a high pain-threatening context. The key idea behind this prediction is that mood provides information about the safety of an activity, with positive mood signaling that the activity is safe and can be continued; and negative mood signaling that the activity is dangerous and should be stopped. Additionally, it was hypothesized that the context may play a role in whether mood is seen as relevant information or not. Because results from Study III showed that it is difficult to induce goals by means of priming, level of pain catastrophizing was not manipulated but measured. In a sample of 89 healthy participants mood (positive vs. negative) and threat context (high threat vs. low threat) were manipulated and task persistence during a painful finger-pressing task was measured. Results confirmed the hypothesis, demonstrating an interaction between mood and pain catastrophizing, only in the high threat context and not in the low threat context. Results indicate that a relevant, goal specific context plays an important role in bringing about Mood-as-Input effects.

Study $V$ (chapter 6) investigated the applicability of the Mood-as-Input model in patients with chronic back pain. More specifically, the combined influence of mood and the habitual preference for achievement versus pain-avoidance or hedonic goals on painful physical task persistence is investigated. It was predicted that individuals who have stronger preferences for habitual achievement goals relative to pain-avoidance goals display greater task persistence when they are in a negative mood than when they are in a positive mood. With respect to the hedonic goal, the opposite pattern is expected. A total of 57 patients $(24.5 \%$ men; mean age $(\mathrm{SD})=47.72$ (10.64) years) with chronic back pain ( $>3$ months) were tested. Mood was manipulated with positive or negative film-fragments; goals were not manipulated but instead patients' habitual goals were measured. The performance task consisted of lifting a bag of $5.5 \mathrm{~kg}$. The dependent measure was the total lifting time. Similar as in study II, results did not provide evidence for the Mood-as-Input hypothesis but instead showed a main effect of goal preferences. In contrast to the results of study II, the painavoidance subscale instead of the mood-management subscale predicted task persistence, demonstrating that pain patients with stronger habitual preferences for pain-avoidance goals as compared to achievement goals showed lower task persistence than those with the opposite preference. Interestingly, pain catastrophizing and pain-related fear were not related 
to task persistence or to habitual goal preferences. The present results are only partly in line with the Fear-Avoidance model and suggest that pain-avoidance goals are not necessarily related to fear-avoidance believes but nevertheless can influence task persistence in pain patients. Furthermore, in contrast to Fear-Avoidance studies, voluntary behavior instead of pain tolerance was measured, shedding light to a different and particularly relevant category of behavior. After all, in daily activities, pain patients not always perform activities until levels of pain tolerance but may use rules other than fear of pain in deciding when to end daily activities. In this case, decisions to avoid or persist in pain-evoking activity do not fully depend upon fear, but also on the goals that are related to that activity.

In Chapter 7, a general discussion and integration of the results presented in the current thesis is provided. A detailed analysis concerning the factors that seem to influence the presence or absence of Mood-as-Input effects is provided. Future directions for research, limitations and possible clinical implications are discussed. 


\section{References}

Breivik, H., Collett, B., Ventafridda, V., Cohen, R., \& Gallacher, D. (2006). Survey of chronic pain in Europe: prevalence, impact on daily life, and treatment. European Journal of Pain, 10, 287-333.

Karsdorp, P. A., \& Vlaeyen, J. W. (2011). Goals matter: both achievement and pain-avoidance goals are associate with pain severity and disability in patients with musculoskeletal pain. Pain 152, 1382-1390.

Lousberg, R., Van Breukelen, G. J., Groenman, N. H., Schmidt, A. J., Arntz, A., \& Winter, F. A. (1999). Psychometric properties of the Multidimensional Pain Inventory, Dutch language version (MPI-DLV). Behaviour Research and Therapy, 37, 167-182.

Martin, L., Ward, D. W., Achee, J. W., \& Wyer, R. S. (1993). Mood as input: people have to interpret the motivaitional implications of their Moods. Journal of Personality and Social Psychology, 64, 317-326.

McCracken, L. M., \& Samuel, V. M. (2007). The role of avoidance, pacing and other activity patterns in chronic pain. Pain, 130, 119-125.

Tait, R. C., Chibnall, J. T., \& Krause, S. (1990). The Pain Disability Index: psychometric properties. Pain, 40, 171-182.

Zigmond, A. S., \& Snaith, R. P. (1983). The hospital anxiety and depression scale. Acta Psychiatrica Scandinavica, 67, 361-370. 
Samenvatting

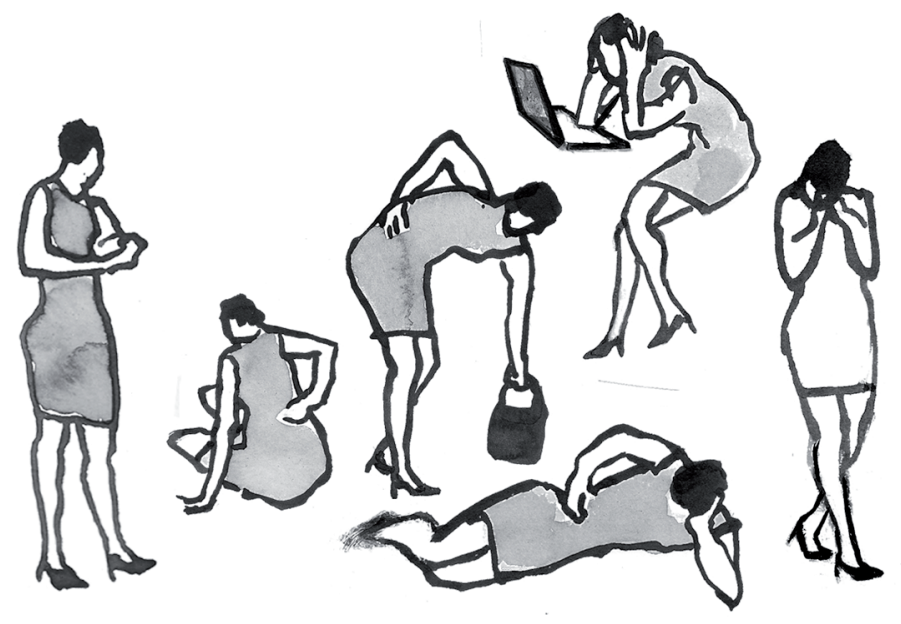


Chronische pijn en de daarmee gepaardgaande beperkingen vormen een groot maatschappelijk probleem. De prevalentie in Nederland bedraagt $18 \%$ (Breivik, Collett, Ventafridda, Cohen, $\&$ Gallacher, 2006). In de voorbije tien jaar is het Vrees-Vermijdings model het overheersende verklaringsmodel geweest wat betreft het verklaren van pijn-gerelateerde beperkingen. Ondanks de accumulerende evidentie voor het model lijkt het minder toepasbaar te zijn bij pijn syndromen die geassocieerd zijn met een verhoogd activiteitenniveaus (persisterend gedrag) in plaats van een verlaagd activiteitenniveaus (vermijdend gedrag).

Recent werd een nieuw alternatief model voorgesteld, dat zijn wortels heeft in de sociale psychologie, en een verkaring kan bieden voor zowel pijn-gerelateerde beperkingen die gesassocieerd zijn met verhoogde activiteitenniveaus als voor pijn gerelateerde beperkingen geassocieerd met verlaagde activiteitenniveaus: het Mood-as-Input model (Martin, Ward, Achee, \& Wyer, 1993). Het Mood-as-Input model stelt dat de tijd dat men spendeert aan een activiteit voorspeld wordt door een statistische interactie tussen stemming en doelen. Twee doelen zijn hierbij vooral relevant: prestatie doelen en hedonische doelen. Het basisidee achter het Mood-as-Input model is dat mensen hun stemming gebruiken als een informatiebron waaruit ze afleiden hoeveel vooruitgang ze ten aanzien van de doelen die ze nastreven hebben bereikt. Positieve stemming in combinatie met een hedonisch doel duidt erop dat de taak nog steeds aantrekkelijk is, wat leidt tot het voortzetten van de taak, terwijl een positieve stemming in combinatie met een prestatie doel erop wijst dat er een goed resultaat is bereikt, wat vervolgens leidt tot het afbreken van de acitviteit. Negatieve stemming in combinatie met een hedonisch of een prestatie doel wordt verondersteld een tegenovergesteld gedragspatroon tot gevolg te hebben.

Tot nu toe is het Mood-as-Input model voornamelijk getest met behulp van expliciete doel instructies. In een typisch Mood-as-Input experiment voeren de deelnemers een taak uit die een open einde heeft terwijl ze in een positieve of een negatieve stemming gebracht worden en expliciet geïnstrueerd worden om, ofwel door te gaan met de taak tot ze het gevoel hebben een goede presatie te hebben geleverd (prestatie doel), ofwel door te gaan tot ze de taak niet meer aantrekkelijk vinden (hedonisch doel).

Omdat in het dagelijks leven mensen vaak niet alleen maar expliciete taak instructies opvolgen is het revelevant om te onderzoeken of de voorspellingen van het Mood-as-Input model ook gelden wanneer er geen expliciete instructies worden gebruikt maar doelen geprimed worden en habituele doelen worden gebruikt.

Hef hoofdoel van deze dissertatie is om te onderzoeken of het Mood-as-Input model kan dienen als een verklarend model voor taak persistentie (gedefinieerd als taak duur) in het domein van pijn, wanneer geen expliciete doelinstructies worden gebruikt maar habituele doelpreferenties en geprimede doelen. Habituele doel-voorkeuren worden gedefinieerd als voorkeuren die mensen van nature bezitten voor een bepaald doel ten gunste van een ander conflicterend doel (Karsdorp \& Vlaeyen, 2011 ). 
Aangezien het Mood-as-Input model een verklaring probeert te geven voor pijn beperkingen die gerelalteerd zijn met zowel verhoogde als verlaagde activiteitenniveaus, hebben we in Studie I (hoofdstuk 2) in een eerste stap, geëxploreerd of acitiviteitspatronen zoals vermijding, pacing en persistentie geassocieerd zijn met het niveau van functionele beperking, depressie en pijn, in patiënten met musculoskeletale pijn. In plaats van deze activiteitspatronen op zichzelf te bestuderen hebben we subgroepen van patiënten bestudeerd die verschillende combinaties van vermijding, pacing en persistentie vertoonden. Activiteitspatronen werden gemeten met de Pain and Activity Relations Questionnaire (McCracken \& Samuel, 2007) en subgroepen van patiënten werden verkegen door middel van een hiërarchische cluster analyse. Een steekproef van 299 deelnemers vulde online een aantal vragenlijsten in die betrekking hadden op functionele beperkingen (Pain Disability Index; Tait, Chibnall, \& Krause, 1990), depressie (Hospital Anxiety and Depression Scale; Zigmond \& Snaith, 1983), pijn (Multidimensional Pain Inventory; Lousberg, et al., 1999) en activiteitenniveaus (Pain and Activity Relations Questionnaire; McCracken \& Samuel, 2007).

De Pain and Activity Relations Questionnaire werd vertaald naar het Nederlands en een exploratieve factor analyse met obliqe rotatie werd uitgevoerd. De resultaten ondersteunen de originele drie-factror structuur van de de Pain and Activity Relations Questionnaire ("vermijding", "pacing” en "persistentie"). De cluster analyse leverde vier clusters op: een clusters gelabeld 'Persisteerders' (gekenmerkt door hoge niveaus van persistentie in combinatie met lage niveaus van pacing en vermijding), ent twee clusters met verhoogde scores op pacing: een in combinatie met verhoogde scores op vermijding, gelabeld de 'Vermijdende Pacers'; en een andere in combinatie met verhoogde socres op persistentie gelabeld 'Persisterende Pacers'. Een vierde cluster werd gekenmerkd door hoge scores op alle drie de activiteitspatronen en werd 'Cyclers' genoemd. Een vergelijking van deze clusters op maten van pijn castatstroferen, beperking en pijn toonde aan dat niet vermijding, pacing of persistentie op zich maar vooral de verhoogde niveaus van alle drie de acitiveitspatronen (de Cyclers groep) geassocieed is met meer beperking, pijn catastroferen en depressie. Tegen de verwachtingen in rapporteerden de persisteerders de laagste niveaus van beperkingen, depressie en pijn.

De resultaten uit studie I bieden geen ondersteuning voor de verwachting dat persistentie gedrag of verhoogde activiteitenniveaus an sich gerelateerd is met meer beperkingen in het dagelijks leven. De resultaten suggereren eerder dat fluctuaties in activiteiten in plaats van een verhoogd activiteitenniveau gerelateerd zijn met minder gunstige uitkomsten.

Het doel van Studie II (hoofdstuk 3) was drievoudig: 1) onderzoeken of het Moodas-Input model ook opgaat als prestatie doelen en hedonische doelen geactiveerd worden door middel van supraliminale priming; 2) onderzoeken of habituele hedonische en prestatie 
doelen, zoals gemeten met de Goal Pursuit Questionnaire (Karsdorp \& Vlaeyen, 2011), een modererende rol spelen in het teweeg brengen van Mood-as-input effecten en 3) het valideren van de Goal Pursuit Questionnaire in een steekproef van gezonde deelnemers. Overeenkomstig de voorspellingen van het Mood-as-Input model werd taak persistentie vewacht een functie te zijn van de interactie tussen geprimede doelen en stemming. Verder werd verondersteld dat habituele doelen het effect van geprimede doelen op taakpersistentie zou modereren: we verwachtten dat Mood-as-Input effecten sterker zouden optreden wanneer de geprimede doelen en habituele doelen congruent zijn.

De Goal Pursuit Questionnaire (GPQ) is een nieuw ontwikkelde vragenlijst die habituele doelvoorkeuren meet. De GPQ meet de mate waarin een persoon een voorkeur heeft voor ofwel een hedonisch doel ofwel een prestatiedoel in een situatie waarin beide doelen met elkaar conflicteren. Er werd een exploratieve factoranalyse uitgevoerd op de Goal Pursuit Questionnaire, in een steekproef van 700 gezonde deelnemers. De resultaten van de factoranalyse leverden een twee-factoren oplossing op. De twee subschalen werden als volgt gelabled: de pijn-subschaal, waarin hogere scores een voorkeur voor pijn-vermijdings doelen ten opzichte van prestatie doelen reflecteren; en een niet-pijn subschaal (of moodmanagement subschaal), waarin hogere scores een voorkeur voor hedonische doelen ten opzichte van prestaie doelen reflecteren. Een substeekproef van 160 deelnemers nam deel aan deze experimentele studie. Het design van deze studie was een 2 stemming (positief versus negatief) X 3 doel prime (hedonisch, prestatie, neutraal) between-subjects design, met habitueel doel als controle variabele. De experimentele studie is gebaseerd op de originele studie van Martin et. al. (1993), waarbij gebruik gemaakt werd van eenzelfde type van stemmingsmanipulatie en impressieformatie taak, met het enige verschil dat doelen niet gemanipuleerd werden door middel van expliciete instructies maar met behulp van de Srambled Sentence Task.

De resultaten bieden geen ondersteuning voor de validiteit van het Mood-as-Input model wanneer expliciete doel instructies niet worden gebruikt. Er werd geen interactie effect gevonden tussen gerpimede doelen en stemming of tussen habituele doelen en stemming. Bovendien werd er geen moderatie effect gevonden van habituele doelen op taak persistentie. In plaats daarvan toonden de resultaten aan dat taak persistentie voorspeld wordt door habituele doelvoorkeuren. Deelnemers die een voorkeur rapporteerden voor prestatie doelen ten opzichte van hedonische doelen gingen langer door met de taak dan zij die een tegenovergestelde voorkeur rapporteerden. Verder demonstreerden de resultaten dat de Goal Pursuit Questionnaire een betrouwbare en valide maat is die taakpersistentie voorspelt in gezonde proefpersonen.

Aangezien de studie die beschreven is in hoofdstuk 3 geen interactie effect tussen geprimede doelen en stemming kon aantonen hebben we in Studie III (hoofdstuk 4) verder onderzocht of de doelen van het Mood-as-Input model daadwerkelijk meer toegankelijk 
gemaakt konden worden door middel van supraliminale en subliminale primingtechnieken. Honderdeenentwintig proefpersonen werden ofwel gerpimed met subliminaal ofwel met supraliminaal gepresenteerde woorden. De toegankelijkheid van doelen werd gemeten met een lexicale decisie taak waarin proefpersonen werd gevraagd om te beslissen of een gepresenteerde reeks van letters een woord vormde of een non-woord. Er werd zowel voor als na de priming taak een lexicale decisie taak afgenomen. De woord stimuli die werden gebruikt in de lexicale decisie taak kunnen worden onderverdeeld in vier categorieën: hedonische woorden, prestatie woorden, positieve maar niet-hedonische woorden en neutrale woorden. Het design voor zowel het supraliminale als subliminale gedeelte van het onderzoek is een $3 \times 4$ mixed factorieel design met geprimed doel (geen, hedonisch, versus prestatie) als between-subject factor en target (hedonisch, prestatie, positief, versus neutraal) als withinsubject factor en reactietijd als afhankelijke variabele.

Er werd verwacht dat deelnemers sneller zouden reageren op prestatie woorden in de tweede lexicale decisie taak relatief ten opzicht van de baseline taak, als ze van tevoren geprimed werden met prestatie woorden in de priming taak. Conform daarmee werd verwacht dat deelnemers sneller zouden reageren op hedonische woorden in de tweede lexicale decisie taak ten opzichte van de baseline taak als ze van tevoren gerpimed werden met hedonische woorden in de priming taak. De resultaten bevestigden de hypothese niet. Zowel wat betreft supralimale als subliminale priming werden er geen snellere responsen gevonden op hedonische doelwoorden op de lexicale decisietaak na de priming met hedonische woorden, noch op prestatiewoorden na priming met prestatie woorden. Deze bevindigen suggereren dat de gerpimede doelen niet significant verhoogd toegankelijk gemaakt werden door middel van de priming mehtode.

Studie IV (Hoofdstuk 5) onderzocht de toepasbaarheid van het Mood-as-Input model op pijn wanneer pijn catastroferen werd gerbruikt als een proxy voor een specifiek pijn-vermijdingsdoel. Overeenkomstig het Mood-as-Input model werd voorspeld dat pijn catastroferen gerelateerd zou zijn met minder taak persistentie indien de deelnemers zich in een negatievere stemmingstoestand bevonden en gerelateerd aan grotere taak persistentie wanneer deelnemers positief gestemd waren. Dit effect werd verwacht vooral op te treden in een context van hoge pijn dreiging. Het basisidee achter deze voorspelling is dat stemming informatie geeft over het al dan niet veilig of gevaarlijk zijn van een activiteit; waarbij positieve stemming dienst doet als signaal dat een activiteit veilig is en dus voortgezet kan worden en negatieve stemming dienst doet als signaal dat de activiteit gevaarlijk is en derhalve gestaakt dient te worden. Er werd verder veondersteld dat een hoge dreigcontext dit effect zou versterken. Omdat de resultaten van studie III suggereerden dat het moeilijk is om doelen te manipuleren door middel van priming werd het niveau van pijn castastroferen niet gemanipuleerd maar gemeten. In een steekproef van 89 gezonde proefpersonen werd stemming (positief versus negatief) en dreigcontext (hoog versus laag) gemanipuleerd en 
taak persistentie gemeten gedurende een pijnlijke repetitieve vinger-druk taak. De resultaten bevestigenden de hypothese; een intractie tussen stemming en pijn catastroferen werd gevonden, alleen in de hoge dreigcontext en niet in de lage dreigcontext. De resulaten onderstrepen dat een relevante, doelspecifieke context belangrijk is bij het teweegbrengen van Mood-as-Input effecten.

Studie V (Hoofdstuk 6) onderzocht de toepasbaarheid van het Mood-as-Input model in patiënten met chronische rugpijn. In het bijzonder de gecombineerde invloed van stemming en habituele (prestatiegerichte en hedonische) doelpreferenties op fyieke taakpersistentie werd onderzocht. Er werd voorspeld dat individuen die een sterkere voorkeur rapporteerden voor habituele prestatiegerichte doelen relatief ten opzichte van pijn-vermijndingsdoelen een groter taak persistentie zouden vertonen wanneer ze zich in een negatieve stemming bevonden dan wanneer ze zich in een positieve stemming bevonden. Wat betreft de sterkere voorkeur voor hedonische doelen ten opzichte van prestatiegerichte doelen werd het tegenovergestelde patroon verwacht. In het totaal werden 57 patiënten (24.5\% mannen; gemiddelde leeftijd $(\mathrm{SD})=47.72$ (10.64) jaar) met chronische rugpijn (> 3 maanden) getest. Stemming werd geïnduceerd met positieve of negatieve filmfrangmenten en habituele doelvoorkeuren werden gemeten met de Goal Pursuit Questionnaire. De taak bestond uit het optillen van een tas van $5.5 \mathrm{~kg}$. De afhankelijke maat was de totale tijd dat de tas werd opgetild.

Gelijkaardig aan studie II, leverden de resultaten geen bewijs voor de Mood-asInptut-hypothese maar lieten deze een hoofdeffect van doel-voorkeuren zien. In tegenstelling met de resultaten van studie II voorspelde alleen de pijn-vermijdings subschaal van de Goal Pursuit Questionnaire taak persistentie. Dit betekent dat pijn patiënten met sterkere voorkeuren voor pijn-vermijdings doelen ten opzichte van prestatie doelen een lagere taak persistentie lieten zien dan participanten met een tegengestelde voorkeur. Opmerkelijk in deze studie is dat pijn catastroferen en pijngerelateerde vrees niet gereleateerd zijn aan taak persistentie of aan habituele doelvoorkeuren. De resultaten zijn dus alleen gedeeltelijk in lijn met het Vrees-Vermijding model en suggerenen dat pijn-vermijding doelen niet noodzakelijk gerelateerd zijn aan cognities die betrekking hebben op vrees en vermijding, maar toch een invloed kunnen hebben op taak persistentie in patiënten met chronische pijn. Bovendien werd in tegenstelling tot Vrees-Vermijding studies in deze studie vrijwillig gedrag gemeten in plaats van pijn tolerantie. Dit werpt een nieuw licht op een andere, relevante categorie van gedragingen. Immers, in dagelijkse activiteiten voeren pijn patiënten niet altijd activiteiten uit tot niveau van pijn tolerantie, maar gebruiken ze wellicht andere regels dan vrees voor pijn om te beslissen hoe lang ze met een activiteit doorgaan.

In hoofdstuk 7 wordt een een algemene discussie en integratie van de resultaten gepresenteerd. We geven een gedetailleerde analyse van de factoren die van invloed kunnen zijn op Mood-as-Input effecten, en bespreken toekomstige richtingen voor onderzoek, de 
beperkingen van de huidige studies en de mogelijke klinische implicaties van de gevonden resultaten. 


\section{References}

Breivik, H., Collett, B., Ventafridda, V., Cohen, R., \& Gallacher, D. (2006). Survey of chronic pain in Europe: prevalence, impact on daily life, and treatment. European Journal of Pain, 10, 287-333.

Karsdorp, P. A., \& Vlaeyen, J. W. (2011). Goals matter: both achievement and pain-avoidance goals are associate with pain severity and disability in patients with musculoskeletal pain. Pain 152, 1382-1390.

Lousberg, R., Van Breukelen, G. J., Groenman, N. H., Schmidt, A. J., Arntz, A., \& Winter, F. A. (1999). Psychometric properties of the Multidimensional Pain Inventory, Dutch language version (MPI-DLV). Behaviour Research and Therapy, 37, 167-182.

Martin, L., Ward, D. W., Achee, J. W., \& Wyer, R. S. (1993). Mood as input: people have to interpret the motivaitional implications of their Moods. Journal of Personality and Social Psychology, 64, 317-326.

McCracken, L. M., \& Samuel, V. M. (2007). The role of avoidance, pacing and other activity patterns in chronic pain. Pain, 130, 119-125.

Tait, R. C., Chibnall, J. T., \& Krause, S. (1990). The Pain Disability Index: psychometric properties. Pain, 40, 171-182.

Zigmond, A. S., \& Snaith, R. P. (1983). The hospital anxiety and depression scale. Acta Psychiatrica Scandinavica, 67, 361-370. 


\section{Addendum}

Valorisation of the present results 
The main purpose of the present dissertation was to investigate whether the Mood-asInput model could serve as an explanatory framework for task persistence in the domain of pain, without using explicit goal instructions, using goal priming and habitual goal pursuit instead. Some tentative conclusions can be drawn on the basis of the present results. First the findings seem to indicate that not avoidance, pacing or persistence per se, but especially the combination of elevated levels in all three activity strategies is associated with more disability, more pain catastrophizing, and more depression. Second, it proved difficult to manipulate goals by means of goal priming. In contrast to our expectations, there was no evidence that the primed goals were made more accessible by means of the goal priming procedure. Third, healthy participants reporting greater preferences for achievement goals as compared to hedonic goals showed greater task persistence in a non-painful task. Fourth, in pain patients, patients with stronger habitual preferences for pain-avoidance goals relative to achievement goals showed lower task persistence than those with the opposite preference, during a painful weightlifting task. Fifth, when the catastrophizing context was manipulated, a Mood-as-Input effect was found. More specifically, high pain catastrophizing was related to less task persistence when participants experienced negative moods, but related to greater task persistence when participants experienced positive moods during a painful finger pressing task. The general conclusion is that the present data do not provide unequivocal evidence for the validity of the Mood-as-Input, and that habitual goal preferences are more important predictors for the level of task persistence.

In the General Discussion (chapter 7) the scientific and theoretical contribution of the present results to the existing body of knowledge was discussed. In this chapter the focus is on the valorisation of the present results. Valorsiation is defined as the process of creating value from knowledge, by making knowledge suitable and applicable for societal and or economical use (Landelijke Commissie Valorisatie, 2011). Some studies in this dissertation are more suitable for valorisation than others. The priming manipulation study is less suitable for valorisation and will be left out. In the following the focus will be on the valorsiation of the role of activity strategies in chronic pain, and the role of habitual goal preferences in task persistence in chronic pain.

In 2006, Breivik and colleagues concluded their survey-article concerning the prevalence, impact and treatment of chronic pain in Europe with the message "Chronic pain of moderate to severe intensity occurs in $19 \%$ of adult Europeans, seriously affecting the quality of their social and working lives. Very few were managed by pain specialists and nearly half receive inadequate pain management. [..] we have documented that chronic pain is a major health care problem in Europe that needs to be taken more seriously" (Breivik, Collett, Ventafridda, Cohen, \& Gallacher, 2006, page 287). 
Since then, a lot of research has been carried out to improve the situation. In general the prevailing model that has been tested is the Fear-Avoidance model (Vlaeyen \& Linton, 2000). However, despite its accumulating evidence, the model is limited in scope to pain complaints associated with avoidance behavior. The Mood-as- Input model was presented as an alternative model which could provide an explanation for both avoidance behavior and persistence behavior (Vlaeyen \& Morley, 2004). This kind of research is theoretically important, giving scientific insight into the mechanisms that contribute to pain but the question can be raised what the societal impact of this research is. More specifically, what are the clinical implications of the present thesis and how can the present research results contribute to an improvement in chronic pain management? Given the scope of this thesis and the relative lack of supportive evidence for most of our hypotheses, it is not possible to derive any direct clinical implications from the Mood-as-Input model applied to chronic pain. Nevertheless, on the basis of the present results we can give some directions with respect to what is important to target in future clinical practice.

First of all, the results from study I, as well as those from previous studies (McCracken \& Samuel, 2007; Huijnen, Verbunt, Roelofs, Goossens, \& Peters, 2009), indicate that treatment programs targeting activity-related dysfunction should not look solely at single behavioral strategies (e.g. avoidance, pacing or persistence) but should consider the full pattern of activity related strategies. As not only avoidance per se, but also switching between these behavioral patterns seems to represent a particularly problematic clinical group, assessing these patterns might contribute to the development more customized treatments.

In general the results of the present thesis did not support the Mood-as-input model. Instead the results showed that habitual goal preferences predict task persistence in chronic pain. One study however, showed that the level of task persistence in healthy participants with high levels of catastrophizing is influenced by mood and goals when they are confronted with a high threatening context. How can we derive some clinical implications from these results?

In a recent study Dash, Meeten, Jones and Davey (2014) tested a psycho-educational intervention to reduce worrying, based on the Mood-as-Input model. Results of this study showed that this brief, low-intensity and low-cost procedure significantly reduced worry scores in a group of highly anxious students. Although the dependent variable of our studies (being level of task persistence) is different than that used in the study of Dash et al., 2014, (being level of worrying) a psycho-educational intervention program could be developed for pain, based on their results. The goal of the intervention would be to provide insight into the relative importance of pain-avoidance as well as achievement goals and to focus on the adoption of a flexible goal pursuit style. Furthermore, when patients have high levels of catastrophizing, the goal would be to provide insight into the mechanisms that influence task persistence in a high threatening context. A 4-session intervention could be developed. 
The first session should be used to determine the activity style of the patient, taking into account the whole spectrum of activity styles and to determine the relative importance of avoidance and achievement goals as well as the level of disability and the level of pain catastrophizing. In a second session the patient is provided insight into their personal goal preferences and how they are related to 'maladaptive' activity levels. This could be done by psycho-education in combination with Acceptance and Commitment Therapy (ACT) interventions (McCracken, Mackichan, \& Eccleston, 2007). One intervention within ACT is learning how to see one's thoughts for what they really are, just thoughts; a process called 'cognitive diffusion'. This process teaches the client to adopt a different perspective on their thoughts, changing its context and its influence on behavior. For example, a pain patient can be fused with an enough stop-rule such as 'I always have to do my best', which in the long run could lead to overuse, more disability, and more pain. Having more insight into one's rules and values can lead to more psychological flexibility, and on its turn to more adaptive responses. Furthermore, if patients have high levels of catastrophizing, they are provided with insight into context factors such as their own level of catastrophizing, their mood state, the threat value of a situation and the potential interaction of these factors. In a third session patients are encouraged to put into practice the information provided in session two and to practice with flexible goal pursuit. When a preference of pain-avoidance goals in combination with dysfunctional decreased activity levels dominates, patients are encouraged to adopt achievement goals instead, and to persist with these goals despite the pain. This could be done within an 'exposure in vivo' framework (Barlow, 2002; De Jong et al., 2005; Vlaeyen, Morley, Linton, Boersma, \& De Jong, 2012). If patients on the other hand show maladaptive persistence behavior, the strategy is to encourage them to prevent persistence behavior when exposed to situations or contexts that elicit an achievement goal. Homework assignments including rating their mood, their level of catastrophizing, their activity levels and their goal preferences as well as practicing with exposure and preventing strategies might be helpful here. In a fourth session, the homework is evaluated and it is determined whether this basic intervention is enough or if a more intensive treatment is needed. As the research results in the present thesis are relevant for both chronic pain patients and health care providers, it could be interesting to provide the second session of the psycho-educational intervention also to health care providers in primary care.

While the research proposal of the present thesis was very promising and innovative, the research results could not live up to this promise. Nevertheless, the results of the present thesis shed light to a different and particularly relevant category of activities than those usually studied in fear-avoidance studies; namely daily activities where rules other than pain catastrophizing and fear of pain are used to determine duration of activities. The clinical implication of this is that interventions should not only target catastrophic beliefs or fear of pain but should also take into account patients' goal- preferences. 


\section{References}

Breivik, H., Collett, B., Ventafridda, V., Cohen, R., \& Gallacher, D. (2006). Survey of chronic pain in Europe: prevalence, impact on daily life, and treatment. European Journal of Pain, 10 (4), 287-333.

Dash, S.R, Meeten, F., Jones, F., Davey, G.C.L, (2014). Evaluation of a brief 4- session psychoeducation procedure for high worriers based on the mood-as-input hypothesis, Journal of Behavior Therapy and Experimental Psychiatry.

Huijnen, I. P., Verbunt, J. A., Roelofs, J., Goossens, M., \& Peters, M. (2009). The disabling role of fluctuations in physical activity in patients with chronic low back pain. European Journal of Pain, 13, 1076-1079.

McCracken, L.M., Mackichan, F., \& Eccleston, C. (2007). Contextual cognitive-behavioral therapy for severely disabled chronic pain sufferers: Effectiveness and clinically significant change. European Journal of Pain, 11, 314-322

Vlaeyen, J. W., \& Linton, S. J. (2000). Fear-avoindance and its consequences in chronic muskoskeletal pain: a state of the art. Pain, 85, 317-332.

Vlaeyen, J. W., \& Morley, S. (2004). Active despite pain: the putative role of stop-rules and current mood. Pain, 110(3), 512-516. 
Dankwoord 
Vol trots en verwondering kan ik eindelijk uitroepen: "Mijn proefschrift is af!" Ik heb heel lang naar dit moment uitgekeken en het feit dat het eindelijk zo ver is heb ik niet alleen aan mezelf te danken maar zeker ook aan de bijdrage van velen. Ik wil hier dan ook van de gelegenheid gebruikmaken om iedereen die een rol gespeeld heeft in het totstandkomen van dit proefschrift van harte te bedanken.

Johan, bedankt voor je altijd rake suggesties, je aanmoedigingen en je geduld. Ik heb zelf nogal de neiging om heel lang na te denken over mogelijke theoretisch problemen en om hierbij alle mogelijke problemen van alle kanten te willen bekijken, wat niet altijd even productief bleek. Jouw denken in mogelijkheden in plaats van in problemen is voor mij heel inspirerend geweest. Ik bewonder je talent om met een helicopterview naar de dingen te kijken, en om zo niet alleen wetenschappelijke kwesties met elkaar te verbinden tot nieuwe innovatieve ideeën, maar ook om mensen met elkaar in contact te brengen en te zorgen voor vruchtbare samenwerkingsverbanden.

Petra, jij was vanaf het eerste moment zeer nauw betrokken bij dit proefschrift. Er is bijna geen zin in dit proefschrift waarover we niet uitvoerig hebben gediscussieerd. Ik heb daardoor niet alleen veel geleerd over het bedrijven van wetenschap in het algemeen en over het onderwerp pijn in het bijzonder, maar ik heb ook veel over mezelf geleerd. Jij weet als geen ander een kritische houding te combineren met een gezonde dosis no-nonsense enthousiasme en een 'let's do it' - attitude. Ook toen mijn contract al was afgelopen was je altijd bereikbaar en bereid tot discussie. Bedankt voor je betrokkenheid.

Ook dank aan de vele proefpersonen voor het deelnemen aan de studies en aan de studentassistenten voor hun hulp bij het uitvoeren van de studies. Angela, bedankt voor de ondersteuning. Rob smeets en Guido van Hamme dank voor jullie hulp bij het doorsturen van patiënten voor de patiëntenstudie. I would like to thank Lance McCracken for his backtranslation in developing the Dutch version of the Pain and Activity Relations Questionnaire and his valuable comments on chapter 2 of this thesis. Een speciaal woord van dank voor Sita en Marionne. Sita, jij bent een organisatorische duizendpoot. Bedankt voor alle hulp en voor je betrokkenheid! Marionne, bedankt voor je hulp, ook in de laaste fase van dit proefschrift stond je altijd klaar om (adminstratieve) zaken te regelen.

I further would like to thank the examination board of this dissertation, Gerjo Kok, Henk Aarts, Carolien Martijn, Stephen Morley and Jeanine Verbunt for taking the time to read and evaluate this thesis. 
De leden van de BM groep:Linda, Madelon, Martien, Petra, Hanne, Yvo, Ivan, Marjolein, Elke, Rena, Andrea, Rilana, Ken, Marlies, Hugo en Johan. Bedankt voor de inspirerende presentaties, de kritische suggesties en de gezelligheid. Ook alle andere (ex) phd-students, bedankt voor de steun en de gezelligheid. Marjolein, we hebben samen ettelijke avonden en weekends op de uni doorgebracht in een 'komaan, we gaan er samen voor'- sfeer. Je was altijd beschikbaar zij het voor een statistische vraag, een inhoudelijke pijn-discussie of een praatje over wat ons zoal bezighoudt in het leven. Je enthousiasme en je humor werken aanstekelijk. En ja hoor: We did it! Hanne, een gesprek met jou (als het nu gaat over een wetenschappelijke kwestie of over een banaal alledaags feit) voelt als een gezamelijke ontdekkingstocht naar de (diepere) betekenis van de dingen. Na een gesprek met jou zag de wereld er altijd veel verrassender en interresanter uit. Bedankt hiervoor. Martien, wij vonden elkaar in wat ik zou noemen 'het kritisch denken in de diepte'. Jij bent altijd in voor een diepgaande discussie, niet alleen over pijn maar over zowat alles eigenlijk. Daarnaast is het ook altijd heel gezellig om dingen met je te ondernemen, zoals uitstapjes naar de film, naar Ikea of naar Aken. Bedankt voor de inspiratie en de gezelligheid.

Collega's van het tinnitusteam in het Audiologisch Centrum Adelante: Dyon, Martijn, Jovanka, Remy, Rachelle, Rilana, Pauline, Marieke, Ken, Math en Ingrid, bedankt voor het meeleven met mijn proefschrift-perikelen en voor de vriendschap. Ook aan Sven en Twan, bedankt voor de ondersteuning in de vorm van tijd en ruimte die ik van jullie kreeg bij het afwerken van mijn proefschrift.

Marieke en Pauline, toen ik op het AC kwam werken kreeg ik er met jullie niet alleen twee nieuwe collega's maar ook twee nieuwe vriendinnen bij. Marieke, je zotte associaties in woord en (lichaams)beeld en je creatieve out-of-the-box spirit maakt het bestaan zoveel kleurrijker en zorgt ervoor dat wij een vanzelfsprekende klik hebben.

Pauline, de manier waarop jij je kunt overgeven aan de slappe lach werkt aanstekelijk en vormt een dagelijks genot. Bij jou kan ik ongebreideld catasroferen over mijn proefschrift of over het leven van alledag, wetende dat het steevast eindigt in een allesverpletterende lachbui. Onze gezamelijke vakanties naar Griekenland zijn nu al legendarisch en ik hoop dat er nog vele mogen volgen.

Ook een woord van dank aan het vriendenclubje van Maastricht: Yvonne, Helen, Marieke, Nina, Christianne en Sanae. Inmiddels zijn de meesten van jullie uit Maastricht vetrokken maar gelukkig zien we elkaar nog geregeld en worden er nu reisjes gepland naar Amsterdam, London, Cambridge en Regensburg. Helen, ik ken niemand die zo vrolijk en enthousiast is als jij. Je lacht werkt aanstekelijk! Yvonne, jij bent altijd in voor het ondernemen van leuke dingen gaande van filosofische discussies over het leven, een reisje naar Spanje of een 
vierdaagse naar Rock Werchter. Marieke, ik herinner me nog hoe je in het eerste jaar, toen je me nog helemaal niet kende, een deel van de leerstof voor me had gekopieerd en op mijn studeerplek in de bibliotheek had gelegd. Vanaf toen is onze vriendschap begonnen. Sanae and Jochen thank you for being part of my life. I know that if I need help with anything, for example assembling Ikea furniture, I can always depend on you. Sanae you are always in for cozy afternoons and sleepovers with lots of nice food and drinks, Woody Allen movies and creative enterprises such as making lace or crocheting. Beste vriendinnetjes, jullie maken het leven zoveel leuker, bedankt voor jullie vriendschap!

Mijn paranimfen, Nina en Christianne. Jullie hebben het hele traject van heel dichtbij meegemaakt, vanaf het prille begin van onze studie psychologie, tot aan het bittere eind, de afronding van mijn proefschrift. Ik ben heel blij dat jullie tijdens de verdediging ook letterlijk langs mijn zijde staan! Nina, bedankt dat ik deel mag uitmaken van je leven. Jij hebt het talent om je vrienden op een vanzelfsprekende manier op te nemen in je familie. Jij, maar ook Jip, Shaun, en je ouders, julie staan altijd klaar voor een bezoekje van mijnentwege. Bedankt voor de gezelligheid, het familiegevoel en je onbeschrijfelijke seven-layer dips. En ja, we gaan nu dat mijn proefschrift af is, zeker nog eens naar de efteling!

Christianne, je vrolijke, enthousiaste aanwezigheid en je onbevangen manier van doen zijn verfrissend en maken dat ik altijd mezelf kan zijn bij jou. $\mathrm{Nu}$ je in London woont, mis ik de manier waarop je je acties begeleidt met een voice-over, je directe vragen, en je spontane zang-uitbarstingen. Ook de pizza-avondjes samen met Nina en Rilana of het samen met jou en Stefan naar 'per seconde wijzer' kijken worden heel erg gemist. Gelukkig zien of horen we elkaar nog geregeld en staan jij en Stefan altijd klaar om me met open armen in London te ontvangen. Bedankt hiervoor!

Sofie en Bart bedankt voor jullie vriendschap. Sofie, ik ken je al heel lang en we hebben samen heel wat meegemaakt en afgelachen. Ik bewonder je open, oprechte en humoristische manier van naar de wereld kijken.

Bert en Marin, bedankt voor jullie vriendschap. Bert, jouw bijzondere manier van naar de wereld kijken, de manier waarop je steeds de kern van de dingen weet te raken is een verrijking en een onmisbaar deel van mijn leven. Bedankt voor alles.

Ken en Rilana, als mijn kamergenoten waren jullie dagelijks heel erg betrokken bij het wel en wee van mijn proefschrift. Onze kamer was een broedplaats van wetenschappelijke, psychologische en filosofische discussies die vaak uitmondden in dolkomische overpeinzingen. Dit zijn momenten die me voor de rest van mij leven zullen bijblijven. De (passieve) rookpauzes, uitstapjes naar de academische boekhandel en koffiecorner breidden 
zich al snel uit buiten de muren van de uni en maakten plaats voor avondjes met Belgische frieten, Nederlandse krulfriet, vispotjes, pizza, sushi, enz...Als er maar wat te eten is. We werden in zeer korte tijd zeer goede vrienden. Ik prijs me zeer gelukkig dat jullie nog opnieuw mijn directe collega's zijn.

Ken, bedankt voor je filosofische humor, je openhartigheid, je onvoorwaardelijke vriendschap en de Belgische vibes.

Rilana, jij bent niet in woorden te vangen; als je al binnen een categorie zou passen dan deze van mijn soulmate. We begrijpen elkaar zonder woorden maar het uitdiepen met woorden van wat we precies bedoelen maakt het leven zoveel levendiger, interessanter, grappiger, hilarischer. Je bent er altijd, ook als ik een duw(tje) in de rug nodig heb. Zonder jou was dit proefschrif nog niet af geweest, of niet op tijd gedrukt geweest, of had ik nu niet de baan van mijn leven gehad. Bedankt dat je er bent.

Mama en papa, jullie zijn een deel van mezelf. Jullie hebben me geleerd om door te zetten als het lastig wordt en ten alle tijde vertrouwen in mezelf te hebben. Dit is van onschatbare waarde gebleken. Bedankt voor jullie liefde en onvoorwaardelijke steun! Mama, ik ben ongelofelijk trots en vereerd omwille van je bijdrage aan de Schoonheid (in Platonische zin) van mijn proefshrift. Zonder enige twijfel heeft dit dit boek naar een hoger niveau getild! Annelies en kris. Kris, je beseft het wellicht niet maar je daadkracht heeft me zeker in de laatste fase van mijn proefschrift enorm geholpen. Annelies, ook al zien we elkaar niet zo vaak als we wel zouden willen, onze connectie blijft even diep en vanzelfsprekend. Jij kent me het langst en het best, en het feit dat jij er bent betekent alles.

Merel en Max, jullie manier van naar de wereld kijken, vol verwondering en met een onbevangen enthousiasme is hartverwarmend en vormt een dagelijkse reminder van wat echt belangrijk is in het leven. 
About the Author 
Saskia, Maria, Gabriella Ranson was born on August $4^{\text {th }} 1977$, in Blankenberge, Belgium. In 1995 she graduated from secondary school, Sint-Lodewijkscollege in Brugge, Belgium. In 1995, she started a study in philosophy at the University of Ghent and graduated in 2000. In 2001 she started her study in psychology at Maastricht University, The Netherlands. She graduated in 2005, and received her master's degree in biological psychology with option neuropsychology. In March 2007 she was appointed as a PhD-student at the Department of Clinical Psychological Science, of Maastricht University. During her PhD-research, she carried out the studies that are included in this thesis. Since February 2012 she works as a psychologist in Adelante Audiologie \& Communicatie, treating patients with tinnitus complaints.

\section{Publications}

Jongen, E., Smulders, F., Ranson, S.M.G., Arts, B.M.G., Krabbendam, L. (2007). Attentional bias and general orienting processes in bipolar disorder. Journal of Behavior Therapy and Experimental Psychiatry, 38(2), 168-83.

Vlaeyen, J., Karsdorp, P., Gatzounis, R., Ranson, S., Schrooten, M. (2011). The PACE trial in chronic fatigue syndrome. The Lancet, 377 (9780), 1834-1834.

Karsdorp, P., Ranson, S., Nijst, S, Vlaeyen, J. (2012) Goals, mood and cognitive task performance during experimentally induce mechanical pressure pain. Journal of behaviour therapy and experimental psychiatry, 44, 240-247.

Karsdorp, P., Ranson, S., Vlaeyen, J. (2012) Pain catastrophizing and the informational value of mood: task persistence during a painful finger pressing task. Pain, 153, 1410-1417. 


\section{Submitted manuscripts}

Ranson, S., Karsdorp, P., Van den Busche, E., \& Vlaeyen, J. Testing the activation of primed hedonic and achievement goals.

Ranson, S., Karsdorp, P., Vlaeyen, J. Distinct combinations of avoidance, pacing and persistence behavior are associated with disability and depression in low back and upper extremity pain.

Ranson, S., Karsdorp, P., Vlaeyen, J. No Mood-as-Input effects for primed hedonic and achievement goals.

Ranson, S., Karsdorp, P., Vlaeyen, J. Goal preferences predict physical task persistence in patients with chronic back pain.

\section{Conference presentations}

Ranson, S., Nijst, S., Karsdorp, P., \& Vlaeyen, J.W.S. (2009) Goals, Mood and Cognitive Task Performance During Experimentally Induced Mechanical Pressure Pain. Poster presented at the 6th Congress of the European Federation of IASP Lisbon, Portugal, September 9 - 12, 2009.

Ranson, S., Nijst, S., Karsdorp, P., Goossens, M., \& Vlaeyen, J.W.S. (2008). Task persistence in patients with work-related upper extremity pain: predictions from the Mood-as-Input model. Poster presented at the 12thWorld Congress on Pain, August 17-22, Glasgow, Scotland.

Ranson, S., Karsdorp, P. \& Vlaeyen, J. Distinct combinations of avoidance, pacing and persistence behavior are associated with disability and depression in low back and upper extremity pain. Poster presented at IASP pain congress 2010. Montreal, Canada.

Ranson, S., Karsdorp, P., Vanhamme, G., Smeets, R. \& Vlaeyen, J. The role of habitual performance goals versus pain avoidance goals in patients with chronic back pain. Poster presentation. Poster presented at EFIC pain congress 2011 Hamburg, Germany.

Ranson S., Karsdorp P., Schrooten M., Kindermans, H., Vlaeyen, J. Facing pain, chasing goals: Physical pain within the context of personal goal pursuit. Oral presentation at First ARPH Conference December 1-2, 2011 Lunteren, The Netherlands. 
